This electronic thesis or dissertation has been downloaded from the King's Research Portal at https://kclpure.kcl.ac.uk/portal/

\title{
Trust and the Politics of Security Risk Management The European Union's Engagement of China in Africa
}

\author{
Barton, Benjamin
}

Awarding institution:

King's College London

The copyright of this thesis rests with the author and no quotation from it or information derived from it may be published without proper acknowledgement.

\section{END USER LICENCE AGREEMENT}

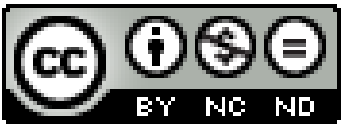

Unless another licence is stated on the immediately following page this work is licensed

under a Creative Commons Attribution-NonCommercial-NoDerivatives 4.0 International

licence. https://creativecommons.org/licenses/by-nc-nd/4.0/

You are free to copy, distribute and transmit the work

Under the following conditions:

- Attribution: You must attribute the work in the manner specified by the author (but not in any way that suggests that they endorse you or your use of the work).

- $\quad$ Non Commercial: You may not use this work for commercial purposes.

- $\quad$ No Derivative Works - You may not alter, transform, or build upon this work.

Any of these conditions can be waived if you receive permission from the author. Your fair dealings and other rights are in no way affected by the above.

Take down policy

If you believe that this document breaches copyright please contact librarypure@kcl.ac.uk providing details, and we will remove access to the work immediately and investigate your claim. 


\section{Trust and the Politics of Security Risk Management}

The European Union's Engagement of China in Africa

Candidate name: Benjamin Barton

Degree title: Doctor of Philosophy in War Studies Research with the University of Hong Kong 
The copyright for this thesis rests with the author and no quotation from it or information derived from it may be published without proper acknowledgement. 


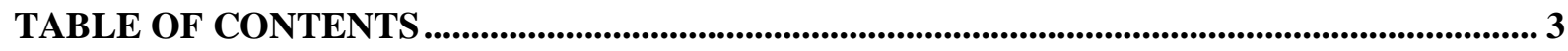

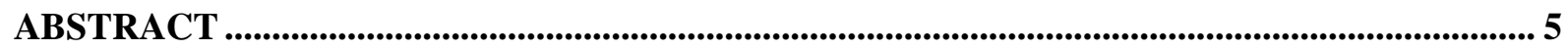

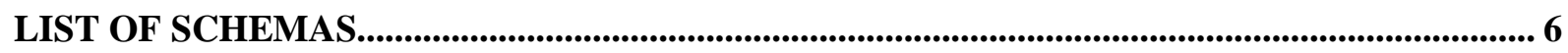

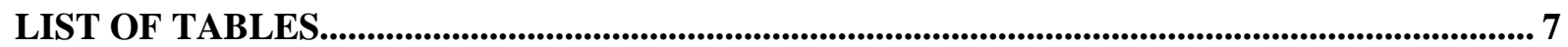

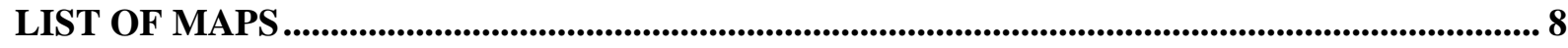

ACKNOWLEDGEMENTS ........................................................................................................................... 9

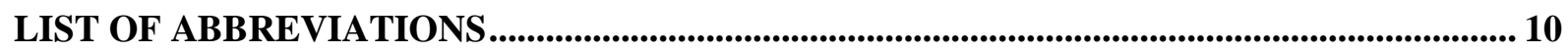

1. AN INTRODUCTION TO THE STUDY OF BILATERAL SECURITY RISK

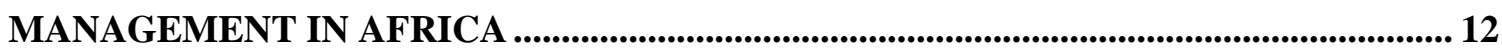

2. CHINA, THE EU AND THE POLITICS OF SECURITY RISK MANAGEMENT IN

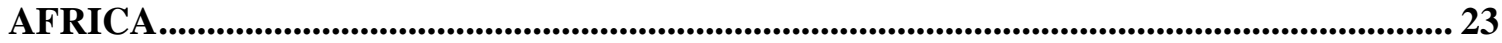

2.1. The Chinese ApProach: The Clash Between Tradition And Modernity ............... 23

2.2. THE EU'S APPROACH: REFLECTIVE OF A PARADIGMATIC SHIFT OR BUSINESS AS USUAL?29

2.3. THE NATURE OF BILATERAL INTERACTION: A VARIABLE StATE OF AFFAirs .................... 37

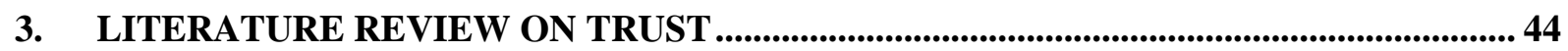

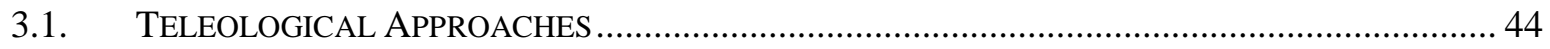

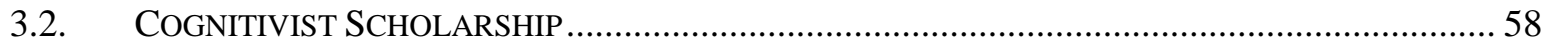

4. CONCEPTUAL FRAMEWORK AND METHODOLOGY .................................................... 68

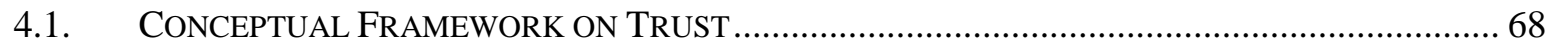

4.2. Methodology: Comparative Case Studies AND Process Tracing ........................... 80

5. CASE STUDY 1: THE EU'S ENGAGEMENT OF CHINA ON THE DARFUR

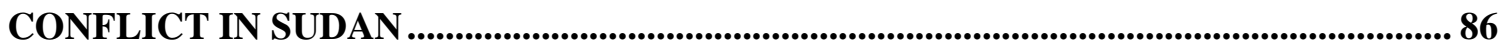

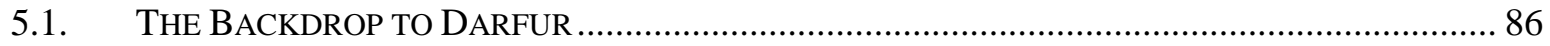

5.2. CHINA's EVOLUTION ON DARFUR: A Milestone FOR SinO-EUROPEAN COOPERATION? 105

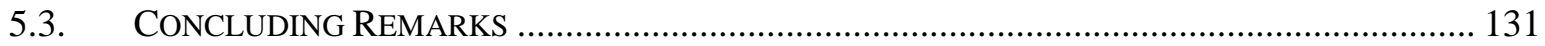

6. CASE STUDY 2: THE EU'S ENGAGEMENT OF CHINA ON COUNTER-PIRACY OFF

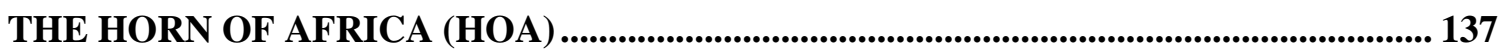

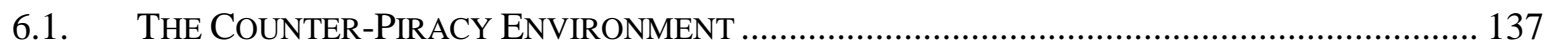

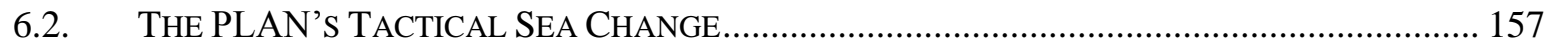

6.3. NAVFOR, THE PLAN AND THE EXERCISE OF BUILDING TRUST ...................................... 162 


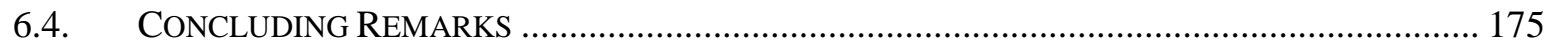

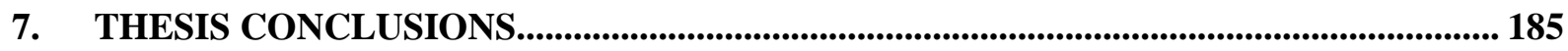

7.1. TRUST AND THE FAILING OF THE BILATERAL INSTITUTIONAL MEMORY ........................... 185

7.2. THESIS SUMMARY AND GUIDELINES FOR A FUTURE RESEARCH AGENDA........................ 204

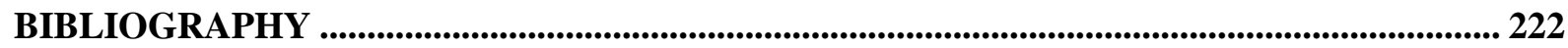

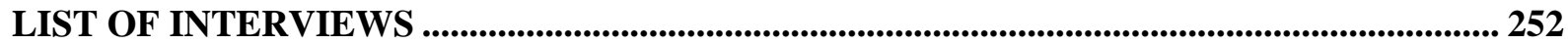




\begin{abstract}
This thesis asks why is trust between respective decision-makers the key factor when it comes to the EU's ability to engage China (or not) on the resolution of security threats on the African continent? This thesis argues that the EU's ability to impact upon Chinese decision-making in the realm of African security risk management relies above all on the capacity of EU policymakers (i.e. operatives on the ground) to foster sufficient levels of cognitive-based political trust with their Chinese counterparts. More specifically, to attain such levels, this thesis demonstrates that these decision-makers have to do more than simply rely upon a convergence of rational interests with their Chinese interlocutors to foster trust, due to the primordial importance that cognitive factors - such as identity, communicative action and displays of empathy - play when it comes to bridging their contrasting political preferences with regard to the resolution of conflict situations on the African continent. This thesis shows that such cognitive factors often serve as the key variable between these actors either engaging in practical cooperation/coordination on the ground to help diffuse a given security threat or adopting conflicting (if not obstructing) views on how best to resolve a given conflict situation. To demonstrate this, the thesis comparatively focuses on two specific case studies: the EU's interaction with China on the Darfur crisis (1) and bilateral dealings on counterpiracy activities in the Indian Ocean (2). The case studies will retrace a situation (1) where the EU's inability to generate sufficient levels of trust with China prevented any form of meaningful diplomatic and practical cooperation, instead leaving both sides on opposing sides of the spectrum and will compare it to this other case (2), where the EU was able to foster enough trust to thereafter trigger a change in China's tactical approach - more in line with its own expectations - to the extent of facilitating actual practical cooperation between the two sides.
\end{abstract}




\section{List of Schemas}

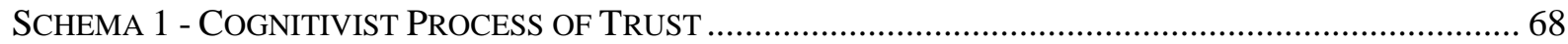

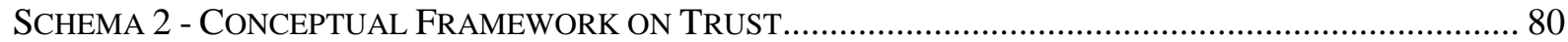




\section{List of Tables}

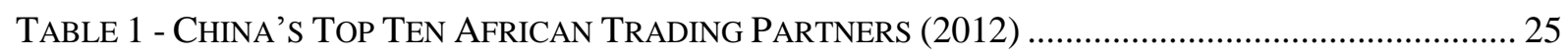

TABLE 2 - CHINA'S CONTRIBUTION TO AFRICAN UNPKOS SINCE 1999 ................................................ 25

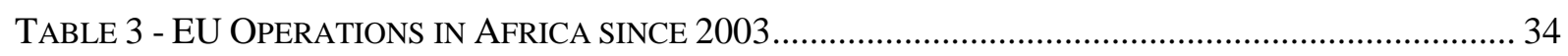

TABlE 4 - MEDIATION PlatFormS FOR DARFUR (INVOLVING THE EU AND CHINA) ......................... 124

TABLE 5 - MAJOR PEACE AGREEMENTS ON DARFUR..................................................................... 124

TABle 6 - Recorded Pirate AtTACKS: The GoA AND the Somali CoAst (2003-2009) ............... 137

TABLE 7 - DisPatch DATES OF KEY COUNTER-PIRACY OPERATIONS ............................................... 147

TABLE 8 - VARIABLES For COGNITIVE-BASEd PolitiCAL TRUST ....................................................... 221 


\section{List of Maps}

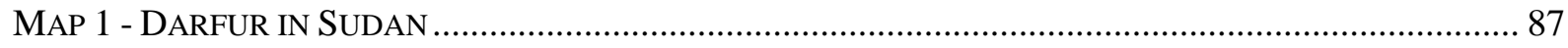

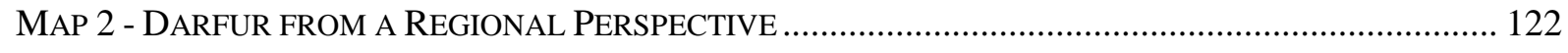

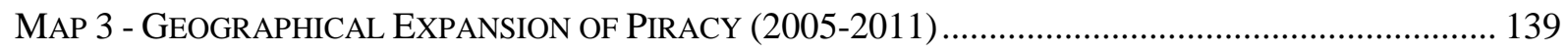

MAP 4 - THE INTERNATIONALLY RECOMMENDED TRANSIT CORRIDOR (IRTC) ............................... 152 


\section{Acknowledgements}

I would like to start my acknowledgements by paying tribute to the academic and research institutions that made it possible for me to undertake this doctoral research project and to write this thesis. I would like to thank King's College London (specifically the Department of War Studies within the Faculty of Social Science and Public Policy) and the University of Hong Kong (specifically the European Studies Programme within the Faculty of Arts) for accepting me as a candidate on the joint-PhD programme which provided me with the platform through which I was able to conduct my research. I would also like to thank the Economic and Social Research Council for providing me with the necessary financial support during my time as a doctoral candidate. I would now like to turn to those individuals who made it possible for me to complete this $\mathrm{PhD}$ over the last four years. In particular, I am indebted to the unbelievable support that I received from my co-supervisors: Dr Alessio Patalano (KCL) and Dr C. Roland Vogt (HKU). I truly appreciate how fortunate I was to have not just one fantastic supervisor but two and without their support, there certainly would not have been any thesis worth mentioning! A mention here as well to Prof. Jackie Gower (KCL) whose input was also vital during this process. I would also like to thank all of those participants and professional contacts who contributed to my research findings - they undeniably helped make this thesis into an unforgettable experience. On a personal level, I would like to thank my parents (as always), my family and friends for playing their crucial part along the way too. Finally, last but not least, I would like to dedicate this thesis to my wife Jessica whom I could never thank enough for her support in making this happen. This one, as you know, is for you. 


\section{List of Abbreviations}

\begin{tabular}{|c|c|}
\hline AFISMA & African-led Support Mission in Mali \\
\hline AMIS & African Union Mission in Sudan \\
\hline AMISOM & African Union Mission in Somalia \\
\hline AOR & Area of Responsibility \\
\hline APC & Armoured Personnel Carrier \\
\hline APF & African Peace Facility \\
\hline APSA & African Peace and Security Architecture \\
\hline AQIM & Al-Qaeda in the Maghreb \\
\hline $\mathrm{AU}$ & African Union \\
\hline CAN & Canada \\
\hline CAR & Central African Republic \\
\hline $\mathrm{CCP}$ & Chinese Communist Party \\
\hline CCTV & China Central Television \\
\hline CFSP & Common Foreign and Security Policy \\
\hline CGPCS & Contact Groups on Piracy off the Coast of Somalia \\
\hline CMF & Combined Maritime Forces \\
\hline CMPD & Crisis Management Planning Directorate \\
\hline CNPC & Chinese National Petroleum Corporation \\
\hline CPA & Comprehensive Peace Agreement \\
\hline CSDP & Common Security and Defence Policy \\
\hline CSG & Council Secretariat General (EU) \\
\hline DPA & Darfur Peace Agreement \\
\hline DPKO & Department of Peacekeeping Operations (UN) \\
\hline DRC & Democratic Republic of Congo \\
\hline ECOWAS & Economic Community of West African States \\
\hline EEAS & European External Action Service \\
\hline EU & European Union \\
\hline EUSR & European Union Special Representative \\
\hline EXIM & Export-Import Bank of China \\
\hline $\mathrm{F}$ & France \\
\hline FCO & Foreign and Commonwealth Office \\
\hline FMPRC & Foreign Ministry of the People's Republic of China \\
\hline FOCAC & Forum on China-Africa Cooperation \\
\hline FPA & Foreign Policy Analysis \\
\hline GCC & Gulf Cooperation Council \\
\hline GoA & Gulf of Aden \\
\hline GoS & Government of Sudan \\
\hline GRIT & Graduated Reciprocation in Tension Reduction \\
\hline HoA & Horn of Africa \\
\hline HR & High Representative \\
\hline $\mathrm{ICC}$ & International Criminal Court \\
\hline ICG & International Crisis Group \\
\hline ICU & Islamic Courts Union \\
\hline IDP & Internal Displaced Person \\
\hline IMO & International Maritime Organisation \\
\hline IR & International Relations \\
\hline IRTC & Internationally Recommended Transit Corridor \\
\hline JAM & Joint Assessment Mission \\
\hline
\end{tabular}




\begin{tabular}{|c|c|}
\hline LAS & League of Arab States \\
\hline LRA & Lord's Resistance Army \\
\hline MAE & Ministère des Affaires Etrangères (France) \\
\hline MINUSMA & UN Operation in Mali \\
\hline MOFA & Ministry of Foreign Affairs (China \& Japan) \\
\hline MSCHoA & Maritime Security Centre for the Horn of Africa \\
\hline NATO & North Atlantic Treaty Organisation \\
\hline $\mathrm{NCP}$ & National Congress Party \\
\hline NGO & Non-Governmental Organisation \\
\hline NIF & National Islamic Front \\
\hline NL & The Netherlands \\
\hline NTC & National Transitional Council \\
\hline $\mathrm{OHQ}$ & Operational Headquarters \\
\hline $\mathrm{OIC}$ & Organisation of Islamic Conference \\
\hline PLA & People's Liberation Army \\
\hline PLAN & People's Liberation Army Navy \\
\hline PRC & People's Republic of China \\
\hline PSC & Political and Security Committee \\
\hline SALW & Small Arms and Light Weapons \\
\hline SCMP & South China Morning Post \\
\hline SHADE & Shared Awareness and Deconfliction \\
\hline SLA/M & Sudan Liberation Army/Movement \\
\hline SPLM & Sudan People's Liberation Movement \\
\hline SSR & Security Sector Reform \\
\hline TCA & Theory of Communicative Action \\
\hline TFG & Trans-Federal Government \\
\hline UAE & United Arab Emirates \\
\hline UK & United Kingdom \\
\hline UKMTO & UK Marine Trade Operations \\
\hline UN & United Nations \\
\hline UNAMID & UN-AU Mission in Darfur \\
\hline UNGA & United Nations General Assembly \\
\hline UNITAF & United Task Force \\
\hline UNPKO & United Nations Peacekeeping Operation \\
\hline UNSC & United Nations Security Council \\
\hline UNSCR & United Nations Security Council Resolution \\
\hline US & United States of America \\
\hline VHF & Very High Frequency \\
\hline WFP & World Food Programme \\
\hline WG & Working Group \\
\hline WMD & Weapons of Mass Destruction \\
\hline WoT & War on Terror \\
\hline
\end{tabular}




\section{An Introduction to the Study of Bilateral Security Risk Management in Africa}

The European Union (EU) and the People's Republic of China (PRC)'s approaches to security risk management in Africa are usually depicted as reflecting a contrasting nature, with the interaction between both sides mostly described as competitive and dominated by feelings of rivalry. Such a portrayal stems because both parties are understood as being intrinsically dissimilar - whether in terms of their political structures, needs and aspirations. This dissimilarity is captured for the most part across a number of publications in the field that have attempted to qualify the dynamics at play between the EU and China with regard to their dealings in the African continent as a whole, or more specifically in relation to the theme of security risk management. Indeed, to quote one expert, the interests of these "Great Powers" would apparently be taking on an increasingly: “[...] ideological tint, pitting two visions of foreign partnership with Africa against one another" (Alden 2009: 93). For all of the spontaneity underpinning China's re-emergence in Africa, it would appear that this contrasting and competitive nature behind their bilateral ties is above all the result of individual historical experiences that have shaped the way they respectively deal with security risk management in Africa, which in turn impacts the perception they have of other noteworthy actors within this specific realm.

As a matter of fact, since the end of the Cold War in particular, the EU and its member states have strived to portray themselves in a new and more 'modern' light as actors mainly concerned by the wellbeing of citizens and innocent victims that need protecting from the ills of conflict - whether driven by local groups skirmishing for control over wealth and power or more recently by groups whose objective is to spread terror. This campaign - which has left a lot to be desired in terms of its systemic application and implementation - was principally devised to mark a break with past post-colonial practices where European actors had seldom given much consideration to the humanitarian dimension of security risk management on the African continent. The PRC's approach still continues to be significantly shaped by the experiences that the Chinese Communist Party (CCP) has endured in trying to assert its authority over China's sovereign territory ever since Mao Zedong and his followers swept to power. Chinese leaders thus tend to interpret security risk management in Africa in the same way that they have been fighting off perceived internal and external threats to the country's political status quo for the past seven decades, by calling for the need to respect state sovereignty and territorial integrity - even if the country's sudden apparent rise to superpower status continues to test the limits of this more 'traditional' mindset. Yet, for all this supposed contrast between modernity and tradition, both the EU and the PRC have shown an infrequent 
ability to temporarily reconcile their differences to the extent that they have been found coordinating their positions, as well as cooperating, in the resolution of a limited number of African security crises over the past few years. ${ }^{1}$ In spite of all of the fallouts over security crises in Zimbabwe, Darfur and Libya from the turn of the century onwards, Brussels and Beijing have been able to share more likeminded views with regards to managing the security implications of more recent events in Mali, while they were even found to be practically collaborating in the fight against Somali pirates off the Horn of the Africa (HoA).

Although the variability of outcomes has only warranted the attention of a small number of scholars and experts alike, there have been few attempts hitherto to comprehend as to why both sides have at times adopted more of a confrontational stance towards one another on cases of security risk management in Africa and why, at other times, they have managed to bridge their apparently inherent differences. As an attempt to help fill this gap within the literature, this thesis will put forward a conceptual framework developed around the concept of cognitive-based political trust in order to make sense of this variability in outcomes in a holistic fashion. ${ }^{2}$ This framework, which is constructed around a process of identification (positive or negative) and which places considerable emphasis upon 'cognitive' empathy and Habermasian ideal-type communicative action, puts forward an analytical approach capable of explaining in a complementary fashion as much the reasons behind their acts of rivalry as those of rapprochement. In other words, this thesis posits that it is the presence of cognitivebased political trust (or the lack of) between European and Chinese decision-makers that primarily determines whether both sides are likely (or not) to cooperate in the context of conflict management on the African continent. More specifically, this presence or absence of

\footnotetext{
${ }^{1}$ Cooperation, in this context, is defined as: "interactional behaviour or a relationship between at least two parties, be they persons, groups or institutions. Their behaviour is coordinated in such a way that some actions of one side facilitate the goal attainment of the other side. Usually, this behaviour is conceived to be voluntary and not the result of yielding to power. [...] It is the rule that both sides support each other in a balanced or symmetrical fashion, at least in the long run. The cooperative partners work towards the same or towards different but mutually compatible goals" (Feger 1991: 284). Naturally, competitive behaviour amounts to the antithesis of this definition.

${ }^{2}$ Trust is qualified in this thesis as political trust for the fact that the concept of trust is being studied in a context that deals with negotiations on issues of an international political order, thus making it specific to this context. Trust, as a concept, exists in many different walks of life since it is a human characteristic that can be nurtured in the same way that it can be obliterated. Mostly, the concept of trust is applied from a social science perspective when analysing human relations in their most basic, emotive form. In this case, trust applies more to the domain of social or personal relations. Trust can also be studied across other scholarly field such as law and finance, where trust pertains to its own applicable definition that does not relate to the concept that is being discussed throughout this thesis. Despite the fact that this thesis alludes predominantly to relations between human beings and stresses the cognitive dimension of this interaction, I have applied the term 'political' trust for the fact that I am discussing first and foremost dealings between international professionals who, more often than not, are only brought together for professional reasons within a specific international context to negotiate upon a specific international issue and thus are assumed not to entertain friendly or close personal relations, even if there are inevitable exceptions to the rule.
} 
cognitive-based political trust is determined first and foremost by the outcome of the identification process (whether positive or negative) undergone between sets of European and Chinese decision-makers. Thereafter, the detection or lack of detection of the expression of cognitive empathy and ideal-type communicative action will go a considerable distance in deciding whether this process of identification translates into trusting or mistrusting patterns of behaviour between the two groups of actors. In turn, it is the diverse complementary elements constitutive of this conceptual framework - which are heavily impacted by the social environment in which the two sets of decision-makers are interacting in - that will primarily determine whether the EU and China are likely to act as rivals or partners when it comes to security risk management in Africa. This introduction will now briefly explain why this concept has not featured prominently within publications in the field of Foreign Policy Analysis (FPA) theory, why the decision was made to apply this concept in the context of this doctoral research project and why a cognitive-based variant was preferred to more mainstream analytical models of political trust. Following on from this, a detailed synopsis of the breakdown of each upcoming chapter will be provided.

The application of the concept of political trust is relatively underappreciated when it comes to the study of FPA and this concept has been particularly underutilised when analysing the fairly novel area of research that is the bilateral interactions between the EU and China on the theme of security risk management in Africa - a statement that is even more accurate when taking into consideration the cognitive-based version of this concept. Political trust's relative neglect within the wider literature on FPA theory or within the more specific writings regarding EU-China relations in Africa is surprising given the importance that the concept plays both consciously and subconsciously in everyday life, including within the realm of international policymaking. As a case in point, trust or "mutual trust" features as a concept that has made a recurrent feature in Chinese foreign and security policy discourse, hinting at least from a rhetorical viewpoint at the importance that Chinese decision-makers attach to this concept. For example, the 2002 Chinese 'Position Paper on the New Security Concept' indicated that "mutual trust" constituted the first of four core principles (which also included mutual benefit, equality and coordination) that shaped the PRC's general approach to international security affairs. ${ }^{3}$ Even if such statements should naturally be interpreted with care, they do nonetheless point towards the fact that political trust is a core component of

\footnotetext{
${ }^{3}$ For Beijing, "mutual trust" was meant to imply that all countries should: "transcend differences in ideology, social systems; discard Cold War mentalities and refrain from mutual hostility and suspicion; engage in frequent dialogue and briefings on each other's security and defence policies" (People's Daily 2002).
} 
international security risk management, albeit one that from the vantage point of the mainstream scholarly literature on FPA has tended to have been underutilised.

There are numerous reasons for this seeming lack of interest in political trust. For one, the immaterial and intangible nature of the concept of trust makes it difficult to measure for scholars wary of not having enough empirical evidence to support their argumentation. To add to this, mainstream FPA theories and particularly research inspired by neorealist thinking would appear to be endemically more favourable to studying mistrust than trust as a concept, as will be explained in greater detail during the review of relevant literature developed throughout chapter 3. In fact, as alluded at the start of this section, a majority of publications that have looked into the EU's engagement of the PRC in Africa in the field of security risk management - as well as other fields of activity related to their bilateral dealings on the African continent - have usually based their entire analysis around the idea that mistrust constitutes the dominant trait characterising their engagement (Berger 2006: 155; Booth \& Wheeler 2007: 231; Schoeman 2008: 404). Even if such authors have intended to paint a comprehensive picture of bilateral interaction in Africa on security risk management (amongst others), the underlying assumption consists of advocating that as the EU and China mostly struggle to bridge the differences pinpointed above, the nature of their relations in this context tends to revolve around competition and rivalry. Any other facet of their dealings that may surface is considered as tributary to this underlying competitive assumption. This is explained by the fact that these analyses take their cues from more classical versions of the study of political trust which advocate that in a game-type situation, two sets of actors who do not appear to be of the same "broader cultural entity" will only achieve the trust needed to cooperate in an anarchic milieu if they enter into a reciprocal relationship and not one devised around a form of cognitive synergy (Gambetta 1988: 233; Huntington 1996: 43, 131; Hoffman 2002: 384; Glaser 2010: 128). Reciprocity in itself implies that both sides in the game are working on the basis of there being a problem which needs solving (via a cooperative remedy).

Nonetheless, as disproved by real events on the ground, decision-makers from either side may in fact aspire as much to cooperate as they strive to compete, depending on whether they are able or not to synergise with one another from a cognitive viewpoint - even within an anarchic environment (Bleiker \& Hutchinson 2008: 116). As a result, this less commonly adopted analytical approach is required in order to comprehensively answer the following research questions that underpin the thesis' primary and secondary hypotheses: why has bilateral interaction on the African continent produced both competitive and cooperative 
outcomes? What connects the patterns of competitive behaviour to the cooperative behavioural patterns and how is the concept of political trust relevant in this respect? Why focus predominantly on a cognitive-based approach to trust rather than other scholarly interpretations of trust? This thesis seeks to redress this balance by championing the trust literature within the field of study of FPA theory as a whole and within the specific theme being discussed throughout this thesis, to show that there exists alternative interpretations that deserve greater consideration.

As aforementioned, it will do so by reasoning that cognitive-based political trust serves as the primary explanatory variable when seeking to understand why bilateral interaction has produced cooperative outcomes across certain cases of security risk management in Africa and conflictual behaviour across others. This variant has been selected on the premise that it can offer the most appropriate research framework and concomitant analytical tools for undertaking research on this variability of outcomes, since the conceptual framework seeks to explain the cooperative and competitive dynamics on an equal footing without initially displaying scholarly bias for one approach over another. In fact, within the relevant cognitivist literature it is understood that this particular variant can precipitate the advent of cooperation, even amongst groups of actors whose ties are governed by fundamental differences, by "greasing the [sic] wheels" of political trust between them (Welch Larson 2000: 249; Tyler 2001: 287; Hoffman 2002: 375; Solomon \& Flores 2003: 114; Xiang \& Zaborowski 2007: 50; Kramer 2010: 83). Certain promulgators of this school of thought are even of the belief that it was primarily the existence of cognitive-based political trust between American and Soviet leaders that proved to be the decisive factor in bringing an end to their enmity in the latter stages of the Cold War (Booth \& Wheeler 2007: 157). The same is true of the other side of the coin though - when this variant is absent or insufficient, the chances that these groups of decision-makers will engage in competing or conflictual relation are higher, thus curtailing the benefits derivable from organising cooperative activity (Deutsch 1973: 56). This view is shared by a prominent China-Africa specialist who believes that the lack of political trust between the West and China has been the source of many problems on the continent, particularly concerning the military component of their interaction (Taylor 2009: 153). Therefore, this approach will allow for a more objective assessment of the bilateral state of affairs regarding security risk management in Africa, by garnering in a holistic fashion an understanding of the most determinant variables which drive and determine the nature of their interaction. 
To be able to provide a thorough answer to each of the primary research questions above and support the hypothesis, we first need to provide more background information regarding bilateral engagement and interaction on security risk management in Africa - this will be covered by chapter 2 . The aim of this chapter will be to highlight that when it comes to discussions on this topic, bilateral interaction is a little more nuanced than simply working on the premise of competitive mindsets, while the reality of the situation on the ground is far from that of a game-type situation. It will do so by contextualising the meaning of rivalry and partnership for the EU and China in relation to this particular theme, by outlining the differences shaping the Chinese perspective on this specific theme from that of the EU's. At the same time, this section will examine how - mainly from the European side - discursive and practical efforts have been made to ensure that cooperation figures as an integral part of this bilateral dynamic, both to minimise the adverse effects of the aforementioned differences and to pinpoint the desire that both sides sometimes share in collaborating. ${ }^{4}$ It will allude to those structural reasons which facilitate a credible discussion regarding cooperation between both sides when it comes to dealing with security risk management in Africa.

Chapter 3 will then be followed by the literature review on trust, so as to delve deeper into the different facets of trust research briefly alluded to above and to expose the rationale behind the supposition that cognitive-based political trust is better suited to the demands of this thesis. This discussion will lay the groundwork needed to launch the discussion that will eventually provide the answers to the primary research questions listed above. To commence, this chapter will first provide a review of the interpretations of the political trust concept as performed by the mainstream 'rationalist' FPA theoretical strands, namely neorealism and neoliberal institutionalism. These strands were selected on the basis of their relevance for the theoretical and conceptual discussion undertaken throughout this thesis. In addition, these strands were also selected for the fact that scholars that identify with neorealist and neoliberal theories have tended to be some of the most active authors on the theme of trust, mistrust and the cooperation/competition dichotomy. Following a critique of these specific theoretical approaches to political trust, the remainder of chapter 3 will be dedicated to reviewing the scholarly literature on trust emanating for a large part from the field of social psychology and, to a more limited extent, from constructivist writings that are destined for an FPA theory audience.

\footnotetext{
${ }^{4}$ Anna Stahl has taken the debate further by positing that: "in light of the constant evolution of Europe and China Africa policies, [...] they mutually influence each other, leading to converging security motives" (2011: 165).
} 
This review of the cognitivist literature on trust is split into two overlapping sections so as to create a platform for the ensuing chapter, which sets out the cognitive-based conceptual framework on political trust tailored for this thesis that later will be empirically tested across the comparative case studies. To begin with, this review of the cognitivist literature will look into the process of identification and more specifically into the distinction made between the notions of ingroup and outgroup. In sum, as shown above, what the cognitivist literature would appear to convey is the impression that cooperation or the lack of a cooperative spirit between two sets of actors is contingent first and foremost upon whether they consider each other - in terms of their contextual identity - as part of their respective ingroup or outgroup. Thereafter, the literature review turns to two sub-concepts that are dealt with interdependently but which have nonetheless been loosely grouped together in light of their apparent complementarity: the notion of empathy and that of ideal-type communicative action. As the review will make clear, the literature foresees both elements as simultaneously playing a pivotal role in the development of cognitive-based political trust between groups of actors, whilst their complementarity is borne out of the fact that the latter serves as a mean of expressing the former (in those cases when empathy is detectable). The decision to take into consideration the process of identification, the notion of empathy and communicative action was driven by the understanding that these are the analytical elements that matter most when it comes to cognitive-based political trust. This decision was influenced by this author's readings, discussions with other academics and to a large extent was shaped by the empirical data collected from the open-ended interviews conducted for the comparative case studies.

These three analytical components will thus serve, over the course of the empirical case studies, as the sub-variables to be tested as part of this conceptual framework on trust in a bid to demonstrate the relevance of this conceptual framework as well as the primary hypotheses underpinning it. What's more, this section of the literature review will also serve as a means of promoting the idea that by applying these three analytical components, there exists a desire to account for the impact that varying social environments can specifically have in terms of preventing or fostering the development of cognitive-based political trust between such actors as European and Chinese decision-makers. Indeed, as it will be shown both across chapter 3 and chapter 4, all of these sub-variables depend to a large extent on the social environment in which they develop (or fail to develop). With these elements having been identified for their relevance during the literature review, they are then examined in greater detail throughout chapter 4 where the objective is to comprehend as much how they function independently as interactively, so as to have a concrete understanding by the end of 
chapter 4 of what is meant by the cognitive-based conceptual framework of political trust referred to throughout this thesis. It will determine which analytical aspects feature as part of the conceptual framework and which aspects do not feature, as well as providing an explanation of the reasons behind these choices. To wrap up chapter 4 , a second section will focus on the methodology needed to apply this conceptual framework. At this stage, it is important to be aware that the methodology is above all concerned with making the study of the intangible concept that is political trust into a credible scientific exercise. Consequently, the methods applied to collect and analyse the data have been selected on the basis that they will best serve this particular type of conceptual framework on trust. In other words, the methodology employed here relies predominantly upon qualitative research techniques and most notably discourse analysis targeting both policy rhetoric (as officially published by the EU and the PRC's respective foreign policy institutions), as well as from answers to openended questions as put to relevant decision-makers by this author over the course of the interviews mentioned earlier. ${ }^{5}$

To reinforce the scientific dimension, this thesis makes use - via chapters 5 and 6 - of the comparative case study which serves its purpose in reducing the uncertainty of empirical data needed to support the thesis' primary and secondary hypotheses. This is achieved by comparing a case where the EU and China's respective officials on the ground were unable to develop trust and subsequently any form of coordinative and/or cooperative interaction (chapter 5), with another case where the EU and China's respective officers were able to develop a trusting relationship (and thus subsequent cooperation) as part of their engagement regarding security risk management in Africa (chapter 6). Using the technique of process tracing, these chapters - that are structured in a systematic fashion to ease the comparative dimension - tell the story of the EU's engagement of the PRC during the uprising in Darfur and during the peak of Somali piracy activity off the Horn of Africa. The narrative developed across each case study is designed to highlight how the cognitive-based understanding of political trust serves as the most determinant aspect when it comes to the nature of bilateral engagement on security risk management in Africa.

Practically speaking, this comparison will present one case (Darfur) where the PRC failed to undergo a meaningful shift in its more 'traditional' approach to security risk management in Africa with another (Somali piracy), where China did perform a meaningful shift to one more in line with the EU's 'modern' approach. In the first case, this absence of a

\footnotetext{
${ }^{5}$ The methodology will recount in greater detail why the technique of interviews was chosen as a means of collecting data, the method employed for selecting interviews and how the interviews were conducted.
} 
meaningful shift naturally translated in the absence of cooperation with the EU and in the second case, the perception of this shift permitted the development of cooperative interaction with the EU. In fact, while the absence of a cooperative spirit only contributed to worsening the situation in Darfur that was never truly resolved, on counter-piracy this cooperative spirit indirectly went some way to eventually bringing down the number of successful pirate attacks in the region. Yet in either case, as this thesis will set out to prove, it was the presence or absence of cognitive-based political trust from the Chinese officials in their European counterparts on the ground that determined whether they were to entertain competitive or cooperative relations with regard to the theme of security risk management.

In addition, the narratives will naturally be designed so as to show how the three aforementioned analytical elements earmarked from the cognitivist literature on political trust specifically contribute to demonstrating the validity of this conceptual framework. In other words, by empirically detecting the presence of a positive process of identification, of empathy and of ideal-type communicative action, this increases the likelihood of a trusting outcome. Vice-versa, the detection of a process of negative identification combined with the absence of displays of empathy via ideal-type communicative action lead to a lack of trust or to mistrust. Indeed, in the case of Darfur, the lack of positive sources of identification coupled with the predominantly mistrusting social environment in which both sets of officials on the ground interacted meant that not only were the expression of empathy and of ideal-type communicative action absent but the environment was simply not conducive to allowing these elements to flourish. In turn, the chances that either side was able to reconcile their prior divergences and move towards a more cooperative mindset on the basis of cognitive-based trust were slim. The case on counter-piracy off the Horn of Africa presented in chapter 6 could not be any more different in this regard since all of these elements - positive identification, direct and indirect expressions of empathetic behaviour, consistent and intense communicative exchanges and depoliticised forms of interaction - meant that the conditions were ripe for the development of political trust between these sets of actors. This explains why the PRC underwent a shift in its approach to this crisis, from its traditional stance to falling more in line with the EU's 'modern' reading of the situation.

The decision to use case studies on the insurgency in Darfur and counter-piracy in the Horn of Africa was made because these represent perfect examples of contrasting fortunes in terms of bilateral interaction on security risk management in Africa, where both sides could consider themselves to have been influential players whether for better or for worse. They are also perhaps the most notorious examples of bilateral interaction, which concurrently provides 
a number of benefits in terms of undertaking research, such as accessing material for data collection (from academic sources, the media, non-governmental organisation reports as well as for conducting interviews with officials having been involved with the resolution of either crisis). In this respect, both cases are neither too distant chronologically speaking to be of little value to contemporary discussions concerning Sino-European interaction on African security matters, nor too recent (which could have implications for the accessibility of sufficient and relevant data). Given that they both unfolded across overlapping time spans also brings salience to the comparative analysis.

To bring the discussion to a close, the concluding chapter (chapter 7) serves two purposes. The first is to pursue with the comparative dimension and explore the continuity of the trust between the EU and China when it comes to security risk management in Africa, by asking whether there exists any place for the institutionalisation of cognitive-based political trust in this context. To answer this question, the conclusion looks into more recent examples of bilateral interaction with the aim to provide an answer - supported by empirical evidence to the question of the possible institutionalisation of trust. What we uncover is that there is still some way to go before we can start discussing the existence of any form of institutionalisation of bilateral political trust. As a case in point, by referring to the events of the Libyan revolution, the concluding chapter demonstrates that there was clearly no cognitive-based political trust between European and Chinese officials on the ground, resulting in the conflicting stances adopted by both sides in terms of resolving this crisis. In itself, this example pinpoints almost to the futility of discussing at this moment in time the idea of an institutionalised pattern of cognitive-based political trust. The example of Mali pertains to a more contrasting outcome. This time around, officials from both sides were able to see eye-to-eye on the need for French intervention in Mali, despite not sharing similar opinions at the outbreak of the crisis. Chinese officials eventually came round to identifying with the approach adopted by their French counterparts and - even if this did not lead to outright cooperation - they were able to coordinate their positions, with the PRC throwing its diplomatic support behind this French initiative. But as this example will highlight, this progressive evolution of the Chinese reading of the situation in Mali had little to do with any form of institutionalised political trust between Chinese and European officials on security risk management in Africa.

The second objective of this concluding chapter is to discuss in greater detail a future research agenda targeting areas of improvement for this thesis' conceptual framework. To do so, this conclusion will start by assessing whether all of the primary and secondary hypotheses 
supporting the conceptual framework have been validated or not. In so doing, this will allow space for this author to reflect upon the lessons learnt regarding this conceptual framework as a result of its application during the comparative case studies, which in turn will allow the identification of analytical elements that may be of little added-value to the conceptual model elaborated in chapter 4. Additionally, it will also give the opportunity for this author to highlight analytical components which were not necessarily covered in chapter 4 but which clearly play an important role when it comes to the concept of cognitive-based political trust within the context of the EU's engagement of the PRC on security risk management in Africa (such as the concept of leadership or professional knowledge and expertise). It is by focusing on these elements that a possible future research agenda may help further improve the analytical robustness of this conceptual framework on political trust, with the aim both of painting a clearer picture of the true nature of bilateral engagement in Africa on the topic of security risk management, as well as ensuring that trust is attributed more importance within contemporary debates on FPA theory. 


\section{China, the EU and the Politics of Security Risk Management in Africa}

\subsection{The Chinese Approach: The Clash Between Tradition and Modernity}

China's approach to the topic of peace and security on the African continent, and in particular the management of crises, is shaped largely by its continuing nation-building process and evolution from a backward nation-state to a more modern and prosperous one. In other words, discussions relating to this approach have produced three trains of thought which are all linked in different ways to the PRC's evolving experiences as a nation-state: a) Chinese leaders conceptualise matters of peace and security according to the country's economic interests on the continent, since their primary concern deals with internal economic modernisation; b) they do so according to the need to preserve a positive international image of China, so as to facilitate the country's ascendance to world power status; c) they interpret matters of peace and security in Africa in accordance with the CCP's own historical experiences with asserting sovereign authority. As will be observed below, it is through a confluence of these three elements that the PRC has often been seen to adopt fairly diametric positions to those taken up by the West, both in terms of understanding African security dynamics and thereafter acting upon them.

As with most analyses of the PRC's return to Africa, the majority of studies - applying a rationalist framework - have come to the conclusion that the multiple facets of this reemergence are all connected with the Chinese government's principle concern: gaining access to sufficient natural resources and business opportunities so as to support its phenomenal economic growth (Alden et al. 2008: 23; Raine 2009). From this viewpoint, security risk management also fits into this logic, with commentators arguing that Chinese officials perceive the PRC's involvement in different aspects constitutive of African peace and security as a means of furthering the development of China's economic aura on the continent. Therefore, this would signify that an 'economics first' logic pervades the four main components of Chinese activism on the theme of African security risk management: arms trading; military exchanges; deploying troops to United Nations Peacekeeping Operations (UNPKOs); providing an international shield for political elite implicated in civil strife across the continent.

In effect, according to rationalists, each of these facets fits into the logic of "package" deals which the PRC usually negotiates with its African counterparts when seeking to increase its economic presence across the continent (Shinn \& Eisenman 2012: 4). Such deals - which are usually presented as a form of mercantilism - can cover an array of themes depending on the needs of local elites but usually result in the exchange of material and immaterial goods in 
return for economic benefits and, more spontaneously, international political support for China (see Alden 2009: 42). This interpretation would imply that, in theory, when bartering with African states' officials Beijing can offer any of the above four elements (or a combination) in order to secure a better concession on energy products or a better deal for Chinese businesses seeking to venture into local markets. In turn, this would mean that when a security crisis arises in a region where China has many economic interests, it is likely to adopt a stance which best suits the protection of these interests while disengaging itself from zones of conflict where its economic activism is comparatively low. For one expert, since the late 1990s, the Chinese government's policies towards Africa have all been closely interlinked to the objectives of its major state-owned enterprises such as the Chinese National Petroleum Corporation (CNPC) (Zhao 2010: 106). This would explain why Chinese-made weapons have been found in conflict-ridden parts of the continent where Chinese companies have a nonnegligible presence such as Burundi, Chad, Liberia, Ethiopia or Sudan (Curtis \& Hickson 2006: 38-9; BBC News 2007b; Lam 2008: 234; Shinn 2009). This would explain why Beijing has not hesitated to show support for leaders such as Robert Mugabe or Omar al-Bashir in the face of castigation by the international community, given the business interests it respectively holds in Zimbabwe and Sudan (Kristof 2008; Tran 2008; Alden 2009: 44, 63-5, 89). ${ }^{6}$ This economic rationale to the PRC's activism would also justify why the People's Liberation Army (PLA) has largely engaged in military exchanges with African states where Chinese investments figure prominently and why, as shown in Table 1, Chinese troops have been dispatched since 1999 to UNPKOs where its commercial activities are sizeable (Holslag 2008: 10-2; Eberling 2011: 81; Lawson 2011: 41; Suzuki 2011: 73; Geoxavier 2012: 100). ${ }^{78}$

\footnotetext{
${ }^{6}$ Of course, taking the rationalist approach here, since everything has a price in return Beijing can also expect international political support from these actors when needed, especially when the PRC may come under fire internationally it can turn to these leaders for support (Alden 2009: 22).

${ }^{7}$ For example, Chinese military instructors have been dispatched as far afield as Sudan and Zimbabwe, while Angolan and Congolese military personnel have received training in Beijing (Holslag 2008: 12; Saferworld 2011: 40). The PLA has organised military training activities with the armed forces of Algeria, Gabon and Zambia, whereas Nigeria has featured as a recipient of Chinese military aid (Holslag 2008: 10-2). Military attachés have been posted to Liberia, South Africa and Mozambique (Bokilo 2011: 39). Furthermore, despite the insistence by Chinese leaders and diplomats that the country strictly adheres to the principle of non-interference, rumours did apparently circulate on the possible opening of a Chinese military base in the Democratic Republic of Congo (DRC) region of Katanga - home to one the largest copper and cobalt reserves in the world (Beuret \& Michel 2008: 377-8; Bokilo 2011: 49). As this last example epitomises, all of the above countries constitute markets where Chinese companies have made substantial investments, either in relation to energy commodities or to the exchange of other goods. In fact, a 2009 White Paper produced by the Ministry of National Defence in China reportedly justified this increased presence as being directly linked to the growing number of Chinese commercial actors (Raine 2009).

${ }^{8}$ As of July 2010, China had played a part in nine African UNPKOs, contributing a total of 2,013 peacekeepers along the way (Saferworld 2011: 73).
} 
Table 1 - China's Top Ten African Trading Partners (2012)

\begin{tabular}{|l|l|l|}
\hline \multicolumn{1}{|c|}{ Rank } & \multicolumn{1}{c|}{ Bulk of Commerce } \\
\hline 1 & South Africa & $\begin{array}{l}\text { Mining products (iron, steel); heavy } \\
\text { chemicals; nonferrous metal }\end{array}$ \\
\hline 2 & Angola & Petroleum \\
\hline 3 & Sudan & Petroleum \\
\hline 4 & Nigeria & Petroleum; timber; cotton \\
\hline 5 & Egypt & Marble; granite; cotton; petroleum \\
\hline 6 & Algeria & Petroleum \\
\hline 7 & $\begin{array}{l}\text { Congo } \\
\text { (Brazzaville) }\end{array}$ & Petroleum; timber \\
\hline 8 & Liberia & Shipping vessels; petroleum \\
\hline 9 & Congo (DRC) & Petroleum; minerals; timber \\
\hline 10 & Morocco & Chemicals; cobalt sand \\
\hline
\end{tabular}

Sources: see footnote ${ }^{9}$ (author's creation).

Table 2 - China's Contribution to African UNPKOs since 1999

\begin{tabular}{|c|c|}
\hline Date & Operation \\
\hline
\end{tabular}

\begin{tabular}{|l|l|}
\hline $1999-2010$ & MONUC (DRC) \\
\hline $1999-2005$ & UNAMSIL (Sierra Leone) \\
\hline $2000-2008$ & UNMEE (Eritrea-Ethiopia) \\
\hline 2003-ongoing & UNMIL (Liberia) \\
\hline 2004-ongoing & UNOCI (Côte d'Ivoire) \\
\hline $2005-2011$ & UNMIS (Sudan) \\
\hline 2007 -ongoing & UNAMID (Sudan) \\
\hline 2010-ongoing & MONUSCO (DRC) \\
\hline 2011-ongoing & UNMISS (South Sudan) \\
\hline 2012-ongoing & UNSMIL (Libya) \\
\hline
\end{tabular}

Source: http://www.un.org/en/peacekeeping/resources/ (author's creation).

This rationalist interpretation has received a lot of play since it corresponds well with the dehumanised vision that many have advocated in the West of the PRC being a rabid actor, starved of resources, seeking to consolidate or reinforce its access to African energy markets. As a result, this "thirst" for commodities and business outlets would shape its vision of

\footnotetext{
${ }^{9} \mathrm{http}: / / \mathrm{www}$.thebeijingaxis.com/tca/editions/the-china-analyst-apr-2012/123;

http://www.mbendi.com/land/as/cj/p0065.htm; http://www.china-briefing.com/news/2011/05/25/the-chinaangola-partnership-a-case-study-of-chinas-oil-relationships-with-african-nations.html; http://news.sudanvisiondaily.com/details.html?rsnpid=225205; http://www.china.org.cn/english/features/focac/183429.htm; http://www.sis.gov.eg/En/Templates/Articles/tmpArticles.aspx?CatID=194\#.Uxr-bD95PIk; http://www.worldsrichestcountries.com/top_algeria_exports.html; USITC 2005: 55;

http://news.alibaba.com/article/detail/business-in-china/100255713-1-bilateral-trade-between-china\%252Cliberia.html; http://globalprosperity.wordpress.com/2011/08/10/is-china-capitalizing-on-the-congo/; http://ireport.cnn.com/docs/DOC-413671.
} 
security dynamics on the continent as well as shape its subsequent approach to security risk management (ICG 2008; Vines et al. 2009). But within the literature relevant to discussions on the motives and rationale behind the PRC's approach to dealing with matters of peace and security in Africa, there are those who seek to promote a different understanding which relates more to concepts of external image (Soares de Oliveira 2008: 105). Indeed, some have argued that the PRC's approach to security risk management in Africa is driven by the need to project a certain image of itself for both domestic and international consumption. For the most part, this has entailed Beijing undertaking initiatives as a response to those who seek to portray it as a mercantilist player in Africa (Alden et al. 2008: 24). It has done so mainly by contributing troops to UNPKOs and establishing military exchanges with African states where it has few or budding economic interests (Taylor 2009: 142). ${ }^{10}$ The rationale, in this instance, stipulates that the PRC guides its approach to security risk management in Africa in a way that meets the expectations that come with proving itself as a "responsible stakeholder" to the international community (Zoellick 2005; Grant \& Barysch 2008: 79; Saferworld 2011: 94) one that is driven by a desire to achieve "harmonious development" rather than engage in the excesses of economic competition (Zheng 2005). As a matter of fact, according to one journal article, Beijing's commitment to UNPKOs should be interpreted as: “[...] an attestation to its commitment to multilateralism and its peaceful development strategy, taking responsibility in the international community's efforts to promote peace and stability" (Holslag \& van Hoeymissen 2010: 8). Striking a balance between the two has thus come to form a vital part of the way with which the PRC usually tackles security concerns in Africa.

It has also been suggested that the understanding of African security dynamics by officials in Beijing, as well as China's subsequent actions in this respect, can be explained through a transposition to African security dynamics of the CCP's own experiences in asserting its sovereign authority. By this, Chinese foreign policy officials draw inspiration from the CCP's rule since 1949 to position themselves on the theme of security risk management in Africa. More specifically, this means that Beijing is usually willing to provide help to African governments via arms transfers, training/logistical support and diplomatic assistance even if the legitimacy of the government in question is deemed questionable by the local populace and/or the international community (Taylor 2007: 10; Alden 2009: 17, 60).

\footnotetext{
${ }^{10}$ For example, Chinese military personnel have been dispatched to Cameroon (Holslag 2008: 12; Saferworld 2011: 40), while Ghana and Uganda have each been recipients of Chinese military aid (Holslag 2008: 10-2). Moreover, military attachés have been posted to Botswana, Lesotho, Malawi, Mauritius, Namibia, the Seychelles, Swaziland and Tanzania (Bokilo 2011: 39). These countries, including Côte d'Ivoire, Eritrea and Sierra Leone (as found in Table 1), cannot be considered as states where the current level of Chinese investment can be described as substantial, even if on current trends this situation may well evolve (Holslag 2008: 11-2).
} 
This was the case in Libya, as shown in chapter 7, where although Muammar Gaddafi's regime was on the point of collapse, the PRC clung to the prospect of Gaddafi's stewardship by advocating the need for dialogue between the government and the rebels. Reportedly, this meant that the PRC was selling US\$ 200 million worth of weapons to the regime while it stalled on the recognition of the National Transitional Council (Smith 2011; The Economist 2011). Other similar examples exist regarding China's assistance to central authorities in their (often bloody) struggle against uprisings organised by more marginalised societal groups. Similar patterns of behaviour by the Chinese leadership have been witnessed in Mali, Sudan and Zimbabwe (Tull 2008: 120-2).

The rationale behind such behaviour does not stem from an exclusive desire to protect commercial interests in these countries but emanates also from the fact that throughout the CCP's history, it too has had to face many internal and external challenges to assert its full sovereign control over China. The most frequently cited examples relate to the struggles the PRC has had to face in imposing/regaining control over Taiwan, its Special Administrative Regions in Hong Kong and Macau and, most pertinently, the Western provinces of Tibet and Xinjiang. Its sovereign control has also been tested since 1949 through a number of border spats with neighbouring India, Japan, Russia and Vietnam. Even to this day, as recent attacks by separatist groups across China demonstrate, the issue of the CCP's sovereign control remains as salient as ever (Branigan 2013; Kaiman \& Branigan 2014). Through these experiences, Beijing has come to relate to the struggles in Africa of seemingly like-minded central authorities having to contend with marginalised groups seeking better recognition and representation or just looking to grab power for themselves. For this reason, the PRC's approach is geared towards supporting the domestic standing of these central authorities. As David Shambaugh points out: "another driver of diplomacy is to support the CCP and keep the regime in power. Diplomacy is supposed to enhance the domestic political legitimacy of the party-state and the head of state" (2013: 56). This feature is best reflected in the "Five Principles of Peaceful Coexistence' which have historically underpinned the CCP's approach to International Relations (IR). The concept of non-interference in the affairs of others and the concept of respecting others' territorial integrity constitute the core of Chinese foreign policy thinking. Such thinking is largely designed to legitimise the protection of a state's central authority in order to prevent, as far as possible, external sources from prying into its affairs and undermining its raison d'être (van der Meulen \& van der Putten 2009: 6). China has thus usually been very wary about international interventions for the resolution of crises unfolding in other sovereign states, for fear that doing so would undermine its principle of preserving 
central authority and, at the same time, set a precedent that could possibly come back to haunt it (Shichor 2007; Lee et al. 2012: 435).

This being said, if the Chinese approach to security risk management in Africa largely mirrors its domestic conception of maintaining the political status quo, over time the PRC's decision-makers have found it demanding to always rigidly stick to this assertive stance and rhetoric on non-interference. As the different aforementioned variables shaping its approach indicate, Chinese officials have faced many contradictions in trying to balance the country's economic interests, its international image and its non-interference mentality. At times, one or the other variable may have dominated in its approach to a given conflict situation in Africa but more and more frequently officials in Beijing are faced with having to balance the logic of non-interference with considerations for its international image. Chapter 5 recalls perhaps one of the most well-known cases of the PRC having to adopt a less dogmatic approach to its traditional non-interference policy over the course of the conflict in Darfur, due to the need to relieve some of the pressure exuded on its image by other members of the international community at a time when the Chinese government was looking to bask in the glory of the 2008 Beijing Olympic Games.

In the interest of pragmatism, Beijing has oftentimes been faced with the need to distance itself from its own favoured approach. This has even been noticeable across the different Action Plans that have come out of discussions held with their partners during Forum on China-Africa Cooperation (FOCAC) meetings. As a case in point, in the 2000 FOCAC 'Declaration,' one could typically expect to read such statements as: "no country or group of countries, has the right to impose its will on others, to interfere, under whatever pretext, in other countries' internal affairs" (FOCAC 2000). Nevertheless, by 2006, not only had the word "interfere" been dropped from the 2006 FOCAC Declaration but one could instead perceive a noteworthy change in discourse: "the two sides vigorously pushed the international community to focus its attention on regional conflicts in Africa and take effective steps to help defuse these conflicts" (FMPRC 2007). For these reasons, it could be argued that a tentative shift has been witnessed in the PRC's approach at least in terms of the way that this approach has been presented. If during the early stages of China's re-emergence in Africa the appearance of the PRC's security risk management policy came across as assertive and inflexible, diverse experiences over the past fifteen years have driven its officials to reconsider its approach in a number of cases.

Clearly, more hesitancy and caution has crept into their reasoning as the weight of the balance increases year-on-year in parallel with China's rise as an international power. Yet, to 
unequivocally state that the PRC has undergone a paradigmatic shift of its own regarding its approach to security risk management in Africa would probably constitute an exaggeration. Chapter 7, in particular, will expose the fact that the last of the three variables still plays an integral part in shaping this approach and ultimately deciding the nature of the engagement that Chinese officials are likely to enjoy or endure with their European counterparts on the ground. Beijing has not yet arrived at a point of no return, where international image concerns trump considerations such as the preservation of the domestic political structure or economic interests. Whether China will undergo such a transition is difficult to predict as its ascendance to world power status remains a prospect rather than a reality.

\subsection{The EU's Approach: Reflective of a Paradigmatic Shift or Business as Usual?}

This approach to peace and security in Africa has progressively become a source of concern for Western actors such as the EU. With the PRC asserting itself as a force to be reckoned with on the continent, the EU's own approach has increasingly come under the spotlight. This is because the PRC's rise at times contradicts and obstructs the EU's favoured approach to security risk management in Africa, which since the end of the Cold War has been driven by two sets of reactive forces: a) the desire to normalise its involvement in matters of peace and security in Africa in the context of the post-colonial era, by shifting its interests from the sovereign protection of African states to emphasising human security; b) a heightened securitisation of its approach driven mostly by the events of $9 / 11$, whereby fighting acts of terrorism sponsored by radical Islam has progressively engulfed the majority of the EU's policies towards Africa, leading to a shift in perspective regarding areas of instability on the continent.

In the first instance, the EU and its member states strove to change their rhetoric and attitudes towards violence on the African continent by using the enthusiasm generated in the West for humanitarian interventions in the post-Cold War era, to attempt to break with past practices. Such enthusiasm found its genesis, to a considerable extent, in the increasingly vocal influence of non-governmental organisations (NGOs) and civil society groups in shaping the Western agenda in relation to security risk management in Africa (Kaldor 2007: 39-40). These actors had emerged in the context of the post-Cold War era as a result of the fragmentation and liberalisation of the 'market' for managing the West's approach to managing security crises - where Western government once maintained a monopoly in deciding how to shape their response and involvement, civil society groups had over time carved out a place for themselves, allowing them to incrementally impact this process 
(Duffield 2001: 11). With geostrategic rivalry now redundant, their priority was to mobilise public opinion to the need to prevent the suffering of the numerous victims that usually accompanied African security crises (Ibid: 127; Kaldor 2007: 22; van der Meulen \& van der Putten 2009: 6; Gallagher 2011: 2302). This meant ramping up the pressure on Western officials to act in the interests of the suffering masses rather than focus on politicking with African elites and/or with their rivals. Unfortunately, it would not take long for Western officials to get the message as the events of the 1994 Rwandan genocide provided the impetus for paradigmatic change (Kaldor 2007: 49).

With these groups publically extolling Western governments for having indirectly contributed to the atrocities, having shown too much indifference or having reacted with insufficient haste, it soon became obvious that the business as usual mentality regarding security in Africa had to be abandoned. In a sense, as much as the debacle over European involvement in the genocide portrayed their actions in a negative light, the paradigmatic shift about the need to care for the welfare of civilian casualties in conflict situations also presented European officials with the chance to improve their image of the Western management of conflicts on the African continent. The West could thus use the opportunity of the debate triggered by the Rwandan genocide to reincarnate itself as an actor striving to 'do good' by prioritising human security. With civil society beating the drum and public opinion seemingly following suit, European officials had every reason to embrace this process of normalisation. Internationally, this momentum eventually led to the adoption by the UNSC, in 2005, of the notion of the 'Responsibility to Protect' (R2P) - which describes as 'human' the populations to be protected and as 'humanitarian' the crisis they suffer, the intervention that promises to rescue them and the agencies that seek to carry out the intervention (Mamdani 2009: 274).

Adhering to this paradigmatic shift constituted only one part of the normalisation process undertaken by the EU and some of its member states. Filling old bottles with new wine did not signify that they could relapse back into the old habits of intervening at will without fear of internal or external scrutiny. Therefore, since the 1990s, European officials have developed a hierarchy of preference implicitly regulating European interventions should political violence erupt anew on the continent. This hierarchy of preference constitutes an attempt to balance the volition to remain involved as credible actors within the realm of African peace and security - precisely to convert the human security rhetoric into reality with the need to show that they are serious with moving away from past practices. To encapsulate this paradigm, I have developed the term 'constricted activism,' as using the human security concept to normalise and legitimise their roles within this realm can only be 
achieved if they abide by a set of creditable rules so as to not overlook the past. Practically speaking, the hierarchy of preferences involves three alternatives with the first option acting as the preferred course of action, whilst the final option could be categorised as the option of last resort: a) promoting African ownership of the crisis situation; b) advocating for a multilateral resolution to the crisis situation; c) European governments intervening alone.

Since this normalisation process reflects a balancing act, at the top of this hierarchy of preferences is the option which usually creates the most headaches for European actors in this respect - the matter of African ownership. In their attempt to normalise their presence within the field of African peace and security, European officials have shown support for the development of endogenous local, regional and continental mechanisms to managing violence in Africa that have undergone somewhat of a renewal in the post-Cold War period. This comes across as a logical choice when set against the need to boost Europe's credibility by seemingly pulling out to let African platforms take responsibility and only becoming engaged when needed to provide support to these endogenous efforts. Doing so though, implies that living up to the promises made about guaranteeing human security on the continent are put at risk since the responsibility for the management of these crises lies with African agencies that may not share the Western interpretation or implementation of human security. This contradiction has caused consternation on a number of occasions between African actors looking to appropriate a crisis in accordance with their preferred means of action and their European counterparts taking an altogether different view of these methods, despite the call for African ownership.

Notwithstanding this conceptual grey area, European actors have keenly invested in building up African peace and security capabilities. Indeed, in 2008, a French Defence White Paper claims that it was in Europe's best interests to promote the concept of African ownership (Ministère de la Défense 2008: 44). Judging by a brief overview of the situation since the turn of the century, evidence on three particular fronts would tend to support this statement. Firstly, the EU and specific member states have looked to help strengthen the structures and capabilities of the African Union (AU) and other regional bodies, such as the Economic Community of West African States by providing them with equipment and by accrediting military attachés to deal directly with these bodies (Faria 2004: 20; Bergeron 2007: 56; Esmenjaud \& Franke 2009: 21; Granvaud 2009: 194). Secondly, they have pooled together significant funds - in the shape of the EU's African Peace Facility (APF) - to help finance some of the costs incurred by African ownership of managing peace on the continent. This has usually meant using APF funds to cover the costs of endogenously-led peacekeeping 
operations headed by the AU (such as AMIS and AMISOM) or the Economic Community of Central African States (Mangala 2010b: 182). In a 2005 press release published by the Council of the EU on the topic of the EU-Africa strategic partnership, when referring to the subtheme of security risk management, the first objective stressed that the Union would:

work with the AU, sub-regional organisations and African countries to predict, prevent and mediate conflict, including by addressing its root causes, and to keep the peace in their own continent. In particular, we will strengthen the APF with substantial, longterm, flexible, sustainable funding. We will help develop African capabilities, such as the AU's African Standby Force, and will build on existing activities by member states to provide training and advisory, technical, planning and logistical support (EU Council 2005b: 2). ${ }^{11}$

Thirdly, considerable means have been expended to improve the quality of African peacekeeping from the ground up, most likely as a subtle way to influence the modus operandi of endogenous efforts to tackle insecurity on the continent (Pirozzi 2009). Whether the French RECAMP project, the British-run African Prevention Pool or the EU's EURORECAMP programme, all were specifically designed to establish and manage a number of peacekeeping training centres. ${ }^{12}$

Should African ownership come up short when dealing with specific security concerns, the EU and its member states can turn to other multilateral venues in order to implement their desire to ensure human security, such as organising military or civilian operations under a UN mandate, an EU mandate or a coalition of the willing (Granvaud 2009: 194). ${ }^{13}$ In comparison

\footnotetext{
${ }^{11}$ To which the European Commission and Council Secretariat added in a 2007 joint policy paper on the EUAfrica strategic partnership: "the EU has been a key partner for African countries to help create the conditions for stability and for the AU and sub-regional organisations to execute their ambitious peace and security agendas. The EU has become a political partner that promotes Africa's lead in tackling African crisis and conflicts" (European Commission \& Council Secretariat 2007: 5).

${ }^{12}$ Launched in 1997, RECAMP offered educational training for peacekeeping forces in English and French; a review of African peacekeeping capabilities and multinational field training with a regional focus; and the prepositioning of material to support African peacekeeping forces in Dakar, Libreville and Djibouti (Faria 2004: 20). For its part, the United Kingdom (UK) helped fund the Kofi Annan International Peacekeeping Training Centre in Accra, the 'Ecole de Maintain de la Paix' in Bamako and the construction of a Planning Element in Kenya (Chafer \& Cumming 2010: 1138). EURORECAMP was created as a follow-up to RECAMP, albeit under a European flag, so as to allow France to share the burden with its European neighbours and access greater sources of European funding in order to boost its flagship project (Ibid: 1139).

${ }^{13}$ If, for whatever reason, European actors are unable to intervene directly either militarily or via a civilian operation in a crisis situation, but yet still harbour hope of impacting proceedings on the ground, they can resort to other means such as sanctions, embargoes (economic embargoes, arms embargoes, travel bans and asset freezes) or threatening the use of legal procedures (usually via the International Criminal Court). Again, what is noticeable here is the emphasis on a form of due process. Most often, such sanctions will accompany or pre-empt an intervention but their use - beyond their coercive nature - serves to reinforce the idea of European actors seeking to reinforce their credibility within this realm by resorting to a transparent form of due process, in the shape of an investigation and a subsequent trial. Sticking to this approach obviously provides more credibility than launching a military intervention to resolve a crisis situation, even if many outside of Europe often question the supposed fairness and lack of bias of applying due process.
} 
to African ownership, other multilateral venues do feature predominantly as default options but at times they have been deemed necessary to complement or even supersede endogenous missions. In this case though, European actors will ensure that complementary multilateral operations - which they may be contributing towards - are set up in such a way to guarantee that these interventions will be considered as legitimate as possible both at home and abroad. Political support from local actors is thus as paramount as receiving the green light from the UNSC prior to launching any intervention (Gounin 2009: 64; Granvaud 2009: 206; Sicurelli 2010: 70; Interview 5). Taking heed from the US' 1993 United Task Force (UNITAF) experience in Somalia, European governments rarely rely upon old-fashioned military interventions when undertaking multilateral missions - since they tend to bring back more sinister memories - and are more inclined to participate in low risk operations. In most cases, as Table 3 clarifies below, this will usually involve short-term missions with clear end-dates and narrow mandates focused on the rule of law, good governance or policing instead of large-scale combat operations. Once more, the idea is to focus on ways which will not bring the reputation of European actors into question while allowing them to impact as best as possible the management of a given crisis situation.

Individual interventions, which usually involve the armed forces of a single European state (such as the British Operation Palliser in Sierra Leone and the recent French Opération Serval in Mali) or the EU/NATO undertaking missions in relative isolation (for example the EU's Operation Artemis in the Democratic Republic of Congo) constitute exceptions that confirm the rule. European actors only seek to establish individual interventions on the African continent when endogenous alternatives are overly complicated or when multilateral venues prove cumbersome when it comes to providing a timely response to a given crisis. Nonetheless, the rhetoric used to justify the intervention will usually be designed to reinforce its legitimacy, with arguments that the intervention was necessary in light of an imminent threat or that - as the French government stated on Mali - there was no other choice but to organise an individual intervention (Ministère de la Défense 2008: 74; Oberlé 2013). ${ }^{14}$ Here too, authorisation from the UNSC is a prerequisite whilst European officials will stress to the furthest extent possible that the host state specifically requested the intervention, as was the case for Opération Serval (Le Nouvel Observateur 2013). In addition, these contemporary interventions will never be exclusively carried out by a single European actor. Often a

\footnotetext{
${ }^{14}$ This argument was also made by former US Secretary of State Madeleine Albright to former UN Secretary General Kofi Annan with regard to NATO's bombing campaign on Kosovo in 1999 (Annan \& Mousavizadeh 2013: 94).
} 
symbolic contribution will be sought from local/regional actors (such as the contribution of the Malian army as part of Opération Serval), whereas allies and multinational platforms will be encouraged to contribute to the longer-term picture since the intervention's remit and time span will generally be narrow (see Table 3 ). ${ }^{15}$

Table 3 - EU Operations in Africa since 2003

\begin{tabular}{|c|c|c|}
\hline Date & Operation & Nature \\
\hline 2003 & Artemis (DRC) & Military \\
\hline $2005-2007$ & EUPOL Kinshasa & Civilian \\
\hline 2005-ongoing & EUSEC RD Congo & Civilian \\
\hline $2005-2007$ & $\begin{array}{l}\text { Support to AMIS II } \\
\text { (Sudan) }\end{array}$ & Civilian and military \\
\hline 2006 & EUFOR RD Congo & Military \\
\hline 2007-ongoing & EUPOL RD Congo & Civilian \\
\hline $2008-2009$ & EUFOR Thad/RCA & Military \\
\hline 2008-ongoing & $\begin{array}{l}\text { EUNAVFOR Atalanta } \\
\text { (Horn of Africa) }\end{array}$ & Military \\
\hline $2008-2010$ & EUSSR Guinea-Bissau & Civilian \\
\hline 2010-ongoing & EUTM Somalia & Military \\
\hline 2012-ongoing & $\begin{array}{l}\text { EUAVSEC South } \\
\text { Sudan }\end{array}$ & Civilian \\
\hline 2012-ongoing & $\begin{array}{l}\text { EUCAP Nestor (Horn } \\
\text { of Africa) }\end{array}$ & Civilian \\
\hline 2012-ongoing & EUCAP Sahel (Niger) & Civilian \\
\hline 2013-ongoing & EUBAM Libya & Civilian \\
\hline 2013-ongoing & EUTM Mali & Military \\
\hline 2014-ongoing & EUFOR CAR & Military \\
\hline
\end{tabular}

Source: http://www.eeas.europa.eu/csdp/missions-and-operations/ ${ }^{16}$ (author's creation).

Constricted activism has come to represent an apparent paradigmatic shift in terms of the limitations that Europeans officials have imposed upon themselves when faced with the need to help manage a security crisis on the African continent. At least with regard to past practices, there would appear to have been a definitive break with the past in that the discourse employed when discussing a possible European intervention or the concept of the physical deployment of European law enforcement and military personnel to zones of conflict is far more conscientious than it may have been in the past (i.e. from the end of the colonial

\footnotetext{
${ }^{15}$ Indeed, the EUFOR Chad/Central African Republic (CAR) operation served to provide a back-up for the UN's own Mission in the Central African Republic and Chad (MINURCAT), while MINUSMA (UN operation in Mali) followed up on the recent French-led intervention.

16 'Civilian' and 'military' appellations taken from the website.
} 
period up until the Rwandan genocide). These working methods have clearly evolved, mostly due to internal political pressure emanating from NGOs raising awareness among public opinion about the ethical ramifications of these dubious past practices. This evolution may also have been caused by the arrival of a new generation of officials into the foreign policy fray of some of the most influential EU member states in this regard. Bernard Kouchner, for example, made a political career from having raised awareness of Somalia's plight in the 1990s among the French public. His promotional campaign and eventual accession to public office obviously would indirectly have made it easier for NGOs with a humanitarian agenda to be heard by foreign policy officials in France. Furthermore, his ascendance was symptomatic at the time of what seemed to be a clear move away from an agenda that too often overlooked the plight of civilians caught in conflict situations.

Yet, if constricted activism has meant that European officials and the EU have bound themselves to a more sensitive approach to managing security risks in Africa, it remains difficult to this day to prove that a paradigmatic shift has unfolded in the way that Mary Kaldor refers to it. Certainly, as proven above, constrictive activism has altered the manner with which European officials conceived security risk management in Africa. However, it remains difficult to argue that humanitarianism and the $\mathrm{R} 2 \mathrm{P}$ principle feature as the primary reference points when it comes to shaping the politics of the EU's security risk management policy for Africa. Naturally, EU and member states officials do strive to demonstrate their concern for the civilian victims of conflicts and have displayed a considerable degree of consistency in sticking to this policy. However, with constricted activism creating a decisionmaking conundrum for European officials, the responses to security crises from a humanitarian perspective have tended to fall under the expectations that were raised by R2P, despite their best indirect efforts to mitigate this gap between theory and practice (i.e. by increasing spending on humanitarian aid relief or sponsorship for NGOs working on the ground).

At least this would seem to be the case if one refers to scholarly or civil society groups' criticisms regarding the record of implementing R2P in conflict situations, or even when referring to the victims of these conflicts themselves, who sometimes question why the international community talks about R2P but does little to make it a reality. The first case study on the insurgency in Darfur represents one such example of R2P having very little effect, as the international community appeared powerless in the face of acts of violence being carried out against innocent groups of civilians. Of course, these examples involve a far greater level of complexity for EU officials than simply deciding upon whether to intervene or 
not as per constricted activism. What it does show though is that, for all the talk of a shift, this evolution of the European approach cannot be considered paradigmatic to the extent that R2P has become the focal point. This can be explained by a number of variables, such as the continued misappropriation of the R2P concept (especially following notorious interventions taking place outside of the African continent), leading to a growing fatigue with the concept of intervention on humanitarian grounds as the Rwandan tragedy loses its impact with time. In addition, dwindling military spending in the EU conjoined to budget cuts resulting from the economic crisis has lessened the availability of resources for actions that are perhaps not considered a priority by European officials. This leads to another key point: over time, humanitarianism has simply lost its prominence in relation to security risk management in Africa. In fact, security risk management in Africa has also witnessed peaks and troughs as a foreign policy concern for the EU, especially in light of other ongoing crises (as seen today in Iraq, Syria or eastern Ukraine).

Launched in the wake of $9 / 11$ though, it is the War on Terror (WoT) though that relegated humanitarianism and the $\mathrm{R} 2 \mathrm{P}$ principle to a secondary source of influence for the EU's security risk management approach in Africa. In effect, if constricted activism has come to shape a large part of the EU's approach since the end of the Cold War, in more recent times a second strand has impacted the way the EU and European officials interpret and act upon instability on the continent: securitisation has become the keyword ever since the WoT got underway. Unsurprisingly, it has often contradicted and conflicted with humanitarianism and the search for legitimacy which European actors have attempted to pursue since the 1990s. Some scholars have argued that the WoT brought Africa back into the EU's strategic mindset after a period of disinterest, triggered by the end of the Cold War rivalry (Steiler 2010: 2; Abrahamsen 2013: 3). This is explained by the fact that European officials began to establish links between the sources of instability on the African continent with acts of terrorism undertaken against Western targets under the name of radical Islam, especially as the bombings in Madrid and London were carried out by citizens of different African countries (Wennerholm et al. 2010). Consequently, in the aftermath of 9/11, terrorism increasingly became the defining lens through which political violence and African security were engaged - in the sense that failed states, poverty and underdevelopment were considered attractive to terrorist organisations, offering them a safe haven from where to conduct their activities (Abrahamsen 2004: 681; Smith 2009: 25). In effect, it comes as no surprise to read that the 2003 'European Security Strategy' lists global terrorism, the proliferations of Weapons of 
Mass Destruction (WMD), regional conflict, failed states and organised crime as the five most prominent threats to Europe's safety (Freire 2008: 14). ${ }^{17}$

Since the WoT had rerouted the EU's approach along a more strategic approach, a number of policy areas and disparate concepts driving its overall African policies were thus regrouped under the heading of the counter-terror ambit. In other words, trade policies, development aid and migration no longer targeted separate individual objectives but were pooled together in an attempt to pre-emptively prevent radical Islam from spreading in supposedly susceptible areas (i.e. failed states, underdeveloped states...) (Dehéz 2007: 32; Abrahamsen 2013: 6). For this reason, should a crisis situation be identified in Africa as forming part of an attempt by different strands of radical Islam to create instability, the chances that European actors are likely to get involved are significantly higher than situations that are not related to the WoT. In this respect, securitisation would seem to have trumped the priority of normalisation via humanitarianism in shaping Europe's approach to interpreting and thereafter tackling security threats on the continent. Taking the French-led intervention in Mali as a case in point, momentum behind the decision to deploy troops was only garnered upon realising that the threats engendered by the nomadic tribes in the north of the country towards the capital, actually formed part of an attempt by al-Qaeda in the Maghreb (AQIM) to seize Bamako. ${ }^{18}$ This being said, the overall record of European actors indicates that this distinction between humanitarianism and securitisation is far from clear-cut and often contradictorily seeks to combine elements from both driving forces.

\subsection{The Nature of Bilateral Interaction: A Variable State of Affairs}

Having established a comparative overview of their respective approaches towards security on the African continent, what matters most at this stage is to garner a better understanding of the implications that these approaches hold within an interactive environment. Since neither China nor the EU operate inside a vacuum on matters of security risk management in Africa, the study of these implications will form part of the rationale behind this thesis. In general, the

\footnotetext{
${ }^{17}$ Even the EU-Africa-Caribbean-Pacific Agreement was revised in order to extend the sphere of action of the EU in Sub-Saharan Africa (SSA) to the areas of counter-terrorism, proliferations of WMDs and mercenary activity (Sicurelli 2010: 42).

${ }^{18}$ Some have posited that the desire to intervene in these conflicts also derives from an opportunistic trend to use the intervention as a means of increasing the domestic standing of political actors within Europe or the international reputation of the EU member states (Ero 2001: 51; Charbonneau 2008: 29; Rye Olsen 2009: 136; Gegout 2010: 133). One example cited in this respect concerns the apparent attempt by Nicolas Sarkozy and his advisors to use French leadership of the aerial strikes in Libya to boost his ratings in the polls - an approach current President François Hollande is also sought to have used to exploit the successful intervention in Mali (Chrisafis 2011; Chrisafis 2013).
} 
overall situation could be described as one where China and the EU adopt relatively diametric positions on matters of peace and security on the African continent, that Jack Mangala has summarised as a struggle between the "traditionalist" view promoted by the Chinese government and the "humanist" version favoured by the EU (Mangala 2010a: 2-3). As far as the EU is concerned, this divergence appears to represent a source of concern as a draft report produced by the European Parliament made clear: "in view of its responsibilities as a permanent member of the UN Security Council, China must be urged to move from favouring state-centred security to supporting "human security"' (2007: 10). These differences are only exacerbated by the fact that both actors operate within a relatively 'anarchic' milieu when it comes to peace and security on the African continent, due to the paucity of credible national, regional, continental or international bodies with the authority to ensure third parties commit to cooperative standards and optimal outcomes striving for the global good and not the lowest common denominator - a situation rendered more complex since many African officials are often unsupportive of such a bilateral rapprochement. As such, it is more a case of exogenous parties behaving individually in ways they see fit, often in response to specific local demands, with local actors oftentimes attempting to play outsiders off against each other. ${ }^{19}$ The chances for cross-cutting, rivalry and double-dealing would thus seem to be fairly prevalent in this type of environment.

This depiction of the contrasting stances adopted by the EU and China when faced with crisis situations tells a large part of the story but does not tell the whole story. Mainly this is the result of the reaction witnessed on an official level in Brussels in relation to China's ascendance in the realm of security risk management in Africa. From a very early stage onwards, the rhetoric employed on the European side has attempted to dispel any misgivings about the interpretation in Brussels concerning the PRC's growing importance in this domain, whilst attempting to lay the groundwork for cooperation to ensure that it becomes the norm as far as their bilateral dealings are concerned. In effect, as early as 2006, the topic of African security dynamics had made its way onto the bilateral agenda, where the EU first expressed its desire to explore opportunities for building a cooperative spirit in order to bridge the bilateral political divide (Steiler 2009: 20). In so doing, Brussels was keen to stress the

\footnotetext{
${ }^{19}$ An op-ed in the Financial Times by former Senegalese President Abdoulaye Wade gave a telling insight into the relief felt by African elite of China's emergence across the continent, both for the fact that the PRC seemed to pay greater attention to their needs but also because it provided the perfect foil with which to leverage Western actors into making greater concessions. As Wade extolled: "China's approach to our needs is simply better adapted than the slow and sometimes patronising post-colonial approach of European investors, donor organisations and non-governmental organisations. [...] Not just Africa but the West itself has much to learn from China. It is time for the West to practice what it preaches" (2008).
} 
conjoined nature of their predicament: "the two sides stressed the importance of their relations with Africa and stated their commitment to work together in favour of Africa's peace, stability and sustainable development" (EU Council 2006d). ${ }^{20}$ Former High Representative (HR) for the EU's Common Foreign and Security Policy (CFSP), Javier Solana, made this case more explicitly when he stated that:

to be more effective, we need better understanding of what we are each doing, of the policies and programmes we are each pursuing, not least that our efforts do not cut across each other as they have sometimes in the past [...]. Africa is an important focus for the EU's cooperative strategic partnership with China. The EU and China are both committed to helping deliver peace, stability, development, prosperity and good governance in Africa. I look forward to working ever more closely with my Chinese colleagues in helping to address these important challenges in partnership with Africa (2007: 3).

These initial reactions confirm the point made in the previous section about utilising cooperation as a vector through which to mitigate the negative ramifications caused by possible differences in perceptions. In the eyes of two commentators, Solana's speech clearly pointed to the EU's desire to get China to abide by norms of international governance in order not to undermine the former's objective for "Africa's long-awaited renaissance" (Huliaras \& Magliveras 2008: 413). A year after Solana's statement, the European Commission published a policy document - entitled 'The EU, China and Africa: Towards Trilateral Dialogue and Communication' - specifically designed to put across the message to the authorities in Beijing that bilateral interaction on this theme did not have to boil down to a zero-sum game, with cooperation utilised exclusively to level out this competitive playing field. The Communication stipulated that:

at the tenth EU-China summit in Beijing [...], the EU and China's leaders welcomed more practical cooperation by the two sides through their respective existing cooperation mechanisms with Africa so as to contribute to Africa's peace, stability and sustainable development on the basis of equality and mutual benefit. The two sides agreed to continue their dialogue on African issues and actively explore effective ways and channels of cooperation amongst China, the EU and Africa in appropriate areas (European Commission 2008: 5).

Once more, this document amounted to an attempt by the EU to convey, in official terms, the following message to the Chinese leadership: "the underlying objective is basically to build

\footnotetext{
${ }^{20}$ Around the same time, the British government had also made similar overtures to Beijing in a bid to reinforce the notion that Europeans sought a cooperative stance towards the Chinese on this matter. In February 2006, former British Foreign Secretary Jack Straw - during a speech to the Nigerian Parliament - stressed that: "China's engagement in Africa is good news [...]. What matters to us is not the fact but the manner of China's engagement in Africa" (cited in Alden 2009: 107-8).
} 
trust and to accept you as a legitimate player; we don't see you as an antagonist, we don't want to have a problem with/over Africa" (Interview 6).

But in the view of academics and officials alike, bilateral cooperation is not only relevant as a means of bridging the political divide to avoid the negative ramifications of competitive behaviour but it is also relevant since it is in the shared interest of both sides to help each other help themselves. To some degree, both sides are equally vulnerable to the collateral effects of instability across the continent even if these effects may transpire differently in practice for both parties. Jonathan Holslag has taken the example of geographical proximity and distance to highlight how both share the common fate of instability, visible albeit for the distinctive symptoms respectively affecting them (2009: 2). As one of the African continent's direct neighbours, the EU directly and indirectly suffers from the latter's instability in the shape of the repercussions engendered by failed states (terrorism, illegal migration, criminal networks...). Despite the geographic distance separating the PRC from Africa, its economic and political ascendance makes it as susceptible to these collateral effects as the EU, as the Chinese government is now beginning to recognise in the light of the threat of instability to the impressive investments made by Chinese companies across the continent and, more worrying, to the human dimension (Saferworld 2011: 24). ${ }^{21}$ Over the past few years, a growing number of Chinese workers have been victims of kidnappings and murder often as a result of terrorist, political or criminal groups looking to attract Beijing's attention for different reasons (ransoms, political recognition, to spread terror...).

Last but not least, despite the African continent representing a somewhat anarchic environment where cooperation would appear difficult to come by for exogenous players such as the EU and the PRC, it does actually offer a more conducive environment for international bilateral cooperation due to its lesser strategic relevance. This is because for the Unites States' (US) foreign policy interests, the African continent and SSA in particular do not pertain to the same degree of strategic relevance for the world's only superpower as the Middle East, the Asia Pacific region and more recently the Eastern borders of Europe. Of course, this is not to say that the Saharan and Sahelian regions matter little for the foreign policy interests of the US but Africa as a whole cannot be said to matter as much as the three other geographic areas listed above. Diplomatic coordination and cooperation on an international level between the EU and China is contingent upon other existing foreign policy interests and relationships -

\footnotetext{
${ }^{21}$ According to Holslag, Beijing has ordered its embassies in Africa to keep a close watch on local security (2008: 9).
} 
such as those of the US. As a result of this lesser strategic focus on Africa in Washington, this has undoubtedly contributed to facilitating this fairly cooperative spirit between Brussels and Beijing regarding their dealings on the African continent. Indeed, for either party, affairs in Africa do not top the list of their respective foreign policy concerns despite their shared vulnerability to the collateral effects of instability that affects numerous parts of the continent, thus facilitating bilateral cooperation.

In the light of the above, this explains why official calls for the past decade for bilateral cooperation on a range of issue areas relative to security risk management in Africa have been put forward (with the support of the relevant academic community) in a bid to stimulate a common response, which infrequently have led to actual cases of diplomatic coordination or practical cooperation. ${ }^{22}$ Five general subthemes are usually pointed to throughout policy papers and scholarly publications as being issue areas where bilateral interests overlap and activism should be encouraged, to strive towards a more optimal outcome all round - as much for local actors as for exogenous parties. These are:

- Peacekeeping: supporting the endeavours of the AU and regional organisations; jointly assisting with the provision of funding to help cover costs and assist with training; ${ }^{23}$

- New Security Threats (NSTs): including pandemics; food security; environmental and climatic threats; refugees and displaced persons; resource-related conflicts; organised crime;

- Arms transfers: including improved controls and disarmament;

- Terrorism: including the risk of non-proliferation;

- Conflict management and coordinated/cooperative responses to crisis situations. ${ }^{24}$

\footnotetext{
${ }^{22}$ Peace and security was listed as the first priority area for the fact that it corresponded - according to one of its authors - as the one area: "where African ownership was very clear, with the African Peace and Security Architecture (APSA), with the principles they had. We knew China had a policy to support peacekeeping through the UN, or the regional organisations, so there was no real obstacle there. We had a big stake in this through financing the AU in this area with a lot of money, but there were also things that we could not do, which China could" (Interview 6).

${ }^{23}$ The annex to the EU's policy document on 'The EU, China and Africa: Towards Trilateral Dialogue and Communication' explicitly talked of the need for: "cooperation to promote stability and prosperity in African countries and economies and to work with the African Union and the UN with China to strengthen the development of the APSA and assist with AU peacekeeping operations, capacity-building and training" (European Commission 2008: 6).

${ }^{24}$ Bibliographical references: peacekeeping (see: EU Council 2006a: 7; People's Daily 2006; FMPRC 2007; Herman \& Davies 2009: 9; Interview 6); NPTs (see: People's Daily 2006; Wild \& Mepham 2006: 69; European Parliament 2007: 6; Herman \& Davies 2009: 10; Interview 18); arms transfers (see: European Parliament 2006: 6; FMPRC 2007; Holslag \& van Hoeymissen 2010: 15; Wheeler 2011); terrorism (see: EU Council 2004e; EU Council 2006a: 10; FMPRC 2007; Stumbaum 2007: 359); crisis management (see thesis).
} 
Up until now, the success rate of implementing these promises into tangible results has been described by one analyst as "mediocre" (Renard 2011: 25-6). This description is justifiable to the extent that not only the call for trilateral cooperation appears to have fallen on deaf ears, but only the first and last issue areas have actually produced the kind of practical coordination and cooperation required to bring the rhetoric to life. Commentators are perhaps though best advised to reserve judgement for the time being in the light of the nascent character of this bilateral area of activity. Some evidence of practical cooperation does exist, notwithstanding its modest output. On peacekeeping, one EU member state (the UK) has provided training (mostly language-based) for Chinese peacekeepers preparing to take up their roles as part of African UNPKOs (Interview 17). As later chapters of this thesis will outline, a fair amount of bilateral interaction has been undertaken on the management of crises on the African continent, which overall has led to mixed outcomes including a couple of 'success stories' (e.g. Somalia and Mali). These examples may not prove to be groundbreaking but their very existence supports the idea that bilateral interaction cannot be categorised as a competitive one-way street, despite the aforementioned differences of perception. Moreover, when acts of coordination and cooperation have taken place, clearly they have been driven as much by the volition to mitigate the possible ill-effects of competitiveness, as by the added-value both sides can draw from collaborating on subthemes where they share similar interests.

This section on the cooperative facet of their interaction has served to show that it should be considered as an integral part of overall bilateral interaction in Africa, even if the political divide naturally favours a competitive outlook. Steiler has even gone so far as to suggest that EU officials are more inclined than ever to aspire to cooperative outputs with the Chinese government in Africa, thus reinforcing the need to consider both facets of bilateral interaction as a whole rather than emphasising one over the other (2009: 134). This part of chapter 2 has sought to convey the idea that the EU and China's bilateral dealings are complex, varied and have not always followed a predictable pattern. This is why, in the view of this thesis, these different interactions should be understood as a whole so as to gain insight from this varying pattern into the true nature of these bilateral ties, the perception that officials on the ground from either side hold of each other and into how these ties operate practically-speaking in this type of environment. But to comprehend this varying pattern as a whole, a suitable analytical framework is first required - it is for this reason that this thesis has opted to apply a conceptual framework on trust, in the belief that political trust (or the 
lack of) between officials from both sides is primarily what determines the nature of their interactions on cases of security risk management in Africa, whether competitive or cooperative. If the concept of political trust can perform this analytical task in this regard, then it is above all a cognitive-based framework (with its own analytical toolkit) that is needed rather than other more mainstream concepts of political trust, as the next chapter will now explain. 


\section{Literature Review on Trust}

\subsection{Teleological Approaches}

\subsubsection{Rationalists}

As explained in chapter 1, the most common approach to the study of trust within the FPA theory literature is based on the premise that the decision to give and/or receive trust is above all a rational one. Drawing inspiration from economic sciences, rationalist theorists have held firm to this belief throughout the history of FPA scholarship and have attempted to sway audiences of the veracity of their beliefs by applying game theory models such as 'Prisoner's Dilemma' or 'Tit-for-Tat.' Usually, these models have been tested in social science laboratories or investigated against the backdrop of real-life phenomena, and they usually focus on the choices two specific actors can make over the course of their interaction on a given predicament. Within the literature on FPA theory, this has most often translated into studies of the US-Soviet rivalry in the context of the Cold War. This approach would thereafter stipulate an instigating actor placing trust in a receiving actor in the belief that the latter will reciprocally act in a way that makes the former better off, and vice versa (Deutsch 1958: 269; Lorenz 1993: 308; Keohane \& Ostrom 1995: 4; Welch Larson 2000: 20; Möllering 2006: 19).

For rationalist scholars, trust should thus be conceived as equating to risk-taking. Indeed, instigating actors not only have to determine whether or not they will be better off placing their trust in another, but primarily they have to ask themselves whether it is worth placing such trust in the first place (Riker 1974: 65; Feger 1991: 295). For this, they need to carefully calculate the risk (Hoffman 2002: 378). In fact, as far as Reinhard Bachmann is concerned, trust neither exists nor has any utility as long as there is no risk (2006: 395). This is so, in essence, because in the rational conceptualisation of trust if an actor is in a situation where he/she/it needs to trust another in order to achieve an outcome that will ultimately be to the former's benefit, that actor is rendering itself vulnerable to the other's behaviour. For rationalists, trust thus makes little sense if one refuses to render itself vulnerable to another (Baier 1986: 235; Heimer 2005: 43; McEvily et al. 2006: 54). Nicholas Wheeler attests to this assumption by stating that:

the most important action, and the one that defines the emergence of a trusting relationship, is a decision by one or both parties to make themselves vulnerable - or at least not seek to eliminate existing vulnerabilities - as a way of communicating their trustworthiness (2012: 2). 
Therefore, as most game theory models implicitly convey, trust - for all the possible gains should in no shape or form be dissociated from the vulnerability one incurs when deciding to trust in another, given the very real probability that the other party could seek to exploit the former's decision to trust (Luhmann 1979: 24; Gambetta 1988: 218-9; Solomon \& Flores 2003: 6; Kydd 2005: 6; Booth \& Wheeler 2007: 241). To summarise the fundamentals of the rationalist approach to trust, this concept should be understood as making sense in situations where a careful balance or "threshold" has been achieved between gains and risk, and making little sense when that threshold is unattainable (Swinth 1967: 336; Kydd 2005: 41, 183).

From this very broad overview of the rationalist literature relative to trust, a few key points need to be raised regarding procedure. Without delving into the specifics of game theoretical models, it is important to mention procedure given that the literature often refers to specific conditions, actions and options which are not only vital in terms of comprehending the logic behind game theory but also matter for the later discussion on cognitive approaches. In effect, although most rationalist model 'games' are expected to unfold in relatively static and sequential environments the perception that actors have of each other plays a large part in determining whether or not, from a rational vantage point, the players will ultimately choose to place trust in each other. This idea of perception should not be confused with any constructivist accounts of the term but instead relates to the players' respective abilities to predict the future behaviour of the perceptible other. Similar to the game of chess, it is this deductive capacity which will allow the instigator to decide whether or not to trust. According to this literature, perception is shaped on the basis of collected information from past interaction(s) or by referring to prototype (Jervis 1976: 410; Axelrod 1984: 140; Burt \& Knez 1995: 284; McKnight \& Chervany 2006: 31). As Roderick Kramer posits:

interactional histories give decision-makers information that is useful in assessing others' dispositions, intentions and motives: this information, in turn, provides a basis for drawing inferences regarding their trustworthiness and for making predictions about their future behaviour. [...] Actors usually possess some general set of beliefs and expectations regarding the trustworthiness of the 'average' or prototypic other within the group/organisation (2010: 84-5).

In this instance, readers must be reminded that this power of deduction is attributed to players in the context of a game theory situation. Consequently, players are perennially at risk - whether risking potential gains to be made from forming a trusting partnership with another or at risk from the inability to rely upon one's perception (Dunn 1988: 73; Heimer 2005: 44). Indeed, there exists the possibility that trust instigators in a Prisoner's Dilemma find 
themselves unable to revert either to past interaction or prototype, in order to shape their perceptive probability of whether to trust or not. To manage such uncertainty, the literature has devised four mechanisms applicable to game theory which can increase the likelihood of players opting for trust, by reaching the threshold alluded to above. These are: reciprocity; verification; third-party intervention; game theory-specific communication.

Regarding the first point, many rationalist studies contend that if the other party is inclined towards reciprocity within this self-interested model, or if the instigating player believes that the other is likely to reciprocate, then the risk of exploitation regresses and the odds of a profitable outcome accrue (Axelrod \& Keohane 1985: 244; Brown 2000: 246; Tyler 2001: 287; Kydd 2005: 9). Of course, in practical terms, rationalists have elaborated upon this rather aloof principle of reciprocity. The most noteworthy account in this respect concerns Charles Osgood's 1962 'Graduated Reciprocation in Tension Reduction' (GRIT) strategy designed against the backdrop of Soviet-American rivalry - in order to break the cycle of suspicion and fear by reciprocating the recipient states' advances or, failing any response, getting the instigating state to initiate incremental advances (Wheeler 2012: 6). In a sense, the GRIT strategy worked on the basis of a reverse "spiral model," where reassuring and conciliatory "signs" would be sent by the instigating actor in the game, as a means of diffusing any potential misgivings about its intentions towards the unfamiliar player, thereafter laying the groundwork for reciprocation and trust to prosper (Lindskold 1978: 774; Kydd 2005: 187).

If reciprocity proves insufficient, scholars have suggested that the path to trust can be paved by both sides instigating verification mechanisms. For Deborah Welch Larson, without such devices, neither party can afford to take the risk to trust due to their inability to monitor the other's performance, thus reducing the deterrence factor of retaliatory action and subsequently leaving the instigator open to exploitation by the recipient party (2000: 3). Her views are confirmed by others in the field who argue that should monitoring and pre-emptive sanctioning become too burdensome, players may never even reach the stage where trust would become feasible (Axelrod \& Keohane 1985: 236). In which case, players can try turning to a third party - a role which, in accordance with the Hobbesian-inspired rationalist literature, can only be performed by a "trustworthy," "neutral" or "serious" hegemonic player (Burt \& Knez 1995: 279; Kydd 2005: 179; Cook et al. 2007: 41). ${ }^{25}$ Such an intervening force would supposedly enable and facilitate acts of trust between two other unfamiliar parties.

\footnotetext{
${ }^{25}$ Some authors have though argued that, a contrario, third parties can also serve as a disruptive and destructive force in a two-player game (Feger 1991: 296).
} 
Lastly, a considerable number of studies on game theory models have found that permitting communication between the two parties leads to a higher probability of trust being fostered, while reducing the chances of opportunistic exploitation and defection (Krauss \& Deutsch 1966: 572; Swinth 1967: 335; Luhmann 1979: 43; McClintock et al. 1983: 218; Good 1988: 36). To the untrained eye this may be all but axiomatic. However, as implied earlier, most laboratory-based game theories were designed in such a way that players were not entitled or encouraged to engage in direct, face-to-face interaction. Some models were nonetheless adjusted to incorporate communicative abilities in the context of rational models, where scholars observed that in so doing, mutual trust was established more frequently than in situations where such communication did not feature (Deutsch 1958: 275). This is because, as Charles McClintock (et al.) underlines:

communication allows bargainers to explore fully the realm of possible outcomes, identify mutually satisfying outcomes, insure full understanding of the reward contingencies and estimate the rewards and costs to self and other of various alternative outcomes. In other words, full communication contributes to the integrity or cooperative aspects of bargaining $(1983: 213) .^{26}$

\subsubsection{Neoliberal Institutionalists}

Advocates of neoliberal theories may not always share the exact same ideas as those referred to in the above section but they have been regrouped under the teleological heading for the simple fact that neoliberalism, in the field of FPA theory, takes its cues from the economic sciences and thus works on the basis of calculated self-interests. The objective of this section is not to review the breadth and depth of this strand of literature with regard to the concept of trust but instead to review the major proposals put forward by neoliberals and, in particular, neoliberal institutionalists on how to create trust between two actors in the realm of a game theory model. Where neoliberal scholarship does differ from more classical rationalist approaches is in the belief that the key to building trust in such anarchic and perilous circumstances, relies upon both parties' ability to develop an interdependent relationship (Loomis 1959: 305; Brown 2000: 252; Cook et al. 2007: 2). In fact, some authors are of the belief that the greater the levels of interdependence, the more crucial the "state" of trust (Boon \& Holmes 1991: 191). Unsurprisingly, most studies of this nature have tended to contemplate the means conducive to the establishment of trust under such conditions. Sifting through this

\footnotetext{
${ }^{26}$ In a later publication, Deutsch made the point that in game theory, communication was: "[...] likely to be effective to the extent that the basic features of a cooperative interrelationship are made explicit in what is communicated. These basic features are: expression of one's cooperative intentions; expression of one's cooperative expectations; expression of one's planned reaction to violations of one's expectations; expression of a means of restoring cooperation after a violation of one's expectation has occurred" (1973: 198-9).
} 
literature, it would seem that three mediums are prioritised: increasing commercial dealings between actors; creating regimes/institutions under which they can conduct their interactions; the instigating actor adopting a "transcender" logic upon the receiving party (Booth \& Wheeler 2007: 18).

Reverting back to classic liberal theory, the first medium argues - in grossly oversimplified terms - that strengthening economic interests among the two actors favours openness and cooperation, ultimately leading to a "virtuous circle" of improved relations and trust (Kydd 2005: 203; Keohane \& Nye 2012: 276). As far as game theory models are concerned this approach is fairly self-explanatory. Yet if the players are unable to do so, or should improved commercial dealings fail to establish the necessary trust threshold discussed above, then the parties are encouraged by neoliberal institutionalists to set up regimes in which they (along with others) can mutually lock and bind themselves in. What Niklas Luhmann named "systems trust" (cited in Bachmann 2006: 398), the idea is to use common institutions as the stepping stone through which to construct interdependence that eventually will lead to the development of trust amongst even the most selfish of players. The literature on the added-value of institutions has developed multiple rationales for justifying the necessity of mutually binding regimes, but all rely on the precept that institutions will provide the incentives unfamiliar actors require so as to put their minds towards interdependence (Keohane 1990: 236; Hardin 2007: 22).

One of the most frequently cited incentives within this neoliberal scholarship posits that regimes facilitate interdependence by lowering the transaction costs associated with trusting behaviour. Usually regimes are seen as being able to do so by designing and implementing specific rules which serve to produce three effects as far as the reduction of transaction costs are concerned: institutions can be relied upon to credibly fill the void with regards to monitoring and sanctioning; to reduce the asymmetry of information by helping to promote transparency and disseminate relevant knowledge; to reinforce reciprocity (Axelrod \& Keohane 1985: 237, 239, 250; Keohane \& Ostrom 1995: 21; Katzenstein 1996: 25; Kowert \& Legro 1996: 458; Glaser 2010: 161). In other words, institutions enforce what unfamiliar actors are incapable of mutually undertaking: reducing uncertainty/enhancing predictability; making defection more costly by substantially increasing the returns for all members of the club in a cohesive fashion; reducing the scope for individual retaliatory action (Axelrod \& Keohane 1985: 250; Bachmann 2006: 396; Booth \& Wheeler 2007: 2; Peters 2010: 51). Actors therefore have little excuse for not renewing the process thereby moving them ever 
closer to the trust threshold, while defection through exploitative opportunism would be counterintuitive given the incentives at stake.

The last element referred to within the neoliberal literature argues that interdependence and, hence, trust can be achieved if unfamiliar actors undergo a homogenisation process or at least behave according to a homogenised set of principles. Paying heed to German philosopher Immanuel Kant's writing on 'Perpetual Peace,' instigating actors would adopt a transcender logic towards the other game players to get them to reform their moral reasoning more in line with the instigator's own practices (Booth \& Wheeler 2007: 17). To function adequately though, such reforms would have to be universal and unequivocal (Ibid: 18). The game, as such, would subsequently no longer be a game but rather an exchange among allies and friends (Keohane \& Nye 2012: 28). The underlying assumption behind this logic stems from another core component of the neoliberal IR scholarship: the democratic peace theory. This theory postulates that democratic actors are more likely to trust likeminded democratic actors than they would non-democratic actors and than non-democratic actors amongst each other (Moravcsik 1997: 540; Kydd 2005: 21). Although a thorough discussion of this theory goes beyond the objectives of this section, it is safe to hypothesise that in accordance with neoliberal institutionalist theory, in game theory-type situations an instigating actor would best be advised to hedge his/her/its bets on the long-term internal reform of the unfamiliar actor along more familiar lines. This would constitute, in itself, the optimal mean through which to secure the other's trustworthiness, for which regimes can serve as a pivotal intermediary for triggering this eventual change (Algieri 2007: 70; Keohane \& Nye 2012: 28).

\subsubsection{Rationalist Critiques and Analytical Relevance}

For all the research that has gone into reworking and refining the rationalist literature on trust, there exists a considerable component of trust researchers that remain partially or wholly unconvinced by the supposition that trust should be conceptualised as a calculative, selfinterested process first and foremost. Some academics are of the view that trust is both the result of a combination of rational deduction with more cognitive elements, whilst others take a more critical stance by declaring that trust is anything but a game and instead pertains exclusively to cognitive factors. The purpose of this section is thus to: a) outline the major criticisms levelled at rationalist approaches to trust research; b) gauge the added-value of such approaches for the purposes of this particular study.

Cognitivists' gripe with rationalist frameworks emanates from the former's belief that trust cannot be made sense of without a study of actors' emotive and ideational composition. 
They charge game theory models of trust for not only largely overlooking core cognitive aspects, but in those cases where such aspects may feature in the models (as witnessed earlier in reference to perception or communication) they usually are taken for granted (Dessler \& Owen 2005: 598; Houghton 2007: 43). For cognitivists, this is problematic for the fact that these aspects are likely to hold the analytical key to discerning whether actors are likely to build trust or not within a given context. In particular, they deride cost-benefit analysis models or Prisoner's Dilemma games for being too mechanical and for simply assuming the following key dispositions in the context of trust-building: identity (Gambetta 1988: 217; Jepperson et al. 1996: 41, 43), ${ }^{27}$ culture (Fisher 1997: 67), emotion (Solomon \& Flores 2003: 103; Fiske et al. 2006: 77; Mercer 2010: 13; Head 2012: 35), faith (Jones 1996: 4; Heimer 2007: 49), ${ }^{28}$ or sincerity/respect (Cook et al. 2007: 4; Booth \& Wheeler 2007: 244). Across the literature, this selection is not exhaustive and the list of cognitivist aspects which these critiques believe matter for trust could run on longer. Yet the message most such studies seek to convey is more straightforward: trust should not be assessed solely as the calculative "predictability" of incentives (Solomon \& Flores 2003: 70). This criticism could be seen as being targeted somewhat unfairly at rationalists who have devoted time to incorporate certain cognitivist elements, although doing so within the confines of the rules of game theory and thus naturally limiting the scope for ideational concerns. As one cognitivist scholar correctly elucidated, this is because the cognitivist aspects highlighted above would only come to "undermine" the sheer purpose of rational decision-making (Head 2012: 33). ${ }^{29}$

\footnotetext{
${ }^{27}$ For example, cognitivists would not look favourably at Andrew Kydd's rationalist work on trust between "security seekers" and "expansionists" in a Cold War setting, given that he provides no information about their agency or how they came to be labelled as such in the first place, other than relying upon the international structure to determine if they qualify as security seekers or expansionists (2005:34).

${ }^{28}$ Faith, here, should be understood as the act of having faith in someone/something to achieve an expected endresult, rather than the religious connotation of the term.

${ }^{29}$ Not to be outdone, rationalist advocates have riposted over the years with counter-criticisms of their own regarding the utility of cognitive elements when undertaking research on trust. For the most part, keeping in mind the study of trust within the realm of a game theory model, rationalists have castigated ideationalist elements when attempting to factor them into these models, as simply not being very "meaningful" (Williamson cited in Nooteboom 2006: 247) or "epiphenomenal" at best (Jepperson et al. 1996: 38). They consider these elements as only being of relevance to trust in the context of very special relations, such as that between family members, friends and lovers but not for the study of interactions between unfamiliar actors within the realm of international affairs (Williamson 1993: 484). Summarising the general feeling among rationalists, Guido Möllering states that: "[...] without actors, expectations, vulnerability, uncertainty, agency and social embeddedness, the problem of trust does not arise and, if this were the case, the conceptualisation of trust would be pretty meaningless or superfluous" (2006: 9). Taking this debate a step further, some rationalist scholars are of the belief that it is not only impertinent to study trust through a cognitive lens, but also unrealistic and unnecessary (Axelrod 1984: 87, 174; Elster cited in Möllering 2006: 19; Glaser 2010: 32). Unsurprisingly, in relative terms, cognitive approaches are simply too "vulnerable" for the rationalist mindset in the context of trust research (Keohane 1990: 236; Tyler 2001: 301).
} 
Beyond complaints of rational models being too rigid and methodical to their liking, cognitivists (as well as some academics that fall outside this categorisation) claim that calculative approaches suffer from a lack of dynamism and remain too simplistic to apply to the study of 'real life' situations, as witnessed in the quotidian affairs of international politics. Despite the simplification of complex activity into theoretical models being sine qua non for the very existence of academic reasoning, cognitivists are dissatisfied at the apparent reductionism within rationalist scenarios of actors pondering over whether to put their faith in trust. Mainly, criticism is aimed at the overly basic matrix of choices and options allocated to trustor and trustee in game theory situations (cooperation or defection), whilst international affairs usually involve more than two players and two alternatives - thus "distorting" reality (Rotter 1971: 444; McClintock et al. 1983: 214; Maoz \& Felsenthal 1987: 179). What may work for trust in the social science laboratory may not necessarily produce the same results when analysing the world of global politics and international security, due to the different dynamics and greater variables at stake. As Robert Jervis ponders: "even harder to gauge is whether the influences discovered in the laboratory are strong enough to make themselves felt, and felt in the same ways when they are intermixed with the other powerful variables that affect political decision-making" (1976: 2). Cognitivists have equally lamented the static nature of trust in the framework of game theory models when in their view, trust should be acknowledged as a lively, repetitive and particularly long-term process to be developed under specific conditions (Müller 2001: 168; Solomon \& Flores 2003: 7; Cook et al. 2007: 4).

Cognitivists have developed this particular criticism further by pointing both to the illsuited structure game theory models bring to the study of 'real-life' phenomena within the field of FPA, especially in terms of the role that agency is attributed within rationalist frameworks. When transposing and adapting these models to the study of international phenomena and more poignantly to the way that officials on the ground go about interpreting the trustworthiness of another group of foreign policy 'players,' cognitivists believe that too many analytical flaws come to the surface if applying game theory models. For example, according to one practitioner-turned-scholar, if trust is meaningful only when studied against the backdrop of game theory, the fact remains that policymakers are unable to consistently take decisions in a "stochastic" or "Bayesian" manner (Sherif 1966: 119; Fisher 1997: 4). In effect, as human beings, the argument goes that they would be unable to regularly display a robotic-like thought processes, unaffected by any emotional "predispositions," especially in the relatively stressful context of international security risk management (Bleiker \& Hutchinson 2008: 121). On top of it being virtually impossible to dissociate emotion from the 
agency of such officials when assessing actual international phenomena, cognitivists have pointed to the ambiguity within classic game theory models regarding actors' abilities to acquire sufficient information and knowledge, whilst being able to process such quantities of material when assessing the trustworthiness of an unfamiliar other. They are critical of the assumption that individual officials could access such quantities of information, relevant knowledge of the environment as well as pertain to a "stable system of preferences" over the course of gauging the trustworthiness of the other in question (Moller Okin 1989: 241).

In Bart Nooteboom's opinion, by conceiving trust as a threshold, this would imply both that officials would be disadvantaged as the slightest asymmetry of information concerning an unfamiliar other or group of others, which in turn would offset the former's ability to correctly predict the future behaviour of others. In light of the "openendedness and incalculability of the $[\mathrm{sic}]$ potential future behaviour" of others, mistrust would trumpet trust in IR every single time (2006: 248). Yet even those with the faintest of knowledge regarding past or contemporary international affairs would appreciate that this in itself constitutes a misperception, even as far as the theme for this particular study is concerned. If question marks over officials' capacities to access and process sufficient information in order to make accurate trusting predictions was not enough, other cognitivist scholars have not taken kindly to the place that communication between players holds in the context of a simulated game. Harald Müller lambasted the use of communication in these approaches for reducing the communicative competences of the actors involved "[...] to the level of three year old children" (2001: 160). Müller put the reason of his vehemence down to the fact that most game theory situations tend to leave the players muted and, in those cases where the actors are allowed to engage in various forms of dialogue, their exchanges are attached with little meaning, leaving little space for language per se and thus diplomacy as a whole (Ibid: 160-1). Naturally, cognitivists argued that if the study of officials' use of language was made redundant in the process of diplomatic interaction relative to trust, such an approach would virtually defeat the whole purpose of studying IR in the first place.

Lastly, picking up on a point raised above by Nooteboom, cognitivists have come to query, from an ethical perspective, the underlying assumption within rationalist frameworks that actors should be biased towards mistrust and consider trusting relations as the exception rather than the rule. The models purportedly encourage trustees to defect, cheat and exploit the trust instilled upon them by an instigating actor, whilst the trustor is advised to use coercion as the most optimal mechanism for 'enforcing' trust when dealing with an unknown quantity. As the introductory chapter contended, this fairly defensive and protective posture- 
endemic of most studies that work on the basis of anarchy in international politics - not only presents a lopsided view of the true state of world affairs and human relations in the eyes of most cognitivists, but also presupposes that the study of FPA theory is inherently deleterious to the development of trust relations (Cheney et al. 1972: 99-100; Dunn 1988: 76; Gambetta 1988: 229; Nooteboom 2002: 72; Chilton et al. 2005: 332). Cognitivists have raised alarm bells about this assumption in the light of it constituting a potentially dangerous self-fulfilling prophecy (Turner \& Giles 1981: 28; Booth \& Wheeler 2007: 87). For this reason, the thesis has favoured a cognitive-based approach to trust due to its greater neutrality in holistically explaining competitive and cooperative outcomes, thereafter facilitating the researcher's ability to evaluate the state of affairs between predetermined actors in a given field.

Turning to the relevance of the rationalist frameworks in terms of their suitability to the objectives of this particular thesis, their fundamental precepts may indeed pertain to nonnegligible analytical utility even if the analytical methods on offer may not quite serve as an ideal fit. If models promoting calculative rationality continue to be applied in contemporary FPA studies, it is because the underlying tenets of these approaches are ageless. This can be explained by the fact that for social scientists and students of international politics alike, game theory models offer a viable gateway through which to provide scientific evidence in support of research on a social subject, in order to put it on an even keel with more naturally scientific subjects. In a sense, those applying rationalist interpretations to the study of FPA have gone some distance to legitimising the academic enterprise in their discipline by incorporating more scientific methods to this field of study. More importantly though, game theory models remain popular for the fact that they work on the basis of key principles which would appear to guide a considerable proportion of human thinking. Within certain tenets of Western thinking, rationality has very few negative connotations and, to the contrary, is considered necessary for staying ahead of the pack, thereby optimising the chances of one's survival. This is an important point to acknowledge as far as the remainder of the thesis is concerned, as officials across the sphere of international politics - although they may not serve as perfect reincarnations of homo seconomicus - should be expected to act in part on the basis of rational thinking to better protect the interests they are put in charge to represent. When it comes to the concept of trust and entrusting others within the realm of world politics, this rational calculation needs to be accounted for.

It is not so much the crux of rationalists thinking that is likely to prove problematic when discussing trust in the context of this particular research topic but rather the methods that are usually applied to demonstrate the relevance of this thinking. Taking into account the 
critiques exposed by cognitivist authors, game theory does not lend itself kindly to the objectives of this study for the fact that its preferences for limited variables make for a difficult fit. As a case in point, not only do modern-day African security threats tend to involve a panoply of divergent actors (internal, external, public, private...), going beyond the conventional two to three player simulation found in game theory, but in the context of bilateral trust-building on security matters neither the EU nor China should be considered as monolithic entities. The EU, being a multinational political organisation with its own organic institutions epitomises multilevel governance in security policy terms, whilst the PRC contrary to popular assumptions - is far from a centralised and unified force. ${ }^{30}$ Hence, adopting such a rationalist approach would undoubtedly paint a distorted picture of the reality on the ground.

It should come as no surprise to indicate at this stage that the large majority of rationalist frameworks studying international security have utilised the Cold War conflict between the US and the Soviet Union as a case study. The merits for applying these models in this particular instance may seem obvious, especially in the view of those authors who have chosen to deal more specifically with nuclear deterrence or proxy wars. Sensu stricto, seeking to apply a direct analogy between the topic of this doctoral research project with that of the Cold War rivalry would be misguided. The contexts and dynamics are far too disconnected, whilst the types of security threats of interest share very few commonalities. What may have worked for the dominant rivalry over the course of the Cold War years may simply not suit this more contemporary conundrum of trust between the EU and China, when dealing with the theme of peace and security in Africa. Furthermore, as chapter 1 highlighted, the focus of this study concerns the way in which European officials engage (or do not engage) in trustbuilding relations with their Chinese counterparts. This self-evidently places the emphasis to a significant degree on agency. Referring back to cognitivists critiques, this is not to say that agency plays no part in game theory models. However, agency too often remains discarded, insufficiently attended to and poorly explored in calculative models. As a result, it would appear that different methods and analytical tools would be more appropriate to fulfil the objectives of this particular project given the primacy placed upon agency. These will be explored in the following section of this chapter.

Despite not having given as much prominence to the neoliberal theories when reviewing the rationalist conceptions of trust, this should not be interpreted as neoliberal

\footnotetext{
${ }^{30}$ For more information on the EU's multilevel governance in the field of international security, please refer to the methodology section in chapter 4 .
} 
theories having less relevance when debating the pros and cons of the applicability of rationalist frameworks to the objectives of the study at hand. In fact, neoliberal institutionalist theories, as it has been argued by specialists on Sino-European affairs, have come to inform a large part of the EU's policies towards the PRC - especially from the mid-1990s onwards. Of particular relevance are the ideas of increasing interdependence, primarily through trade, and to a lesser extent that of 'transcendence.' Back in 1995, when the European Commission adopted its first post-Cold War policy paper targeting China, it sought to reduce the traditional distance between the two sides. At the same time, it hoped to put in place a strategy to ensure that European economic interests would be well served by the numerous reforms instigated under Deng Xiaoping's reign during the late 1970s and 1980s. Its strategy, coined by EUChina scholars as "constructive engagement" (that later evolved to the term strategic partnership) was designed to 'lock' China into a set of bilateral economic and political arrangements of a conditional nature (Casarini 2006: 21; Zhu 2007: 156; Balme 2008: 140; Pan 2012: 39).

By using 'carrots' and 'sticks' as incentives for Beijing to respect these arrangements, the EU aspired to foster greater levels of interdependence between the two which naturally served its interests on a number of commercial and ideological fronts. International institutions, such as the World Trade Organisation, were also exploited by the EU officials to further reinforce this process:

as such, it was accepted that a variety of international institutions that collectively made the global system - from developmental to financial and monetary, to health and welfare, to security and other dimensions - should contribute their institutional resources to China so as to help its development and simultaneously socialise it into the existing norms of international behaviour. The strategy definitely treated China as an object, both as a recipient of resources and as a nation to be moulded and shaped normatively (Shambaugh 2013: 130).

Taking the analysis further, it has been argued that this strategy's aim, at heart, was to trigger a process of political homogenisation and convergence between the two, by providing the topdown and bottom-up economic incentives for China to continue to undertake reforms of its domestic system that corresponded to the EU/West's political preferences (Shambaugh 2004: 247; Algieri 2007: 77; Balme 2008: 140). As Holslag summarised, this amounted to the EU's attempt not to: "floor the dragon, neither to cage it, but to discipline it" (2006: 567). Consequently, EU officials clearly constructed a large part of their approach around neoliberal institutionalist concepts. For one author, this is so because the EU had no other strategy alternatives at its disposal when dealing with the PRC (Vogt 2012a: 9). 
Fast-forwarding nearly two decades, economic interdependence has flourished to the point where bilateral trade patterns - totalling $€ 433.8$ billion in 2012 (European Commission 2013) - can have repercussions stretching far beyond their bilateral remit. In this sense, the strategy of constructive engagement could be seen as a success, although not one which can be entirely explained by the implementation of the strategy in itself. But from a political standpoint, it cannot be argued that the two parties have developed any form of interdependence, let alone making any headway in terms of bridging their endemic political gap - and this despite having considerably expanded the policy scope falling under the strategic partnership heading, creating in parallel more opportunities for interdependence and socialisation (Zyla 2008: 94; Steiler 2009: 85). ${ }^{31}$ This signifies that not only the EU's neoliberal strategy of engaging China would appear, in the eyes of some scholars, as having been a "failure" (Holslag 2006: 578) but also presupposes that every one of Brussels' initiatives towards Beijing should not be seen in relation to interdependence or transcendence. In other words, should trust develop over the course of engagement between officials on the ground from both sides on the specific theme covered in this thesis, then this phenomena may very well be unrelated to the possible spillover effects caused by the EU's supposed loftier attempts at transcendence - particularly since it is difficult to transfer trust across contexts and since bilaterally the EU and China have very few credible mechanisms to function as an institutional memory for trust (as discussed further in chapter 7).

Taking security risk management on the African continent as an example, it would be erroneous to assume that when the EU seeks to engage China, it does so with the idea of furthering bilateral interdependence or with the ultimate aim to socialise and homogenise the PRC. If this was the case, then the EU would have hitherto been far more proactive in seeking collaborations with the PRC, especially in light of the 'Communication' on trilateral dialogue and cooperation. Yet, moving from rhetoric to practice has proven tricky, with the concrete cooperative results hinted at in chapter 2 generally qualified as having been "mediocre" (Renard 2011: 25-6). This current lag between theory and practice begs the following questions: why has the EU not made greater use of the carrots and sticks at its disposal to entice/coerce the PRC into a bilateral rapprochement within this field of activity? If this approach really does inform the EU's strategy in this respect, then why has it not applied it

\footnotetext{
${ }^{31}$ The EU and China conduct most of their bilateral dealings in the shape of 'sectoral dialogues,' of which there are now 56 at the time of writing, covering areas as diverse as customs cooperation, human rights, employment and social affairs or nuclear energy (EEAS 2012) - leaving plenty of scope for enhancing interdependence and socialisation, due to the fact that they: "[...] form the basis for mutual learning and the improvement, where possible, of governance in China" (Balme 2008: 140).
} 
more rigorously and systematically? This analytical framework of conditional interdependence, socialisation and eventual homogenisation simply cannot always be relevant when it comes to discussing trust in this respect. ${ }^{32}$

Neoliberal scholars would probably retort that there are 'domestic' reasons as to why the EU has not been able to convert discourse into practice, pointing to the interests of its member states as the major barrier in developing the bilateral interdependence needed to make China a more trustworthy other (Stumbaum 2009). Some academics have argued that the EU would probably stand a better chance of achieving this goal if it had the actual democratic accountability to support its approach - which it clearly does not (Vogt 2012b: 66, 78). In itself, this counterargument opens up a whole new series of interrogations. If member states do not express direct support for closer collaboration with the PRC in this subfield or if this is not part of their national agendas, can we assume de facto that the objective of socialisation and interdependence constitute nothing more than sheer diplomatic rhetoric? Does this entail that if the EU has not explicitly received the autonomy to do so under a specific Common Security and Defence Policy (CSDP) mandate for peace and security operations on the African continent, building trust with China will be unthinkable? If this is the case, then what would these commentators make of instances where EU decision-makers - in possession of a CSDP mandate which did not explicitly allude to engagement with the $\mathrm{PRC}^{33}$ - managed to build sufficient trust with the latter to trigger cooperative bilateral outcomes? Such questions raise doubts about the viability of using 'domestic' precepts so as to garner the reasons behind the ability of EU decision-makers to foster sufficient trust (or not) with their Chinese counterparts.

Finally, two last points are worth highlighting that serve to reinforce the idea that neoliberal institutionalist methods may not prove best suited to the demands of this specific research project. Firstly, as referred earlier throughout the thesis, rationalist methods (including neoliberal theories) are not best equipped when it comes to discussing elements which cognitivist scholars deem as important to the study of trust such as identity, perceptions and beliefs (Katzenstein 1996: 25). As aforementioned, this is due to the bias of materialist imagery underpinning neoliberal institutional thought, restricting it from prioritising these

\footnotetext{
${ }^{32}$ Also, this idea of conditionality may have been permissible in the mid-1990s but nowadays, it would seem illsuited for European decision-makers to adopt such an approach, given that the bilateral situation has evolved, due to the fact that economic asymmetries have been substantially reduced thanks to China's prodigious economic growth while Europe struggles under the weight of its economic and financial woes.

${ }^{33}$ Mandates that require all 28 member states to unanimously agree upon so as to be ratified and sanctioned by the EU Council and, for which, each member state is in possession of a national veto if it feels the need to revoke the item under discussions.
} 
aspects and therefore taking them somewhat for granted (Jepperson et al. 1996: 33). ${ }^{34}$ The same critiques made above regarding agent-level analysis have also been levelled at neoliberals, which implies once again that applying their methods would make the task of studying trust in the particular topic that much harder. Secondly, neoliberal institutionalist approaches come across as less relevant in the light of the reality that there exists no institution or regime in which the EU and China are plenipotentiary members per se, which they use to handle their bilateral interaction on the specifics of peace and security in Africa (Steiler 2009: 134). Sarah Raine, in her book on China's African Challenges, argues that both parties require a functioning multinational framework - respecting and enforcing current codes of conduct - to manage their rivalry (2009: 222-3). However, neither are members of the AU or any other African regional security mechanism, while interaction at the UN or in bilateral fora is problematic from an analytical viewpoint. Indeed, the EU - in spite of its member states, who often act in accordance with national and not European interests - is not in itself a member of the UNSC, while fora that cover bilateral affairs in/on Africa do not correspond to the image of regimes as conceived by neoliberal institutionalist theory.

\section{2. $\underline{\text { Cognitivist Scholarship }}$}

\subsubsection{Trust and the Cognitive Identification Process}

This chapter now turns to the second major component of the literature on trust relative to the study of world politics and international security: the cognitivist scholarship. Having outlined their various critiques of game theory model and other rationalist approaches to trust research, we will now put forward the ideas cognitivist scholars hold on trust and trustworthiness. As explained in the introductory chapter, given the diversity and multi-disciplinary nature of this scholarship this section covers those parts of the literature which have been deemed relevant to this particular discussion on trust, following a screening of large parts of this wide body of literature. The objective of this review is to demonstrate the added-value of the cognitivebased approach to trust research as opposed to the versions presented in the sections above, in terms of how it can help comprehend the EU and China's interaction on security risk management in Africa in a holistic fashion.

\footnotetext{
${ }^{34}$ In an article published at the turn of the century, Jennifer Sterling-Folker attempted to make a strong case in arguing that these 'cognitive' notions and instruments were not new to the study of IR or should not be considered exclusively linked with social constructivism. Instead, she argued that neoliberal institutionalist scholars originally paved the way for the integration of perceptions, beliefs and social change into their analytical frameworks used for the study of IR (2000: 109-10). The author's argument would have gained further credence had she not admitted that neoliberal institutionalist scholarship, however, tends to be less inclined towards commitment to exogenous interests and identity (Ibid: 113).
} 
By choosing to look into these specific parts of the cognitivist scholarship, the review thus lays the foundation to the conceptual framework for which the added-value stems from the fact that no previous work relevant either to this strand of literature or even to that on EUChina studies has attempted to connect these distinct parts under one conceptual roof - these are the process of identification, the notion of empathy and that of communicative action. For the most part, academics who have chosen to apply these tools separately, whereas the view promoted in this thesis contends that a combination of certain of these parts is necessary to comprehending the mechanisms underpinning cognitive-based trust (as explained in more detail in chapter 4). To reiterate the message conveyed in chapter 1 , this thesis takes the view that these three elements are key to the cognitive-based version of political trust promulgated in this thesis, which in turn plays a predominant part in defining the nature of bilateral interaction on the topic of security risk management in Africa.

For a majority of works falling under the cognitivist ambit working on trust, the key starting point is to suggest that actors trust others on the basis of their identity as a primary prerequisite - trusting those that figure as part of their wider "ingroup" network and mistrusting those categorised as falling under the heading of the "outgroup" networking (Sherif 1966: 156; Turner 1981: 78; Brown 2000: 312; Hopf 2002: 5-6; Cook et al. 2007: 67; Heimer 2007: 55; Cook-Huffman 2008: 27). Taking a quote from Samuel Huntington's seminal yet controversial work, The Clash of Civilisations and the Remaking of World Order, the author makes the case that this phenomenon is above all natural and human:

people are always tempted to divide people into us and them, the ingroup and the other, our civilisation and those barbarians. Scholars have analysed the world in terms of Orient and the Occident, north and south, centre and periphery. Muslims have traditionally divided the world into Dar al-Islam and Dar al-Harb, the abode of peace and the abode of war (1996: 32).

Identification, above all, remains an exercise in relativity. More specifically, this entails that a process of "positive identification" between two or more groups is more likely to lead to a trusting outcome, than situations in which negative identification occurs (Booth \& Wheeler 2007: 105). In brief, the literature puts this causality down to equal status and similarities among groups (Turner 1981: 89; McAllister 1995: 28; Huntington 1996: 34, 126; Herrmann cited in Alexander et al. 1999: 79; Brown 2000: 343; McKnight \& Chervany 2006: 42; CookHuffman 2008: 25; de Waal 2009: 80); ingroup bias (Brown 2000: 326); interchangeability and attractiveness between group members (Sherif 1966: 149-150; Brown \& Turner 1981: 39); the ability to identify with a similar group's needs (Nooteboom 2002: 81); positive 
interdependence (Herrmann cited in Alexander et al. 1999: 79) and because of an overlap between the groups" "lifeworlds" or "cultural programmes" (Rokeach, Byrne \& Festinger cited in Brown \& Turner 1981: 47, 51; Lose 2001: 186; Grobe 2010: 7). Whereas negative identification processes are unlikely to lead to trusting outcomes, cognitivists put the cause of this down to the ingroup's inability to capture the outgroup's mindset, leading to misperception and mistrust (Fisher 1997: 90); the ingroup's inability to understand the outgroup's feelings and beliefs (Jervis 1976: 187; Head 2012: 37); to the ingroup's "closed mindedness [sic]" towards outgroups (Kelman 2008: 178-9; Cameron 2011a: 4); to "cognitive distance" with the outgroup (Nooteboom 2002: 26); to feelings of hostility towards the outgroup (Jervis 1976: 68; Brown \& Turner 1981: 42); to a "dehumanisation" of the outgroup and its members (Halpern \& Weinstein 2004: 567); and because of an incompatibility of goals and stature amongst the groups, in which the outgroup would likely benefit at the ingroup's expense (Alexander et al. 1999: 80-1; Brown 2000: 227).

The enumerations above represent only a rapid account of the generic rationales laid out to help make sense of why ingroups, at first view, positively discriminate towards supposedly fellow ingroup members and discriminate against apparent outgroup members. But this overview highlights only the tip of the iceberg. Within the cognitivist literature, identification - considered here as the crucial variable for trust - comes to be understood as a multilayered process that forms a circular whole, which in turn justifies how and why ingroups members can categorise between those they perceive as similar to themselves and those they visualise as being polar opposites. This process subsequently regulates their behaviour, actions and interests when interacting with others. To commence, cognitivists promulgate the assumption that groups, regardless of their identity, need other groups whether for better or for worse - in order to exist (Neumann 1996: 147; Brown 2000: 3, 7). As Iver Neumann reminds readers in his book on the Uses of the Other: "The East" in European Identity Formation, philosophers and IR scholars alike, such as Mikhail Bakhtin, Michael Shapiro and Alexander Wendt all referred to the epistemological as well as ontological necessity of the ingroup having an outgroup and vice versa (1999: 13, 24, 34). In fact, Neumann cites German philosopher Friedrich Hegel, with the latter having developed a similar line of reasoning when he argued that by knowing the outgroup, the ingroup has the power to give or withhold recognition so as to be constituted as ingroup at the same time (Ibid: 3). Henri Tajfel took the argument further by advocating that ingroups need outgroups, although outgroups do not necessarily have to take a human or physical form - an important point in the debate on identity that will be touched upon in the next chapter. He elaborated 
that: "the ingroup is a cognitive sine qua non for the cognitive existence of the outgroup, and one or both can be, in various conditions, either real or mythical or somewhere in between" (1978a: 56).

But ingroups do not simply need outgroups for their very being, they are also needed for their "self-enhancement" or their "self-righteousness." This explains why the ingroup/outgroup paradigm is often characterised by their mutual demonisation (Tajfel 1978b: 61; Turner 1981: 105; Vertzberger 1990: 83; Brown 2000: 312; Tyler 2001: 289). Although this depiction of ingroup/outgroup rivalry could amount to justifying the need for the existence of an other on the basis of pure self-glorification, the literature expands on this point by proclaiming that this process reflects a fundamental need for groups to protect their distinctiveness and thereafter ensure their survival (Fromkin cited in Lemaine et al. 1978: 290; van Knippenberg 1978: 178; Huntington 1996: 129). ${ }^{35}$ In fact, rather than requiring other groups for self-gratification, outgroups are needed almost as a reassuring presence in the ingroup's quest for the protection of its distinctiveness and ultimate survival. This is what William Connolly coined "self-certainty," whereby the outgroup permits the ingroup to justify the latter's existence as much as its decisions and actions (1991: 64; Chilton et al. 2005: 332).

Going beyond the mere rationale for the ingroup/outgroup paradigm, cognitivists have dug deeper into this multilayered process of identification in the sense that the genesis of every group is underpinned by special cognitive operations that shape their perception of the world. These, as referred to earlier, are known as "lifeworlds," "mindsets" or "cultural programmes" that compute group's thought-processes, behaviours and interests in one way or another (Fisher 1997: 4, 23; Hopf 2002: 16). Jürgen Habermas equated lifeworlds to: “[...] linguistically acquired and organised stock of patterns of understanding and, hence, constitutes an intersubjective structure of collective understandings" (cited in Lose 1991: 185). It is these lifeworlds and cultural programmes which consequently determine how outside actions and speeches will be interpreted for members of a group, as well as separating what is meaningful from what is meaningless for those same members (Sherif 1966: 132; Vertzberger 1990: 260-1; Fisher 1997: 32; Farrell 2002: 50; Hopf 2002: 23). ${ }^{36}$ Crucially, this will permit group members to process identification when interacting with others by evaluating whether the actions and speeches of others are cognitively consonant or dissonant with their own norms, principles, values and interests which guide their respective behaviour. It is at this

\footnotetext{
${ }^{35}$ To support his argument, Huntington uses the example of the historical clash of Christian and Islamic civilisations, which the author believes has occurred over time in part for the fact that: "Islam is the only civilisation which has put the survival of the West in doubt, and it has done that at least twice" (1996: 210).

${ }^{36}$ Or as one group of scholars professed: “[...] who we are influences what we want” (Abdelal et al. 2006: 698).
} 
juncture that the ingroup/outgroup differentiation unfolds, which according to cognitive suppositions will determine the probability of groups engaging in trusting relations or not and thus determine the likelihood of their propensity towards competition or cooperation (Turner \& Giles 1981: 27; Miller et al. 1991: 57; Brown 2000: 6). Cognitivists have posited that such slogans, motives and desires are shaped by the specific socialisation that each group member undergoes consciously or subconsciously as a requisite part of the group membership socialisation which is itself determined by the group's geographic conditions, historical experiences, fundamental religious beliefs, conceptions of time and/or human purpose (Vertzberger 1990: 65, 307-8; Fisher 1997: 26, 70; Finnemore \& Sikkink 1998: 891-3).

Cognitivists do go on to specify that for all the ability to categorise and differentiate other ingroup members from outgroup members on the basis of their actions and speeches, they also realise that often such categorisation will not be achieved by collecting or processing perfect data. It is not physically possible for members of ingroups to be fully cognisant about the attributes of each and every member of other groups, making the categorisation process anything but a linear one. The argument put forward in the literature therefore concludes that in light of the complexity of the real world, categorisation via simplification represents a vital human function (Brown 2000: 264). In this instance, group members, as part of their group socialisation, access a number of available cultural stereotypes and "schemata" which they use to fill in the missing knowledge gaps when inferring about the classification of another into the ingroup or outgroup (Cook et al. 2007: 27). These heuristics act akin to a "guide" for social action, most poignantly in cases where the group and its members are dealing with an unfamiliar other and his/her/its concomitant behaviour. This guide, moulded by the socialisation referred to earlier by Fisher, allows ingroup members to come to expect certain sets of behavioural qualities from others which ultimately serves as a focal point for determining similarity or dissimilarity from these specific others (Holsti 1962: 245; Sherif 1966: 70; Shapiro \& Bonham 1973: 161; Rosati 1995: 54; Fisher 1997: 26; Ruggie 1998: 868; Brown 2000: 301; Herrmann 2002: 125-6; Nooteboom 2002: 80; Cook et al. 2007: 28). Most publications that have dealt with this point though, have usually come to the conclusion that - parallel to the general ingroup/outgroup paradigm - stereotypes are utilised against outgroups to the benefit of the ingroup (Sherif 1966: 70; Turner 1981: 100; Vertzberger 1990: 151; Brown 2000: 265). Indeed, as groups seek self-enhancement, their lifeworlds are only likely to filter cognitively consonant information about wider ingroups from cognitively dissonant information about outgroups, 
which only reinforces the paradigm. Herbert Kelman comes to a similar assessment, by agreeing that:

people are most likely to seek out and be exposed to information that confirms their existing attitudes and to perceive and remember new information in ways that fit into pre-existing cognitive frameworks. [...] People tend to screen out information that is congruent with their existing beliefs and attitudes (2008: 180).

Coming full circle with regard to cultural programmes, ingroup members are attributed a sense of bounded expectations across the cognitivist scholarship thus setting the background for expectations that members will have of others within their wider ingroup network (Gambetta 1988: 217; Kramer 2010: 85-6) - expectations that will usually be benevolent and favour bonding between such members (Tyler 2001: 288). Whereas those identified as falling outside of the ingroup are likely to be dealt with cautiously and suspiciously, due to the hostile - and sometimes aggressive - images that will be projected upon these members (Sherif 1966: 156; White 1991: 295; Kelman 2008: 175). Although ingroups may need outgroups for the purpose of their very existence, they will act to ensure that their lifestyles are protected against the subliminal menace created by the presence of outgroups, so as to guarantee their own survival (Sherif 1966: 69). The chances of trust and ultimately cooperation being built in this situation would naturally appear unfavourable, thus paving the way for more competitive patterns of behaviour, unless the perception of the members evolves from outgroup to wider ingroup.

\subsubsection{Cognitive Empathy and Communicative Action}

Sifting through the cognitive literature, it would appear that two particular conducts are appreciated by authors in this respect: an actor's capability to express empathy as well as engaging in sincere dialogical practices with members of the wider ingroup. Both aspects are deemed to play an important function in moving from pure identification to actual trustbuilding. As aforementioned, these concepts are usually dealt with by scholars in their own right. However, as the conceptual framework on trust promulgated throughout this research project contends, the process of identification alone cannot do justice to the mechanisms underpinning cognitive-based trust and requires a complementary dimension incorporating social interaction. Without this dimension, the process of identification would remain very difficult to determine - especially for observers looking from the outside in - as the channels needed to express such identification would be overlooked. Without acknowledging the social conduits of identification, there would be no way of determining how these groups of actors 
negatively or positively associate with one another, since there would be no means of knowing whether they were able or not to express empathy or engage in 'ideal-type' communicative action. Both empathy and communicative action have been selected on the premise that these are qualities needed to convert positive identification into actual trusting behaviour between groups and, vice versa, to reinforce the effects of negative identification when they are missing or poorly executed. In effect, they are tributary to the identification process in that their detectable quantity and quality will vary depending on the nature of the process itself: empathic behaviour is either detected or not; either the parties are detectably closer to ideal-type communicative action or their communicative interaction is understood as being a long way from the ideal (de Waal 2009: 80). Although quite similar, they play slightly different roles within this process and in their own indirect way impact the outcome of interaction as sub-variables of trust, even if most scholars do not favour interpreting them as such.

Regarding empathy, or to be more precise "cognitive empathy," its virtues are highly regarded by cognitivists as far as trust is concerned (Nooteboom 2002: 24; de Waal 2009: 80; Cameron 2011a: 8; Engelen \& Röttger-Rösler 2012: 4; Mageo cited in Hollan 2012: 74). ${ }^{37} 38$ In particular, authors contributing to research on security risk management have not hesitated to elucidate the impact empathy can have on triggering rapprochement between seemingly distant parties, or in getting one party to convincingly persuade the other about mutually beneficial outcomes (Wendt 1992: 422; Head 2012: 47). Indeed, cognitive empathy is implied in the literature as an emotive medium through which an actor can understand and appreciate another's feelings and thoughts (whether hopes or fears), through a process of individualisation of the other group member or group as a whole (Lose 1991: 191; White 1991: 291; Nooteboom 2006: 251; Booth \& Wheeler 2007: 237) ${ }^{39}$ This amounts to switching over to the "quasi-first person point of view" of the interlocutor, allowing the instigator to

\footnotetext{
${ }^{37}$ A distinction in the cognitivist literature is made between "cognitive empathy" and "affective empathy." The former is referred to as the ability to project oneself into the shoes of another by "inferential processing," whilst maintaining a clear differentiation between self and other (Engelen \& Röttger-Rössler 2012: 5; Head 2012: 39). This requires the need to: "[...] know and understand the other and their experience, and to be able to put one's own emotional responses on hold while considering theirs" (Cameron 2011a: 5). Affective empathy is defined as sharing feelings with others.

${ }^{38}$ In cases where no positive identification or unearthing of common identities takes place, "dyspathy" rather than empathy is likely to occur (Cameron 2011a: 5). Dyspathic behaviour between actors will consequently imply that emotional barriers are constructed between ingroup and outgroup members, where the former will ensure that members of the latter group are rendered: "[...] undeserving of attention or perceived as evil in some way so that emotional attachment is resisted" (Cameron 2011a: 11; Ibid 2012: 2).

${ }^{39}$ Welch Larson brings up an interesting point that because empathising requires substantial cognitive effort, decision-making acting in crisis situations will usually revert to heuristics as a means of simplifying already complex situations (2000: 24). If this is true, the implications for trust-building between distant actors may be considerable.
} 
better perceive the pressures impinging on the recipient and thus resulting in a lower probability that snap judgements would be made about the latter's "personality traits" (Welch Larson 2000: 24; Hollan 2012: 72). In sum, as a fairly creative endeavour, empathy: “[ ...] involves imagining and seeking to understand the perspective of another person" (Halpern \& Weinstein 2004: 568).

These definitions within the cognitivist scholarships have gone to great lengths in putting forward rigorous definitions of cognitive empathy, mostly by making distinctions between empathy and other related emotional actions. Establishing these distinctions is considered important in terms of empathy's academic utility, especially in the context of ingroup members dealing with more distant others within their ingroup network or with outgroup members. This is so because following the initial identification process, empathy may well be the difference between actors actually fostering trust or not fostering trust, as explained earlier. For example, empathy is often approximated and associated with sympathy but cognitivists have been quick to dispel any confusion between both emotional actions by pointing to the fact that empathy simply entails understanding the other's complex point of view, although not necessary accepting it (Risse 2000: 11-3; de Waal 2009: 88). This is not the same as liking or even agreeing with that person or group which may find their roots more so in the act of sympathising with another (White 1991: 292; Halpern \& Weinstein 2004: 580). As such, empathy implies a certain degree of objectiveness or emotional distance as opposed to sympathy, where trust will not be blind but more likely to be carefully thought through, giving empathisers a real reason to trust instead of doing so on a whim.

In actuality, the cognitivist literature calls for a number of necessary personal attributes which actors need to display in order to be in a position where they are thereafter likely to express empathy when dealing with relatively similar others. The following characteristics are usually associated with the capacity of group members to act as empathisers towards such others: "prosocial" competences (Miller et al. 1991: 60); being able to treat others in an equal manner (Engelen \& Röttger-Rössler 2012: 4); to entertain pleasant and smooth relations with others (Triandis 1991: 86); to tolerate other's emotional and moral ambivalence (Nooteboom 2002: 28; Halpern \& Weinstein 2004: 569; Head 2012: 39); and to be willing to make self-sacrifices and invest into dynamic interactions with the other, in order to get into his/her/its “skin” (Jervis 1976: 187; Triandis 1991: 86; Cameron 2011b: 6; Engelen \& Röttger-Rössler 2012: 4). ${ }^{40}$

\footnotetext{
${ }^{40}$ Jervis also warns readers that should empathy come to be misplaced or misdirected, it could lead to possibly "disastrous outcomes" between actors and groups (1976: 34).
} 
Many of these traits actually feature heavily in the work published on Habermas' theory of communicative action (TCA), where empathy and successful argumentative rationality share an intimate connection. For Thomas Risse, the former is vital to the latter given that the latter's successful undertaking rests upon the need to see the world through the eye of the interlocutor, to avoid mirror-imaging and to supply a common interpretation of the world as provided by language, culture or a common history (2000: 10). While for other likeminded specialists communicative action plays an important part too, serving as a gateway through which empathy is expressed, subsequently aiding the build-up of trust if detectable or by allowing mistrust to predominate if undetectable in a scenario of negative identification (Lose 2001: 180; Avuch 2008: 249). As explained earlier, the reality is that empathy and communicative action in the Habermasian sense remain difficult to dissociate as separate entities, with both playing simultaneously important roles regarding trust (Head 2012: 35, 45). Both are entwined, with the only slight difference residing in the sense that empathy would feature more as a latent predisposition for trust (actors are predisposed with it in certain contexts or they are not) whilst communicative action makes empathy happen. Of course, communicative action should be foreseen as an 'ideal-type' going beyond simple dialogue or body language. ${ }^{41}$ To briefly summarise, for TCA to operate in practical terms, partners engaging in dialogue need to do so on the basis of "mutual recognition" (Lose 2001: 183-4; Grobe 2010: 8) in order for each to respectfully allow the other "equal access to discourse" (Risse 2000: 11-3; Lose 2001: 184; Watson cited in Lose 2001: 193; Broome 2008: 194). Both actors must be fully consenting, must strive towards impartiality and be open for the other party to shift position at any time over the course of the dialogue, for the proceeds of communicative action to take form (Johnson 1991: 192; Risse 2000: 13; Müller 2001: 162; Chilton et al. 2005: 332).

Through the dialogue, actors will look to develop a "collective language" to mediate their engagement and serve as a bridge to understanding (Jönsson cited in Lose 2001: 198; Lose 2001: 191). Interaction must preferably be repeated, but only so if - analogously to the empathy 'experience' - it is pleasant for both sides and that either side can express this pleasantness with "sincerity” and "integrity” (Feger 1991: 292; Müller 2001: 169; Nicholson

\footnotetext{
${ }^{41}$ In the literature, a majority of published material on the topic of empathy would argue that this action is conveyed by face-to-face oral communication (Turner 1981: 74; Möllering 2006: 88; Cameron 2011b: 4). For Robert Solomon and Fernando Flores, trust established on the basis of empathy represents not: "[...] a medium but a human virtue, cultivated through speech, conversation, commitment and action" (2003: 87). Jeffrey Checkel states that this is best achieved however when undertaken in private (2004: 238). A minority of scholars do posit that empathy can be expressed by other means, without reverting to oral communication (Fisher 1997: 186).
} 
et al. 2001: 2; Head 2012: 42). If actors are able to get close to this ideal-type, only then will they be able to aspire to the possibility of reaching a mutually satisfactory outcome that will lay the groundwork for trust to be established. Empathy will play a critical part in this respect if it is detectable, both in terms of getting parties to listen and appreciate each other's weaknesses and concerns, whilst fostering mutual understandings (Jönsson cited in Lose 2001: 190; Solomon \& Flores 2003: 145; Booth \& Wheeler 2007: 96; Cameron 2011b: 6). Subsequently, if the actors in question are working on the basis of positive identification then they should be sensitive enough to the needs and emotions of their partners as to be able to utilise, through collective language, adequate arguments to persuade he/she/it of the need to strive towards mutually beneficial outcomes - a process of persuasion that could be the difference between merely identifying fellow ingroup members and establishing actual trusting relations (Müller 2001: 174; Booth \& Wheeler 2007: 102; Mercer 2010: 22). However, if they are working on the basis of negative identification, then empathy and idealtype communication are likely to produce little effect on the overall dynamics characterising interaction, but their absence or misuse will serve as a variable having generated further mistrust and competitive behaviour. 


\section{Conceptual Framework and Methodology}

\subsection{Conceptual Framework on Trust}

\subsubsection{The Process of Identification}

To recap, this study seeks to understand in holistic terms the main factor underpinning as much the competitive as the cooperative dynamics characterising bilateral interaction on the theme of African security risk management, and doing so without relying upon rationalist frameworks as an analytical basis. The primary hypothesis developed in this respect argues that, on the one hand, the probability of cooperative outcomes would be higher in situations where officials on either side were able to foster sufficient levels of trust to bridge the political divide. On the other hand, the absence of sufficient trust between officials would most likely result in the probable absence of bilateral cooperative behaviour on this theme, due to the pre-eminence of mistrust and the inability to bridge the divide. Identification whether negative or positive - and to a lesser extent empathy and ideal-type communicative action largely determine the nature of the relationship two groups of officials are likely to entertain. This thinking is captured by Schema 1. In sum, trust would serve as the primary explanatory variable when it comes to assessing the bigger picture of bilateral interaction in relation to this part of their dealings on the African continent.

\section{Schema 1 - Cognitivist Process of Trust}

\begin{tabular}{|c|c|}
\hline \multicolumn{2}{|c|}{ Nature of Identification } \\
\hline Positive \\
\hline Strong \\
\hline \multicolumn{2}{|c|}{ Retectable Presence and Impact of Empathy } \\
\hline Likely \\
\hline \multicolumn{2}{|c|}{ Weactment of Ideal-Type TCA } \\
\hline High & Unlikely \\
\hline
\end{tabular}

As a starting point, this primary hypothesis lays the groundwork for the thesis' conceptual framework. Yet, relying on these foundations alone does not suffice, as more detail and input is needed to build a more thorough conceptual framework. This section of chapter 4 will look to put some of the cognitivist precepts under the microscope to investigate 
their viability vis-à-vis the thesis' conceptual framework and, more importantly, the project's analytical objectives. In so doing, this section will spend time assessing two key aspects relative to the conceptual framework: a) scrutinising the identification process further; b) examining the impact of social context and environmental factors on trust and understanding the importance of incorporating these facets within the framework as a whole, rather than relying upon them in a disconnected fashion.

The cognitivist literature on trust, as often reiterated in this chapter, places much emphasis upon the notion of identification and intimately links it to the overarching probability of trusting outcomes. For the most part, this assumption has widely been touted within the literature even if some commentators have taken exception. Ted Hopf, as a case in point, disagrees with this assumption by stating that to the contrary collective identification with others within a wider ingroup network may not be sufficient in producing trusting or cooperative outcomes. Hopf is more of the opinion that: "being secure in difference might, in some cases at least, make identification [...] and consequently cooperation, more likely, not less" (2002: 286). The author's seminal work on the role of identities in foreign and security policy signifies that his thoughts should command the interest and respect of scholars working on parallel issues. However, taking the case of European and Chinese officials interacting on cases of security threats on the African continent, Hopf's assertion makes for an unlikely fit or represents the exception that proves the rule. In effect, as the introductory chapter made clear, endemic political differences between both sides implies that being "secure in difference" constitutes a veritable way of life for these officials. And, as the examples referred to in chapter 1 highlighted, this lack of identification has not resulted in both sides displaying a finite proclivity towards cooperative interaction.

To add to this, if we adhere to the assumption professed across both the rationalist and cognitivist literature that, particularly under the duress of attempting to manage crisis situations, officials usually revert to prototype to guide their actions, the security in difference proposal is only likely to be reinforced in this case. As a consequence, the chances of European officials resorting to negative heuristics when attempting to comprehend the PRC's role in the context of managing security risks in Africa will be higher, when taking into account their inherent political divergences. It remains very difficult to imagine a scenario whereby a negative process of identification caused by political divergences and negative heuristics would facilitate trusting and cooperative outcomes in this particular context. Going against Hopf's supposition, the conceptual framework used in this thesis will work on the basis that positive identification plays a key role for trust-building and cooperation, whereas 
negative identification significantly reduces the likelihood of trust and subsequent cooperation from taking place.

Taking the moral high ground on identification, certain cognitivist scholars proclaim that academics working on the concept of identity should be wary of such debates on the necessity of factoring in a process of positive or negative identification - especially negative identification. Using arguments similar to those levelled at rationalists regarding the moral dilemma of applying game theory models to emotively-laden constructs such as trust, some cognitivists have criticised the manner with which their contemporaries have assumed that identities can be negatively differentiated. Their rationale is founded on the apprehension that advocating this message across academic publications would only create a similar selffulfilling prophecy to the ones that rationalist models induce, by favouring defection and cheating over cooperation. Ned Lebow and Sybille Reinke de Buitrago amongst others have come down heavily upon the views held by Huntington in particular that encourage the idea of identification processes always having to be dichotomised into a good (ingroup) vs. evil (outgroup) paradigm (Alexander et al. 1999: 80-1; Lebow 2008: 487-8; Reinke de Buitrago 2012: xvii). They prefer to take a stance against this oversimplification transcending many FPA studies inspired by social psychology, whereby dichotomisation between ingroup solidarity and outgroup hostility as a basis for identity represents "flipsides of the same coin" (Lebow 2008: 478).

These authors should be commended on raising awareness of the fact that processes of identification are anything but clear-cut. Huntington's Clash of Civilisations which in its own way incarnates an ode to Manichean approaches to identification - despite making for a fascinating read - is rife with the sort of dichotomisation that has caused the ire of specialists such as Lebow. So much so that Huntington's book suffers in terms of analytical credibility as a result of having overplayed and overhyped the good ingroup vs. evil outgroup nexus. This being said, as far as the conceptual framework for this thesis is concerned, identification processes will still be depicted as ingroups differentiating themselves against outgroups and vice versa, although without needing to adopt the same nexus of extremes as favoured by Huntington. This is because ingroups and outgroups do not develop their identities in a vacuum: they need others for the purposes of developing their identities and lifeworlds, otherwise identities would be rendered meaningless and portray human beings as soulless, which is unrealistic. For this reason, acknowledging the existence of outgroups is important in understanding the nature of the relationship between European officials and their Chinese counterparts when tackling on the ground a given security dilemma in Africa - whether the 
Chinese themselves are part of the wider outgroup for EU foreign policy agents or not. The fact is that there will always be an outgroup, whose existence plays a non-negligible part within the identification process and, therefore, will need to be carefully accounted for as part of this thesis' conceptual framework.

It is at this juncture that we return to Hopf's work on identity and the social construction of world politics, given that his publication sheds light on another way of conceiving the debate on identification. Hopf argues that the focal point of discussions on identification should not just amount to questioning if and to what extent the ingroup/outgroup paradigm is worthy of scholarly merit (2002: 3). ${ }^{42}$ Instead, he shifts the debate onto the objectification of the outgroup by the ingroup. In other words, he reasons that the identification process does require an 'other' upon which to develop its sense of identity, but that other in question should not perennially be conceived as a foreign human other. In his book on Soviet/Russian/Muscovite identity, he develops the argument that the source of leaders' identities may stem as much from a process of 'domestic' identification and/or identification with non-human, non-physical, imaginary, immaterial elements $(2002: 3,9){ }^{43}$ Foreign outgroups may in fact be simply treated as an extension of domestic outgroups by specific members of an ingroup, perceiving the outside world through this domestic lens.

Thus, the most relevant source of identification for a select group of European officials may relate more so against that of another European political/human collective, than using the values and slogans constituent of the Chinese officials' cultural programmes as a means of building their identity in a given context. What's more, this process of identification may in fact be more pertinently built against succinct immaterial factors, such as specific political ideologies, philosophies, legal references, religions, history (etc.). The presence and identities of Chinese officials may have no relation whatsoever as an outgroup to the identification process of the European officials themselves. Hopf's welcome contribution to the debate on identification in a sense quells the to and fro between the proponents and opponents of demonising foreign others within the literature. Indeed, Hopf points out that such exchanges may be misguided due to scholars looking in the wrong places when analysing the roots of the process of identification.

There does appear to exist another aspect in the debate of identification processes that the cognitivist literature has either overlooked or has deemed unworthy of interest. Drawing

\footnotetext{
${ }^{42}$ Alexander Wendt had previously made a similar point (1992: 422).

${ }^{43}$ Checkel is another such specialist who has promoted the need for this awareness amongst his contemporaries (2004: 237).
} 
inspiration from legalese, I have entitled this element 'associate fallacy' or more simply put, being 'guilty by association.' Naturally, the analogy to criminal behaviour should not be heeded. Instead, this assumption is needed for cases which involve more than the rather basic ingroup/outgroup paradigm, which fails to sufficiently grasp the complexity of situations in modern-day world politics and international security risk management as we know them. This is not to say that specific ingroups, for which foreign policy officials may be a part of, will not construct their identity against a limited number of perceptible outgroups. Rather, the spectrum between ingroup and outgroup should not be interpreted as being constituted in a linear fashion, given that some actors involved in the dynamics of international conflict management, for example, feature neither as categorical members of ingroups or outgroups. Their place may be somewhere in between and harder to define, requiring as a result more careful scrutiny.

Nevertheless, within this spectrum, the more the number of actors at stake the greater the chances that members of the ingroup may attribute heuristics to third actors that have an influence over the process, but remain harder to position within the identification conundrum. The genesis of these heuristics may be exogenous to the dynamics of the situation at hand or be derived from an impression left by the third party in question. Whatever the case, influential third parties will need to be factored into the ingroup/outgroup paradigm at one stage or the other where, particularly in conflict situations, given that ingroup officials are likely to have to choose between labelling them within the wider ingroup network or as part of the outgroup. If, under the pressure of the situation, ingroup officials opt for the latter of the two choices by referring to prototype (thus disavowing empathy), third parties will be deemed 'guilty by association' and ushered into the amorphous outgroup. Looking at cases of peace and security in Africa, 'association fallacy' deserves acknowledgement for the fact European officials may very well locate their Chinese counterparts within the outgroup due to the latter's relationship with more readily available outgroup members (such as African officials working for authoritarian governments). Past cases have proven the relevance of this practice in the context of Sino-European interaction on African affairs, even if doing so clearly overlooks the greater complexity that lies behind Chinese behaviour and actions in this regard. What this is also shows is that the local actors, who may be directly or indirectly concerned by the conflict situation at hand, clearly also have their part to play within this identification process and are clearly anything but passive outliers (as explained below in the discussion on the role of social environment on this trust-building process). 
There is one final discussion regarding identification worthy of mention as far as the conceptual framework is concerned, relating to scholarly exchanges over whether identity should be dealt with as a reified or more fluid construct. This discussion has again caused scissions within the cognitivist scholarship with some arguing for a rigid concept of identity, whilst others proclaim the need for a far more fluid approach. One set of scholars researching the matter have found that the normative contents of identity: "must appear to be fixed meanings and set collective expectations" (Abdelal et al. 2006: 697). They are of the belief that identities should be seen in this light for one because identities are by nature unitary and contingent properties, but also due to the fact that a fluid and open interpretation of identity in academic terms will only lead to identities meaning either: "too much, too little or nothing at all" (Brubaker \& Cooper 2000: 1, 20, 31; Cook-Huffman 2008: 26). Without a considerable degree of rigidity and stability over time, identities are unlikely to fulfil their "purpose" and therefore unlikely to be of any particular relevance (Fisher 1997: 24). Other cognitivist scholars beg to differ, with Checkel leading the charge by arguing that the concept of identity should be anything but "frozen or reified" (2004: 235). For Gordon Allport too: "not all categories have such a granitic character. Some are flexible and discriminated" (1954: 172). This is not to say that the cultural programmes that come to shape the eventual guiding principles behind the identity in question will not be long-standing and, once engrained, difficult to reverse. But this does equate to saying that they will not be infinitely "impossible" to reverse, for they too can be transitory (Vertzberger 1990: 65, 307-8; Cook-Huffman 2008: 19). Seeking to mediate the debate, Peter Katzenstein came to the conclusion that: "identities are neither totally fluid nor primordial. They are historically contingent and must be understood contextually" (1996: 534).

From the outside, this specific intellectual exchange on identity does seem to be caught somewhat in a status quo, whilst also giving the impression of ships passing in the night. Advocates of reification may not be necessarily responding to the same cues as advocates against. The former are rightly clamouring against tendencies within the cognitivist literature to treat identity as a void which needs exogenously filling with ad hoc qualifiers, and doing so without a succinct methodology. Although a more intense debate on this point goes beyond the objectives of this thesis, the principles underpinning the arguments advocates for reification are sound, even if advocates against may just happen to be arguing that nonreification does not equate to a lack of methodology. Instead, they are promulgating the need for scholars to look at identity as a malleable construct, which can change and evolve, whether slowly or illogically. In their view, the cognitive, cultural and normative components 
of identity should not be understood as finite and immobile, unaffected by context and exogenous evolutions. To answer both sides of the debate, the conceptual framework for this research project would position itself firstly by insisting that in spite of actors pertaining to a myriad of divergent and often contradictory identities, when these actors are framed in a given environment as part of an ingroup or outgroup, a core identity and ensuing sub-identities (with its distinct 'lifeworld') will dominantly rise to the surface. Morton Deutsch has made a similar point by explaining that: "it is evident that situational factors help determine sub-identities are likely to be most salient and most influential in different social situations" (1973: 62).

The identities of European or Chinese officials in the context of crisis management on the African continent will most often be shaped by their professional backgrounds - whether political, diplomatic, bureaucratic, humanitarian or military - and thereafter hinge on whether they fall within the ingroup or outgroup. Other aspects of their respective identities may come to the fore in light of the specific context, but the professional identity and its concomitant sub-identities will likely prime above the rest. Secondly, if the cognitive components shaping identities are long-standing and deeply engrained into each member of the given ingroup or outgroup, the concept of identity has to be conceived as partially flexible. Without such flexibility, human behaviour would be predictable, which again would amount to an unrealistic assumption. A margin for the evolution or temporary relaxation of, and compromises on, certain cognitive components (and not a wholesale reversal of the entirety of an actor's cognitive components) must be taken into consideration. If not, the possibility for European and Chinese officials to evolve beyond their inherent bilateral political differences, whether in relation to their dealings on African security or other relevant topics, would be a non-issue as their relations would forever be characterised by a status quo.

\subsubsection{The Role of Contextual and Environmental Factors}

In the presentation of those aspects deemed important to trust by the cognitivist scholarship, little reference was made to the social context factor. The explanation for this virtual absence of discussion on the impact of environmental factors stems from the fact that few studies directly refer to them or if they do, they tend to factor them in as independent variables (or sometimes make them the conceptual object of their entire study). Nonetheless, in this case an exception to the norm will be made, as they will be treated as an integral part of the conceptual framework applied here on cognitive-based trust and mistrust because of the assumption that the: "social context both enables and constrains trust relationships" (Cook et al. 2007: 68). Obviously, the social environment will have a direct impact on trust for the fact 
that it gives meaning to a specific number of multifarious actors and their respective interests, subsequently rendering others less meaningful. Given the determinacy of the identification process to trust, the social context's inherent inclination to rank the relevant from the extraneous will naturally play a consequential part in the ingroup/outgroup dynamic (Boon \& Holmes 1991: 198). This matters as far as members of an ingroup are likely to foresee their role in the social context, as well as those played by wider ingroup and outgroup members.

Environmental factors are not simply essential for the structural implications they hold over the actors' perceptions, but also for the way that they are themselves shaped by actors' respective perceptions and understandings of the context (Fisher 1997: 29). Without falling into the conventional trap of giving finite prominence of structure over agency or agency over structure, both are noteworthy in varying ways. Structure will set the scene in terms of which actors are involved and who will matter in the context of a crisis situation on the African continent. Structure will also account for the situation's geographic location (as well as the nature of the conflict situation), which is intimately entwined with the 'natural' selection of relevant actors (which applies to both the EU and China). In addition, structure - as seen below - will define the modalities, quality and quantity of interaction among all concerned parties. Agency is, though, required at this stage to allow the different actors to give meaning to the context and therefore situate themselves with regard to the nature of the crisis and to the actions/reactions of others. Without agency, it would be near impossible to comprehend the dynamics behind security risk management such as those discussed in this thesis, for it would overlook the significance and symbolism actors attach to a given geographical region, their interpretation of the region's history as well as to the modalities of interaction with other actors.

Furthermore, a lack of interest towards agency would render futile the study of actor's interpretations of the situation but doing so would give very little indication neither of actor's relevant identities and cultural programmes, nor of how these lifeworlds match up within the specificities of the context at hand. Overlooking agency is also problematic for it undermines the impact that local officials can have on the trust-building process on the ground between European and Chinese agents. Structure and agency are thus as crucial to context as context is to structure and agency in that they determine which aspects will be of importance to the identification process. It goes without saying that trust is a highly contextual phenomenon, which means that cognitive-based trust developed between groups cannot be transferred across contexts unless contextual parameters are identical in terms of structure and agency and unless a specific institutional memory subsists to make trust transferable. Indeed, the 
cognitive-based version of trust as presented in the previous chapter's review of the relevant literature made clear that trust inherently featured as a concept that necessitated time in order to be developed between two actors or a number of groups of actors. Usually, trust is depicted in modern-day Western thinking as a fragile intangible element that is difficult and timeintensive to achieve as part of a personal relationship (as per the concept of social trust), but easy to erode. Since political trust involves interaction between groups of human beings, it is difficult to conceive that the fragility of the concept of trust would not apply - in fact it could be considered as even more pertinent than for social trust. Time thus represents a key part of trust-building for political trust, since it allows for repetitive interaction between groups of actors that creates opportunity for diffusing initial apprehensions and misconceptions (which may automatically happen), whilst making it possible for groups to express empathy for one another via communicative action (that hinges on the earlier process of identification). Repetitive practices across time, through trust, thus are understood as playing a vital role in building trust where trust did not previously exist, even if it does guarantee that sufficiently high levels of trust will be achieved by the groups in question or will be maintained over the medium- to long-term.

Taking this thesis as a case in point, it is improbable that groups of officials from either side involved in dealing with security risk management in Africa will be able to consistently build trust across the various cases in which their interaction may be needed. History has proved as much, since the outcomes of their interactions have tended to fluctuate. Taking into account what has been mentioned concerning political trust-building, time and the importance of repeated interaction in producing predictable behavioural patterns, the outcomes have most likely fluctuated due to the high turnover of different individuals tasked with managing bilateral interaction across the entire spectrum of their dealings on security risk management in Africa. Furthermore, in the absence of a specific joint mechanism for institutionalising trust across contexts - despite official bilateral dialogues on African affairs time and repetitive practice become less potent and more contingent upon the characteristics of the social environment specific to the case where their interaction is called upon. The institutionalisation of repetitive practice as a means of building trust between distant actors does certainly constitute one way of ensuring that trust is not only fostered but maintained between such actors, notwithstanding the possible rotation of officials.

Yet, if institutionalisation is weak or non-existent then the unique nature of each social context will pertain to a considerable level of influence on the eventual trusting outcome. This is even more poignant if the mechanisms in place that involve interaction at a higher political 
level struggle to reproduce the same level of trust that existed between both sets of officials dealing with the crisis situation on the ground. Political trust is thus naturally more vulnerable to erratic and inconsistent foreign policy choices (which may frequently undermine both the PRC and the EU's respective external action decision-making). Without a solid institutionalised basis for political trust, the latter is likely to be more complex to build. As such, the institutionalisation and transferability of trust in this context would appear improbable, albeit not impossible. As chapter 7 will explore in greater detail, if the institutionalisation of political trust is beyond the capacity of groups of officials in terms of the entirety of their dealings on a given topic, then their capacity to build trust and cooperate will rest even more upon the specific characteristics of the social environment in which they are operating. As things stand, this description reflects well the state of play between the EU and China when it comes to political trust on the theme of security risk management in Africa.

As far as this conceptual framework is concerned, as referred to in the previous paragraph, the social context is also of relevance for the way it can determine: "[...] the class of communication for which trust is an issue" (Cook et al. 2007: 32). Indeed, the interactional environment will decide upon both the quantity and quality of engagement between actors, which is of particular relevance for the study of empathy and ideal-type TCA. Referring to the points made about context in terms of structure and agency, both will have their own say as to whether a process of identification can evolve into the kind of trust needed to trigger cooperation between actors such as European and Chinese officials, thanks to empathy and ideal-type communicative action. Or, both will help to maintain in their own way the predominance of mistrust in a given social environment. This leads us onto the following questions: will the structure of the specific context at hand facilitate the expression of empathy and ideal-type communicative action between European and Chinese officials? Will their contextually-contingent cultural programmes permit their expression or their potential evolution over time? Different social contexts are likely to alter the variables both on structure and agency, which sequentially will affect the potency of empathy and communicative action as well as an overall incidence of trust-building between actors.

More specifically, by shaping the structure, the social context will impact upon the capacity for actors to engage in the sort of dialogical interaction required for instigators to express the empathy needed towards their interlocutors, as a vital step in the overarching trust-building process. The same can be said for the impact on the capacities to mould their dialogical interaction so as to meet the ideals of Habermasian reasoning. For example, within the cognitivist literature, arguments are often made along the lines of Habermasian reasoning 
whereby the probability of trusting outcomes will be boosted if interaction is carried out by actors in purposefully-built "non-hierarchical, network-like" platforms, characterised by a high density of mostly informal interaction (Finnemore \& Sikkink 1998: 899; Risse 2000: 15; Checkel 2004: 240). For all the virtues of this reasoning, its feasibility is firstly determined by the material possibilities of the environment under scrutiny. There is in fact no guarantee that actors will have access to the material and immaterial resources required to put together and sustain such a framework over the course of the long-winded trust-building process (with institutionalisation virtually irrelevant as aforementioned). The geographic conditions and location of the conflict situation may also not be conducive to communicative action and the concurrent expression of empathy. Influent third parties in particular may simply find that the conditions needed to develop trusting ties, following a process of positive identification, are simply not adequate due to a lack of time, resources and human capacity/capability. ${ }^{44}$ The social environment surrounding a crisis situation will have an incidence on the quantity and quality of interaction among the concerned parties, thus restricting or enhancing the effectiveness of empathy and communicative action accordingly.

But this is not just a matter of material possibilities alone. Empathy, to a certain extent, and especially ideal-type communicative action rely on the assumption of "good human nature" (Mitrović 1999: 221). Yet, for all the ethical virtues underpinning this assumption, within the realm of security risk management on the African continent - whether between those directly involved or third party 'mediators' - not all contexts are likely to be permissive to support this assumption. Not only is this highly subjective criteria questionable in methodological terms (who and how do you attribute it), but even if it were detectable among European and Chinese officials, their respective interpretations of the context may simply make it impossible for them to express it. This is not so much a case of asking whether they can empathise or cannot strive towards the ideals of communicative action via dialogical interaction, but more a case of being willing or unwilling to do so. In certain contexts, predominantly in highly politicised ones, the hand of "good human nature" will be forced by the process of identification as actors have to 'choose sides' or run the risk of finding themselves alienated. As we will also witness across the two case studies, the positions adopted by local officials within these specific social environments may also favourably or unfavourably impact the ability of European and Chinese officials to express empathy and foster ideal-type communicative action.

\footnotetext{
${ }^{44}$ This will especially be the case if we go along with McClintock (et al.)'s rationale that: "[...] the more communicative channels available in bargaining, the more cooperative are the negotiated outcomes" (1983: 224).
} 
Given that modern-day conflict situations are highly political by nature, the intensity of the context may push actors into a hurried although necessary identification process, leaving empathy and communicative action exposed and volatile as a result. Although for cognitivist scholars of a Habermasian inclination it may be suitable to theoretically assume the need for actors to carry their good nature into even the most poisonous of security dynamics, the actors themselves may feel the urge to place a premium on identification following their perception of the context. In so doing, the potential for good human nature, empathy and communication are likely to be muffled and pushed aside for the benefit of identification, which actors may justify as being essential for the survival of their own identities (even as third parties) in the context of a given conflict situation. Due to empathy and communicative action's relative contingency upon identification, in addition to the process of identification's own contingency upon the social environment, trust for reasons of structure and agency is in itself dependent on context. This is especially true if trust is conceived as a dynamic and long-term endeavour, social context may indeed become a determinant component of trust and mistrust alike.

By having returned to the discussion on those more contentious aspects of the cognitive literature on trust relative to the conceptual framework, this section has etched a path towards a more concise and reworked version of Schema 1. In order to provide a conclusive summary to this section, this version is presented below in the shape of the matrix constitutive of Schema 2: 


\section{Schema 2 - Conceptual Framework on Trust}

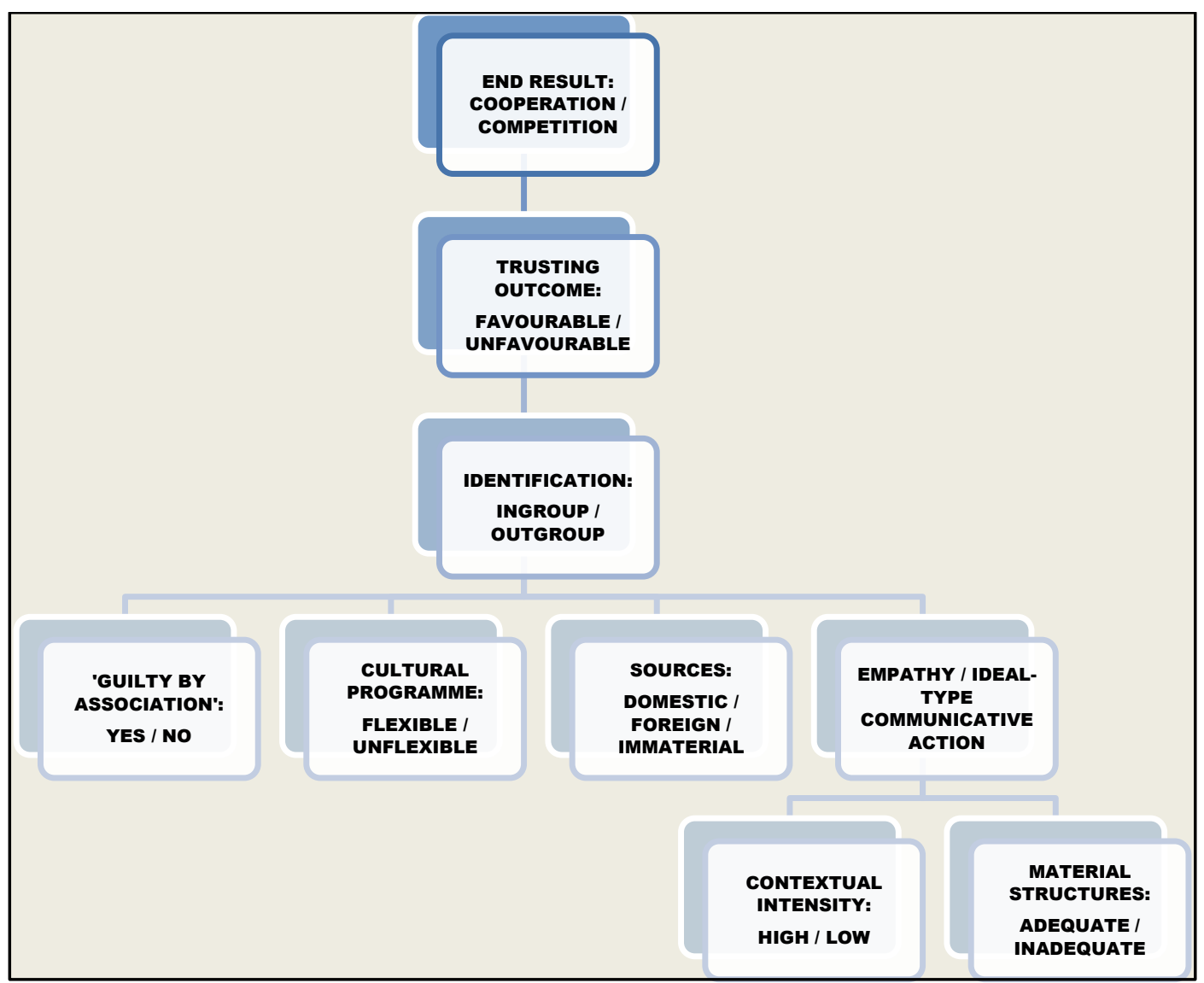

\subsection{Methodology: Comparative Case Studies and Process Tracing}

Now that the merits of this conceptual framework have been spelt out, more detailed information will be provided on how it will be applied in practice - for any such framework is only valid for as long as it can be supported by solid empirical evidence. This section will now turn towards the thesis' methodological design, to showcase how evidence will be collected and compiled - evidence that will highlight the analytical prevalence of cognitivebased trust/mistrust in the context of Sino-European interaction on crisis management in Africa. To produce the kind of evidence needed to lend credence to the conceptual framework in relation to the wider body of literature on trust in the field of FPA theory, the design must be of an impermeable nature particularly since it places such emphasis upon intangible cognitive elements and qualitative research techniques.

Generally speaking, the thesis' empirical basis will rely upon a comparative analysis composed of two principal case studies. The focal point of research will revolve around the first cases' contrasting culminating outcomes, which were primarily caused by the differing levels of cognitive-based trust witnessed between European and Chinese officials in each instance. As will be shown in the thesis summary (chapter 7), it is the respective contrasting 
endpoints of the two case studies that demonstrates above all the potency of cognitive-based political trust and mistrust when it comes to explaining the outcome of interaction between European and Chinese officials on the theme of African security risk management. In other words, in the first instance (insurgency in Darfur), despite talk of a "paradigmatic" shift in the PRC's stance as observed over the course of the conflict, this shift was the cause of indirect coercive pressure put on Chinese officials by their European (and Western) counterparts but not the result of sufficient levels of mutual cognitive-based trust between both sets of officials. Consequently, the evolution of the Chinese stance on Darfur did not prove paradigmatic, neither with regard to European expectations of the PRC's greater activism nor in terms of the overall resolution of the conflict as a whole (whereas bilateral cooperation based on cognitivebased trust may well have had a greater impact on the crisis). Darfur would naturally go down as an example of competitive interaction in the history of bilateral affairs within the realm of African security risk management. However, in the second case (counter-piracy efforts off the Horn of Africa), Chinese officials on the ground did develop sufficient cognitive-based trust in their European counterparts to subsequently shift their original policy approach of their own free will, towards one which benefited both the EU's own position as well as the overall outcome of the counter-piracy activities. In this case, cognitive-based trust made it possible for both sides to change the dynamics of their own interaction from a relatively competitive outlook, towards a far more cooperative one. ${ }^{45}$

Each case will pertain to a fairly symmetric organisation, structured around a historical narrative that will draw the reader's attention to the mechanisms (process of identification, impact of social environment) involved in producing causation between cognitive-based trust and the respective competitive/cooperative outcome of bilateral interaction. This entails breaking complex chains of events into smaller pieces, as well as distant relations between antecedent and outcomes into more proximate cause-and-effect coupling, until the cause-andeffect relationship is so high that further explanation is unwarranted (Clarke \& Smith 1989: 172; George \& McKeown cited in Steinberg 2007: 193). Such historical narratives - better known as 'process tracing' in scholarly jargon - will help to produce, in a more scientific manner, the evidence needed to support the assumptions promoted in the conceptual

\footnotetext{
${ }^{45}$ For an explanation of the rationale for selecting these particular case studies, please refer to the introductory chapter.
} 
framework by linking intangible concepts to behavioural outcomes (Adler 2002: 102; Farrell 2002: 61-2; Hopf 2002: 7). ${ }^{46}$

The narratives will be reconstructed by collecting data from four types of sources that will be used to foster empirical evidence, either by relying upon their factual/historical content or by using them for the purpose of discourse analysis. These are: policy papers, official statements and governmental reports; academic publications; news media sources, electronic sources and nongovernmental reports; open-ended interviews with relevant officials. Although the first three are self-evident, the methods employed for collecting data from interviews requires a more detailed explanation. Interviews were mostly undertaken in person, over the telephone (lasting between 30 to 60 minutes) or via email correspondence on a oneon-one basis, over the course of a five-month period for each case study. The rationale for conducting interviews was twofold: on the one hand, some interviews were used either for collecting relevant factual information directly from the participants or as a means of setting up parallel interviews with other participants capable of providing more acute factual information. In particular, these interviews were highly valuable in terms of triangulating data collected across the three other sources (and vice versa). Although the bulk of participants, as explained below, represented the EU institutions or member states in Brussels, a number of these interviews were held with professionals from other backgrounds (public sector, private sector, NGO) who had worked on the cases in different ways, whilst a lesser number of openended interviews were conducted with Chinese officials and experts. ${ }^{47}$

On the other hand, a smaller number of interviews were used purely for cognitive purposes to glean empirical evidence from analysing participants' answers. These were held with officials directly involved with the subject matter (mostly for the major case studies but also for those found in the concluding section), including the management of interaction with third party stakeholders. In the words of Roy Ginsberg, the objective of these interviews is to extract "subjective impact" from responses to open-ended questions of qualitative nature, usually dealing with perceptions of the EU/West's role, China's role and the quality of bilateral interaction on the subject matter (2001: 52). From this "subjective impact," "cognitive political impact" can then be inferred which can play a non-negligible part in the

\footnotetext{
${ }^{46}$ The added-value of using a variant of process tracing as a methodological tool in this thesis stems from its complementarity with a case study-based approach, since it can help provide a wider empirical body upon which to test the validity of the conceptual framework, rather than relying upon a single narrative. In consequence, this reduces theoretical uncertainty by putting the hypothetical assumptions underpinning the conceptual framework to the test across multifarious settings, making the eventual findings more thorough and credible in the process.

${ }^{47}$ This figure currently stands at 100. For reasons of confidentiality, the interviews are cited anonymously throughout the thesis (more information on the interviews can be found in with the bibliography).
} 
empirical evidence presented to support the conceptual framework (Ibid). These interviews were of greater intensity but were also fewer in number, which explains why the number of interviews referred throughout the thesis belies the total amount conducted for this project.

As the object of this thesis is to look at the EU's engagement of China on the topic of African peace and security, the large majority of interviews were organised with European/Western actors - a decision taken in the interests of time and resources allocated to the project - whilst most information on the perceptions of Chinese decision-makers was extracted from policy papers, academic publications, media sources and as aforementioned a far more reduced number of interviews. ${ }^{48}$ With regard to the selection of participants, since the EU has no officials specifically tasked with following up on China's ascendance on the African continent (on peace and security or other themes), the bulk of the interviews with European/Western participants were conducted with individuals who had been mandated to develop the EU's response to the crisis at hand and whose job also entailed interacting with third parties, such as China. In the case where the EU was mandated to act on behalf of the member states to help resolve a given crisis (as seen in chapter 6), this involved organising interviews with those put in charge of running the EU's operation, as well as the supporting cast in Brussels working for relevant supranational institutions and the member state's permanent representations alike (the latter are mentioned as they oversee the work of supranational actors in this instance). ${ }^{49}{ }^{50}$ In the case where the EU was not mandated to act on behalf of member states, or only weakly designated to do so, the scope for selecting participants for interviews was broadened (see chapter 5). Despite the EU's best attempts to formalise its interaction with China on inter alia matters of peace and security in Africa (as seen with the 2008 'Communication' or with the bilateral dialogue on Africa), the absence of institutionalisation leaves much more room for adhockery. If member states decide not to attribute a strong and well supported mandate to the EU to deal with a conflict situation in Africa, then those member states with the capacity to play a role in solving the crisis may look for alternative ways to impact the situation on the ground (all the while respecting the demands of constricted activism). They are, constitutionally speaking, perfectly entitled to do

\footnotetext{
${ }^{48}$ The bulk of interviews was organised in Brussels, while some were held in London, Paris and Hong Kong.

${ }^{49}$ As far as the supranational actors are concerned, interviews took place with officials working for: the European External Action Service (EEAS), the Crisis Management and Planning Directorate (CMPD), relevant Directorate Generals of the European Commission and the Council Secretariat. As the European Parliament plays almost no role in the decision-making and execution of EU security policy (see below), interviews held with officials are not specifically mentioned even if they did take place.

${ }^{50}$ Member state representatives are mentioned here as they do oversee the work of supranational actors, despite not necessarily being involved in the intricacies of the decision-making process once the mandate has been approved.
} 
so given that they monopolise the decision-making process relative to the EU's international security policy.

The monopoly stems from their dual role of policy entrepreneur and exclusive executive power (Smith 2000: 616). In effect, they can decide on what items appear on the agenda, on what items should be removed, before choosing the items they believe require collective action (Ibid). Even once a decision has been taken by one or several member states, the decision-making process is structured in such a way as to preserve their sovereign control (Gebhard 2011: 124). For one or more member states to seize an opportunity to list an item onto the agenda constitutes in itself only half of the story. Once at the level of the Council of the EU, member states are under the obligation to horse-trade amongst themselves in order to obtain consensus in a voting environment formally characterised by the need for unanimity and the potential for vetoes (Haaland Matláry 2009: 120). In short, the consensual nature of decision-making among member states leaves little room for the supranational institutions to exert influence (Smith 2004: 98). ${ }^{51}$ Supranational input can be classified as minimal, despite the Treaty of the European Union attributing the European Commission with the right of initiative and consultation at the lower echelons of the CSDP policy machinery, which it has symbolically seldom put to use (Chapter V, Article 27). In addition, formally speaking, the European Parliament only serves as a consultee producing reports/resolutions, putting questions to the Council of the EU and receiving ex-post feedback on the state of affairs of CSDP (Quille 2008: 67-9). The creation of the EEAS was designed in part to help bring the intergovernmental and supranational elements closer together but for the time being, member states are still very much in charge when it comes to the EU's international security policy.

It is thus left to the Political and Security Committee (PSC) - composed of ambassadorial-level member state representatives - to organise the quotidian management of the Union's security policy, which it does by monitoring the international outlook, delivering opinions and engaging in initial exchanges within the Council of the EU in case of a common decision (Peclow 2008: 33). In 1997, the EU Council further reinforced its intergovernmental control via the appointment of a High Representative (HR) - Solana - who was assigned to improve the coherence and consistency of the Union's CFSP. Solana was granted a similar right of initiative as the European Commission but recent publications also allude to the HR's subservience to the views of (influent) member states (Major 2011: 187). This explains why -

\footnotetext{
${ }^{51}$ Even if the EU treaties encourage member states to act collectively. As the 2009 Lisbon Treaty stipulates (Title V, Chapter 2, Article 24, Paragraph 3): "The Member States shall support the Union's external and security policy and shall comply with the Union's action in this area."
} 
beyond the EU - there are a number of other platforms at their disposal which they can use when dealing with security risk management on the African continent, which only multiplies the number of platforms European actors can use when engaging their Chinese counterparts in this respect, if no specific mandate exists for collective action. Therefore, as many interviews were conducted with those directly responsible for handling the EU's portfolio during the respective crises as they were with member state diplomats responsible for implementing national strategy - given that in their own way, they each tried to set the tone for how Europe should be acting in this context, which thus necessitated a broader interpretation of what is meant by the 'EU' in this case. 


\section{Case Study 1: The EU's Engagement of China on the Darfur Conflict in Sudan}

\subsection{The Backdrop to Darfur}

\subsubsection{The International Community's Belated Reaction}

By the time Western governments, civil society groups and public opinion had got to grips with the atrocities in Darfur, the bloodiest episode of this conflict had almost come to pass. When the international community eventually caught wind of the scale of the violence, Darfur was rapidly transformed from a crisis which garnered very little attention from the mass media, to one which hit the headlines worldwide. Yet, as with all violent crises, the tensions underpinning this latest uprising in Darfur's history had been simmering for some time between the rebel groups representing different regional tribal groups and the central authorities in Khartoum, dominated by a minority ethnic group within Sudan's extensive identity patchwork. ${ }^{52}$ Indeed, using the terminology adopted by scholars to describe post-Cold War conflicts, Darfur had all the makings of a "new war" even before violence broke out in early 2003 (Kaldor 2007). ${ }^{53}$ Since a large body of specialist literature has already provided much detailed analysis about the reasons behind the outbreak of conflict, only a brief summary of the three most prominent factors will be provided below - three factors which should have alerted the international community to the high level of risk that conflict was brooding beneath the surface, due to Khartoum's bias against the region's tribal groups. ${ }^{54}$

\footnotetext{
${ }^{52}$ Andrew Natsios has suggested that three 'Arab' tribes from the Nile Valley region of Sudan have historically come to dominate the country's political sphere since 1956, despite representing no more than $5.4 \%$ of Sudan's demography (2012: 11).

${ }^{53}$ Mary Kaldor defines "new wars" as being: "[...] fought by networks of state and non-state actors, often without uniforms, sometimes with distinctive signs, like crosses, or Ray-Ban sunglasses as in the Croatian military in Bosnia-Herzegovina. They are wars where battles are rare and where most violence is directed towards civilians as a consequence of counter-insurgency tactics or ethnic cleansing. They are wars where taxation is falling and war finance consists of loot and pillage, illegal trading and other war generated revenue. They are wars where the distinction between combatant and non-combatant, legitimate violence and criminality are all breaking down. [...] Above all, they construct new sectarian identities (religious, ethnic or tribal) that undermine the sense of a shared political community. [...] The various warring parties have a vested interest in continuing violence for both political and economic reasons. Moreover, they tend to spread through refugees and displaced persons, criminalised networks, and the sectarian ideologies they manufacture" (2007: 3-4).

${ }^{54}$ The following publications offer, in their own distinct way, a very detailed and comprehensive understanding of the crisis in Darfur, its roots, causes and consequences: The Poverty of Nations: The Aid Dilemma at the Heart of Africa (Morton 1996); The Root Causes of Sudan's Civil Wars (Johnson 2003); Darfur: The Long Road to Disaster (Burr \& Collins 2006); Darfur's Sorrow: A History of Destruction and Genocide (Daly 2007); The Devil Came on Horseback: Bearing Witness to the Genocide in Darfur (Steidle \& Steidle Wallace 2007); A History of Modern Sudan (Collins 2008); Darfur: A New History of a Long War (Flint \& De Waal 2008); Darfur: A $21^{\text {st }}$ Century Genocide (Prunier 2008); The Darfur Sultanate: A History (O'Fahey 2008); The Translator: A Tribesman's Memoir of Darfur (Hari 2008); Saviours and Survivors: Darfur, Politics, and the War on Terror (Mamdani 2009); Darfur and the International Community: The Challenges of Conflict Resolution in Sudan (Barltrop 2011); Sudan, South Sudan and Darfur: What Everyone Needs To Know (Natsios 2012).
} 
Map 1 - Darfur in Sudan ${ }^{55}$

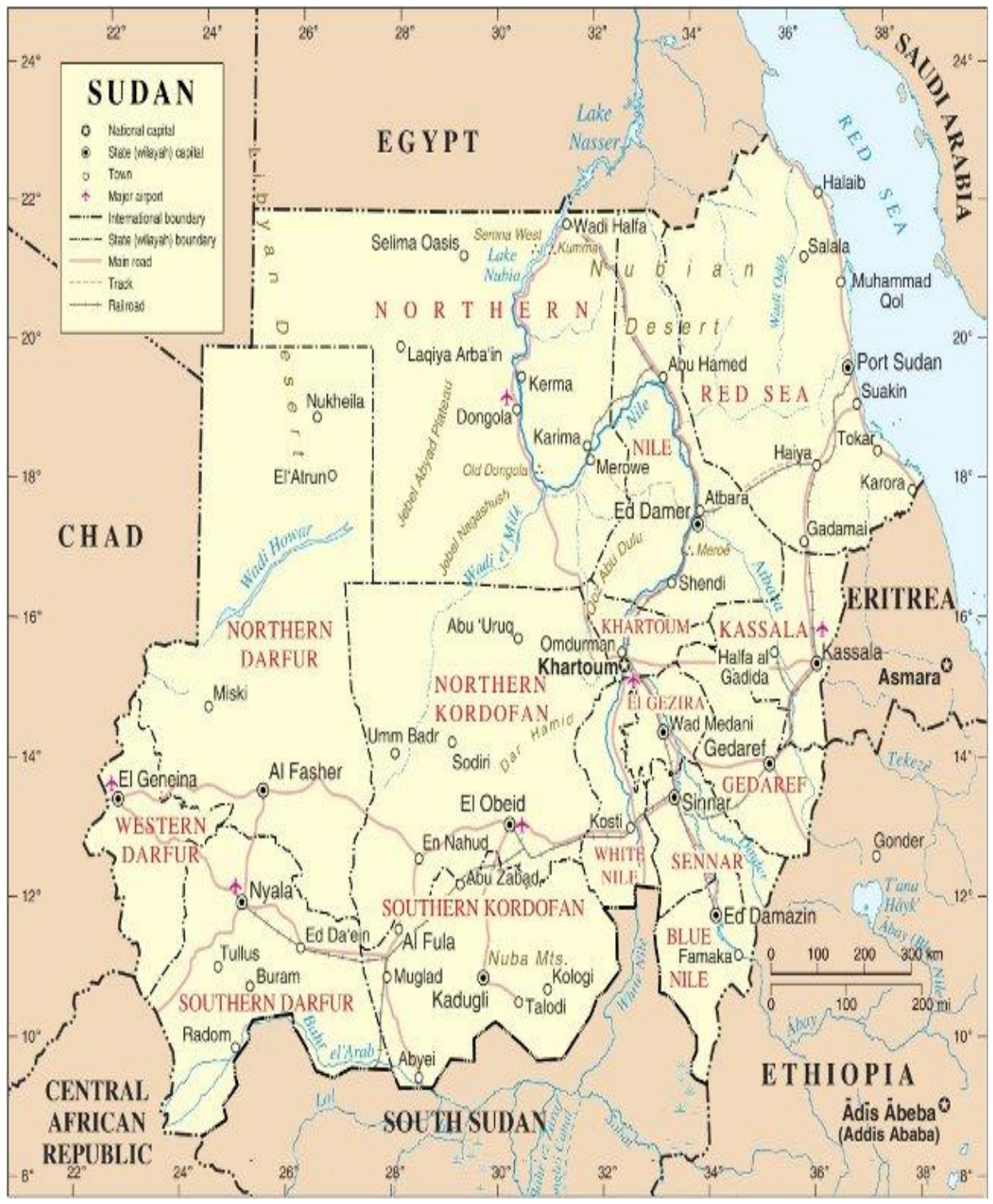

First of all, the respective histories of Darfur - in its time as a self-standing sultanate and Sudan have both been marked by long-standing episodes of violence and instability, whether caused by internal factors, external factors or a combination of the two. Especially since the creation of the Sudanese nation-state, the country has known an almost incessant stream of protracted, dormant and reignited conflicts. As a case in point, the last significant internal conflict prior to Darfur, opposing the Government of Sudan (GoS) to those forces fighting for cessation in the south of the country, lasted almost 21 years, resulting in approximately 1.5 million deaths and the displacement of 4 million people (HRF 2008: 4). Darfur, in particular, has a history of "communal violence" stretching back far beyond the

\footnotetext{
${ }^{55}$ Map retrieved at: http://www.sudantribune.com/spip.php?mot512.
} 
advent of the modern Sudanese state (Macfarlane 2012: 164). Although rivalry amongst these tribes reflects a part of Darfur's rich history, since the region's incorporation into The Sudan its struggles have usually been directed towards authorities in Khartoum with a pattern of recurrent violence pitting the "periphery" against the "centre" (and vice versa), largely triggered by feelings of aggravated institutionalised discrimination (Tubiana 2008: 24; Barltrop 2011: 27; Natsios 2012: 12). ${ }^{56}$ For example, during Sadiq al-Mahdi's rule in the 1980s, after militant groups representing certain tribal factions had lashed out against Khartoum's discriminatory practices they were subjected to a campaign of oppressive tactics, whereby the GoS hired proxy militants to fight back (Natsios 2012: 22, 37). Often, these militants were already sworn enemies of some of the tribal factions themselves and once allied to government forces, were given a free hand to vengefully wreak havoc so as to reinstate Khartoum's authority. In so doing, the use of proxies only added to the growing endemic spiral of violence characterising interaction between the centre and the periphery, deepening mutual feelings of vindictiveness and the desire to exact retaliation among the divergent parties to the conflict. As will be explained below, this pattern of violence simply reared its head once more throughout 2003 and early 2004.

Secondly, to add to the feelings of institutionalised economic and political discrimination, fairly dramatic changes in the region's geographic and demographic make-up would prove deleterious to Darfur's already fragile agrarian economy. In turn, this second factor only served to accelerate the use of violent conflict as a means of expressing dissatisfaction as much towards those occupying the halls of power in Khartoum, as between the tribes themselves - with fighting over scarce resources becoming increasingly commonplace from the 1980s onwards. Following years of mismanagement that had left the region's economy in ruins, matters were made worse by the climatic changes of the 1980s. Following a $40 \%$ reduction in precipitation caused by Sahelian drought, not only did approximately 100,000 inhabitants lose their lives through famine between 1984 and 1985, but the region suffered the full effect of desertification, facilitated by the poor administration of the region's forestry (Zhang 2008: 60; Barltrop 2011: 22; Macfarlane 2012: 164). To compound an already tricky environmental situation, Darfur's demographics paradoxically experienced sustained growth (from 3 to 6 million over the past 20 years) as a result of improved healthcare and drought-induced migration of populations from Chad and Niger

\footnotetext{
${ }^{56}$ Many in Darfur have felt institutionally neglected and segregated against by Khartoum whether through the country's legal system, political structure or media. More recently, their grievances have stemmed from having seen almost nothing of the wealth accumulated by the GoS, as a result of the late 1990s and early 2000 s oil boom (El-Tom 2003; Patey 2007: 1000; Natsios 2012: 109).
} 
(Zhang 2008: 60; Cockett 2010: 172; He 2010: 156; Interview 35). ${ }^{57}$ With the shortage of rainwater leading to poor harvests, in addition to the influx of people putting pressure on already scarce resources, the historical coexistence in the region between farmers, pastoralists and nomads became tense (Murithi 2008: 76; Zhang 2008: 60). On top of the flood of small arms and light weapons (SALWs) into the region, as a result of the centre's bid to arm allied tribesmen, the conditions for rapid degeneration were set (HRF 2008: 33). Whereas, up until the 1980s, the conflicts arising from this conducive environment would have customarily been arbitrated and settled within a local framework (mostly by tribal elders), to assert its authority the GoS increasingly ensured mediation would take place within a governmental framework. ${ }^{58}$ For the GoS, changing these dynamics entailed greater control over the region's political dynamics, by prioritising: "[...] allegiance to Khartoum over community respect as a basis for leadership" (Ibid: 33). This only heightened the chances that tribal disputes offset by competition over regional resources would be settled by gunfire rather than by dialogue, as the tribal groups were no longer dealing only amongst themselves - they were simultaneously jostling for the GoS' attention.

This leads us to the final factor which undoubtedly played its part in the build up of tension both within Darfur and between the rebel groups and Khartoum: ethnic tension and the GoS' policy of ethnic favouritism. Again, much has already been made about this specific point within the academic literature and in media/NGO reports on the conflict. In short, Darfur as a region is replete with myriads of tribal and ethnic identities, which although they have their own specificities and distinct histories, are connected by certain commonalities. The majority of tribal factions in Darfur, like that of most other social groups in post-2011 Sudan, are of Muslim confession. Nonetheless, particularly since the late 1980s, there has been an incremental desire emanating from the centre to manipulate identities in Darfur into ingroup and outgroup, so as to increase its political hold over the region (Tubiana 2008: 26; Cockett 2010: 174). ${ }^{59}$ This meant that those groups which Khartoum deemed reliable and acceptable in its conceptualisation of the region were labelled 'Arabs' (ingroup members),

\footnotetext{
${ }^{57}$ According to Richard Cockett, the first census in Darfur recorded a total of 1.12 million inhabitants. By 1973, this figure had more than tripled to reach 3.6 million and twenty years later it had increased to 5.4 million. By 2002 , it was estimated that the population had risen to 6.5 million, thus amounting to a fivefold increase across a fifty year window (Cockett 2010: 172).

${ }^{58}$ Cockett states that: “from the 1970s onwards Khartoum's politicians, beginning with President Numeiri, began to dismantle the traditional tribal structures in the name of modernisation and reform - a cover, in fact, for the more ignoble aim of destroying the political opposition movements that were sustained by those traditional structures, most notably the Mahdists of the Umma Party" (2010: 173).

${ }^{59}$ This dichotomy gained prominence for the first time during the 1987-9 conflict between the Fur (a tribal group) and the 'Arabs,' favoured by the authorities in Khartoum (ICG 2004b: 5).
} 
whilst those who did not make the grade were castigated as 'African' (outgroup members). Such a dichotomisation, in actuality, made very little sense since physically, ethnically or culturally, differences between 'Arabs' and 'Africans' were scant if non-existent especially in light of the strong tradition of intermarriage between groups throughout the region (ICG 2007a: 4; Brosché 2008: 5).

However, for reasons of power and politics, this bifurcation of regional identities became especially salient during the 1980s with the scission somehow becoming ingrained within the different tribal identities - depending on which side of the spectrum they found themselves - particularly in times of strife. ${ }^{60}$ Of course, the complexities of the situation fall outside the scope of this dissertation, yet they are mentioned here since they contributed to feelings across the region that certain tribes were being unfairly discriminated against by the identity politics promulgated from Khartoum. Even if the 'Arabs' in Darfur were not actually all made better off in the long-term by this positive discrimination in their favour, those placed under the 'African' banner were logically prone to feelings of exclusion by mainstream Sudanese society, thus enhancing their hostility towards those who strove to engineer this divide. Unsurprisingly, the gradual build-up of resentment towards Khartoum by tribal groups would inevitably struggle to contain itself. Friction had already come to a head on this basis in the 1990s and early 2000s, but it reached a paroxysm in 2003.

As far as the majority of the international community was concerned though, this incremental build-up of tension largely went unnoticed due to two concurrent events which guaranteed that global attention would be distracted by events unfolding elsewhere - leaving Darfur's conflicts “invisible" to the world (Flint \& De Waal 2008: 167; Cockett 2010: 170). ${ }^{61}$ The WoT was on the points of being expanded as the George Bush Junior administration, along with a number of select allies, decided to inflict regime change upon Saddam Hussein in Iraq. The actual intervention by the coalition of the willing as part of Operation Iraqi Freedom commenced a month after fighting had broken out in Darfur. Yet, it was the international debacle and fallout over the intervening forces' justification for the intervention which captured attention for weeks in the run-up to the first airstrikes being carried out over

\footnotetext{
${ }^{60}$ One example often given to prove the GoS' volition to divide and rule over Darfur's different tribes, concerns the decision made in 1994 to split Darfur from a region administered as a unique entity into three different regions, which naturally contradicted the region's tribal composition (ICG 2007a: 8).

${ }^{61}$ Or in the words of the then UN Secretary General, the Security Council: "[...] had no desire to place the complicated and heavy demands of Darfur on its agenda" (Annan \& Mousavizadeh 2013: 119). Furthermore, the same author claims that few including the UN in New York "took any notice" at the time of the rebels attacks on the GoS' barracks in February 2003, while the government of Pakistan - the incumbent Security Council President at the time - rejected requests to put Darfur on the Council agenda because it apparently wanted to avoid discussions on what it saw as another possible international intervention in a Muslim state (Ibid: 120, 125).
} 
Baghdad. Any other international development was only going to be treated as a secondary affair for as long as it did not involve either transatlantic interests or directly relate to the WoT (for which Darfur did not appear to count, since al-Qaeda had no involvement in the uprising or subsequent retaliation).

The lack of interest in Darfur was also compounded by the emphasis the international community seemed to place upon negotiations over the Comprehensive Peace Agreement (CPA) - the deal that eventually brought an end to the longest civil war in Africa by allowing South Sudan to secede from Sudan - which had already been ongoing for several years prior to the Darfur conflict. Within the literature related to the crisis, two noteworthy points have been made connecting the CPA negotiations with developments in Darfur. In effect, the point is often argued that the international community chose to ignore reports of the violence between 2003 and early 2004 in Darfur, since its energies were still focused on getting the CPA signed and ratified (Panapress 2003; Cockett 2010: 176; Keane \& Wee 2010: 123; Annan \& Mousavizadeh 2013: 124; Interview 39). Consumed by the fear that the violence in Darfur could scupper the progress made in the protracted talks between the north and the south over the landmark peace deal, the international community shielded the CPA from any negative ramifications ensuing from Darfur by taking a hands-off approach on the latter, or at best dealing with it as an unrelated phenomenon. ${ }^{62}$ But some commentators believe that the factor which ultimately led the rebel groups to launch the February 2003 attacks concerned their apprehension over the future of their region, as they had been left out of the CPA talks, while tribes in the south of Sudan - who suffered from a similar exclusionary plight - were being allowed to break free and form their own state. Rebel groups feared that this decision was being made: “[...] over the head of the region's people and without regard for the severe social, political and economic inequalities that were producing unrest" (ICG 2004a: 8). With their eyes firmly set on the CPA though, the international community had apparently been oblivious to the unexpected ramifications offset elsewhere in Sudan.

By the beginning of 2004, the international community was caught off-guard by this decision to look the other way on Darfur, as reports of the horror stories of the ongoing

\footnotetext{
${ }^{62}$ As a case in point, Annan instructed his staff at the time to: "[...] only subtly pursue the emerging Darfur issue, discussing it on the margins of other meetings, rather than allowing it to appear centre stage in negotiations with the government. It was terrible to have to make such a choice" (Annan \& Mousavizadeh 2013: 124). Another similarly telling example of this type of behaviour is recounted by Cockett: "[...] this political and diplomatic context conditioned the way that everyone reacted to the Darfur insurgency when it first blew up in April 2003. In particular, all sides were anxious that nothing should jeopardise the measure of trust that was building up over the north-south negotiations and the intelligence sharing on al-Qaeda" (2010: 178). In his words, the CPA had become the "holy grail" for the Europeans, the British and the Americans and thus could not be jeopardised by developments in Darfur (Ibid: 176, 195, 198).
} 
violence began to trickle back to audiences worldwide. Television broadcasts, highlighting the brutality of the violence between the government-sponsored forces (combining the armed forces and the Janjaweed militia) and the different rebel groups did not leave spectators indifferent - especially when they recounted gruesome details about execution-style killings of adults and children, widespread use of rape as an instrument of war, bombings and the reported use of chemical weapons on civilians, burning of entire villages, lootings of homes, destruction of livestock/crops, kidnappings (etc.) (Zuckerman 2004; ICG 2007a: 2; Williamson 2011). The reality became ever more pressing for outside onlookers as estimates of the body count poured in from different sources, claiming that anywhere between 6,000 to 10,000 people were losing their lives every month, either as part of the warring parties or collaterally from the conflict (Hagan \& Polloni 2006: 1579; van Dijk 2009: 147) ${ }^{63}$ In addition, by the end of 2003, 600,000 citizens of Darfur had become IDPs - a figure which would come to affect a third of the region's population only a year later (Barltrop 2011: 32).

International media outlets had taken about as much time to react to the brooding conflict as the international community. However, when they began investigating developments on the ground and broadcasting Darfur into living rooms across Europe and the US, Western governments were compelled to react. Former UN Secretary General, Kofi Annan, confirmed this necessity during his appeal for international intervention in April $2004 .{ }^{64}$ The reasons for this sudden course reversal on Darfur stemmed not only from the brutality of the acts of war committed by either side of the conflict, but it was made newsworthy by the interpretation in some quarters that the conflict was the result of a genocide being committed by 'Arabs' against 'Africans.' Even if this perception would later be rebuked following an investigation led by UN experts, this perception sparked a frenzy in the Western media, which chromatically could not possibly come at a better time for these outlets with the commemorations for the $10^{\text {th }}$ year anniversary of the Rwandan genocide getting under way at around the same time. ${ }^{65}$ As one journalist stationed in Darfur at the time testified in his book, this simplistic narrative of 'Arabs' attacking 'Africans' sold itself against the backdrop of the Rwandan genocide commemoration and the WoT without much effort: “[...] Darfur was easy. It was a holocaust. The good guys were African. The bad guys were

\footnotetext{
${ }^{63}$ Figures deducted on the basis of this author's calculation from data provided by the UN in 2008 (cited in the article by Meine Pieter van Dijk) and by research conducted on this topic by John Hagan and Alberto Palloni.

${ }^{64}$ Annan had made an earlier appeal, in December 2003 that, according to his memoirs, went undetected by the Security Council due to a lack of interest and to the absence of UN member states with sufficient "resolve" to issue serious and credible threats of an intervention in Darfur (2013: 119).

${ }^{65}$ Stoking the fires, the UN's resident representative for Sudan at the time, Mukesh Kapila, drew a comparison between the scale of the violence in Darfur and that of the "ethnic cleansing campaign" witnessed during the 1994 Rwanda genocide (cited in ICG 2005b: 3).
} 
Arab. And the bad guys really were bad - the Sudanese government had even given shelter to Osama bin Laden in the 1990s" (Crilly 2010: xiv). As brutally simplistic as it sounded, this narrative contributed to pulling the international community out of its inertia on Darfur.

\subsubsection{The EU's Response to the Crisis}

Staying true to the humanist values shaping its approach to African crises, the EU's initial response made halting the violence against, and saving the lives of, "beleaguered civilians" its primary objective in terms of resolving the conflict (Collins 2008: 291; Baltrop 2011: 97; Interview 40). A statement released to the press in February 2004, by the then Presidency of the EU, emphasised the primacy of the humanitarian aspects of the crisis for the Union:

the EU wishes to express its serious concern at the situation in the Darfur region of Western Sudan. The scale of the humanitarian crisis continues to escalate, with IDPs [...] requiring urgent humanitarian assistance. The EU calls on the Sudanese government to grant UN agencies and other relief organisations continued and full access to all areas of Darfur, as the plight of the local populations require urgent attention (EU Council 2004a: 1).

In practical terms, this meant effectively distributing vast quantities of emergency humanitarian aid to alleviate as best as possible the ordeal of IDPs and other suffering civilians in the region, whilst working hard to finalise institutional arrangements so that aid agencies could reach out to the largest possible number of victims (Barltrop 2011: 97; Interview 3). ${ }^{66}$

Nonetheless, with Annan's appeal confirming the necessity of an international intervention so as to provide the most efficient form of assistance to those in need, rumours circulated about the possibility of the EU launching a CSDP operation. Such rumours were only short-lived, as constricted activism reminded those sitting at the Council of the EU that African ownership ruled out any chance of the EU exercising leadership through a fullyfledged CSDP mission (EU Council 2012b: 3). Indeed, the AU was the first on the scene in this respect in the shape of its observer mission the African Union Mission in Sudan I (AMIS I), rendering obsolete the proposal for an autonomous CSDP mission. Anyhow, the proposal was further shot down by the negative vibes coming from Khartoum and the AU's headquarters in Addis Ababa, as well as from the overstretched EU military staff, already

\footnotetext{
${ }^{66}$ Some estimates claim that the EU disbursed between $€ 776$ million in aid between 2003 and 2010 (van der Meulen \& van der Putten 2009: 16). Natsios believes Western governments spent about US\$ 1 billion to sustain IDPs in Darfur, at the peak of the conflict (2012: 3).
} 
busy with Operation Althea in Bosnia-Herzegovina (Howorth 2007: 224; Interview 1). ${ }^{67}$ In accordance with its hierarchy of preferences in the African security realm, the EU thus purposefully stepped aside and let the AU assume leadership in bringing an end to the conflict, especially from a military perspective (Williams \& Bellamy 2005: 34) ${ }^{68}$ For one insider, the EU strove to abide by the principle of African ownership throughout the entirety of the crisis, making sure that the: "[...] AU could play the role that it wanted to play and to support different kinds of efforts that they made" (Interview 3) - even if EU decision-makers would then have to largely rely upon it to implement the bulk of its humanitarian targets.

In this respect, the EU held true to its word. European military and civilian staff were dispatched to AMIS I, while work got under way among the institutions and member states to determine how the EU could do more without undermining constricted activism. When the AU announced that its operation in Sudan would be upgraded by the end of 2004 to one which promised to do less observing and more peacekeeping, the UK and the EU Council Secretariat suggested a complementary police mission to support the upcoming AMIS II operation (Howorth 2007: 224). The idea soon gained traction, as the AU had specifically invited the EU to consider ways of supporting its fledgling operation (EU Council 2005a: 2). A fact-finding team was expedited out to Darfur to figure out how a staff of around 50 could mentor and train local police and under what conditions they could do so (whether as a direct part of AMIS II or under a Sudanese-led chain of command) (EU Council 2004d: 4). Eventually, the EU settled on its support mission to AMIS II, that saw the light of day in May 2005 and offered a wide range of assistance on both civilian and military fronts, while the EU reached deep into its pockets to cover a large part of the operational costs incurred by AMIS II throughout the three years of its existence. ${ }^{69}$ Constricted activism did not just work on a military level but also on a political one too, as European negotiators took on backseat roles

\footnotetext{
${ }^{67}$ The only time throughout the duration of the crisis where the EU was able to launch an autonomous military operation of relevance to the Darfur crisis, came in the shape of Operation EUFOR Tchad/RCA in 2007. Taking place beyond Darfur's boundaries, in neighbouring Chad and the north-eastern part of the CAR, the mission was mandated to: "[...] protect civilians in danger, particularly refugees and displaced persons, and to facilitate the delivery of humanitarian aid and the free movement of humanitarian personnel by helping to improve security in the area of operation" (European Parliament 2008; Gya 2010: 13).

${ }^{68}$ Cockett recounts that the UK FCO minister with responsibility for Africa, Lord Triesman, had asked for military assets to enforce a no-fly zone over Darfur but he was soon informed by the Ministry of Defence that: "[...] Britain was already fully committed in Afghanistan and Iraq" (2010: 228). Thereafter, it was hoped that NATO or France, through its military presence in Chad, could have taken the lead in this regard but as Triesman is quoted as saying in Cockett's publication: "in the end nobody would actually bite the bullet" (Ibid.).

${ }^{69}$ By providing equipment, assets, technical and planning assistance, additional military observers (on top of those dispatched to AMIS I), training of African troops and observers, strategic and tactical air transport, support to the AMIS II police chain of command, support for training of AMIS II CIVPOL personnel and support to the development of a police unit within the AU Secretariat (EU Council 2005b: 2-3). Using the funds available in the APF, Brussels transferred a little over $€ 300$ million from the APF to AMIS I \& II to help pay the salaries and allowances of soldiers, as well as insurance, food rations and medical costs (EU Council 2008b: 1-2).
} 
with regard to the various mediation activities for Darfur - preferring instead to adopt a "quiet diplomacy" strategy (Gya 2010: 11, 15). In other words, it contented itself mostly with writing cheques to the AU to support the latter's leadership of the Darfur Peace Agreement (DPA) through talks held with the warring parties in Abuja that had begun in October 2004 (Interview 34; Interview 36; Interview 38; Interview 39). ${ }^{70}$

With the need to respect constricted activism superseding the EU's ability to impact developments on the ground more forcefully and directly, alternative avenues were pursued in parallel to: a) ensure a better protection of, and access to, the victims of the conflict; b) deter the warring parties from engaging in fighting and carrying out more atrocities on civilians, especially the GoS, which many Western officials considered by then as the main culprit. Therefore, the EU began supporting a number of measures pushed through the UNSC as part of a combined Western effort. In July 2004, the EU supported UNSC Resolution (UNSCR) 1556, which demanded the immediate and unconditional disarmament and neutralisation of the militia by the Sudanese government (EU Council 2004a: 3). This threat though, made almost no impression whatsoever on Khartoum as it repeatedly promised to live up to the stipulations laid out in the Resolution but either failed to fulfil them or staged the entire ordeal, by making "fake" arrests of Janjaweed militia and then reintegrating some of these fighters into the ranks of the Sudanese armed forces (ICG 2006: 17).

Frustrated by the apparent mockery made by the Sudanese authorities' attempts, a number of EU member states sought to collectively pressure the GoS into action by raising the threat of sanctions at the UNSC (EU Council 2004b: 3; EU Council 2004c: 2). If insufficient progress on disarmament continued, they suggested both economic sanctions on individuals (particularly those having committed atrocities or officials proven to have collaborated in these acts) and an investigation into reports of mass violations of human rights and international humanitarian law. This led, in September 2004, to UNSCR 1564 (international commission of inquiry) and, in March 2005, to UNSCR 1591 (individual asset freezes) and to UNSCR 1593 (referring the situation in Darfur to the ICC). As far as UNSCR 1593 was concerned, the thinking on the European side behind this particular Resolution sought to crank the pressure up on the GoS by letting an international criminal investigation take place into the roles played by individuals within or close to the state apparatus, if the former did not immediately hand over what the EU saw as the main perpetrators of the

\footnotetext{
${ }^{70}$ As a case in point, the EU reportedly shelled out close to $€ 12$ million to support these talks (ICG 2005b: 9; Keane \& Wee 2010: 123).
} 
violence. Being a firm advocate of the ICC, Brussels was unsurprisingly the "prime mover" behind this Resolution (EU Council 2004c: 3; Keane \& Wee 2010: 123; Interview 32).

By relying upon alternative venues such as the UN and the ICC, this highlighted two facets of the EU's approach. On the one hand, Brussels and member state capitals sought to use the Darfur crisis as another launch pad for the normalisation of their reputations in the realm of African security risk management. They did so by constructing their approach to Darfur, by that stage of the crisis, around a form of legitimate due process (to which the UNSC contributed the legitimacy and the ICC the due process). On the other hand, legitimate due process masked the reality that the WoT and constricted activism had tied the hands of many European actors on Darfur. Brussels may have used strong rhetoric when condemning the violence, to the extent of extolling the GoS and Janjaweed for having committed acts "tantamount to genocide," but on the ground this rhetoric seemed to count for little as Western efforts continued to be short-changed by the warring parties' own persistence in seeking a military solution to the conflict (European Parliament 2004). ${ }^{71}$

The principle explanation for this apparent impotence derived from the EU's virtually non-existent leverage over the al-Bashir regime. When the National Islamic Front (NIF)'s coup brought Omar al-Bashir and his associates to power in 1989, the reception in Europe and across the West was frosty. With the NIF looking to push a radical Islamist agenda as much domestically as internationally, Sudan lost a number of its allies in the West who receded in their economic and political support, adopting instead various types of sanctions in response to the regime's courting of Islamist terrorist organisations (Natsios 2012: 7). ${ }^{72}$ The end of geostrategic rivalry from the Cold War period signified that the West was no longer happy to look the other way when Sudan dealt with the international community's new foes: radical groups promoting jihad. As radical Islam filled the void left by the Soviet Union as the West's ideological nemesis, the al-Bashir regime's activism implied that it then had to be looked upon as a 'rogue element' or 'pariah' state in the post-Cold War era. The EU thus suspended

\footnotetext{
${ }^{71}$ The European Parliament's statement came in the wake of Colin Powell's earlier declaration that the GoSsponsored raids in Darfur were genocidal in character. Jack Straw made the sort of comment reflective of the fact that for all the threatening discourse made towards Khartoum, most of it rang hollow, since it did little to affect proceedings on the ground: "The international community will not leave unpunished those who are guilty of gross violations of human rights or who block the peace process. We know who they are. The UK will not at all feel uncomfortable in denouncing the guilty parties and neither does it exclude having the UN declare itself in favour of heavier sanctions, if the parties continue to drag their feet. The ICC, with the full support of the Security Council, plans to undertake investigations against those responsible for war crimes and violations of human rights in Darfur. It will not hesitate to look where responsibilities lie. The patience of the international community has its limits" (Le Figaro 2006).

${ }^{72}$ The EU and the member states held a collection of sanctions against the GoS, ranging from individual member state visa bans on targeted government officials, to a prohibition against economic transactions (HRW 1998: 8; IKV 2008: 11-2).
} 
formal bilateral cooperation in 1990 (with the exception of humanitarian assistance) and imposed an arms embargo on the country in 1994 (IKV 2008: 10). ${ }^{73}$

By the end of the 1990s, the EU's diplomatic collaboration with Sudan had reached a standstill. A slight change of approach did take place at the dawn of the $21^{\text {st }}$ century. Following the example set by Washington, European actors sought to build bridges with Khartoum through their policy of constructive engagement so as to reward the Sudanese government for the efforts it had been willing to make on the CPA (Gya 2010: 10; Baltrop 2011: 116). Not only did it hand out $€ 15$ million worth of humanitarian aid in 2001 but the EU further rewarded the GoS for holding its part of the bargain on the CPA, by releasing $€$ 450 million of development aid frozen since the 1990s (ICG 2005a: 5; Barltrop 2011: 121). Additionally, in spite of the aforementioned economic embargoes, European businesses (such as the ABB Group, Alstom and Lahmeyer) had been encouraged to maintain a small presence in Sudan, mostly to benefit from the oil boom and from the ensuing infrastructural demands (Payne 2007: 1008; Srinivasan 2008: 64). Trade volumes though, rarely reached dizzying heights and only briefly flirted with the $€ 1$ billion threshold as European companies played only a minor role in the country's oil industry (Prendergast \& Thomas-Jensen 2007). All of this indicated that the EU and European actors in general could not aspire to be heavyweights on Darfur, since they had few valuable levers at their disposal to hit Khartoum where it would hurt the most - the economy and the petroleum sector - contrary to those actors whose national companies were major stakeholders (Barltrop 2011: 125). This explains why country sanctions and the threat of individual sanctions did little to change the behaviour of the Sudanese government as it had already become accustomed to Western sanctions and, from experience, knew how to circumvent them. Brussels could only rely upon emergency aid, debt relief or the normalisation of relations to persuade Khartoum to pay heed to its coercive demands and abide by its humanitarian objectives (van der Meulen \& van der Putten 2009: 20; Gya 2010: 10). These clearly were not having the desired effect.

By May 2006, the EU supported the latest Western initiative to change the situation in Darfur - a situation which although it had subsided in intensity showed no signs of abating. This time, the West thought best to upgrade AMIS II into a hybrid UN-AU mission - a de facto UNPKO - to give a serious boost to its objectives and have a more direct say over the conduct of peacekeeping in Darfur, rather than rely exclusively upon the AU. This initiative

\footnotetext{
73 The arms embargo was subsequently renewed in 2004 and 2005, when it incorporated the updates made to the UN's own arms embargo on Sudan (and Darfur), via the intermediary of UNSCR 1556, which prevented the sale of weapons to all non-governmental entities and individuals (including the Janjaweed), as well restricting any form of technical training.
} 
came to prominence via UNSCR 1679. For the EU, this meant backtracking on the weight it had thrown behind promoting African ownership. However, by then, it had become apparent that AMIS II was undermined by flaws in the design of the operation, on top of lacking the basic means needed to carry out orders effectively (Appiah-Mensah 2005: 12; Williams \& Bellamy 2005: 25; Cockett 2010: 213). ${ }^{74}$ The EU and other Western actors may have tried their best to support African ownership in this instance but in the eyes of more critical commentators, such support served as a convenient sideshow to divert attention away from their limited ability and interest to impact proceedings properly, leaving others to carry the flame instead (Prunier 2008: 124; Badescu \& Bergholm 2009: 289-90). Neither of these concerns appeared to bother officials in Brussels and across European capitals, who by this stage were more concerned by end product and less about philosophical debates. As the EU Council made clear: "the EU believes it to be essential for the transition from AMIS to a UN operation in Darfur to happen as quickly as possible" (EU Council 2006b).

The hardest part had yet to come. For this idea to gain traction the West needed the approval of the AU and the GoS. Given the diplomatic sensitivity behind this proposal, a hybrid mission was understood as the best option to assuage any fears emanating from the African continent and to make the abovementioned failings more palatable for the AU. Once more, this initiative did not appear to get the EU and the West very far. Although some AU member states wanted an improved contribution, which they knew AMIS II could not provide, the organisation as a whole initially put up resistance to the West's manoeuvring and was supported by other influential voices such as the League of Arab States (LAS) and other dissenting voices at the UNSC. Most prominently, the AU required that if the future UN-AU Mission in Darfur (UNAMID) operation was to go ahead, it first needed the approval of the GoS as a precondition. Khartoum's answer was public knowledge even before the Resolution had passed, since it favoured preserving AMIS II and wholeheartedly rejected international intervention. The West once again threatened the possibility of more sanctions if it did not cooperate but to no avail. Finding a way of overcoming this apparent stalemate would from this moment onwards become one of the West's holy grails on Darfur.

The fuss created by this latest initiative would not quite mask the reality that the EU did not hold the keys needed to resolving problems in the region and to improving the plight

\footnotetext{
${ }^{74}$ AMIS II was perennially short of cash, men, equipment and devoid of a clear mandate for carrying out its tasks (Prunier 2008: 162). It lacked sufficient intelligence, adequate planning, the ability to absorb financial and logistic donations and operational capacity, and struggled to clearly identify boundaries between the warring parties making preventative deployment improbable, leading it to lose much of its reputational credibility (Gya 2010: 18). Political disagreements within the AU relating to the operation's mandate and size only added to the list of shortfalls undermining it (Badescu \& Bergholm 2009: 289-90; Dagne 2010: 23)
} 
of the conflict's victims, causing its collective approach to unravel somewhat. Indeed, influential member states, particularly those sitting at the UNSC, more and more began bypassing collective initiatives, preferring to work either in smaller groupings or through individual efforts. ${ }^{75}$ For all the rhetoric, European actors could not trust themselves to play a coherent role in the resolution of the crisis and by dispersing only made it easier on the warring parties to carry on as usual. In sum, this meant that the EU, as well as most other Western actors, found itself having to search for indirect ways of influencing events on the ground. One such alternative involved working more closely with actors like the PRC, recognised as holding the leverage over the GoS which Brussels and European capitals collectively lacked. However, as will be shown over the course of this chapter, European officials (in conjunction with their Western allies) found themselves having to indirectly coerce these other third parties into assisting Western objectives, instead of working together on the basis of a cooperative approach. This was caused by a number of factors but principally stemmed from the insufficient levels of cognitive-based political trust between actors on both sides. Thus, getting other influential third parties to play along was understood as only being achievable by indirectly forcing them to do so, since the foundations (common sources of identification, cognitive empathy and communicative action) necessitated to foster trust - and thereafter bilateral cooperation - were absent throughout the conflict. But European actors mostly went along with the belief that only a credible "stick" would get the PRC to act in a more conciliatory fashion (EU Council 2006e: 3; Jian 2012: 10; Lee et al. 2012: 429; Macfarlane 2012: 178).

\subsubsection{China's Response to the Crisis}

The Chinese government's contribution to the resolution of Darfur remains to this day one of the most discussed sagas in the West when it comes to the wider debate of assessing the PRC's stature as a responsible global power. As will be outlined in the next section of this chapter, many question were raised about whether China's participation in attempts to resolve Darfur constitutes something of a watershed moment in its modern history - the cue that it had finally realised the need to give back more actively to the same system that had facilitated the advent of its domestic economic miracle. Although at times such debates are exaggerated, it is of little surprise that some analysts use Darfur as evidence that the leadership in Beijing

\footnotetext{
${ }^{75}$ Although this behaviour goes against the stipulations of the Treaty of the European Union, which demands that: "Member States that are members of the Security Council will, in the execution of their functions, defend the positions and the interests of the Union" (Chapter V, Article 19, Paragraph 2).
} 
had finally come to this realisation. After all, the Chinese government's evolution on Darfur took off from such a low starting point that any positive signs witnessed thereafter were always likely to be interpreted by some as evidence of the 'modernisation' of Chinese foreign policymaking. Indeed, from the start of the conflict until late 2006, official policy on Darfur coming out of Beijing denoted a certain apathy towards events on the ground, with statements emerging from the Ministry of Foreign Affairs absolving the PRC of any wrongdoing and implications in the crisis (Chinese Mission to the UN 2008; van Dijk 2009: 154; Interview 30; Interview 33). What ensued was a progressive revision of this initial policy stance, labelled by some as a "paradigmatic shift" (Srinivasan 2008: 81; Carmody \& Taylor 2010: 8; Macfarlane 2012: 178; Richardson 2012: 6). As this section will now explain, analysts rightly observed an evolution in China's stance, albeit not one reminiscent of a paradigmatic shift - whether in terms of the factors which spurred such change in the first place or in terms of its wider impact on the crisis as a whole. As aforementioned, it was mainly a reactive move to alleviate the pressure of indirect coercion engineered by the EU and the US targeting the Chinese leadership.

During this first phase of the conflict, for Beijing, Darfur represented nothing more than a distant local conflict for which it had little time. Certainly, in line with its traditionalist mindset, it did not put the destiny of the civilian victims of the conflict at the forefront of its interpretative worldview in the same way that many civil society groups, sections of public opinion or governments in Europe and the Western world had. To the contrary, officials in Beijing were naturally more inclined towards the fate of the local sovereign actor and, to a lesser extent, the voices of neighbouring states/regional organisations supportive of the sovereign actor in question. Therefore, the PRC seemed satisfied to take its cues on the crisis from the GoS and, additionally, the AU or LAS (Srinivasan 2008: 67; van der Meulen \& van der Putten 2009: 12; Ahmed 2010: 6; Jian 2012: 8). This tactic of aligning itself with the fairly harmonious understanding of events in Darfur as adopted by these actors - which purported the "internal" dimensions of the conflict (and its resolution) as well as the preservation of the political status quo in Sudan - naturally led it to taking a conflicting stance to that of the EU. For Sara van Hoeymissen:

providing support to the AU's efforts in Darfur came to be seen as a convenient way for China to respond to international calls to alleviate the Darfur crisis, to enhance its image in Africa and to prevent its economic interests from being adversely affected by international intervention or sanctions (2011: 105). 
However, since the PRC had demonstrated indifference towards Darfur in its early stages, the obtrusiveness it put on show at the UNSC to postpone or curtail Western initiatives between 2004 and 2006 did not seem uncharacteristic in the eyes of Western officials. Over the years, the EU and its allies have grown accustomed to seeing Chinese officials put up resistance towards its initiatives, particularly when the topic at hand strikes to the core of the PRC's traditional concern over the respect for the non-interference principle.

Few European eyebrows were then raised when Beijing worked hard to undercut the Western momentum towards enhancing country and individual sanctions on the GoS via the $\mathrm{UN}$, even if the PRC never once went to the extent of vetoing these propositions. ${ }^{76}$ Nonetheless, it invested time and energy to get any such propositions weakened before mostly abstaining on Resolutions it felt were most contentious. In fact, from its overall voting record at the UNSC on Darfur, between 2004 and 2007, China is believed to have succeeded in removing tough language on the GoS in 9 out of the 14 Resolutions whilst abstaining on the other five (HRF 2008: 18). It started, in October 2004, by rejecting proposals for a strengthened arms embargo (for which its abstention made no difference). As far as sanctions were concerned, it saw more moderate success on country sanctions as well as sanctions on individuals. In the first instance, the argument had often been made that being Sudan's largest foreign investor it would have been self-defeating for China to accept international economic sanctions (Tanca 2006: 122; Barltrop 2011: 128). Particularly with regard to the oil industry as statistics shown below highlight - Chinese companies had simply invested too much across the country, shipping over tens of thousands of personnel in the process, to allow the international community to curtail its activities in Sudan for the sake of developments in Darfur. Chinese officials usually saw such sanctions as ineffective and preferred to emphasise dialogical and diplomatic methods instead (Zhang 2008: 71; Bradbury 2012: 308; Macfarlane 2012: 173). ${ }^{77}$ They subsequently worked hard to ensure that no such sanctions would be strengthened at the level of the UN.

\footnotetext{
${ }^{76}$ Most probably out of fear of finding itself internationally isolated.

${ }^{77}$ The Chinese government also took the view that Darfur's resolution would only be possible if the region's economic development was prioritised (Xinhua News Agency 2007c). Few other exogenous actors to this conflict actually advocated this long-term approach, regardless of the logic behind, simply because doing so overlooked the more pressing concern about putting an end to the violence in the short-term. This message may perhaps have gained more credence had the PRC lived up to its rhetoric, by providing aid contributions to the region. In 2004, it pledged US\$ 640,000 worth of aid (much of which was designed to support humanitarian endeavours) - a figure which had reportedly increased to US\$ 11 million by the latter stages of the conflict (HSBA 2007: 9; Large 2008b: 8; Macfarlane 2012: 181). Chinese companies did also supposedly assist with the construction of wells, schools, roads and power stations in the region (Macfarlane 2012: 181). However, in absolute terms, its development assistance fell short of the total amounts disbursed by European actors.
} 
In terms of the sanctions on individuals, Chinese representatives naturally baulked at the prospect that sitting members of the GoS could face investigation in an international criminal tribunal over events in Darfur and thus abstained on Resolution 1672 in April 2006 that listed the persons up for investigation. ${ }^{78}$ Its traditionalist mindset necessitated that it could not let individuals close to an allied sovereign state fall victim to the manoeuvring of unwelcome outside interference, for fear of setting a precedent of damaging domestic repercussions. Subsequently, it again did its best to support Khartoum by pointing out that any such investigation (leading to individual sanctions) could only take place under the aegis of the Sudanese judicial system - a counterargument reiterated by the AU, LAS and the Organisation of the Islamic Conference (OIC) (Spencer 2008; Sudan Tribune 2008c; Saferworld 2012: 106). Chinese diplomats were eventually successful in impacting the final draft of UNSCR 1672, as they helped trim the original US-sponsored list of individuals nominated for sanctions from seventeen down to four (Holslag 2007a: 81). The Resolution may have passed regardless but the PRC had stood up for Khartoum without overextending itself from its usual obduracy at the UNSC in the face of Western initiatives.

At the prospect of UNAMID superseding AMIS II, the PRC opted to overlook the AU's own decision to come round to the idea - when the AU's Political and Security Committee voted in favour of re-hatting in late spring 2006 - citing Khartoum's consent as an irreplaceable precondition for its own support. ${ }^{79}$ The GoS had called into question the legal validity of this decision and stipulated that as long as no political agreement had been reached as part of the DPA talks, it could not agree to allowing an international peacekeeping force onto its territory (Ibid: 74). Chinese officials on the ground seconded this proposal and demanded the unconditional support of the AU before being able to change its opinion.

For as long as the EU believed that it was making headway as part of a united Western front to stop the fighting, the PRC's international obduracy only came under casual scrutiny. However, as of April 2006, when the EU realised that the last card up its sleeve on Darfur transforming AMIS II into UNAMID - could potentially be scuppered by the need to obtain Khartoum's consent, some European actors understood that the best possible means through which to get to the al-Bashir regime came from pressuring third parties with leverage to play

\footnotetext{
${ }^{78}$ The list comprised one member of the Sudanese army, one militia leader and two members of different rebel groups.

${ }_{79}$ Initially, the AU's PSC had recognised the need to shift to UNAMID during a meeting held in January 2006 and in February 2006, it had authorised the UN's Secretary General to start preparations for such a mission, before giving its final blessing during the following spring (Richardson 2012: 4). The AU eventually turned to UNAMID because an increasing number of its member states disapproved with Khartoum's actions and feared for the safety of their troops deployed to AMIS II, despite having categorically emphasised the African dimension of the resolution of the crisis at first (van Hoyemissen 2011: 106).
} 
their part. As far as they were concerned: “China's non-interference policy had [sic] by no means protected it from becoming a key actor inside internal affairs" (Saferworld 2011: 87). Now there were seeking to exploit the PRC's leverage to their ends, under the illusion that indirectly coercing their Chinese counterparts constituted one of the last viable channels through which to make a difference on the ground.

Indeed, from an economic vantage point, by the early 2000s it was no secret that Chinese companies held the lion's share of commercial activity in Sudan, with most of their interests revolving around the oil and infrastructure sectors. This rapid ascendance was greatly facilitated by the virtual absence of competition from American and European corporations, for which Khartoum atoned for by encouraging Asian commercial rivals to exploit the vacuum. For China, this was a particularly attractive proposal since it could enter a market which had proven reserves of untapped energy resources, in a host country willing to forego potential sources of government income in order to entice Chinese investments. ${ }^{80}$ On top of this, the Chinese National Petroleum Corporation (CNPC) was able to take advantage of the preparatory work largely undertaken in Sudan's oil fields by Chevron, prior to the latter pulling out of the Sudanese market place as a result of US trade sanctions (van Dijk 2009: 142). CNPC thus moved to acquire a number of business assets in the mid-1990s and thereafter largely finalised the construction of the entirety of Sudan's petroleum infrastructure (HRF 2008: 7). True to China's business blueprint in Africa, CNPC's work was facilitated by its ability to rely upon cheap Chinese labour. By the year 2000, 8,300 Chinese labourers were reportedly registered as working in the Sudanese oil sector, a figure which had risen to 24,000 by 2005 (and included about another 40,000 unregistered workers) (Wikileaks 2007).

It was not long before CNPC was moving close to 200,000 barrels of oil out of Sudan and back to China for both domestic and international consumption, allowing it to take home close to $96 \%$ of the country's oil output or 6.5 million tons of oil (Holslag 2007a: 71). For a brief reign, in 2002, Sudan even occupied pole position as China's largest supplier of oil which amounted to $40 \%$ of the latter's total African oil imports, as well as $9 \%$ of its overall energy imports (HSBA 2007: 2). By 2007, this outlook had changed somewhat given that China imported only $40 \%$ of Sudan's total oil production which came to represent less than $1 \%$ of its total energy imports (ICG 2008: 24). Nevertheless, it still remained the most prominent external actor in Sudan's oil industry. As Holslag clarifies:

\footnotetext{
${ }^{80}$ Khartoum agreed to the absence of restriction on profit reparation and to the exemption of all taxes on exported oil (Zhao 2010: 109).
} 
CNPC is by far the largest investor and [...] is the main shareholder of the Greater Nile Petroleum Company, Sudan's national oil company. It acquired several oil exploitation concessions. It has a near monopoly over a vast oil block in Darfur. CNPC plays a central role in the development of Sudan's oil infrastructure. In 1998, CNPC's construction branch [...] participated in the building of the 1,500 km pipeline from [...] oilfields in Western Khordofan to the main oil refinery in Khartoum. [...] The Chinese also hold a 50\% share in the Khartoum Chemical Industry Company and is the full owner of the Sudanese Petrochemical Trade Project (2007: 71-2). ${ }^{81}$

Chinese business interests naturally did not end there, as construction companies became deeply entrenched in meeting Sudan's burgeoning infrastructural demands, triggered by accruing oil revenues - a process also aided by the Chinese government peppering its counterparts in Khartoum with incentives to entice it to repay the favour by allocating attractive construction contracts to Chinese companies. In 2001, China reportedly cancelled $63 \%$ of Sudan's US\$ 67.3 million debt (and a further US\$ 70 million in 2007), providing instead a US\$ 13 million interest-free loan (Saferworld 2012: 111). ${ }^{82}$ The GoS duly obliged, allowing Chinese firms to build illustrious projects - either single-handedly or as part of consortia - such as the Presidential Palace, the Friendship Hall, Khartoum International Airport and the controversial Merowe and Kajbar Dams (HRF 2008: 8). As a consequence, by 2006, China had reinforced its position as Sudan's leading importer, exporter and external investor with estimates of as much as US\$ 4 billion tied in investments, thus consolidating its long-held economic leverage over the al-Bashir regime (van Dijk 2009: 144).

Beyond the relative scale of Chinese commercial activities in Sudan, the two countries also hold fairly strong historical affiliations that find their roots in their shared experiences of colonial occupation. ${ }^{83}$ Although China has not maintained a consistent presence in its dealings with Sudan since the latter gained independence in 1956, symbolically, it has shown its solidarity with Khartoum at crucial times. As early as 1955, Beijing allied itself with Khartoum against the Anya Nya rebel movement during the first phase of the civil war between the north and the south, and again in 1971 when it helped then President Gaafar

\footnotetext{
${ }^{81}$ Another report complements this analysis by claiming that CNPC owns a 35\% stake in the Red Sea Petroleum Operating Company (HSBA 2007: 2).

${ }^{82}$ The China Export-Import (EXIM) Bank also reportedly provided the GoS with up to US\$ 1 billion in loans between 1998 and 2008 (HRF 2008: 9).

${ }^{83}$ One particular bond that ties Sudan and China involves the story of British General Charles George Gordon, who also went under the alias of 'Gordon Pacha,' 'Gordon of Khartoum' and 'Chinese Gordon.' In brief, in Chinese modern history, the Sudanese are celebrated for the killing of General Gordon because of the role the latter played during the Opium Wars (Ali 2007). Today, in order to honour and respect the legacy of the man seen as having ended Gordon's life, Chinese diplomats annually visit the Mahdi's tomb in Omdurman (near Khartoum) to: "[...] emphasise their common cause with the Sudanese against Western - British - oppression, as they argue that General Gordon had both Chinese and Sudanese blood on his hands" (Natsios 2012: 22). In addition, according to Chris Alden: "the Chinese claim that this event, which 'finally punished' the imperialist, brings the two states closer together" (2009: 18).
} 
Nimeiry in repressing a coup by supplying equipment and military training (HSBA 2007: 1; Saferworld 2012: 104). During the second phase of the civil war, Beijing further replicated this support to the incumbents in Khartoum in the wake of the challenge posed by the Sudan People's Liberation Movement (SPLM) (Saferworld 2012: 104). China has also been there during the darker days of al-Bashir's reign. Following the coup which brought the leader and the NIF to power in 1989, Beijing opted to "cultivate" friendship with Khartoum despite the fact that the latter had "turned Islamic," which drove the international community to pull out of Sudan (Ali 2007; Saferworld 2012: 104). In some way, China became the al-Bashir government's "all-weather friend," making amends where it could for Sudan's isolation and the denigration it suffered from the international community as a rogue element, especially when it came to purchasing weapons and armament (Ali 2007; Collins 2008: 231). ${ }^{84}$

From this synopsis, it would appear that since Khartoum had often relied upon Chinese assistance to ensure its survival in the face of domestic as well as international threats, and partly continued to rely upon such assistance during the crisis, the PRC was in effect one of the few exogenous actors which had the legitimacy to reach out to the GoS. For the EU, the trick now consisted of indirectly forcing Beijing to align itself with the Western effort of getting Khartoum to respect the demands and expectations of the international community.

\subsection{China's Evolution on Darfur: A Milestone for Sino-European Cooperation?}

\subsubsection{Mapping China's "Paradigmatic” Shift}

As explained above, some commentators are of the view that the Chinese government's position on Darfur evolved in a "remarkable" fashion because of the visible change it underwent from apparent disinterest in the region, via obduracy in the face of Western initiatives, to a far more cooperative and proactive stance (Holslag 2007a: 76). Such change is understood as having played an important part in helping to solve the conflict. Furthermore, this evolution was considered significant for it appeared to hint towards the 'modernisation' of Chinese foreign policy, particularly in relation to the principle of non-interference as Chinese officials on the ground were often obliged to push the boundaries of this principle to

\footnotetext{
${ }^{84}$ From the numerous reports published regarding China's arms transfers to Sudan, many important deals were recorded during the first decade of al-Bashir's tenure. For example, in 1989, the Chinese government reportedly oversaw the sale of 40 tanks, 40 Armoured Personnel Carriers (APCs), field- and anti-aircraft artillery and SALWs. In 1991, Beijing's relations with the NIF were further improved by an Iranian-funded Chinese arms deal worth an estimated US\$ 300 million (Huntington 1996: 275; Large 2008a: 95). Throughout the 1990s, the GoS reportedly acquired Chinese-made T-54 and T-59 tanks, MiG-helicopters, howitzers, anti-personnel mines, bounding mines, anti-tank mines, anti-aircraft guns, more SALWs, mortar shells, rockets, heat-seeking missiles, SCUD missiles and other forms of lighter ammunition (HRW 1998: 5-6, 24-6, 37). It is estimated that Sudan purchased US\$ 210 million worth of arms from China in 1997 alone (SIPRI cited in Saferworld 2012: 98).
} 
get Khartoum to budge. This section will now outline the key moments which lend weight to arguments about the existence of this supposed "paradigmatic" shift.

Early signs of this shift were noticeable prior to April 2006, when the then Assistant Foreign Minister Lü Guozeng made two trips to Darfur, setting the tone for this change of approach, which was confirmed a month later when PRC representatives retracted from abstaining on UNSCR 1679 - on the transition to UNAMID - following high-level talks between Bush Junior and former Chinese President Hu Jintao (Natsios 2012: 159). ${ }^{85}$ Despite having managed to apparently calm the GoS about the overall concept behind UNAMID, China's behaviour did continue to cause consternation as it abstained on the definitive Resolution regarding the re-hatting of AMIS II (UNSCR 1706), citing the absence of Sudanese consent as the cause behind its own absence of support (Interview 34). ${ }^{86}$ What's more, in July 2006, it provided the GoS with a US\$ 3 million loan aimed at rehabilitating the latter's national infrastructure (Alden 2009: 62). Such doubts were though soon eviscerated. During the third FOCAC meeting, Hu began by calling for Sudan to show more flexibility on the idea of the hybrid peacekeeping force which was followed by the strong showing of the then Chinese Permanent Representative to the UN, Wu Guangya, during high-level international consultations on Darfur in Addis. Indeed, China's performance during the talks held in November 2006 is often regarded as the first concrete piece of evidence of this paradigmatic shift (Holslag 2007a: 77; Large 2008b: 11; Richardson 2008: 291; Alden 2009: 65). During these talks, it is widely reported that $\mathrm{Wu}$ worked tirelessly to get Khartoum to agree in principle to the 'Annan Plan' - designed as a three-tier roadmap to soften the GoS' resistance to UNAMID - by offering an incremental implementation of the operation and thus attributing a false sense of control to Khartoum over proceedings (Interview 4; Interview 29; Interview 31). ${ }^{87}$

Of course, this did not signify that the GoS had given UNAMID the go-ahead. Staying true to itself, the regime laced the upcoming negotiations on the technicalities of the Annan

\footnotetext{
${ }^{85}$ Lü had made an appearance at the January 2006 AU Summit to express China's support for replacing AMIS II but according to one author, he did not play an active role in the talks (Richardson 2012: 3).

${ }^{86}$ Indeed, in May 2006, Minister of Foreign Affairs Li Zhaoxing had emphasised strengthening AMIS II and had refused to make any comment about UNAMID replacing AMIS II (Richardson 2012: 3).

${ }^{87}$ The Annan Plan involved three distinct phases. The first phase, entitled the "light support package," involved the UN assisting with the funding (comprising a financial donation of US\$ 21 million), logistics, technical resources and equipment of the hybrid force on top of sending personnel, in the shape of police advisors (24) and civilian staff (43). Military advisors (105), police officers (33) and civilian staff (48) from the UN Mission in Sudan (UNMIS) were also transferred as part of this phase. Once this was accomplished, the second phase - the "heavy support package" - commenced. This involved getting 3,000 UN troops (including 1,000 military engineers and civilian personnel) and 6 attack helicopters deployed to support the 7,800 AMIS II troops. Lastly, the final step would result in the deployment of a hybrid force composed of 17,000 troops and 3,000 police officers (Richardson 2012: 5).
} 
Plan with obstacles. Inter alia, it requested that UN troops only be used should those from AU or LAS member states be unable to fill the void, that the command and control of the operation rest exclusively with the $\mathrm{AU}$ and not in New York and that all UN military/technical advisors be junior in rank to their AU counterparts (UN 2006: 2). Therefore, Chinese officials also spent the next few months working behind the scenes to exploit as much as possible the opening it had helped to carve out in Addis, in order to get Khartoum to fully endorse the Annan Plan. Turning up the pressure further on Khartoum, during a speech made in Sudan during his customary yearly winter tour of the African continent, $\mathrm{Hu}$ decided to rhetorically mark a break with the country's traditionalist reading of the conflict by calling for an improvement in the humanitarian situation in Darfur as well as for improvements in the delivery of humanitarian aid (ICG 2008: 27). ${ }^{88}$ In the meantime, Assistant Foreign Minister Zhai Jun had paid a visit to IDP camps in the region as a hint to the GoS that the PRC may have to revise its allegiance with Khartoum if the former continued to stall on the Annan Plan (Huang 2007: 838-9).

The endeavours of these Chinese officials appeared to have paid off as a month later, during the last day of its UNSC Presidency, China claimed to have clinched international consensus on the Annan Plan only for Khartoum to reject the 'heavy support package' by sending a letter to Secretary General Ban Ki-Moon withdrawing Sudanese support for it (ICG 2007b: 16; Richardson 2012: 5). Questioning its rationale, the leadership in Beijing (Wang Guangya in particular) showed its disapproval for the GoS' correspondence with Ban by summoning a member of al-Bashir's entourage to Beijing for an explanation, before sending its Assistant Foreign Minister and Special Envoy back to Sudan, in April and May 2007 respectively, to inform the GoS that China expected more flexibility on its behalf (ICG 2007b: 16; ICG 2008: 28; Richardson 2012: 5). What followed was the apparent culmination of Beijing's efforts - assisted by the input of the UNSC, LAS and AU - as Khartoum eventually backed down on the technicalities of the Annan Plan over the course of that summer while UNSCR 1679 came into full effect in July 2007 (Richardson 2012: 4). Commentators have often pointed to this particular achievement as yet another non-negligible indication of the Chinese leadership's willingness to revise its initial stance on Darfur and work in favour of Western objectives to bring peace to Darfur (Aning \& Lecoutre 2008: 44; Brosché 2008: 72;

\footnotetext{
${ }^{88} \mathrm{HRW}$ petitioned Hu himself in an open letter published in major international newspapers on the occasion of the former President's visit to Sudan in January 2007 (Alden 2009: 111).
} 
HRF 2008: 20; ICG 2008: 28; Srinivasan 2008: 78; Large 2009: 610; van der Meulen \& van der Putten 2009: 12; van Dijk 2009: 148; Carmody \& Taylor 2010: 503; Kuo 2012: 3). ${ }^{89}$

The last fact to which analysts often point towards as proof of this evolution concerns the appointment of Special Envoy Liu Guijin in May 2007. ${ }^{90}$ Although as seen from the excerpts above, Liu was neither the first nor the only personality appointed by the CCP to manage the Darfur portfolio, whether on the ground or at the UN. But the personal involvement of Liu mattered because in the eyes of one scholar, this appointment came across as the most telling piece of evidence of the paradigmatic shift since it:

demonstrated very clearly that the PRC had developed a 'mediating interface.' It became a point of contact 'that actively seeks to build consensus between all the parties involved, but instead of simply facilitating negotiations, China also made its own ideas very clear to the Sudanese government' (Holslag 2007a: 80).

Beyond this "mediating interface," Liu was seen as reflective of the paradigmatic shift for some of the rhetoric he used when discussing Darfur, as well as some of his actions, and because his nomination meant that China was ready to push forward with making the AU-UN joint operation a reality (Richardson 2012: 6). ${ }^{91}$ In effect, Liu pursued the rhetoric adopted by $\mathrm{Hu}$ during his February 2007 speech by railing against violence targeting innocent citizens and by referring to the "humanitarian disaster" in Darfur (Ahmed 2010: 10-1). Additionally, according to one author, Liu even agreed to meet the Sudanese opposition leader of the displaced people of Northern Sudan at the Houses of Parliament in London (Ibid: 12). This particular point would indeed figure as a break away from China's traditionalist stance due to the fact that not only did their conversation revolve around the civilian victims of the crisis and not the predominance of state actors, but the PRC was caught going behind the back of another sovereign government (and ally) - a practice it routinely denounces for example when Western politicians do likewise with the Dalai Lama.

\footnotetext{
${ }^{89}$ The PLA would also end up contributing in and around 300 troops (from an engineering corps) to UNAMID at the inception of the operation, which some Western officials saw as the culminating point in China's policy shift towards Darfur (UN 2012: 8).

${ }^{90}$ In actuality, China did not stop there. According to reports, it assisted the West to get the GoS to scale back on some of the Sudanese legislation regarding the efforts of humanitarian aid agencies, which had created countless administrative hurdles for these international NGOs seeking to help the victims of the conflict. Furthermore, Beijing apparently agreed to front Khartoum a loan to help pay compensation for the same victims - even if the implementation of this financial assistance has yet to be proven (for the entire paragraph, see: Huang 2007: 840; van Dijk 2009: 148).

${ }^{91}$ For another specialist of China's participation in the resolution of the Darfur crisis, Liu's appointment was "historic" for as the Special Envoy explained himself, this was the first time China had named an envoy regarding a country so far from the PRC (Richardson 2012: 6).
} 


\subsubsection{No Trust, No Effective Cooperation}

Evidently, a perceptible shift occurred over this specific period. Yet, to qualify this evolution as paradigmatic rests above all on a thorough understanding of the motives behind it. As this section will reiterate, although China may have cooperated to a certain extent with the objectives promulgated by the EU on Darfur, such cooperation could hardly be interpreted as paradigmatic. This is because this shift was coaxed out of Beijing by the EU and others, following an international campaign to indirectly coerce PRC to change its stance and was not the result of its own free will to cooperate - a decision it could have taken had sufficient levels of trust existed between leaders on both sides ${ }^{92}$ - but ultimately a side-effect of the latent mistrust that characterised bilateral interaction throughout their dealings on Darfur. However, as the rest of the chapter will make clear, with the foundations for cognitive-based trust absent, Chinese officials were unlikely to willingly cooperate with their European counterparts on the ground in Darfur, which resulted in the belief mentioned earlier on the European side that only sticks would get the PRC to become more proactive. In synthesis, there was nothing particularly paradigmatic about this entire situation.

As per usual, rational explanations are most commonly associated with the Chinese government's decision to switch from supposed passive follower to active mediator. Rational thinking posits that this switch came about from Beijing's fear that chaos in Darfur could spread to the rest of Sudan, resulting in negative repercussions for Chinese companies and their investments (see HRF 2008; IKV 2008: 44). Supposedly apprehensive that the deadlock in 2006 between the GoS, the rebels and the internationals could potentially extend beyond the region's border into areas of Sudan where Chinese companies ran projects and employed thousands of Chinese personnel, Beijing is believed to have preferred to act pre-emptively in the name of stability, rather than ultimately paying a heftier price caused by its disengagement. Undoubtedly, economic interests are omnipresent when it comes to most decisions made by the leadership in Beijing regarding China's contribution to the realm of security risk management on the African continent. However, these can only constitute one part of the explanation and relying strictly upon this explanation only leaves a number of other important questions unanswered. ${ }^{93}$ For example, if the Chinese government was so concerned about the

\footnotetext{
${ }^{92}$ Annan indicates that "in theory," there was scope for negotiation and the alteration of the Chinese position (Annan \& Mousavizadeh 2013: 125). What the author fails to explain though is that this scope was never exploited due to the aforementioned lack of trust.

${ }^{93}$ Other scholars are not entirely persuaded by the argument that China's response to the crisis was shaped exclusively by the desire to protect its national economic interests in Sudan (Large 2008b: 8; Carmody \& Taylor 2010: 505). After all, using statistics to back up their standpoint, they argue that the evolution of the PRC's oil interests in Sudan were actually in the midst of a sharp downturn from the inception of the crisis onwards, both
} 
possibility of chaos spreading beyond Darfur, then why did it wait almost three years before becoming implicated in finding a resolution to the conflict? Since the violence and fighting was graver and more intense between 2003 and 2004, Beijing surely would have been far more proactive at that time when the risks were obviously higher, rather than coming to life at a later stage in the conflict when the intensity of the fighting had somewhat cooled off.

A more probable factor to have brought about a change in China's assessment of the crisis relates to the fear of its inertia damaging its international reputation as a responsible stakeholder, at a time when the leadership in Beijing was trying actively to promote a positive image of the country in the run-up to the 2008 Beijing Olympics. Or to be more precise, it was the fear that Western civil society groups - quietly supported by the EU and the US could exploit this inertia to the detriment of China's global image which drove it to upgrade its contribution in bringing peace to Darfur. This meant that the PRC's sudden cooperative endeavours were triggered as a way of dealing with the coercion that EU and other Western officials were exercising on it, to apply the sort of leverage on Khartoum which they could not.

Even if this did not form part of an overt EU strategy, European officials were nonetheless more than happy to rely on international civil society-led movements castigating the Chinese government for not having done enough on Darfur (Interview 20; Interview 32). Taking the Save Darfur Coalition as a case in point, this US-based consortium of NGOs and other civil society groups had been working since the inception of the crisis to promote awareness of the plight and suffering endured by ordinary inhabitants of the region, mainly to avoid a repetition of Western inertia observed during the Rwandan genocide (Flint \& De Waal 2008: 180). The campaign gained particular notoriety when actress Mia Farrow lent support by serving as the coalition's patron, allowing her to raise awareness of this cause with fellow Hollywood film stars. ${ }^{94}$ Almost instantaneously, this all-star cast increased the media spotlight on the campaign, providing it with a stronger base with which to lobby the political institutions in Washington, such as Congress and the White House. At around the same time the campaign began to make waves with the American political establishment, China began its countdown to the summer Olympics. Riding high, the Save Darfur coalition tweaked its campaign strategy in and around April 2007 by focusing less directly on the effects of the conflict as such but shifting the discussion onto China's role in the situation in Darfur (Cooper 2007). Under the banner of the 'Genocide Olympics,' the campaign sought to highlight what

in absolute terms and with regard to the pattern of China's worldwide energy imports (Taylor 2010: 188; Lee et al. 2012: 432).

${ }_{94}^{94}$ Farrow managed to rally movie stars such as George Clooney, Don Cheadle, Matt Damon and Brad Pitt (see CNN 2009). 
they viewed as China's complicity in the atrocities. Namely, they accused the PRC of having caused the violence in Darfur, having turned a blind eye to the genocidal counter-insurgency war in the region and of not wanting to help the West broker a deal for peace (Reeves 2007; Greenberg 2008). One of the most prominent voices behind this campaign, Eric Reeves, used threatening language to coax cooperation out of Beijing:

the Chinese leadership must be forced to make a choice: work now to halt genocide in Darfur, or see the Olympic Games used, at every turn, as a means of highlighting the Chinese role in sustaining the ultimate human crime (2008).

If the thoughts of Ian Taylor are to be believed on this matter, the authorities in Beijing paid little mind to the smear campaign promoted by the Save Darfur coalition. However, when US legislators and the American state apparatus began to get involved on the back of the coalition's advocacy, this spurred the Chinese leadership into getting their officials to become far more proactive on the ground in Darfur (Taylor 2010: 183). In effect, in April 2007, 97 members of Congress signed a letter urging greater Chinese activism which then US Vice President Jo Biden delivered to Hu (Carmody \& Taylor 2010: 502). ${ }^{95}$ Two months later, Congress voted to pressure China on Darfur by passing a non-binding resolution on the matter (Xinhua News Agency 2007a). On the other side of the Atlantic, European dignitaries showed they too had heard the message of the civil society uproar surrounding the Genocide Olympics with some contemplating the boycott of the Games' opening ceremony, as was the case for Sarkozy in France (Reuters 2008). Although none actually followed through on this threat, they only added to the pressure exerted by the Save Darfur coalition on the Chinese government to do more on the conflict - which, by then, had reached something of a fever pitch in light of Steven Spielberg's decision to stand down as artistic consultant for the opening ceremony. ${ }^{96}$

This is why the explanation relating to the exploitation of indirect coercion of China's international image in the context of the Darfur crisis makes more sense when attempting to discern the rationale behind the latter's shift from the end of 2006 onwards. Indeed, there are no coincidences when looking at the chain of events which unfolded between 2006 and mid2008: from European officials running out of options in their bid to making an impact on the ground in Darfur and turning, as a last resort, to the idea of UNAMID in 2006; via Western

\footnotetext{
95100 British Members of Parliament would follow suit with a similar letter signed and delivered in October 2007 (Ahmed 2010: 18). These letters were credited as having directly triggered the appointment of Liu Guijin.

${ }^{96}$ Spielberg resigned from his position in February 2008, after the very public denunciation of his collaboration by Farrow, who made the analogy between Spielberg's collaboration with Beijing to the work of Leni Riefenstahl - the German filmmaker who produced Nazi propaganda (Cooper 2008).
} 
civil society groups witnessing the beginnings of a surge in momentum from 2007 onwards, when they turned their attention more towards China through the 'Genocide Olympics' campaign; to getting an influential albeit previously uninterested third party, in the shape of the PRC, to convince Khartoum to agree to an international intervention in Darfur on the back of Western political institutions taking a more vocal stance against China. Despite the presentation of this domino effect tending to overlook other important nuances which contributed to this chain of events, the fact remains that each of these steps are interconnected. The PRC's decision to move up several gears over the space of a year, from disinterest to concerted activism, was caused above all by the fear that the EU and others in the West could indirectly harm its international reputation at a time when it was meant to be celebrating its Olympian "coming-out party" (Miles 2006; Cockett 2010: 230). During an interview with a European diplomat working in China at the time when the NGO campaigns on Darfur peaked, the latter admitted to not hesitating to put the following rhetorical question to his Chinese interlocutors during bilateral meetings: "which would you prefer: to try to find a way to stabilise the region - to the benefit of your investments - or would you rather let the situation degenerate, at which point most fingers will be pointed at you?" (Interview 20). ${ }^{97}$

Indeed, the international civil society movement condemning China's role on Darfur was intelligently orchestrated in the sense that its timing and methods could not have been any more on point. Chinese public diplomacy found itself under the cosh in what was supposed to be its long-awaiting moment of glory, which thrust it into action in a way which would thereafter be met with approval from Brussels, London, Paris and Washington. This matters, especially in terms of the bigger picture regarding the Darfur crisis because as they were forced decisions made by Beijing in the belief that this would appease public and official criticism coming from Europe and North America, it implied that the PRC was never going to make a thorough attempt at bringing an end to the crisis. It did what it had to do to protect its interests but a lack of cognitive-based trust from its leaders in their Western counterparts meant that they were never likely to collaborate in a meaningful fashion, in terms of the broader issue of putting an end to the region's endemic violence. Instead, the Chinese government papered over the cracks in terms of its performance on Darfur, making up where possible from its slow start in order to simultaneously give the impression that it was working firmly in the international community's best interests, mainly to silence civil society critics so as to not lose sight of the international marketing campaign behind the Olympics. For many

\footnotetext{
${ }^{97}$ Author's translation.
} 
within European officialdom, the PRC's superficial shift may have been greeted with approval but this implied that China would be adopting superficial remedies to Darfur's ills, rather than more sustainable solutions which it may have been able to help develop if it had fostered thorough cooperative interaction with EU officials on the ground (amongst others). For this to happen though, trust would have been needed by actors on both sides of the spectrum to bridge their political differences and cooperatively work towards finding a more suitable outcome. Of course, this is not to say that the EU, the West and China could have resolved Darfur overnight had they hypothetically engaged in cooperative endeavours but since the PRC possessed the leverage over Khartoum which the EU lacked to turn its rhetoric into reality, a rapprochement may have generated sufficient pressure to move all the warring parties in the same direction (ICG 2007b: 17; van der Putten \& van der Meulen 2009: 21; Interview 30). However, China was never likely to take on the exogenous leadership role the West imagined it could to help find a way out of the crisis given the mistrust between the two sides (HSBA 2007: 9; ICG 2008: 30-1; Richardson 2008: 292; Srinivasan 2008: 73; Zhang 2008: 71). Its evolution did not go far enough in terms of the overall outlook of the conflict, with some critics extolling it for not having made life more uncomfortable for Khartoum whether publicly or privately (Cooper 2007; HRF 2008: 20; Cockett 2010: 230: Large 2008b: 11). ${ }^{98}$ As one interviewee rather understatedly put it: "we would have liked for them to intervene more, but that's not where we were with China" (Interview 32). A shift in China's stance may then certainly have occurred but calling it paradigmatic would constitute an exaggeration. Writing over forty years ago, Deutsch's thinking summarises well where the EU's strategy of indirectly coercing China came up short. He wrote: "cooperation that is elicited by coercion is less likely to be minimally productive and less economical as well as less reliable than cooperation that is self-chosen" (1973: 119).

\subsubsection{Absent Trust: A Lack of Common Bilateral Identification}

Getting China to cooperate out of its own free will was no longer a distinct possibility for those European officials in the institutions and member state capitals working on Darfur, especially during the latter stages of the crisis where cognitive-based trust was beyond the reach of both sides for the following two reasons: a) they lacked a common source of positive identification, leading to European actors negatively identifying with their Chinese

\footnotetext{
${ }^{98}$ As Cockett explains: “[...] the Chinese shift of position was only limited. Although the Sudanese were pushed by the Chinese into abandoning their outright objective to allowing UN blue helmets into Darfur, Chinese support remained sufficient for the Sudanese to win unprecedented control over the make-up of the force and its command-and-control structure" (2010: 230-1).
} 
counterparts (even if they mostly did so by association); b) mistrust was pervasive of the social environment constitutive of the Darfur conflict, making it difficult for officials to express empathy or to engage in ideal-type communicative action with those on the other side of the political divide - a situation which may have been in line with the interests of local African officials.

As the discussion on the conceptual framework made clear in chapter 4 , the process of negative identification can work as much as a direct process, whereby an ingroup distinguishes itself from an outgroup - whether human or other - as it can indirectly. In this respect, the ingroup differentiates itself from a target outgroup as well as any others which it believes forms part of this outgroup's wider network. In the context of the Darfur crisis, it would be disingenuous to put forward the idea that European officials imperatively sought to mark a difference between themselves and Chinese representatives. Nonetheless, for many of them, the PRC's reputation had been tarnished by its willingness to stand up to the West and stand up for the GoS by acting as its "protector" (Cockett 2010: 224). This assumption is inferred from the view of some interviewees working for the EU and EU member states at the time on Darfur, who held critical views of China's behaviour notwithstanding the belated shift in policy stance. In the opinion of one EU official, the PRC's performance had been "extremely negative" in terms of the former's objectives regarding the crisis and this largely stemmed from the view held by some in Brussels that Khartoum and Beijing shared similar agendas on Darfur (Interview 1; Interview 21; Interview 33). ${ }^{99}$ There was clearly very little room for empathy in this regard especially as the West's demonisation of al-Bashir naturally ruled out any chances of European officials being able to empathise with the predicament of

\footnotetext{
${ }^{99}$ In this particular instance, reference is being made to the heightened military assistance which Beijing is believed to have sanctioned across the first few years of the conflict in Darfur, when it seemingly upgraded its cooperation with the GoS, providing enhanced military-to-military training around 2002 followed by a "wave" of high-level meetings taking place between the PLA and their Sudanese counterparts in December 2003, late 2005 and April 2007 (HSBA 2007: 6; Large 2008b: 9). This image was not aided by the fact that at the time of the onset of the crisis, other reports surfaced stating that China had officially become Sudan's largest exporter of arms, with mounting evidence of Chinese-made weapons being found scattered across Darfur and Eastern Chad (Aning \& Lecoutre 2008: 45). Some reports estimate one arms deal to have taken place between China and the GoS, just as the violence was erupting in Darfur, at US\$ 3 million (HRF 2008: 12). Sudanese orders for Chinesemade weapons only increased as the crisis dragged on, with UN data finding evidence of an increase from US\$1 million worth of weapons exchanges in 2002, to US\$ 23 million in 2005 (cited in Macfarlane 2012: 170). Beijing even agreed for Chinese arms manufacturers to help oversee the construction of three small arms assembly plants in Sudan during the same time period in Kalakla, Chojeri and Bageer, where heavy and light machine guns were produced along with rocket launchers, mortars, antitank weapons and ammunition (HRF 2008: 15). At the Giad industrial complex near Khartoum, Chinese engineers have supposedly been spotted supervising the construction of tanks, military vehicles and small arms (Ibid). PRC representatives to the UN did their country's reputation few favours when they regularly criticised reports produced by the Panel of Experts on the state of the UN's arms embargo on Khartoum (Al Jazeera 2010; BBC News 2010c). These reports often made allusion to the possible circulation of Chinese-made weapons in Sudan and more pertinently in Darfur, which Beijing always attempted to discredit as unprofessional reporting (BBC News 2010b; The Guardian 2010).
} 
those individuals holding key positions within the Sudanese government. As a result, China in essence gained a co-conspirator label which was difficult to shed both for Chinese officials and in the minds of European actors dealing with Darfur (Interview 1; Interview 8; Interview 19). Daniel Large accurately summarises the mindset that most would have adopted, in general terms, when it came to assessing China's role in the conflict:

the close association between China and the NCP in Khartoum means that the Chinese government's efforts to demonstrate an active commitment to the Darfur peacekeeping mission or to show progress in other areas, such as its oil operations, are compromised. [...] China's close association with the NCP renders it vulnerable to the uncertain course of Sudanese politics (2008b: 15).

A more likely process, however, would have seen European officials negatively associate with their Chinese counterparts in this social context by reverting to stereotype and classifying the Chinese as part of an amorphous opposing camp, since it stood tall with others behind Khartoum in a bid to defy the West. This led China to be seen as the "villain of the drama" (Macfarlane 2012: 176). In a sense, both sides did actually share a paradoxical common source of identification when it came to Darfur - in the shape of the GoS - which respectively produced contrasting outcomes with the European actors marking their distance as part of Khartoum's outgroup whilst Chinese leaders situated themselves within the regime's wider ingroup network. In light of what has already been said of the GoS up until now in this thesis, one cannot help but imagine that this situation was partly engineered by Khartoum in order to satisfy its own interests.

European officials could not positively identify with Khartoum - beyond labelling the GoS as the principle culprit for Darfur - due to the al-Bashir regime's chequered past (when pictured from a Western perspective), to suspicions about the GoS' ideological intentions and because of its attitude towards some of its neighbours, some of whom are strategic allies of the EU and its member states. As outlined earlier in this chapter, the EU's ties with the regime were at its lowest ebb at the end of the 1990s. For the most part, this was because al-Bashir's regime had put in place during the 1990s an open door policy attracting terrorist organisations that preached radical Islam, had declared a jihad against the West and would eventually cause the securitisation of the EU's policies towards Africa following fatal attacks on Western targets and European soil alike. ${ }^{100}$ Despite efforts having been made on both sides to bridge

\footnotetext{
${ }^{100}$ Mainly the brainchild of Hassan al-Turabi, upon taking up power following the 1989 coup, the NIF implemented a visa free policy to citizens of any other Muslim states, which attracted a number of radical organisations to Sudan, who were given a free reign (and oftentimes a helping hand) by the GoS to pursue and develop their radical agendas. The most notorious, as already mentioned several times in this chapter, was bin
} 
political differences, 9/11 only further complicated an already strained relationship. Indeed, the WoT would only serve to remind European officials that it was in Sudan, under the alBashir regime, where al-Qaeda flourished in the first place. Sudan's status as a rogue element under al-Bashir was only reinforced in this respect by its affiliation with a cast of other colourful actors on the world stage which the West had castigated as bogeymen - affiliations it needed in order to survive and circumvent international isolation (as it did with the PRC). ${ }^{101}$ For one high-ranking UN official, the regime's chequered past consequently lulled some European leaders such as Tony Blair into making "lazy" assumptions that al-Bashir was the new Saddam Hussein, as part of their early assessment of the crisis (Interview 29).

Such prominent stereotyping of Khartoum as the EU's foe was only reinforced by stories often repeated in the West over the course of the Darfur crisis about the GoS' desire to promote an intolerant strand of Islam across the country and beyond. According to Richard Barltrop, the al-Bashir regime may have made efforts to amend for this past misgiving by purging the government in 1999 of al-Turabi's influence at the same time that European actors began loosening their containment policies on Sudan - yet the state of their relations were never going to change overnight (2011: 118). Whether the accuracy of such reports of a change of direction by Khartoum could be verified or not mattered little, for they only confirmed what officials in Europe had long suspected about the Sudanese government's ambitions when it came to the vision of Islam the latter sought to promote. One report told the story of the "Arab Gathering" - a supremacist movement in Darfur that openly admitted to upholding "civilisational” aspirations for the region whereby 'Arabs' would represent: “[...] the standard bearers for religion, culture" (ICG 2007a: 10; Brosché 2008: 9; Collins 2008: 302). ${ }^{102}$ The Janjaweed militia was believed to be replete with members of the Arab Gathering.

Laden's al-Qaeda which took refuge in Sudan until 1996, given the close family and business connections between bin Laden and al-Turabi (Natsios 2012: 95). Al-Qaeda were not alone though and were joined by a host of like-minded organisations that found a home in Sudan such as Egyptian Islamic Jihad, Hamas, Hizbollah, the Iranian Islamic Movement and Palestinian Islamic Jihad (Barltrop 2011: 112; Natsios 2012: 7, 93). Sudan was also once home to Venezuelan born terrorist Illich Ramírez Sánchez - better known as 'Carlos the Jackal' - until he was handed over to French authorities in 1994 (HRW 1998: 4).

101 These are: Saddam's Iraq (which Khartoum supported during the Gulf War, in return for weapons and military training); Iran (weapons, military training, diplomatic support); North Korea (weapons); Belarus (weapons and trade); the Islamic Courts Union (ICU) in Somalia (political support) and Joseph Kony's infamous LRA movement (weapons) (Huntington 1996: 177; HRW 1998: 4, 34; Large 2008b: 2).

102 On the "Arab Gathering," the International Crisis Group (ICG) writes: "the arrival of the NIF in 1989, with its 'civilisational project' and social engineering policies, was premised on the ideology of Islamic and Arab cultural supremacy. The Arab Gathering used the opportunity to advance its own agenda both in Darfur and Khartoum in order to acquire more resources for its tribes. [...] The aims of the Arab Gathering and the National Congress Party (NCP) [read GoS] continue to be complementary in Darfur, which explains the close relationship. They need each other for survival. In general, the former wants land controlled by non-Arab tribes, and the latter wants Darfur to remain divided [...]. In fact, given the objectives of the Arab Gathering, the action taken by the 
When the association was made between Khartoum, the Arab Gathering and the Janjaweed, it became axiomatic for some actors that the GoS held aspirations for an ethnic reconfiguration of the region.

This report was complemented by a second one which circulated about the poor state of the GoS' relationship with some of its close neighbours, namely Chad, which badly deteriorated during the crisis. Neighbourly differences are nothing new in IR, however, it was both the nature of the fallout and the fact that Chad entertains close ties to an important EU member state (France) which drew attention. In this instance, emerging reports of the deteriorating state of bilateral relations between these neighbouring countries were being interpreted by some in the West as being caused by Khartoum's growing frustration that Chad's leadership was ethnically closer to rebel groups in Darfur than to itself - Idriss Déby, President of Chad, was a descendent of one of the same tribal groups fighting the central government and therefore became an enemy. These reports clearly overlooked the fact that Khartoum's frustration with the elite in N'Djamena boiled down to its meddling in the Darfur conflict - which by 2006 had evolved into a proxy war between the two countries as the rebel groups used bases in Eastern Chad to launch attacks on the GoS - and probably explained why it sought regime change in Chad (Tubiana 2008: 11). ${ }^{103}$ Nonetheless, an ethnic twist was given to it in the same way that the GoS' actions were heralded as genocide when the conflict remained within the confines of the Darfur region (ICG 2007a: 2; Brosché 2008: 77; Natsios 2012: 191). Whatever the case, for French officials in particular, such news did not sit comfortably. The French government took particular exception to the physical and psychological threats emanating from Khartoum towards N'Djamena, whom the West generally portrayed as yet another victim of Sudanese aggression (Fisher-Thompson 2007; Granvaud 2009: 254).

France made promises to retaliate against any direct or indirect attempts made by the GoS to overthrow Déby, following through on them by providing vital intelligence to the latter's security services and even bombing rebel positions when necessary (Marchal 2009; Cockett 2010: 245; Hansen 2011). Stability in Chad had become an important component for French diplomats working on Darfur (Interview 31; Interview 32). Under Sarkozy, the French government even managed to drag the EU into this scrap by persisting in setting up a CSDP operation officially designed to provide a protective corridor for IDPs crossing the border into

Arab tribal militias and the Janjaweed, and the NCP's support, it can be argued that the Janjaweed are part of the military wing of the Arab Gathering in Darfur, and perhaps beyond" (ICG 2007b: 15).

${ }^{103}$ Such reports also overlooked the fact that al-Bashir's regime had consented and supported Déby's own accession to power in Chad, back in 1990. 
Chad (where they joined more than 400,000 others), at a time when tensions were flaring on either side of the border area. EUFOR Tchad/RCA therefore fitted the bill as far as constricted activism was concerned, since the mission had been requested by local and international actors alike while its military component was dissimulated by its humanist intentions. Anyone taking a closer look at the timing and unfolding of the operation could not be fooled by French - and to a lesser extent European - pretentions to address a clear message to Khartoum by posting European forces on Darfur's doorstep (Berg 2009: 61, 67-8). Obviously, this did little to abate any lingering animosities there may have already been between the GoS and European actors, which symbolically came to a head in March 2008 when a soldier deployed to EUFOR was shot dead after his vehicle had provocatively strayed across the border into Sudan (BBC News 2008). Sudanese government troops posted on the border had been instructed to implement orders of shooting down any EUFOR troops setting foot within Sudanese territory.

On the contrary, when having to make a choice within this highly politicised environment, Chinese officials made what in their view was the logical choice in siding with the GoS given their efficient bilateral business relationship. Instinctively though, even if Chinese officials had objectively assessed the importance of the PRC's relationship with Khartoum against the international backlash being rallied by the West against the GoS for the violence in Darfur, it is unlikely that they would have switched allegiance from one to the other. In its attempts to foster a place for itself both as an emerging responsible stakeholder and a symbolic leading nation among the developing world, situations as those in Darfur figure as problematic scenarios for contemporary China - caught between tradition and modernity. Ultimately, the decisive element in the PRC's identification process was the interpretation by the leadership in Beijing that the US and the EU seemed to be implicitly threatening regime change as their preferred course of action to resolve Darfur. Introspectively, the CCP could not join the camp whose approach to problem-solving in Darfur undermined the concept of its own authoritarian leadership, thus setting a dangerous precedent. As a matter of fact, in the opinions of two EU-China scholars: "Beijing still, to some extent, follows a logic of challenging the immorality of Western criticism of current authoritarian regimes" (Kerr \& Liu 2007: 74). In light of the PRC's having been a fierce critic of the 'coalition of the willing's' botched justification of Operation Iraqi Freedom, it would have been inappropriate for the Chinese government to conduct an about-turn by suddenly approving similar Western meddling in the internal affairs of the Sudanese government (BBC News 2003). 
By transposing its non-interference mindset to its interpretation of the events in Darfur, the only actors with whom it could empathise were with members of the Sudanese leadership and neither the rebels who questioned sovereign authority, nor the victims who amounted to the unfortunate collateral damage in the centre's attempts to reassert its authority over the periphery - regardless of the humanitarian discourse employed above (Zhang 2008: 60, 63). Officials in Beijing were said to relate to the "predicament" that its "profound" Sudanese friend had found itself in (Chinese Mission to the UN 2008; Xinhua News Agency 2008b). This identification process was inevitably at its strongest at the start of the crisis, as frustration and discontent with their respective evolving stances on Darfur between Beijing and Khartoum may have distanced the two partners over time. Fundamentally though, Chinese officials featured within the GoS' wider identification network throughout the entirety of the period under study. One scholar with inside knowledge has asserted that even as late as 2009, Beijing continued to try its best to reassure the al-Bashir regime that it would provide its utmost political support in favour of the latter's cause (Zhao 2010: 113). In turn, this led EU officials to negatively associate with China due to its perceptibly close association with Khartoum while Chinese officials responsible working on Darfur did likewise towards their European interlocutors, given the proximity of the former's ties to the GoS.

Empirically speaking, this was most visible in the rhetoric adopted by various Chinese officials when discussing the conflict. On the one hand, this discourse attempted to legitimise certain of the 'sacrifices' made by Khartoum over the course of the crisis to help restore a degree of normalcy to its reputation, which thereafter served to legitimise China's own rationale on Darfur. The process of normalisation, as aforementioned, served to justify the decision to identify with the wider ingroup network of the GoS - and thus against the Western outgroup - because doing so provided the positives needed to underpin this choice of positive identification. In other words, it had to give itself reasons other than simply confronting the West over its lax interpretation of the non-interference policy to identify with Khartoum. By outlining aspects which it believed constituted accomplishments on the GoS' behalf, this comforted Chinese officials in their decision to situate themselves within the former's wider ingroup network. This explains why, in the face of criticism coming out of Brussels and European capitals about the GoS' behaviour on Darfur, Chinese officials would retort back either by preferring to see the glass half-full or by mimicking the discourse directed by the GoS at the West.

In the first instance, when the GoS was characterised as a dictatorship which had to fight tooth and nail to assert its authority outside of Khartoum, the Chinese made short shrift 
of any talk of Sudan being a failed state, preferring instead to perceive the country as a land of opportunity (Macfarlane 2012: 168). ${ }^{104}$ When Western media consistently portrayed the situation in Darfur as having achieved scant progress, the Chinese press relayed the thinking of their officials on the ground who viewed these reports as "exaggerated," qualifying the situation in Darfur as "stable" (China.org.cn 2008; Xinhua News Agency 2008a). When the regime was scolded for acting as a spoiler during peace talks, Chinese officials painted the picture of Khartoum being a force for stability by pointing to evidence of its supposed disarmament of the Janjaweed, its power and wealth-sharing initiatives, its fight in combating impunity and its courage in allowing a foreign peacekeeping force onto its territory (Macfarlane 2012: 167). If a similar uprising would have taken place in the Autonomous Provinces of Tibet or Xinjiang, in Yitzhak Shichor's view, the authorities in Beijing would never have permitted UN peacekeeping forces onto its territory - instead they would have quickly and forcefully resolved the situation (2007). For Chinese officials, granting UNAMID access to its sovereign territory amounted to a laudable sacrifice on behalf of the GoS which the rest of the international community needed to respect as such (China Digital Times 2008; Zhang 2008: 61). Whereas the EU and others in the West had done their best to denigrate Khartoum in anticipation that alienating it from the international community would bring the GoS back to its senses, Chinese officials preferred to see the positives in the latter's behaviour whether in terms of its hardships or its achievements.

To a more limited extent, Chinese officials replicated the dissenting language and behaviour adopted by Khartoum against European actors and the US, both to show its solidarity and to vent its own apprehensions about external parties bringing into question the legitimacy of sovereign authority on a domestic affair. Indeed, whereas the GoS clamoured about being the next victim of the West's "crusade," with al-Bashir making personal promises to fight back against the "colonisers" who sought to enslave Sudan anew by using Darfur as a smokescreen, Chinese officials also made dismissive comments about Western interference. The reference to the "colonialist" attitude of certain European actors could infrequently be heard by CCP mouthpieces partly summarising the mood in Beijing, in a bid to condemn the interventionist mindset the West tended to carry around with it in Africa and beyond (Xinhua News Agency 2007b; Flint \& De Waal 2008: 197; BBC News 2009; Cockett 2010: 229).

\footnotetext{
${ }^{104}$ This is why, during an important juncture of the crisis, the Chinese government continued to conduct bilateral relations with Sudan almost as if the goings-on in Darfur were not worthy of acknowledgement. For example, in November 2006, it pulled out the red carpet for al-Bashir, giving the Sudanese front row seats during the FOCAC summit in Beijing (IRIN 2006). Since al-Bashir rarely made trips to countries other than those neighbouring Sudan or in the Arab world, this symbolic example is testimony to the extent to which the PRC sought to normalise the international appearance of the GoS at the time.
} 
Evidence of the Chinese officials' positive identification with their interlocutors in Khartoum could also be found in terms of their perception of the rebel groups in the context of the conflict and vice versa, from what the rebel groups (and IDPs) made of Beijing's close association with the regime. It is fair to say that neither side held the other in high regard since Chinese representatives to the UNSC often pushed for harder sanctions against the rebels, who reciprocated by avenging themselves on Chinese oil workers in Western Khordofan, while IDPs feared for their lives upon hearing that a Chinese engineering corps had been deployed to UNAMID (BBC News 2007a; Sudan Tribune 2007; Sudan Tribune 2008a).

\subsubsection{Absent Trust in a Tense Social Environment}

If EU and Chinese officials engaged on the ground in Darfur struggled to find the common identifiers needed to build cognitive-based trust, then the social environment which encapsulated the crisis was not permissive for distant actors to bridge their political differences. These were not the kind of favourable conditions required for ideal-type communicative action to take hold, even between two actors exogenous to the conflict. Even if there was the slightest prospect that social interaction could brake and reverse the motion more towards a middle ground where either side could build a modicum of mutual identification, the environment was an obstacle rather than a facilitator because: a) in general terms, the social environment was typified by a lack of centralised leadership in addition to the plethora of conflicting actors, initiatives and mediation platforms, which only fuelled mistrust between all actors involved in the process; b) more specifically, the EU's scattered approach to the crisis and poor reading of China's role by some of its political leaders, meant that the cognitive-based trust needed for officials from both sides to aspire to any form of hypothetical cooperation on the ground would struggle to subsume the general mistrust characteristic of the social environment.

As has often been pointed out in this chapter, since the EU and its member states were tied down at the inception of the Darfur crisis by other international priorities in the security realm - on top of the EU's sufficient lack of leverage over the GoS - their inability to provide any kind of international leadership on the crisis rapidly became evident. Brussels was not alone on this front as its transatlantic ally was similarly mired by more pressing business elsewhere. The AU - despite all the talk of African ownership - after finding that it had overextended itself due to a severe lack of sufficient material resources and to internal squabbling, often made matters more complicated by refusing to let others come to the fore in spite of these shortcomings (Flint \& De Waal 2008: 196; Interview 38). This attitude was quite 
symptomatic of the behaviour of many of the local/regional actors caught up in the resolution of the crisis, who often displayed lukewarm enthusiasm both for finding sustainable avenues for a peaceful outcome (as shown below) in addition to a certain reluctance for cooperative interaction amongst the key international officials involved with Darfur. For its part, the UN played a key role throughout the crisis but had been cautious from the start to take on the job of managing it in view of its many other responsibilities (Ibid). China, staying true to Deng's proclamation about keeping a low profile, never conceived playing a leading role on Darfur even if the shift in its policy stance may have betrayed this feeling somewhat. All of the above meant that other disparate centres of leadership could try their luck - which many did although none eventually succeeded in demonstrating the discipline and qualities needed to get all the parties to work under one roof (Interview 37). In consequence, when retrospectively looking at the conflict from 2010 backwards, the social environment characteristic of Darfur amounted to a minefield composed of cross-cutting third parties, overlapping mediation platforms and a stillborn peace agreement rushed through despite there being no peace to keep (Interview 8; Interview 36).

\section{Map 2 - Darfur from a Regional Perspective ${ }^{105}$}

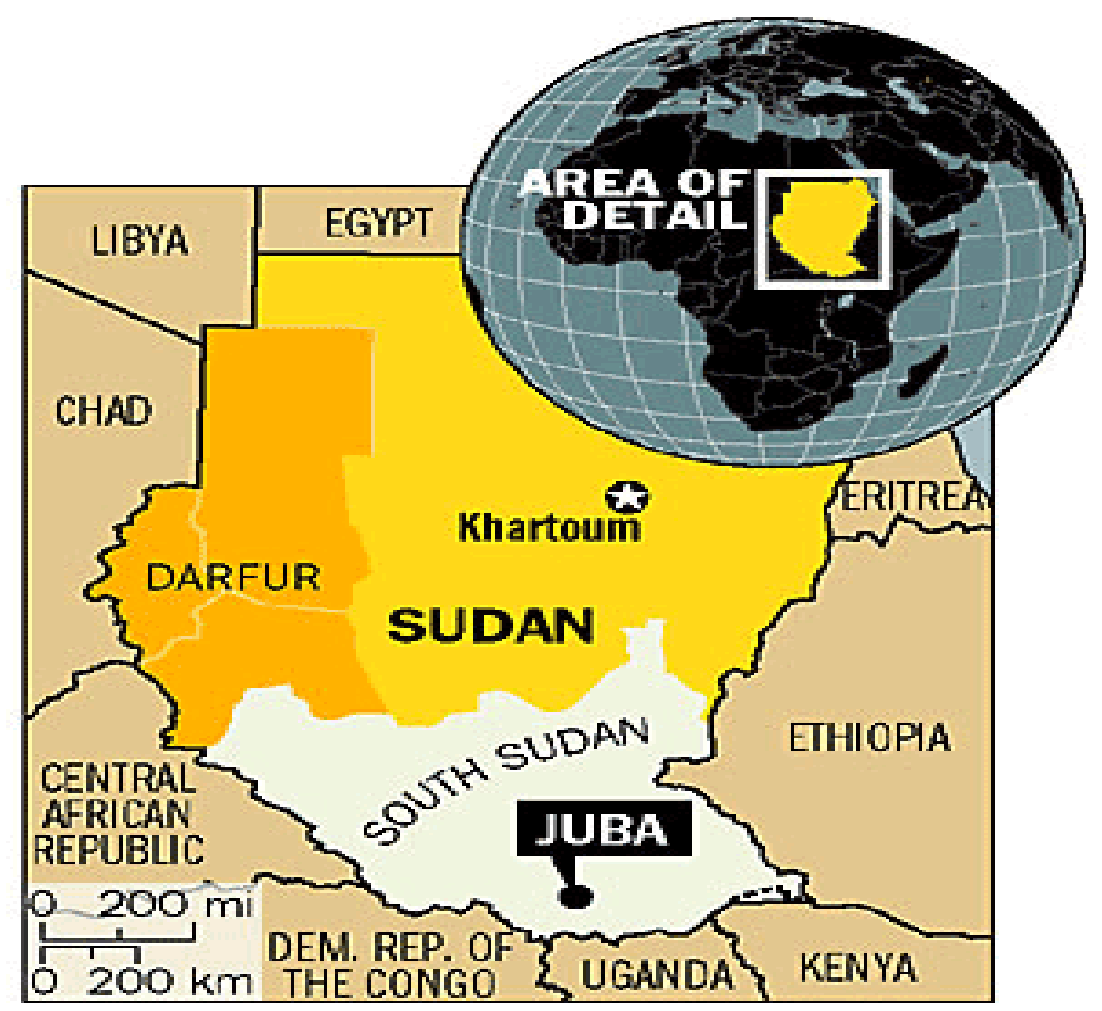

105 Map retrieved at: http://www.warsintheworld.com/index.php/2011/12/23/darfur-justice-and-equalitymovement-jem-rebels-said-marching-on-khartoum/. 
With regard to the principle other third parties, Qatar, Egypt, Libya, Chad, Eritrea, the LAS and the SPLM are all worthy of a mention for their different attempts at bringing peace to the region - whether for better or for worse. None of the parties were able to convincingly fill the leadership void given that for various reasons they could not come close to enacting ideal-type communicative action when regulating their overall behaviour on Darfur and, specifically, when attempting to reach a peace agreement. In fact, as the text of one such peace deal alluded: "the regional dimension of the conflict has sometimes complicated the search for a solution" (UN 2006: 2). First of all, too many were either too close to Khartoum (Qatar, Egypt, LAS), too embroiled with it/too close to the rebel groups (Chad, Eritrea, SPLM) or too busy trying to play both sides off against each for their own benefit (Libya) (BBC News 2004; Avni 2006; Leopold 2006; Sudan Tribune 2006b; Security Council Report 2007; Mamdani 2009: 252; Cockett 2010: 226; People's Daily 2010; Adebajo 2011; Barltrop 2011: 31, 66; Natsios 2012: 126). Indeed, some of these local and regional actors clearly were not interested in promoting an agenda for peace and a cooperative way out of the crisis. Secondly, not enough of these actors could strike a happy medium when it came to debates over the need for international intervention, with some too staunchly opposed to the concept (Libya, Eritrea) and others too quick to suggest it (Chad, SPLM) (Ibid). Thirdly, among these quasineighbouring countries and regional organisations, too many of their efforts were undermined by their own bickering and rivalry. Egypt, Libya and Qatar in particular stood out for their detrimental efforts at trying to outdo each other rather than seek a genuine end to the ordeal the region was experiencing (Ibid). Finally, some simply displayed either too much humility to be taken as a serious exogenous force in solving Darfur (LAS) whilst others would have been well advised to have shown a little more (Libya, Eritrea) (Ibid).

With so many third parties getting involved, this led to the establishment of a panoply of mediation platforms as each actor sought to promulgate its own take on how strife in the region should be ended. By 2006, the ICG estimates that 12 such international initiatives had been established in addition to approximately 100 local initiatives (2007a: 21; Cockett 2010: 200). As Julie Flint and Alex De Waal observed, this led to a social context overrun by: "too many cooks, with too many artificial solutions" (2008: 273). ${ }^{106}$ The Addis Agreement of November 2006 had specifically warned against this trend, although to little avail: "the proliferation of initiatives [...] must be streamlined and brought under a unified umbrella to

\footnotetext{
${ }^{106}$ And in Cockett's view, the Darfur crisis had by then drawn in: "[...] a whole new cadre of people who had never campaigned before, let alone heard of Darfur" (2010: 207).
} 
guard against forum shopping" (UN 2006: 1). Since each platform would have had its own set of highly politicised agendas, purposes and dynamics, it may have been difficult for actors with political differences to build trust in such a confusing and inconsistent environment. Indeed, divergent platforms usually meant sending different teams of representatives, doing little to help the consistency of the overall bilateral interaction. Table 4 provides an overview of the mediation mechanism created to support peace talks on Darfur in which both the EU and the PRC were directly represented. These platforms do not take into account discussions in New York at the UNSC between diverse European actors and their Chinese counterparts.

Table 4 - Mediation Platforms for Darfur (Involving the EU and China)

\begin{tabular}{|c|c|}
\hline Platforms & Participants \\
\hline 'Envoy 6' meeting & China; EU; France; Russia; UK; US \\
\hline $\begin{array}{l}\text { High-level consultation on } \\
\text { the situation in Darfur }\end{array}$ & $\begin{array}{l}\text { AU; China; Egypt; EU; France; GoS; LAS; } \\
\text { Russia; UK; US; UN; (others) }\end{array}$ \\
\hline $\begin{array}{l}\text { International conferences on } \\
\text { Darfur (x3) }\end{array}$ & $\begin{array}{l}\text { AU; Canada; Chad; China; Egypt; Eritrea; } \\
\text { EU; Finland; France; GoS; Italy; Japan; LAS; } \\
\text { Libya; Netherlands; Norway; Russia; UK; } \\
\text { UN; US }\end{array}$ \\
\hline $\begin{array}{l}\text { Meeting of the international } \\
\text { envoys to Sudan (x2) }\end{array}$ & AU; China; EU; France; Russia; UK; US; UN \\
\hline $\begin{array}{l}\text { Ministerial meeting of the } \\
\text { enlarged Contact Group on } \\
\text { Darfur }\end{array}$ & $\begin{array}{l}\text { African Development Bank; Belgium; } \\
\text { Canada; China; Denmark; Egypt; EU; France; } \\
\text { Germany; Italy; Japan; LAS; Netherlands; } \\
\text { Norway; OIC; Portugal; Russia; Spain; } \\
\text { Sweden; UK; UN; US; World Bank; (others) }\end{array}$ \\
\hline
\end{tabular}

Source: see footnote ${ }^{107}$.

Multiple platforms obviously entailed multiple peace agreements, none of which actually successfully achieved their target of long-term sustainable peace, with the possible exception of those deals concluded towards the end of the conflict (although the viability of these accords remains under scrutiny). The most prominent of these agreements are listed in Table 5 below. Again, the multiplicity of these agreements is symptomatic of the complex social environment constitutive of the Darfur crisis.

Table 5 - Major Peace Agreements on Darfur

\footnotetext{
${ }^{107}$ This table contains data based on the author's findings, as collected across a number of different sources (news media, policy papers, interviews). The platforms have been ranked by alphabetical order and may have been held more than once.
} 


\begin{tabular}{l}
\hline \multicolumn{1}{|c|}{ Date } \\
\begin{tabular}{|l|l|}
\hline \multicolumn{1}{|c|}{ Agreements } \\
\hline $03 / 09 / 2003$ & Abéché Ceasefire Agreement \\
\hline $08 / 04 / 2004$ & $\begin{array}{l}\text { Humanitarian Ceasefire Agreement on the Conflict in } \\
\text { Darfur, N'Djamena }\end{array}$ \\
\hline $08 / 02 / 2006$ & Tripoli Agreement \\
\hline $05 / 05 / 2006$ & Darfur Peace Agreement (DPA), Abuja \\
\hline $13 / 06 / 2006$ & $\begin{array}{l}\text { Declaration of Commitment to the Darfur Peace } \\
\text { Agreement, Addis }\end{array}$ \\
\hline $13 / 03 / 2008$ & Dakar Accord \\
\hline $17 / 02 / 2009$ & $\begin{array}{l}\text { Agreement of Goodwill and Confidence Building for the } \\
\text { Settlement of the Problem in Darfur, Doha }\end{array}$ \\
\hline $14 / 07 / 2011$ & Doha Document for Peace \\
\hline
\end{tabular}
\end{tabular}

Source: see footnote ${ }^{108}$.

In addition to the mistrustful and politicised nature of the social environment, the EU's own evolving approach to the resolution of the crisis made matters worse as its political leaders turned to short-term gains and opportunism, somewhat out of desperation, to prove to domestic audiences that they had something to "show" for their efforts (Collins 2008: 295; Interview 32). Yet, such short-termism would only render irrelevant the concept of building trust for the EU's officials on the ground with its counterparts from distant third parties. During the early years of the crisis, the EU had responded in what appeared to be a fairly coherent and united manner. Although the Union's belated reaction to the crisis forced it to play catch-up, like the rest of the international community, its early performance came across as promising given that it actively and collectively sought ways around the impasse. EU diplomats played an important part in setting up the N'Djamena Ceasefire Agreement in April 2004 and while constricted activism did halt this momentum somewhat, the EU held firm to its promise to put African ownership first. Financially, politically or in terms of human/material resources, the EU contributed its fair share to the AU's peacekeeping and mediation initiatives even if it could always have done more. Its support missions and "quiet diplomacy" strategy meant that it retained influence without appearing to openly break with the process of its hierarchy of preferences. These initiatives though, began to unravel rapidly when the AU suffered its own expected shortcomings both on the peacekeeping and mediation fronts, while the lack of leverage over the Sudanese economy and oil industry exacerbated the impotence of the other indirect avenues it utilised to pressurise the GoS into action.

\footnotetext{
${ }^{108}$ This table contains data based on the author's findings, as collected across a number of different sources (news media, policy papers, interviews).
} 
By the time negotiations were underway to get UNAMID up and running, the pressure felt by Western officials to cease the violence in Darfur emanating from civil society groups and public opinion had started to tell. The coherence and assurance shown in the early part of the conflict had slowly fragmented with individual initiatives by different concerned European actors becoming the norm - especially for those sitting at the UNSC who often preferred using venues other than the EU to make a mark (van der Putten \& van der Meulen 2009: 20; Interview 32; Interview 38). Of course, they still formed part of an amorphous Western approach but the EU per se was relegated to a "second tier" role, overly focused on the humanitarian side of the conflict (Prunier 2008: 141; van der Putten \& van der Meulen 2009: 20; Interview 32). Any form of strategic vision about what to do about Darfur had fallen foul to the need to "show something," leading to a suboptimal medley of initiatives feeding into the overall disarray of the social environment (Keane \& Wee 2010: 124; Barltrop 2011: 61, 170; Interview 32). Gérard Prunier draws up a caricature in his book on the Darfur conflict of the performance of European actors by the latter stages of the conflict, without even mentioning the EU and its institutions. The caricature is damaging in its description but only so because it sheds light on the reality of the situation on the ground for the EU: France was only interested in protecting Déby; the UK blindly followed Washington; the Scandinavians and the Netherlands gave money but remained silent; the Germans criticised the GoS without backing-up its words with actions; whilst the Italians remained "bewildered" (2008: 140-1).

As the conflict reached somewhat of a crux moment between the latter parts of 2006 and 2008, the attitudes of those representing the EU bordered on the despondent as typified in an assessment provided by one well-placed insider:

there was a sense which was shared by everybody, for which a decision was unanimously taken at the EU level, that it was the right moment in time to engage the way we did. Of course our expectations and hopes were somehow dashed by the inclination of the parties to continue the confrontations, which from a longer term perspective reduced the possibility for the huge number of IDPs in Darfur to return to their villages. As you've seen over the years, we didn't really succeed at the end of the day to establish such a situation in the short-term, leaving the peace efforts to be carried on elsewhere (Interview 3).

With mistrust seeping even into its own ranks, the EU cut a pale figure in comparison to the pretentions some of its decision-makers may have harboured for the Union at the inception of the crisis (Keane \& Wee 2010: 124, 129; Baltrop 2011: 132). 
Not that this prevented other European political leaders from thinking that they could single-handedly make a difference. Yet, the longer the conflict drew on, the greater the frustration grew from the lack of tangible progress, the more European political leaders came up with fleeting and uncoordinated initiatives which either fizzled out or failed to produce the desired results and certainly did not facilitate the trust building endeavours of EU officials with their Chinese interlocutors on the ground. For example, in September 2006, former President of the European Commission, José Manuel Barroso and then EU Commissioner for Development and Humanitarian Assistance, Louis Michel, travelled to Khartoum to convince the al-Bashir regime to approve UNSCR 1706, to not undermine the DPA talks and to improve access for humanitarian NGOs operating in Darfur (Sudan Tribune 2006a). Kouchner, in the wake of Sarkozy's victory during the 2007 French Presidential elections, had set the target in his role as French Foreign Minister of improving the situation in Darfur, largely relying upon French resources in the process. He soon backpedalled when faced with the scale of the problem at hand, leaving EUFOR Tchad/RCA as his only legacy on Darfur which may have contributed in some way to improving the humanitarian situation in the short-term but was largely criticised for being seen as the French government manoeuvring to preserve the political status quo in Chad (Interview 32).

In 2008, Gordon Brown also tried his hand at bringing peace in Darfur with an initiative to bring all the warring parties for talks in London in the hope of sealing a deal, without realising that this played perfectly into the hands of the GoS and the rebels who were only really interested in prolonging the fighting (Suleiman 2008). The more European political leaders sought to apply different individual and/or collective remedies the less clear the EU's "mediation methodology" became, to the extent where by the latter stages of the conflict this methodology was no longer discernible (Keane \& Wee 2010: 124). Indeed, virtually every European country contributing towards the resolution of the conflict had a Special Envoy, on top of the EU Special Representative for Sudan (EUSR) appointed by the European institutions, without there seeming to be any concern about the need for a division of labour. If some European officials had been able to build up sufficient cognitive-based trust with Chinese representatives, it is unlikely that this would have produced any meaningful and lasting effects as the lack of methodology renders obsolete the notion that such trust could have been institutionally stored or transmitted to other European actors involved in finding a solution for the region.

In turn, by adding frustration to fragmentation, European political leaders adopted the habits of their American counterparts by looking for opportunities to produce supposedly 
game-changing effects on the crisis, rather than work on the basis of a longer-term timeframe and investing resources into producing sustainable results from the bottom up (Flint \& De Waal 2008: 273; Stedjan \& Scott-Thomas 2010: 170). These political and high-flying negotiators were often too caught up in the hype they had helped create on Darfur to objectively realise where their approaches were coming up short. The Darfur Peace Agreement (DPA) talks were symptomatic of this desire to put results over substance but they were flawed from the very start, as they had been dressed up as the flagship moment in the resolution of the crisis in the same way that the CPA had brought an end to Sudan's civil war. Such a misconception only served to hike the pressure further on the participants and mediators, who for the best part of two years barely kept the talks alive as they recurrently appeared on the verge of stalling. The EU's quiet diplomacy strategy had left it to work in the shadows of the AU and the UN but seeing that this was leading them down a blind alley, European political leaders upped the ante conjointly with American officials by getting more involved and looking to secure a deal at all costs. Their intention was to complement the decision to launch UNAMID with a political agreement between the warring factions under a deal overseen by the AU and the UN, allowing them to believe in the possibility of the insurgency and counter-insurgency being brought to an end. Given the lack of subtlety in this approach, the levels of mistrust between all the concerned parties only worsened as a result.

To implement their plan, they believed the best course of action rested in pressurising both sides of the negotiating table. "Deadline diplomacy" became a preferred tool, as did using sticks - like threatening to cut the funding they provided which had kept the talks going in the first place (Mamdani 2009: 265; Williams 2010: 40; Interview 35). The international media spotlight was invited to focus on the deliberations rather than being reserved exclusively for the signing ceremony in the belief that transparency would spook the warring parties into showing greater urgency towards a peaceful settlement. High-profile Western political leaders - then US Secretary of State Bob Zoellick for the Bush Junior administration, then Secretary of State for International Development Hilary Benn for the UK government were "parachuted" in to ensure that a deal was struck (Stedjan \& Thomas-Jensen 2010: 170; Barltrop 2011: 148; Interview 35). Eventually a deal was reached: the GoS signed up, as did one of three main rebel groups, whilst other important sections of Darfuri society were kept out of the deal. Notwithstanding these obvious faults, Western negotiators hastily declared the DPA a victory, promising to pressurise those who had refused to sign up to adhere in the near future (Prunier 2008: 179; Barltrop 2011: 148). Despite trying to acclaim the DPA with much fanfare, celebrations should have been put on ice since the pattern of recurring violence 
continued almost unabated. Unsurprisingly, the DPA was the last peace initiative to which EU political leaders significantly contributed as the agreement's legacy - in the words of one author - "handicapped" them and specifically their officials on the ground for the remainder of the crisis (Barltrop 2011: 148). Regional actors, most notably the Qatari government, picked up the mediation baton from that point onwards.

What this particular episode illustrates is that European political leaders, whether using the EU or their national resources when involving themselves with Darfur, did not appear in favour of pushing their representatives on the ground to work on developing relationships from the bottom up as a means of generating influence. Instead, orders came from the top down to drive the process on as rapidly as possible, to obtain concrete results (regardless of their sustainability) in order to close the Darfur case once and for all, allowing leaders to move onto issues where more interesting political kudos could be extracted. Few seemed to appreciate that in light of the warring parties' stubborn resistance to fostering peace, in addition to the plethora of exogenous actors involved, substantial human resources on the ground would be needed over a sustained time period (ICG 2005a: 7; ICG 2007b: 2; Mamdani: 292; Barltrop 2011: 67; Interview 36). ${ }^{109}$ Charles Snyder, the chief US diplomat appointed to oversee the CPA negotiations from the American side, admitted as much when he declared that it was: "the small boys that are the key to these peace deals. [...] As the big politicians take over, with big megaphone politics, the UN etc.... that is what changes and why it falls to bits" (cited in Cockett 2010: 220). Naturally, this shortcoming affected most of the EU's endeavours regarding Darfur including its interaction with the PRC. During the interviews conducted for this case study, a number of participants did affirm that regular and close contacts took place between officials from both sides: "to try and establish as much common ground in terms of stabilising and de-escalating the situation" (Interview 1; Interview 3; Interview 32). This may have been true in Brussels, Beijing, New York, European capitals and in other multilateral settings. However, in Khartoum and in Darfur, contact was described as "rare" especially up until 2006 where for EU diplomats on the ground, China did not really feature on their "radar screens" - obviously rendering the task of creating a common language and worldview of the conflict that much harder (Interview 34; Interview 38).

\footnotetext{
${ }^{109}$ As one article on the DPA concluded: "[...] the government's [GoS] objective is not to resolve the conflict, but rather to weaken the negotiation position of the rebels, bog them down in local conflict to prevent them from possibly expanding beyond Darfur, and portray itself as an innocent bystander of a complex, decades-old local conflict. It has made no serious attempt to find a solution other than by the gun" (ICG 2005a: 7). The same could however be said of some of the different rebel groups.
} 
With hindsight, in the opinion of one participant, more of an effort should have been made to engage those Chinese officials tasked with managing quotidian exchanges with the al-Bashir regime (Interview 35). As a priority, interaction with Chinese officials came too little, too late for European representatives. Taking a closer look at the mandate of the EUSR - Brussels' main port of call on Darfur - the wording did not exactly incentivise the EUSR to go out of his/her way (in 2006-2007) when on the ground to establish contact with the Chinese: "the EUSR ensures coherence between the EU's supporting action to AMIS II, political efforts to promote peace in Darfur and activities relating to the implementation of the CPA as well as overall policy objectives of the EU towards Sudan" (EU Council 2006c). In practical terms, this translated into the following: "whatever else took place in discussions among the major powers on broader international solutions was somehow outside the framework of what the EUSR and his team was mandated to do" (Interview 3). Too often, some of the EUSRs were criticised for not being seen either as belonging to the movers and shakers on Darfur or as visibly engaging with the other leading actors, probably as a result of the quiet diplomacy strategy enforced upon them (Gya 2010: 15; Natsios 2012: 116; Interview 32). Yet it is difficult to see how focusing efforts on AMIS II and the CPA would have helped in this respect.

The idea of building a working relationship with an endemically distant political other to bridge differences on the basis of cognitive-based trust, within an environment rife with mistrust, appears somewhat remote. Even if those extra steps had been taken to engage Chinese officials with greater consistency and greater drive over a longer period of time, it is not certain the outcome would have necessarily been that much different. This is because the negative identification (by association) outlined in the previous section made European and other Western officials wary of the Chinese and certainly did not endear them to the notion that Chinese diplomats needed treating as equals and empathising with. It is unlikely that from the European side, lower-level negotiators would have been willing to abide by the criteria necessary to implement ideal-type communicative action, especially at the time when the leadership in Beijing was being pressed to tip the balance of events in Darfur. The patience and humility required to strike up sufficient levels of trust would have been few and far between, while the time and investment needed to foster them would have been unlikely to materialise. When questioned on this point, one European actor having been involved at length on the crisis, gave an answer capturing the extent of the bilateral political divide between sets of officials - thus highlighting the dearth of these necessary qualities: "when I 
asked a member of the Special Envoy's office in 2009 whether anything could be learnt from the Chinese approach, his mouth fell open" (Interview 35).

\subsection{Concluding Remarks}

A decade has passed since fighting broke out in Darfur between the various rebel groups and the Sudanese government, backed by its militia forces. As the intensity of the fighting has progressively waned, the Darfur conflict has come across as a relic of yet another civil conflict in post-Cold War Africa, despite all the talk of genocide having been the source of much debate during the first decade of the $21^{\text {st }}$ century. Looking back at the political dynamics surrounding the crisis, one is soon hit by the relatively chaotic nature of proceedings towards which endogenous and exogenous actors each contributed to render more complex regardless of their respective ambitions. The EU and its member states initially saw Darfur through the prism of their aspirations to normalise their reputations in the African security realm, by being seen as doing their best for the most vulnerable in the context of the crisis. This intention was undoubtedly sound but as this chapter has highlighted, the EU did not possess sufficient collective political will or resources to implement these aspirations, whilst constricted activism narrowed Brussels' realm of possibilities.

Therefore, following numerous failings over the first half of the conflict, the EU - in tandem with other Western government and civil society actors - sought to indirectly pressure third parties perceived to hold leverage over Khartoum to use this leverage to the benefit of Western objectives for Darfur. This resulted in deflecting Western shortcomings and turning the attention towards the shortcomings of these other select third parties, notably the PRC an easy target at the time for a number of aforementioned reasons. Instead of trying to build the rapprochement needed with China on the ground in Darfur so as to allow a cooperative bilateral mindset to guide Beijing towards channelling its leverage over the GoS more in line with Western objectives, actors such as the EU had to indirectly coerce China to fall in line by relying upon the global message of outrage voiced by certain civil society groups. As some analysts have pointed out, EU officials should never have relied in the first place on the momentum generated by this civil society movement which coerced leaders in Beijing into adopting a more proactive stance on the conflict (Abramovitz \& Kolieb 2007). They argue that because of the difference in political values between the two sides, the EU (and the US) should not have been looking to China to act as its "moral compass" on Darfur towards the latter stages of the conflict. Had they opted for a strategy based on rapprochement over 
coercion, they may have set bilateral interaction on Darfur on a different course - one which possibly may have improved the overall situation on the ground.

Nevertheless, such claims remain purely speculative as practically speaking the levels of cognitive-based trust needed to spark a bilateral rapprochement between officials on both sides were unlikely to ever materialise. European officials did not believe it necessary to steer clear of the path of negative identification they were heading down with the PRC from the start of the conflict. No implicit moves from either side were sought to avoid this selffulfilling cycle. From there onwards, the cycle of mutual negative identification was reinforced by the increasing politicisation of the social environment consuming Darfur, where mistrust had propagated. When the time came for the EU to indirectly lean on the Chinese to help make progress, the concept of building the trust necessary for developing potentially useful bilateral cooperative endeavours had become irrelevant. This left European actors with no other choice but to indirectly coerce China into action - which it managed to achieve, but not to the extent of having offset a "paradigmatic" shift either with regard to the EU's specific humanitarian objectives for Darfur or for the situation in the region as a whole. By opting for coercion, this entailed that meaningful cooperation became out of reach which subsequently implied that any meaningful change of the situation on the ground as a result of this shift was always likely to be minimal.

Therefore, it is erroneous to argue that the existence of common interests (with time and options running out for the Europeans, whilst China sought to protect its international image at this important juncture in its recent history) provided the opportunity for both sides to move closer together on the topic of the resolution of the crisis in Darfur and thus triggering the so-called "paradigmatic shift." This is so because, on the one hand, when taking into consideration the wider picture of the conflict as a whole, this shift never contributed towards any sense of real closure to the crisis in Darfur and therefore this evolution cannot pertain to any form of "paradigmatic" nature. In effect, how can we talk about a shift towards cooperation when from a broader viewpoint, such apparent cooperation did not produce any meaningful contribution to the resolution of the conflict as a whole? On the other hand, this rapprochement - for all its apparent catalytic effects - was only ever going to produce little meaningful impact on the fate of the region as it was above all the product of cognitive-based mistrust and thus should not be confused with actual cooperation. This is why the concept of cognitive-based trust/mistrust should be understood as the primary explanatory variable when it comes to making sense of the evolution and implications of bilateral interactions between European and Chinese officials regarding the Darfur crisis. It is cognitive-based mistrust 
which explains why both sets of officials became engulfed in the spiral of mistrust characteristic of the social environment in/on Darfur, in the same way that it is the lack of cognitive-based trust which explains how and why - via coercive practices - they temporarily overcame their differences by moving towards an apparent common ground. Furthermore, it is cognitive-based mistrust which also explains why such a "paradigmatic shift" failed to produce a similar "paradigmatic" evolution of the state of affairs on the ground in terms of the lasting resolution of the crisis in Darfur.

Contrary to other possible scholarly interpretations, the conceptual framework promulgated in this thesis puts forward the idea that cooperation is above all the product of meaningful trust between actors who develop solid foundations behind their desire to put trust in their given counterparts. In turn, such meaningful trust can only translate practicallyspeaking into meaningful and quasi-paradigmatic acts. Yet, where there is no such cognitivebased trust, similar acts do not take on such meaningful ramifications and although acts of cooperation may appear to transpire, fundamentally they cannot be interpreted as such since cooperation or coordination without meaningful trust does not constitute actual cooperation. Where genuine cooperation fails to emerge, the ramification of such acts will naturally be minimal. This was the case for the EU and China in the context of the crisis in Darfur regardless of the evolution in their bilateral dealings.

Unsurprisingly - in part of a result of the above - by 2010, it could not be said that the situation had markedly improved especially for the victims of the conflict. Although conflictrelated deaths were less commonplace, tentative peace agreements had been signed and the largest UNPKO in world history had been deployed, normalcy at least in the short-term was unlikely to return for those same people the EU considered as the priority in Darfur (Flint \& De Waal 2008: 145; Charbonneau 2009; Lavallee 2010; BBC News 2012b). ${ }^{110}$ Many such victims had lost everything and faced the prospect of spending a sizeable part of their future lives inside unstable IDP camps, where they would remain targets for violence both from inside and outside the camps. If reports of one NGO are to be believed, there were 1,043 conflict-related deaths as well as 268,000 new displacements between January and November 2010 (Crisis Action 2011: 5). Sexual violence targeted against women in the camps continued to remain a grave source of concern despite UNAMID's presence (Ibid: 7). During one

\footnotetext{
${ }^{110}$ As numerous experts on Darfur have attested, the GoS and militia forces either partially or totally destroyed everything that made life possible for the inhabitants of Darfur: food, animals, clinics, schools, pumps, wells, mosques, Qurans, people and villages (Flint \& De Waal 2008: 145; Crilly 2010: 227). The case of the mass rape of over 200 women in the region in October 2014 highlights how the situation on the ground remains as precarious as ever (Troup Buchanan 2015).
} 
interview, one diplomat well-versed in Sudanese affairs explained that the situation in Darfur could be described as the following in 2010 (when compared to the situation in 2003-2004): “it's not solved, it's just not as bad as it was at that time" (Interview 28; Cockett 2010: 246).

This may be so but the outlook for the victims of the conflict seems to remain as bleak as ever, particularly if we take into consideration the suggestion put forward in some reports on how prospects could be improved for these victims. Some have suggested that one key criterion to restoring hope of a way of out this perpetual cycle of violence would be for the GoS to carry out internal political reforms to national political structures in Sudan, which would positively discriminate in favour of Darfur's inhabitants (ICG 2007a: 4; ICG 2010: 14; Interview 39). Despite some timid attempts at constitutional reform, Darfur remains a region divided into three political and administrative blocks while no Darfuri tribe members hold any key positions within the current Sudanese government, in the same way that some Southern Sudanese did in the run-up to the referendum on secession (Salva Kiir was Vice President of Sudan between 2005 and 2011). Another suggestion which has been thought up would consist in bringing the perpetrators of the conflict to trial so as to bring a sense of justice to those who have suffered the most from the crisis (ICG 2007a: 4). Since Khartoum continues to flaunt the principle of rule of law, the only other credible alternative of potentially bringing the culprits to justice - in the shape of an ICC investigation - soon found itself bereft of any credibility (ICG 2009: 6).

Following the UNSC's decision to handover a list of suspected culprits to the ICC in 2005, the prosecutor in charge of the affair (Luis Moreno Ocampos) went for style over substance and decided to pursue charges against al-Bashir himself (in addition to the other listed individuals) on grounds of committing genocide and other acts of war. Ocampos' decision originated out of frustration with the regime's refusal to pay heed to Secretary General Ban's appeals for the GoS to cooperate on UNSCR 1672 and to conduct legal proceedings against two of the four individuals listed for sanctions who held close ties to the GoS (Ahmed Haroun and Ali Kushayb). This was a first for the ICC - both in terms of putting out an arrest warrant against a sitting head of state and one who sat atop of a nation that did not recognise the Rome Statute. Symptomatic of the social environment in Darfur as a whole, the decision - regardless of the intentions behind it - stoked the fires of a social context overrun by mistrust, polarising further those who supported the ICC from those that did not (Zhang 2008: 77; Interview 32). For example, Chinese officials suggested freezing the investigation and possibly calling for a deferral at the UNSC through the application of 
Article 16 of the Rome Statute, while putting forward possible counter-proposals. ${ }^{111}$ Beijing subsequently lambasted the ICC for having triggered more instability across Darfur as a result of the arrest warrant, instead of acting as a force for peace. The European parties to the UNSC rebutted the proposals to freeze the investigation and publicly declared themselves ready to put up a fight to prevent an Article 16 deferral (Sudan Tribune 2009). ${ }^{112}$ Obviously, this climate of polarisation confirmed the extent to which both parties continued to find themselves on apparently irreconcilable sides of the political spectrum on Darfur, even if we take into account the "paradigmatic shift.",

For the victims of the violence in the region, many had welcomed the arrest warrant in the hope that they could at last see some form of retribution (ICG 2009: 23). At the very least, the arrest warrant could have created a useful window of opportunity for the international community to draw compromises from Khartoum of direct benefit to the conflict's victims (such as compensation or assistance in returning to/rebuilding destroyed homes), given that al-Bashir and his entourage apparently lived in fear of the consequences of the arrest warrant (Flint \& De Waal 2008: 183; ICG 2009: 16; Interview 34). ${ }^{114}$ Yet with the prosecutor politicising the investigation, this only reignited tension between all the parties concerned by Darfur and ultimately featured as another missed opportunity in the quest to improve the plight of innocent civilians. With virtually every country bordering Darfur having endured their own civil instability and bloodshed in the years since events in the region quietened (or at least were no longer reported in the mass media) - from Egypt and Libya, to the CAR and South Sudan - it is surprising that fighting has not relapsed. Only time will tell whether the underlying tension between the centre and periphery resurfaces as the absence of a sustainable peace deal will continue to haunt the region. ${ }^{115}$ Events in South Sudan have been grabbing the headlines since the end of 2010 onwards as the world awaited the latest newcomer into the

\footnotetext{
${ }^{111}$ By drafting in judges from other North African countries and LAS states into the Sudanese legal system to oversee proceedings, along with AU observers.

${ }^{112}$ Article 16 of the Rome Statute states that: "no investigation or prosecution may be commenced or proceeded by the ICC for a period of 12 months after the SC, in a resolution adopted under Chapter VII of the Charter of the UN, has requested the Court to that effect. The later request may be renewed by the Council under the same conditions" (CICC 2008). Yet even after throwing their weight behind the Prosecutor's decision, many European actors did remain wary that the arrest warrant could compromise their already fragile leverage over the GoS, especially in light of Khartoum's accusations that European actors hid behind the arrest warrant (Interview 32). Rumours even circulated at one point that the European Commission and certain EU member states had even contemplated dropping their support for the arrest warrant altogether (Gya 2010: 15; Saferworld 2012: 100).

${ }^{113}$ The ICC took the decision to halt the investigations as of December 2014, in order to focus their energies on other cases (The Guardian 2014).

${ }^{114}$ The regime even sent envoys to London, Paris and Washington to lobby in favour of an Article 16 deferral, which demonstrated the extent of their concerns about the ICC arrest warrant (ICG 2009: 16).

${ }^{115}$ By the recent accounts of one expert, the situation on the ground is ripe for a repeat of the 2003 uprising (Adam 2015)
} 
realm of statehood, causing the simmering tension in Darfur to recede once more into obscurity - probably to the relief of the Western officials having worked on this particular crisis (Interview 3; Interview 8). Yet, no longer mentioning this conflict should not serve as a pretext for ignoring the lessons to be drawn from it, particularly in light of the absence of a sustainable post-conflict settlement for the region. For the EU and its officials, Darfur should be remembered as the crisis of missed chances where alternative opportunities to make a real difference - such as in its dealings with Chinese representatives - did not hold as much weight as they should have done (Baltrop 2011: 127). Had this been the case, perhaps Brussels would have been a step closer to achieving its ultimate stated objective in the context of this crisis, whereby the people of Darfur could hope to one day enjoy: “[...] the benefits of economic and social development concentrated on the needs of the entire population" (EU Council $2007: 2$ ). 


\section{Case Study 2: The EU's Engagement of China on Counter-Piracy off the Horn of Africa (HoA)}

\subsection{The Counter-Piracy Environment}

\subsubsection{The Rise of the Somali Piracy Phenomenon}

By taking a fleeting look through the print and other mass media outlet reports on Somali piracy published in and around spring 2008, one could easily get the impression that this phenomenon had risen out of the water in a completely haphazard manner, catching many "by surprise" in the process - almost in the same way as the Darfur crisis (Marley 2011: 95). Somali pirates caught the short-term attention of the Western media during that period because of the rampant successes of the phenomenon and because of the audacity of the attacks carried out by the pirates themselves. The idea that three Somali pirates on 10-foot speedboats could successfully hijack a 330-metre long oil tanker captured the media's imagination largely due to its sensationalist value and for the obvious parallels that the readership could draw with a certain cinematographic trilogy. Somali piracy though was hardly as spontaneous an event as it was made out to be. Ever since the collapse of the Siad Barré regime in 1991 - otherwise understood as the tipping point of Somalia's evolution into a failed state - this threat had been brewing off the coast of the HoA. Waves of pirate attacks, although inconsistent and cyclical, were not uncommon since two thirds of all maritime abductions worldwide took place off the HoA, while nine attacks were recorded off Djibouti/Somalia and thirteen along the southern arm of the Red Sea in the year 2000 alone (Murphy 2008: 101-2; Pettreto 2010: 11). ${ }^{116}$ As data collected by David Marley highlights (see Table 6), although the number of attacks prior to 2008 had not dramatically varied, a steady pattern had built up in the Gulf of Aden (GoA) and along the Somali coast without the international community making any significant attempt to eradicate this phenomenon. By 2009 and 2010, these figures had respectively reached 217 and 219 attacks reported across the region as a whole (Kupferschmidt 2010: 69; Pettreto 2010: 10; Larik \& Weiler 2011: 83).

Table 6 - Recorded Pirate Attacks: The GoA and the Somali Coast (2003-2009)

\begin{tabular}{|l|l|l|l|l|l|l|l|}
\hline Location & 2003 & 2004 & 2005 & 2006 & 2007 & 2008 & 2009 \\
\hline
\end{tabular}

\begin{tabular}{|c|c|c|c|c|c|c|c|}
\hline GoA & 18 & 8 & 10 & 10 & 13 & 92 & 116 \\
\hline Somalia & 3 & 2 & 35 & 10 & 31 & 19 & 80 \\
\hline
\end{tabular}

Source: Marley (2009: 175). Author's creation.

\footnotetext{
${ }^{116}$ Furthermore, these figures do not account for those attacks which went unreported by merchant shipping companies, who - in a bid to protect their reputation and other interests - would not divulge information of attacks to government agencies, insurance companies or international bodies responsible for collecting such data.
} 
In the opinion of one piracy expert, there are seven factors which are likely to spur acts of piracy if detectable. These are: legal and jurisdictional opportunities, favourable geography, conflict and disorder, under-funded law enforcement, a permissive political environment, cultural acceptability/maritime tradition and reward (Murphy 2008: 28). Since 1991, the conditions listed above have clearly ripened in Somalia, favouring the development of pirate activity. In sum, with impending civil instability perennially raging across the country for the best part of three decades, Somalia's status as a failed state has meant that it has neither the capability, legitimacy or will to curb the piracy phenomenon whether at the national, provincial or local level. ${ }^{117}$ The authorities needed to uphold law and order were absent and had often dissolved into clan-based militia, which provided an excellent environment for the spread of illegal activities and organised crime (Lehr \& Lehman 2007: 11). Consequently, pirates were free to pursue their endeavours since they benefited from Somalia serving as their sanctuary.

But their success was as much dependent on these permissive conditions as it was on the seeming success of the business model keeping it afloat. It soon became obvious that the pirates were in fact the street-soldiers for a sophisticated enterprise involving anonymous financiers, negotiators and bookkeepers, all playing their part within a neat hierarchical structure. Given that the first few investments had paid off handsomely the piracy business wanted more, which entailed the development of a larger and more sophisticated organisation (Murphy 2008: 5). Those supporting this structure had obviously drawn enthusiasm from the purple patch they began enjoying around 2007 and thereafter did not hesitate to up the stakes by pouring greater investments into their business model (material/human resources) in the hope of hijacking vessels from which larger ransoms could be extracted, even if this meant travelling further afield. Quickly, pirate attacks were even reported close (and sometimes within) the Exclusive Economic Zones of countries such as Iran, Mozambique or Pakistan (see Map 3) - but more importantly, they were seeing a greater ratio of successful attacks and thus successful returns (Jarle Hansen 2012: 528).

\footnotetext{
${ }^{117}$ This interpretation is not entirely accurate in the opinion of some specialists, given that during the ICU's brief reign over the country, the number of acts of piracy did subside as a result of the pressure the ICU applied to curb the phenomenon domestically (Chalk 2010: 94).
} 


\section{Map 3 - Geographical Expansion of Piracy (2005-2011) ${ }^{118}$}

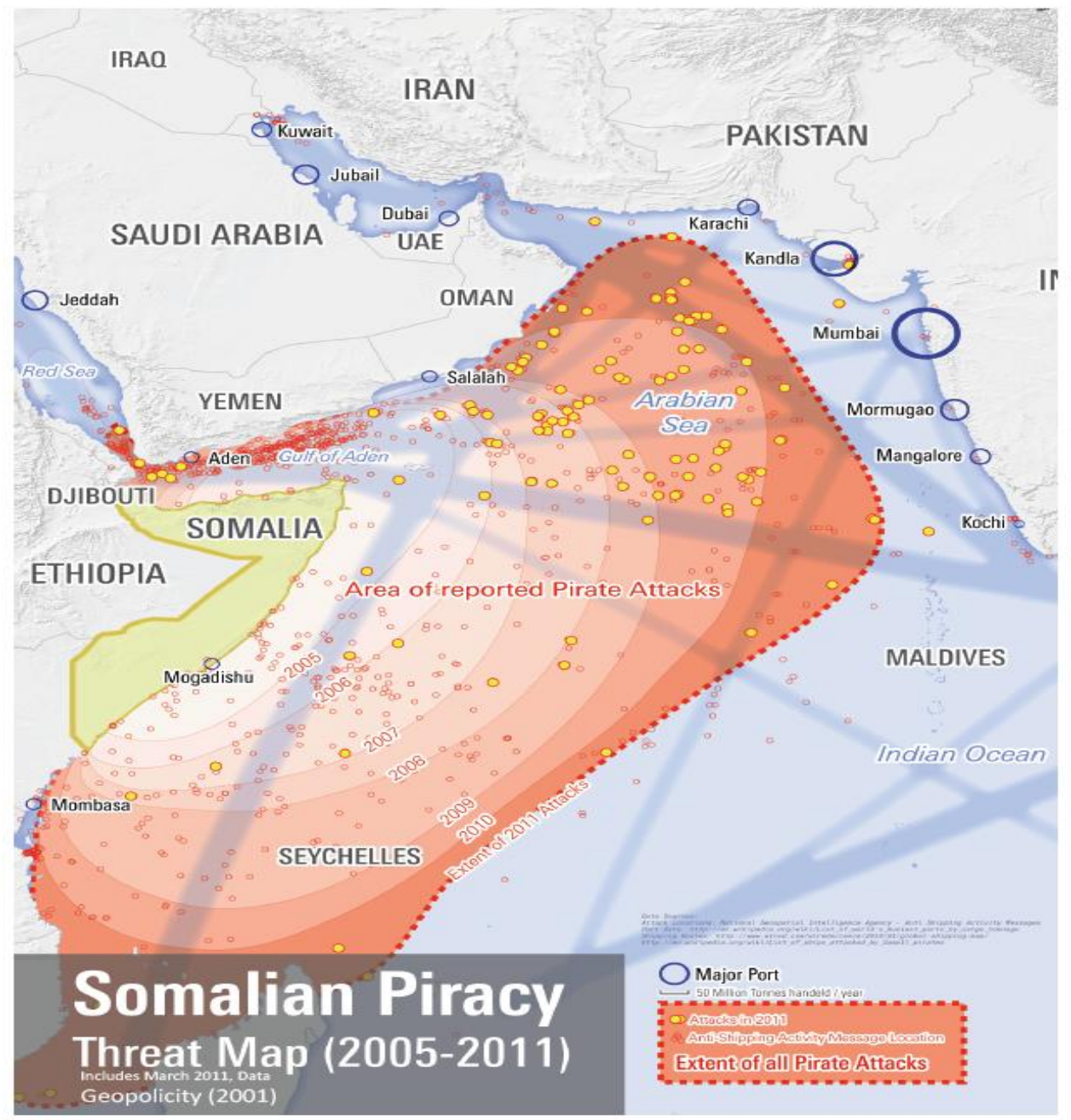

During the years before the surge of attacks around 2008, the international community's response had remained fairly muted despite the UNSC and International Maritime Organisation's (IMO) best attempts to raise awareness or to the Combined Maritime Forces (CMF-150) sporadic attempts at deterring attacks (IMO 2007a). ${ }^{119}{ }^{120}$ At the time, as

\footnotetext{
${ }^{118}$ Retrieved at: http://timemilitary.files.wordpress.com/2011/05/pirate-map.png.

${ }^{119}$ In 2005, the IMO Assembly adopted a resolution following a spate of attacks, first bringing the matter to the attention of the UNSC. In March 2006, the UNSC issued a 'Presidential Statement' encouraging members with naval vessels and military aircraft operating in international waters and airspace adjacent to the coast of Somalia to be vigilant for piracy incidents and to take appropriate action to protect merchant shipping, particularly those vessels transporting humanitarian aid (IMO 2007b). In May 2006, UNSCR 1676 referred to the: "[...] increasing incidents of piracy and armed robbery against ships in waters off the coast of Somalia." The number of attacks temporarily subsided as a result of the phenomenon having been brought to the attention of the international community, but not for long.

${ }^{120}$ According to one interviewee, CMF-150 began adopting a more aggressive posture towards pirates in and around 2005, even if this endeavour did not form part of its original mandate which focused on counter-terror activities (Murphy 2008: 104; Interview 22). At heart, CMF-150 had been deployed to patrol the North Arabian Sea Peninsula from the Pakistani coast to Somalia as part of Operation Enduring Freedom in Afghanistan because of fears that high-ranking members of al-Qaeda would try to escape via Pakistan and the Arabian
} 
one specialist put it, piratical acts in the region were considered nothing more than an "annoying activity" which was largely ignored: "[...] in the hope that, sooner or later, it would [sic] go away" (Snoddon 2007: 225). The explanation for this apparent disinterest in these repeated assaults - which later would cause the international community to be caught blindsided - is twofold. On the one hand, the insignificance attributed to these attacks was triggered by the fact that they were perceived as opportunistic strikes conducted close to shore on small boats, which gave: "[...] the false impression that such unbridled outbursts in Somalia's [sic] lonely coastal stretches only posed a minor threat to commercial shipping" (Marley 2011: 60). On the other hand, the international community judged these attacks insufficient to warrant its full attention simply because the WoT had channelled most of its maritime energies elsewhere, whilst the prospect of getting involved in security affairs connected to Somalia remained taboo (in light of the 1993 UNITAF experience referred to in chapter 2). ${ }^{121}$

The emphatic increase in attacks, coupled to a number of additional important variables, ensured that piracy would begin to hit the headlines beyond its sheer novelty value. First of all, the hike in attacks took place around the time that the (Western) world entered into recession as a result of the international financial crisis. Although piracy remained a mere secondary concern when compared to the downturn of the global economy, it risked causing further political embarrassment in the light of its potentially detrimental economic, political and human repercussions during what was already a difficult time. In effect, with Somalia's coastline situated almost at the epicentre of one of the busiest trade routes in the world caught between Africa, Asia, Europe and the Middle East - the risks for the international transportation of merchant, humanitarian and military goods soon became apparent. On average 20,000 commercial vessels transit through the area every year, carrying approximately $12 \%$ of total international commerce (Larik \& Weiler 2011: 85-6). Whereas, from a strategic viewpoint, this situation raised the alarm as about $30 \%$ of global crude oil deliveries pass through the region, amounting to roughly six million barrels a day (Germond \& Smith 2009: 580). As a case in point, the capture of the MV Sirius Star on 15 November 2008 caused considerable concern given that for one it happened to be carrying two million barrels of crude Saudi oil (or US\$ 100 million worth) destined for the US and secondly it

Peninsula to the HoA (Murphy 2008: 102). Beyond the Western contributors, Bahrain, Japan, Jordan, Kuwait, Malaysia, Pakistan, the Philippines, South Korea, Saudi Arabia, the Seychelles, Singapore, Thailand and the United Arab Emirates partook in the coalition.

${ }^{121}$ As one well-informed observer explains: "[...] in the post-Somalia international climate, there was no appetite in the international community for taking even the slightest risks with the lives of peacekeepers" (Annan \& Mousavizadeh 2013: 53-4). 
measured three times the size of an aircraft carrier, weighing in at 162,250 tons (Chalk 2010: 93; Marley 2011: 1).

Secondly, Western politicians were being hard-pressed by various shipping companies - often important sources of national revenue and sometimes political support - to provide a response and some form of protection. Shipping companies felt the full brunt of such acts of piracy on a multiplicity of levels. At the peak of piratical attacks off the HoA, the shipping industry (without accounting for the fishing industry) was losing anywhere between US\$100160 million a year, footing almost $80 \%$ of the total extra costs incurred by acts of Somali piracy (Rotberg 2010: 1; One Earth Future Foundation 2011: 15, 39). Indeed, they were obliged to pay off ever larger ransoms in a bid to protect crew, ship and hull, ${ }^{122}$ whilst financing and training stopgap crews to ensure deliveries (Interview 16). In preventative terms, they also faced rising costs. Primarily, the cost of insurance on all levels for crossing the GoA skyrocketed by $350 \%$ in 2009 as Lloyd's of London - the reference point for underwriters and insurers - declared a large part of the Indian Ocean a 'war zone' (Mildner \& Groß 2010: 27; Interview 15). Other preventative costs would also need factoring in, such as reinforcing measures of self-defence in case of an attack as recommended by the 'Best Management Practices. ${ }^{123}$ Placing armed guards onboard - which would later become the norm for certain commercial vessels - also featured as another preventative remedy, although a costly and risky one. Others, preferring not to consider the extra costs of preventative action sought possible alternatives such as a making detours round the Cape of Good Hope instead - an alternative that soon became unthinkable because of the exorbitant costs involved (Interview 15). In sum, with the total economic cost of Somali piracy being estimated anywhere between US\$ 7-12 billion per annum, the international community was faced with the need to confront a problem that had gained prominence in light of the world economy's sharp downturn (Hirono \& Neill 2012: 16).

Finally, when reports began to make the headlines about Western holidaymakers being caught in the crossfire of Somali pirate activities - with stories emerging in the news about successful hijackings and, in worse case scenarios, tragic recounts of lives lost - politicians could no longer ignore these happenings in the waters off the Somali coast. ${ }^{124}$

\footnotetext{
${ }^{122}$ In 2006, the average ransom for a hijacking at sea stood roughly at US\$ 150,000. Five years downstream and this figure had ballooned to US\$ 4.5-5 million (Murphy 2011: 9).

${ }^{123}$ For more information, visit: https://www.ssrs.org/noticeboard/document/bmp/BMP4.pdf .

${ }^{124}$ A number of Western countries witnessed at least one tragic incident involving the hijacking or sometimes the unfortunate killing of hostage-taken holidaymakers off the Horn of Africa. In the UK, the plight of the Chandlers dominated the headlines in 2010 (see Rice \& Percival) and that of the Tebbutts too in 2011 (see Bagenal et al.). In France, similar stories were recounted in the mainstream media with the hijacking of the
} 


\subsubsection{The International Community's Response}

As seen above, one of the first actors on the scene to combat the threat of Somali piracy was CMF-150, which had held a relatively long-standing presence in the region on counterterrorism duties (Ehrhart \& Pettreto 2012: 270). NATO was quick to follow suit in October 2008, as a temporary response to the UN Secretary General's request for naval assets to escort World Food Programme (WFP) shipments to Mogadishu (Muratore 2010: 92). ${ }^{125}{ }^{126}$ Out of the three 'coalitions' to partake in counter-piracy initiatives off the HoA, the EU was the third to dispatch a flotilla but only after much internal politicking.

In actuality, several EU member states were among the very first to both bring awareness to the problem and seek either a diplomatic or naval response. These member states were reacting primarily to protect their national self-interests, choosing eventually to do so under the aegis of the EU (inter alia), as tackling Somali piracy unilaterally was far beyond their reach and of that of their individual naval forces. Of course, as more than $90 \%$ of Europe's external freight trade is transported by sea and as coastal trade amounts to $40 \%$ of trade within the EU (an industry which employs around 3 million), Somali piracy could quite easily be cast as a problem requiring a collective solution (Rogers 2009: 22; Mildner \& Groß 2010: 20). The European Commission had already implicitly made the point about Europe's collective interest in keeping the seas safe abundantly clear in its 2007 maritime strategy paper, given that:

the seas are Europe's lifeblood [...] they are the EU's trade routes, climate regulator, sources of food, energy and resources, and a favoured site for its citizens' residence and recreation. Europe's well-being is inextricably linked with the sea, shipbuilding and shipping, ports and fisheries remain key maritime activities, but offshore energy (including oil, gas and renewable) and coastal and maritime tourism also generate massive revenues. Seaports and shipping allow Europe to benefit from the rapid

Delanne's yacht in September 2008, which needed rescuing by French special forces (see Le Point), and the kidnapping of the Lemaçon family's yacht in April 2009, which ended in the death of the father despite the intervention of special forces (see 24 Heures). The tragedy of these stories, however, has often masked the fate suffered by non-Western sailors often held captive in atrocious conditions by Somali pirates - a problem granted very little attention by the mainstream media but which at times has affected more than 1,000 sailors, mostly originating from India, Bangladesh, the Philippines and Western Africa (Kraska \& Wilson 2009: 227; Ndumbe Anyu \& Moki 2009: 108; Pettreto 2010: 12; One Earth Future Foundation 2011: 13).

125 After NATO's temporary escorts were scheduled to come to an end, a number of its member states expressed a desire to continue with a presence in the region for the Atlantic Alliance, which thereafter took the shape of Operation Ocean Shield. For more information, visit: http://www.mc.nato.int/ops/Pages/OOS.aspx.

${ }^{126}$ WFP shipments had indeed become a favoured target for the pirates, mostly because of the slow speed and low boarding of the vessels making the deliveries, despite the shipments being needed to help fight famine which had come to affect many of the pirates' fellow countrymen (Drossinos 2009: 6; Interview 14). 
growth of international trade and to play a leading role in the global economy (2007: 2-3).

Additionally, EU member states accounted for the world's largest merchant shipping industries with more than $40 \%$ of the world's fleet owned by European companies, principally of German and Greek origin (Mildner \& Groß 2010: 20; Riddervold 2011: 388).

Yet before a collective consciousness began to take shape, concerned member states were exploring their options. Spain and France were particularly active in this respect. Spain had eyes on instability in Somalia as a possible source of terrorist activity since the 2004 Madrid train bombings in accordance with the securitisation of European security policy in Africa, whilst its tuna fishing fleet - the most important in the Indian Ocean - was repeatedly coming under attack by Somali pirates (Phillips 2009; Interview 24). ${ }^{127}$ Once again, these attacks were not unheard of as Spanish tuna trawlers had endured a few similar experiences prior to 2007, although not on the same scale as attacks in 2008 and 2009. For example, in April 2008, the FV Playa de Bakio was hijacked and captured with Spanish crewmen onboard before being released in exchange for a reported US\$1.2 million ransom (Gros-Verheyde 2008; Fachada 2012). As a result, the Spanish government - under pressure from its fishing industry - was looking for a collective or multilateral response to the problem given that it did not feel capable or willing to act individually (Wikileaks 2008c). As a supporter of CSDP's development, the EU came across as the preferred option in this respect (Interview 16). Fortunately for Spain, the French government had also taken a keen interest in counter-piracy in the Indian Ocean and was also looking to collaborate with others in the framework of a possible EU mission.

The French government was at the time making moves to better protect its interests because of similar concerns. During the same month as the raid on the FV Playa de Bakio, the French luxury cruise yacht MY Le Ponant was also hijacked. Five months later, another luxury yacht the MY Carrée d'As $I V$ also needed freeing by French commandos under Sarkozy's watchful eye (Ndumbe Anyu \& Moki 2009: 118). France though, had been implicated almost from the very start of the piracy phenomenon. The Ministry of Foreign

\footnotetext{
${ }^{127}$ Illegal fishing was often cited as one of the triggering effects of the explosion of Somali pirate attacks off the HoA in 2008, along with the alleged dumping of nuclear waste by multinational corporations - permits for both of which according to some reports could be easily purchased from corrupt local officials (ENA 2009: 21; Valin 2009: 4). France's tuna fishing interests were comparable to Spain's. In fact, the French tuna fishing fleet constitutes the second largest European fleet operating in the Indian Ocean, with the industry recording a $€ 100$ million profit in 2008 from its activities in the region (ENA 2009: 36). With regards to nuclear waste, European companies naturally found it much cheaper to dump it in and around the Somali coast at the cost of US\$25 per ton, rather than recycle it in Europe in accordance with international regulations at a cost of US\$1,000 per ton (Marley 2011: 71).
} 
Affairs (MAE) had been actively promoting the need for a national response across different ministries and in discussions with Kouchner (Interview 27). In turn, this led to France responding to the IMO and the UNSC's earlier call for action regarding the escort of WFP shipments to Mogadishu by temporarily providing escorts. ${ }^{128}$ Opération Alcyon, coordinated from France's ALINDIEN naval base in Djibouti, offered limited escorts to the WFP in the light of the severity of the economic and humanitarian crisis unfolding in Somalia (GrosVerheyde 2012a; MAE 2013). Furthermore, in diplomatic terms - spurred on by the support it received domestically - the MAE worked hard to push through several UNSCRs from February to December 2008 to legitimise the fight against Somali pirates as an international concern. $^{129}$

Individually therefore, France and Spain were at the forefront of moves to open the international community's eyes to the implications of the problem at hand. Nevertheless, it was not until both actors recognised that their national interests would best be protected by acting in unison under the aegis of the EU that the institutional machinery in Brussels began to turn. Both governments also shared the view that the EU, above NATO or CMF, was better placed overall to deal with the causes and symptoms of Somali piracy and this resulted in the publication of a joint 'non-paper' following the June 2008 Zaragoza summit (ENA 2009: 63; Interview 19). The 'non-paper' sought above all to convince other member states of the need for an EU operation and followed on from UNSCR 1816, which relieved the EU of any concerns about constricted activism as it cleared the path for the EU to forego the principle of African ownership without any doubts being raised about the legitimacy of a possible CSDP mission. ${ }^{130}$ Most notably, the Resolution earmarked the need and openness of Somalia's Trans-Federal Government (TFG) towards international assistance before granting naval forces the right to: "enter the territorial waters of Somalia for the purpose of repressing acts of piracy and armed robbery at sea" (UNSC 2008a: 2). Not only did the Resolution in itself provide the international legitimacy needed with regard to the normalisation of the EU's activities within the realm of African security risk management in this particular instance, but with the Resolution explicitly calling for actors like the EU to do more, Brussels was under a moral obligation to put aside ethical doubts and act. The Spanish and French governments were able to use this to their advantage and managed to sway more reluctant member states by

\footnotetext{
${ }^{128}$ As outlined above, NATO eventually took over this function for a predetermined period of time. In between time, the Netherlands, Denmark and Canada had succeeded the French navy escort.

${ }^{129}$ These concerned UNSCRs 1801, 1814, 1816, 1838, 1846 and 1851.

${ }^{130}$ AU member states simply did not possess the capabilities necessary to provide a credible response and leadership on counter-piracy. At no point in the debate on the need for an international response was the AU mentioned as a possible intervening force.
} 
emphasising the humanitarian nature of any future CSDP mission since the Resolution "deplored" the adverse effect of pirate attacks on aid supplies to Somalia, calling for the international community to protect such shipments (Ibid). Benefiting from its turn as rotating President of the Council of the EU (from July to December 2008), this granted the French government considerable power of initiative and influence to get the EU counter-piracy operation up and running. One final hurdle needed overcoming before the collective response could be completed - accommodating the lack of British enthusiasm for the idea of an EU-led response.

The UK, in line with its traditional take on CSDP matters, opposed the proposal for an EU operation on the grounds that it violated territory which it believed only NATO or some other form of US-led coalition should occupy. Not only did the UK feel largely unaffected by happenings across the GoA but contrary to its French neighbours, it had yet to suffer any damage to its national interests. Therefore, the prospect of agreeing to an EU operation constituted an affront to its national interests in the sense that doing so could jeopardise its special transatlantic partnership (Germond \& Smith 2010). Indeed, the French government was threatening at the time to veto discussions at NATO on prolonging the latter's presence in the region if the EU operation was consequently forced to have to play second fiddle to NATO in terms of amassing capabilities (Wikileaks 2008a). Simultaneously, this stance had upset the American position, which not only doubted the EU's capacity to manage such an operation but wanted resources either pooled into NATO or into CMF (Ibid). Such wrangling created a conundrum for the UK, which neither wanted a diplomatic stalemate in view of the urgency of the piracy situation in the region nor wanted to have to pick sides in the event of an EU-NATO inter-institutional clash. Much was also at play for those member states in favour of an EU operation because not only did the UK have to give its consent but more importantly it possessed all the experience, knowledge and capabilities needed to make the mission into a success. Without the backing of the Royal Navy, the operation may never have taken place.

Eventually, under pressure from Sarkozy, the shipping industry and the Foreign and Commonwealth Office (FCO), Brown's government conditionally sanctioned the FrancoSpanish initiative (House of Commons 2012: 5; Interview 23). Britain made conditional its support on the need for France to remove its veto regarding a possible concurrent NATO mission and, symbolically, that it be granted the role of framework nation. Doing so implied that the UK would indirectly lead the operation (a fact that the French begrudgingly accepted), providing both the Operation Headquarters (OHQ) as well as a number of the leading 
members of staff (Operational Commander, Chief of Staff) (Wikileaks 2008c). ${ }^{131}$ The British government could then rest assured that should the mission go ahead as planned, they would be best placed to influence its development with Royal Navy officers running the show at the helm (even if they would be officially working for the EU).

Following this protracted saga, the EU was finally able to agree on its NAVFOR Atalanta operation by October 2008, which began proceedings at sea the following December. The two-star British Rear Admiral serving as Operational Commander would eventually lead a team of around 60 and a Commodore at the Military Component Command, with personnel supporting the UK Marine Trade Operations (UKMTO) (Seibert 2008; Wikileaks 2008c; Germond \& Smith 2010; Willet 2011: 21). EU NAVFOR was attributed an initial year-long mandate with its main objectives listed as the protection of WFP deliveries, the protection of vulnerable vessels off the Somali coast and deterring acts of piracy (EU Council 2008a: 3). In practical terms, the Operational Commander was handed a budget of $€ 8.4$ million covering common costs as well as a total annual contribution of $€ 400-450$ million, while on average 510 surface combat vessels, 1 auxiliary ship and up to 4 maritime patrol aircrafts would form part of the operation's capabilities (Helly 2009: 391-2; Ehrhart \& Pettreto 2012: 273; Interview 26). Finally, NAVFOR's chain of command was specifically designed to be as economical as possible in terms of its hierarchy, thus placing a premium on flexibility and efficiency. Atop, the Council Presidency and the EU's PSC would sit and survey developments, intervening only when it felt the Command in Northwood had overstepped the mandate. ${ }^{132}$ The main port of call for Northwood, however, was Solana who served as the intermediary through which messages and policy proposals were transmitted between Operational Command and the PSC (Interview 22). Under Solana, the Operational Commander had considerable power of oversight and influence over NAVFOR's quotidian management and longer-term planning to direct operations as he and his team saw fit.

As seen from Table 7 below, aside from the Western-dominated 'coalitions,' a number of so-called 'independent deployers' had/would dispatch naval forces to the region, especially after the first UNSCRs on counter-piracy had been passed. China, India, Iran, Japan, Malaysia and Russia - amongst others - had sent their military vessels to the region between October 2008 and May 2009 on slightly divergent mandates but all with virtually the same objective of

\footnotetext{
${ }^{131}$ The OHQ is located in Northwood (Greater London) - an experienced British naval command base - which also acts as the OHQ for NATO's counter-piracy operation.

${ }^{132}$ The PSC consists of the 28 member state ambassadors to the EU and serves as the penultimate echelon within the EU's foreign policy decision-making process, prior to reaching the Council, where such agreements must be mandated for any such decision to be given the go-ahead.
} 
protecting national interests. Impressively, the Indian Ocean soon became the venue for the largest influx of out-of-region naval forces in the world since World War II. By sending two destroyers and one supply ship from the People's Liberation Army Navy (PLAN), the PRC launched its own counter-piracy mission on the 6 January 2009, marking a significant moment in its national history. In effect, this move came to represent the first time since the $16^{\text {th }}$ century and Zheng He's legendary expedition under the rule of the Ming Dynasty that China had dispatched such a flotilla to this part of the world.

Table 7 - Dispatch Dates of Key Counter-Piracy Operations ${ }^{133}$

\begin{tabular}{|c|c|}
\hline Navy & Known Dispatch Date to GoA \\
\hline
\end{tabular}

\begin{tabular}{|l|l|}
\hline China & January 2009 \\
\hline CMF 151 & January 2009 \\
\hline EU NAVFOR & December 2008 \\
\hline India & October 2008 \\
\hline Indonesia & March 2009 \\
\hline Iran & May 2009 \\
\hline Japan & March 2009 \\
\hline Malaysia & September 2008 \\
\hline NATO & March 2009 \\
\hline Russia & October 2008 \\
\hline Singapore & April 2009 \\
\hline South Korea & March 2009 \\
\hline Thailand & October 2010 \\
\hline Turkey & February 2009 \\
\hline Sources: seob
\end{tabular}

Sources: see footnote ${ }^{137}$ (author's creation).

\footnotetext{
${ }^{133}$ This table does not include other notable naval contributors to the international counter-piracy effort, such as Pakistan, Saudi Arabia and the Ukraine.

${ }^{134}$ CMF-151 actually followed on from CMF-150 (referred to earlier in this chapter), which had been set up in May 2002 (see footnote 115 above for more details).

135 As indicated earlier in this chapter, although the date indicated gives the impression that NATO only started fighting piracy in the area from this date onwards, it gives an erroneous impression as many NATO member states' naval forces had been fighting piracy in the region - either individually or as part of CMF-150 - long before NATO's Operation Allied Enforcer was launched in March 2009 or before the follow-up mission Operation Ocean Shield was convened in August 2009.

${ }^{136}$ Contributed under the ambit of NATO's Operation Ocean Shield.

${ }^{137} \mathrm{http}: / /$ news.xinhuanet.com/english/2009-04/13/content_11180769.htm;

http://combinedmaritimeforces.com/ctf-151-couter-piracy/;

http://combinedmaritimeforces.com/ctf-150-maritime-security/;

http://eeas.europa.eu/piracy/containing_piracy_fr.htm;

http://thediplomat.com/2011/04/india-takes-fight-to-pirates/;

http://www.hiiraan.com/news2/2009/mar/Indonesia_sends_warship_to_help_secure_somali_waters.aspx; http://in.reuters.com/article/2009/05/25/idINIndia-39868320090525;

http://www.nytimes.com/2009/03/14/world/asia/14pirates.html;

http://www.chathamhouse.org/sites/files/chathamhouse/public/Research/Africa/1008piracysomalia.pdf;

http://www.mc.nato.int/page13974522.aspx;

http://www.mc.nato.int/ops/Pages/OOS.aspx;

http://www.gwu.edu/ ieresgwu/assets/docs/pepm_057.pdf;
} 
Beijing's decision to implicate the PLAN arose from repeated attacks on Chinese commercial or fishing vessels or on vessels comprised of Chinese crewmembers. Strategically, Beijing also justified its motives for deployment on the basis that neither Taiwan, Hong Kong nor Macau could realistically fend for commercial vessels flying their respective flags. Indeed, throughout 2008, up to $20 \%$ of all commercial vessels being targeted by Somali pirates were Chinese, registered in China or carried Chinese mariners (Saferworld 2011: 66). For example, the Hong Kong-flagged Great Creation was held in September 2008; the FV Tianyu $N^{\circ} 8$ was captured by pirates on the 17 November 2008; in December 2008, the Zhou Hua 4 was also attacked (Pham 2009). Beyond these elementary concerns and the likelihood of further embarrassment, a significant part of the PRC's livelihood was also coming under threat. As outlined earlier, up to $80 \%$ of its trade with the EU passes through the region - a statistic which overlooks China's budding trade with Africa and the Middle East (Larik \& Weiler 2011: 86). Of equal importance in the maintenance of its thriving economy, China relies increasingly heavily on oil imports transiting the area whether originating from western Africa, north-eastern Africa, the Middle East or the Gulf (MIT 2009: 5).

Indeed, out of all the African oil shipments destined for China approximately a quarter are readied at the Marsa al-Bashair terminal near Port Sudan (see Map 1). It is then transported down the Red Sea through Bab-el-Mandeb and the GoA (Pham 2009). Interestingly, Chinese oil companies have progressively targeted Somalia as a possible site for petroleum extraction, theoretically placing an even greater premium on stability off the HoA. The Chinese National Offshore Oil Company struck such a deal with the TFG with the objective of exploiting oil reserves in 2007, repeating earlier attempts made back in the 1990s (Ibid; Lanteigne 2013: 5). Similarly to its European counterparts, the maritime industry contributes a sizeable part to the PRC's economy. Not only do they own the world's second largest merchant marine but these industries accounted in 2006 for US\$ 270 billion in economic output, representing close to $10 \%$ of Gross Domestic Product - while its shipbuilding industry is the largest worldwide in terms of dead weight tonnage (Cole 2008: 344; Shambaugh 2013: 289-90). Finally, China's fishing companies have made substantial

http://www.navy.mil/submit/display.asp?story_id=44606; http://belfercenter.hks.harvard.edu/files/globalkorea_report_roehrig.pdf; http://www.turkishnews.com/en/content/2009/02/06/turkey-to-send-warships-to-gulf-of-aden/; Source for Thailand in online article by Royal Thai Navy Captain Wachiraporn Wongnakornsawang: "The Royal Thai Navy's Policy on Anti-Piracy as a Part of Naval Diplomacy." 
investments to carve out a place for themselves in the Indian Ocean in order to ease growing demands back home (Kaufman 2009: 8).

On the grounds of the defensive protection of interests Beijing could thus easily justify its participation in accordance with its traditionalist mindset, as pirates were taking aim at Chinese property - property that played a part in maintaining the robustness of the country's economic growth and thus the preservation of the CCP's leadership. Offensively though, China's interest in dispatching its own convoy was founded on more complex motives. As a matter of fact, doing so figured as a unique opportunity to provide a real-time training exercise for the PLAN's untested and untried capabilities and personnel (Pham 2009; Erickson \& Strange 2012: 95). This would also bring to life Hu's 2004 aspiration to see the PLAN participate in "historic missions" (cited in Christoffersen 2009). For others, the decision to deploy constituted the expression of the PRC's desire to lay down a marker as a future regional hegemon. In this instance, participation in a prolonged out-of-area expedition would act as a clear warning to neighbouring naval powers of the PLAN's proven ability to hold its own (Kaufman 2009: 9-11). Some scholars have gone a step further in interpreting Beijing's decision to support deployment as its first step in seeking greater control over the Indian Ocean - which in the words of naval historian Alfred Mahan would eventually lead to the domination of the Asian subcontinent (ENA 2009: 21; Murphy 2012: 79).

With such debates remaining more conjecture than actual fact, China green-lighted the decision to participate in counter-piracy activities with the mandate to protect Chinese citizens and national commercial interests, following a carefully planned campaign to test the waters regarding its possible participation both domestically and internationally. To start with, the PLA published an online article justifying the need for its navy to participate in counterpiracy activities off the HoA, since the scope of its activities had been broadened beyond its traditional objective of defending the Chinese coastline and concomitant territorial waters to encompass other parts of the globe where the PRC's presence could no longer be overlooked (Roell 2011: 1). This was followed by a media campaign to gauge the receptiveness of other members of the international community towards the idea of Chinese participation (Ibid). In reality, Beijing had no reason to be overly cautious. Like the EU's hierarchy of preferences, a number of important criteria had already been met which encouraged the Chinese leadership to consider deploying vessels to the region, such as getting the approval of the 'host state.' Moreover, in December 2008, UNSCR 1846 had explicitly: "called upon states and regional organisations that have the capacity to do so, to take part actively in the fight against piracy and armed robbery at sea off the coast of Somalia" (UNSC 2008b: 3). Clearly, the language in 
the Resolution helped push aside any last-minute hesitations and instead galvanised the leadership to amend for the time lost, as the PRC was the last permanent member of the UNSC to send warships to the HoA. China, however, compensated for this by sending a large cohort of brand-new destroyers, supply ships and seafarers: it dispatched its 2004 Guangzhouclass Type 052B destroyer Wuhan, the 2003 Lanzhou-class Type 052B Haikou and the Qiandahou-class supply ship Weishanhu as well as 800 seafarers on the first rotation, including 70 Special Forces personnel trained to board vessels and fight pirates (MIT 2009: 19; Pham 2009; Weitz 2009: 33; Larik \& Weiler 2011: 82). This impressive commitment to the international counter-piracy cause certainly caught the eye - and even more so since the PLAN was able to assist 1,300 merchant ships with their journeys across the GoA in the space of one year, despite its gaping inexperience (Larik \& Weiler 2011: 92).

\subsubsection{The PLAN: A Potential Outgroup Member?}

By January 2009, the various naval forces found themselves in a close perimeter ready to deter acts of piracy, although on differing mandates and with widely varying tactical approaches, which subsequently made an already tricky task that much more complex. The TFG, UNSC or IMO may well have legitimised these respective interventions at the behest of the international community, but in no shape or form did this represent a united international response to the piracy phenomenon, as attested by the lack of coordinated command and control centres or tactical clearing houses. In short, what may have appeared as an act of solidarity against the Somali pirates actually had the potential to become an international recipe for disaster, with uncoordinated naval forces playing "kid's soccer" whilst the pirates would simply watch, learn and exploit any tactical shortcomings (Interview 25).

As one of the first actors on the scene, with what one participant described as something of a tactical carte blanche, the NAVFOR OHQ in Northwood soon came to the realisation that solely protecting European goods was a tactical error. In their view a far more inclusive approach was needed. Fortunately, they soon found themselves on the same tactical wavelength as CMF and NATO, which mattered since it provided the basis for these natural allies to form an influential triumvirate in the context of the ongoing international counterpiracy effort. This implicit alliance was largely facilitated by the numerous personal contacts which existed between the different officers posted across the coalitions. Some had been classmates at naval college or formed part of the same division. Others had worked together as part of the same missions despite not being of the same nationality, while some had prior experience working in either NATO or CMF and happened to be part of the NAVFOR staff 
for this specific operation (Interview 22; Interview 25; Interview 26). Thus, despite not all being Royal Navy staff officers, they shared collective norms for the creation of a common identity and understood without any difficulty their respective working cultures and respective tactical logic (Interview 25; Interview 26). Indeed, as one interviewee admitted, these personal connections were highly conducive to establishing "good working relationships" between the coalitions (Interview 25). ${ }^{138}$ Even in spite of the frosty nature of NATO-EU interinstitutional relations, these naval decision-makers were able to put aside any political rivalries (Interview 22). NAVFOR staff knew instead that they could almost unreservedly count on their counterparts within CMF and NATO, principally because they positively identified with the latter as members of their fellow ingroup.

As a consequence of their training and professional culture, leading OHQ staff could draw from the Royal Navy's institutional memory in deciding how best to plan counter-piracy, sifting among the meaningful and meaningless tactical approaches (Barnett 2009: 20). This cultural programme allowed them to justify their preference for a tactically inclusive approach on the basis that the piracy threat largely targeted globalised commercial shipping within a stretch of water for the most part falling within the legal ambit of the High Seas. According to Geoffrey Till, this behaviour is emblematic of the post-modern navies who, in this type of situation, are more likely to focus on: "[...] the maintenance of international rather than national security. They will embrace inclusive rather than exclusive attitudes towards sea control" (2013: 40). This transpired in practice into the desire to devise a system which would most efficiently protect the highest number of commercial vessels for the greater good of keeping the Sea Lanes of Communications open. As a case in point, to demonstrate the extent to which the concept of an integrative approach formed part of these mariners' belief systems, leading members of the OHQ's first priority dealt with convincing the member states to backtrack on the desire of solely protecting "European goods" (Interview 26). Following several early meetings in Brussels, the member states eventually backed down.

\footnotetext{
${ }^{138}$ For the Western naval forces that would eventually participate in counter-piracy, this mission could not have come at a more crucial timing in the light of the brooding financial crisis. As many of the constitutive navies had progressively been witnessing incremental cuts to their budgets in the years leading up to the financial crisis, the turn of events in terms of the world economy in 2008 and 2009 would only beckon more bad news. Adopting severe austerity measures, many Western governments would turn to their armed forces as one medium through which to scale back on expenses which they could no longer afford. As the navies had been the most discreet members of the WoT, fears arose within naval circles that they could end up bearing the brunt of the austerity measures. In a sense, the surge in Somali pirate attacks came as a blessing in disguise, allowing naval forces to display their value-added at the forefront of this operation. Bringing home timely and cost-efficient results thus became even more incentivised. As one interlocutor summarised, many of the naval officers going into the GoA or working on counter-piracy were: “desperate to deliver, desperate to sort something out" (Interview 25).
} 


\section{Map 4 - The Internationally Recommended Transit Corridor (IRTC) ${ }^{139}$}

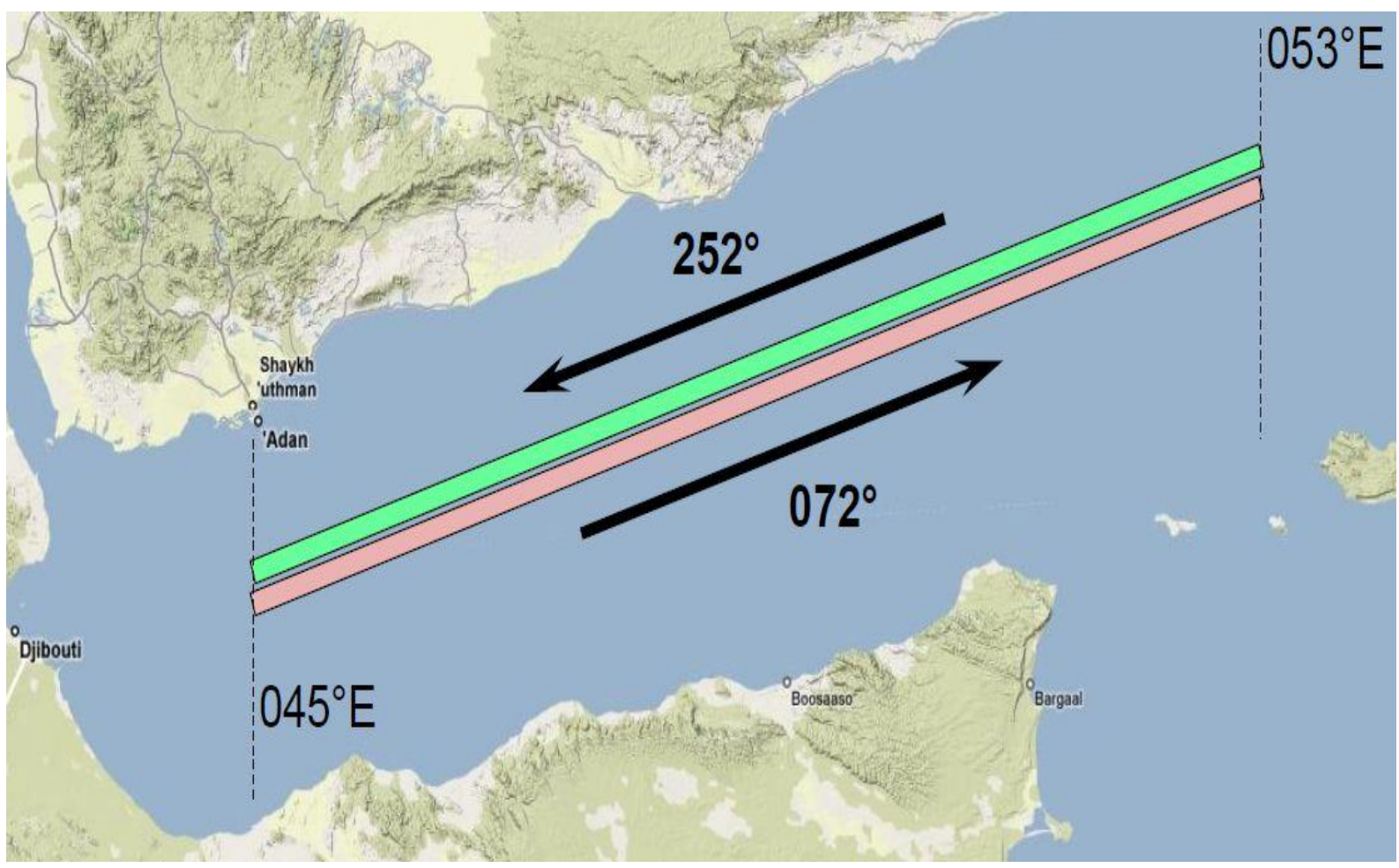

This integrative norm would result in the creation of the Group Transit System. In short, running along a 480 mile-long stretch of water situated within the GoA - coined the International Recommended Transit Corridor (IRTC) (see Map 4) - this system intended to preposition naval forces along the corridor, allowing them to intervene when necessary within their allocated geographic perimeter (Larik \& Weiler 2011: 95; Ehrhart \& Pettreto 2012: 271). ${ }^{140}$ Contrary to convoying, these vessels would not travel with the merchant ships, which instead would be regrouped at one end of the tunnel at a given time and instructed to cross in relative unison before reaching the other side. Prepositioned naval forces would intervene only in case of an attack. Commercial vessels would not, however, be accounted for on the basis of nationality. Instead, the Group Transit System would remain open to all on condition that those seeking protection input key data (regarding speed, size, destination) into a database operated by the OHQ (called the Maritime Security Centre for the Horn of Africa or MSCHoA). ${ }^{141}$ Staff at Northwood would thereafter evaluate the data and liaise with the

\footnotetext{
${ }^{139}$ Retrieved at: http://www.shipping.nato.int/SiteCollectionImages/GroupTransit01.JPG.

${ }^{140}$ Promulgated on the 1 February 2009, the IRTC parallels the Yemeni coastline, lying roughly $12^{\circ}$ North, $58^{\circ}$ East and $10^{\circ}$ South, extending between the US base in Djibouti and the US naval forces in the Arabian Sea (Murphy 2008: 102).

${ }^{141}$ Using vessel speed and positional data provided by shipowners to organise groups upon entry into the IRTC, MSCHoA can coordinate each vessel's starting point, with slower ships stationed up front and faster vessels well
} 
merchant vessels in order to prepare the cohorts. These were the early ideas emanating from the OHQ in terms of organising counter-piracy and in proposing such plans provided an insight both into how they understood the piracy problem and how they pictured themselves and their role within this context. Inclusiveness towards other naval forces would soon come to constitute one of the key facets guiding their identity formation, thus defining many of their interests along the way.

As aforementioned, NAVFOR officers were eased in their travails by the likeminded vision characterising the CMF and NATO camps. CMF had laid the foundation to the IRTC in the shape of its Maritime Security Patrol Area (ICS 2009: 2; Ehrhart \& Pettreto 2012: 271). All shared similar views on the importance of inclusiveness as the dominant guiding norm in the organisation of the counter-piracy effort. Institutionally they soon set this precept in stone through the inauguration of the Shared Awareness and Deconfliction (SHADE) mechanism, which originally emerged as a result of three-way talks between Captains representing the coalitions as a framework through which to coordinate their respective activities at sea. The SHADE helped fill the void of coordination needed to put in place the workings behind the IRTC and Group Transit System. However, it soon became obvious that these ideas would be short-changed if other naval forces were neither implicated nor coordinated their activities in some shape or form with the coalitions. Getting them to do so though would prove easier said than done.

Even within this particular context, getting agreement between the different naval decision-makers necessarily required diplomatic nous. Indeed, if NAVFOR had no difficulty considering CMF and NATO as part of its ingroup the same patterns of positive identification were not necessarily replicated by the independent deployers, either with the coalitions or amongst themselves. In particular, certain actors such as the Russian and Chinese navies remained wary of the coalitions' recommendations for coordinating counter-piracy activities which they foresaw as a possible "American ploy" (Larik \& Weiler 2011: 95). In this instance, these naval forces would fall into Till's categorisation of the "modern" navy, as opposed to the "post-modern" navy, where the focus would tend less towards integrative approaches and more towards state interests: "they will concentrate on the defence of their own shipping rather than shipping in general, irrespective of flag, and may in practice be wary about participation in collective action" (2013: 34). This situation, however, needs interpreting with

behind, so that by dawn - the time of day most susceptible to pirate attacks - the faster vessels have caught up to those at the front (Muratore 2010: 99). Consequently, this makes the protection of merchant shipping much easier for naval forces, whilst commercial vessels are kept informed about the whereabouts of the nearest naval vessel, in case of an attack, thanks to MSCHoA and the UKMTO (Ibid). 
greater nuance. Perhaps China, Russia, India and other independent deployers pictured integrative initiatives as cloaked imperialism but this did not imply that they simply negatively identified with the coalitions. A more realistic description of events would contend that the independent deployers, for the most part, perceived the other naval forces present in the region not so much with enmity but as deploying to the region to protect their national interests. However, when it came down to the need to make compromises on self-interests for the greater good of collectively organising the naval means available to fight piracy, the paradigm of negative identification appeared to gain prominence between the coalitions and certain independent deployers. Both sides found themselves putting forward different and sometimes competing tactical designs despite being faced with the pressing need to improve coordination, which had apparently rendered obsolete any initial international goodwill on counter-piracy (Interview 26). Inclusiveness began to pay the price for the process of negative identification.

Entering into this bracket, the PLAN - closely scrutinised in its every move by Beijing - held contrasting views to NAVFOR's tactical design. This contrast could not be described as diametric opposition or confrontational in its stance but China could well have figured on NAVFOR's negative identity radar by this stage because not having the PLAN's consent amounted to the need to overcome yet another obstacle in the realisation of the former's preferred plan of action for counter-piracy. China had initially shown reluctance towards the counter-piracy approach promoted by NAVFOR and the coalitions, as best reflected by Ambassador Liu Zhimin's fairly pessimistic statement that: "an effective fight against Somali piracy still [sic] awaits an integrated solution" (CCTV 2009). ${ }^{142}$ Indeed, this statement clearly highlighted the tactical chasm that had opened up between the two sides, with the PLAN favouring its more 'traditionalist' vision to structure the counter-piracy effort. The PLAN's tactical design revolved less around the norm of integration but related more to one of the constitutive norms of its own belief system: sovereign protection. This feature would remain constant throughout the timeline of the PLAN's contribution to counter-piracy and when talks commenced on the need for better coordination, Beijing was not willing to compromise on this constitutive part of its foreign policy identity. Its lack of trust in foreign - and particularly Western - naval forces would come to dictate its early stance on counter-piracy in this respect.

China's general reticence was best encapsulated through its alternative counter-piracy proposal. In its 2009 concept paper (MOFA 2009), entitled the 'Proposed Implementation

\footnotetext{
${ }^{142}$ Emphasis added.
} 
Plan on Area of Responsibility Escort Cooperation in the Gulf of Aden and Waters off Somalia,' the PLAN outlined its vision for the organisation of counter-piracy along the following criteria:

- the command and control of each individual state or organisation shall remain intact;

- the GoA shall be divided into 54 Area of Responsibility (AORs) and each AOR allocated to warships of regional organisations and individual states, according to available force flow (as discussed and divided by all participating states) ${ }^{143}$

- escort requests shall be submitted to the IMO or other designated coordination organisations beforehand;

- within its AOR, warships are free to choose any escort method such as accompanying, patrolling or standing-by;

- the escorting warship shall inform its next AOR duty warship twenty minutes before the first vessels of the escorted group leave its AOR;

- when pirates attack, warships within the AOR are free to react as they see fit;

- all participating countries enjoy independent command and control in AOR escort cooperation. ${ }^{144}$

In synthesis, this concept paper presented a number of similarities to NAVFOR's visualisation but also several stark nuances which could lead to possible conflicts of interest if left unresolved. Like NAVFOR staff, PLAN officers foresaw the establishment of a corridor comparable in size to the IRTC, split up among different naval forces. In itself, this suggestion was relatively pioneering for China given that it had restricted itself to convoying mostly Chinese-, Hong Kongese- or Taiwanese-registered vessels. ${ }^{145}$ Yet the allocation of naval perimeters would be divided up into 'sovereign' boxes for which the naval forces would be constrained by the boxes' delineated boundaries, thus confirming the PLAN's preference for its traditionalist approach and preference for limited/controlled forms of cooperation instead of adopting a more integrative approach (Weitz 2009). As confirmed by Major

\footnotetext{
${ }^{143}$ Emphasis added.

${ }^{144}$ Emphasis added.

${ }^{145}$ To be precise, the PLAN's plan conceived a 540 nautical mile-long safety corridor, with adjacent north and south lanes in the GoA. These northern and southern lanes would measure two nautical miles in width and would be separated by a 0.5 nautical mile buffer zone from the corridor. The corridor itself would be divided into the 54 AORs or 'boxes,' each of ten nautical miles in length, 4.5 nautical miles in width and with a six nautical mile "build-up area" on each side of the corridor (MOFA 2009). Indeed, initially, the PLAN reneged on the IRTC, instead convoying vessels approximately five nautical miles north and south of the corridor's delimitation (Moore 2012).
} 
General Qian Lihua - the then Director of the National Defence's Foreign Affairs Office - the PLAN was practically-speaking in favour of approach whereby merchant shipping would sail across the boxes, supervised or partly convoyed by the allocated warships, until the naval force in question had performed its supervision from one side of the box to the other, before passing the buck to the following naval force in the adjacent box (SCMP 2009). Transgressing boxes would be forbidden among warships due to the risk of jeopardising already fragile levels of trust, with each box remaining sovereign in its own right. In other words, what goes on in one box would remain the exclusive business of the naval force occupying it, simultaneously preserving the interests of its maritime occupier from potentially prying onlookers. The PLAN was so adamant about wanting to shape the counter-piracy effort in this direction that it held a meeting in Beijing - from the $6^{\text {th }}-7^{\text {th }}$ November 2009 - where it invited other navies, including EU NAVFOR, to discuss this proposal (SCMP 2009d).

Other nuances would create more of a headache for the OHQ. Firstly, as outlined in the description of the criteria above, the PLAN's plan of action emphasised above all the predominance of state actors, relegating the coalitions and especially the regional organisations to a bit-part role. For officials in Beijing, this approach pertained to a degree of self-evidence as: "the national division of responsibility would, according to the Chinese navy, increase escort operations and reduce the risk of hijacking" (Ibid). For OHQ staff, such reasoning not only proved antithetical to their integrative cultural programme but confirmed the growing hypothesis that the PLAN was becoming a "difficult partner" (Interview 26). Secondly, the PLAN's concept paper questioned the authority behind the ad hoc establishment of a mechanism designed to enhance collaboration, preferring instead to solicit the UN or IMO as coordinating platforms for counter-piracy. If Beijing was not comfortable with the SHADE, it was because it could not tolerate the idea of ceding sovereign control of a subsequent part of its operation to this Western (read American) conception (Weitz 2009: 37; Erickson \& Strange 2012: 99). Beijing had earmarked from the very start the absolute necessity for PLAN Commanding Officers to be in full control of China's participation at every moment. For this reason, the PLAN's concept paper supported the idea of utilising the $\mathrm{UN}$ or IMO as cooperative fora given that Beijing's veto would crucially protect its sovereign interests (MIT 2009: 11).

As this dichotomisation of the foundational norms of sovereignty versus inclusiveness incrementally sharpened, NAVFOR staff (as well as staff from the other coalitions) began portraying the PLAN's tactics in derogative terms. Some scoffed at the "land footprint" approach adopted to a maritime equation, comforting their sense of superiority drawn from 
centuries of experience in comparison to the PLAN's obvious situational rustiness (Interview 22). One naval officer, disregarding the similarities of tactical approaches between NAVFOR and the PLAN's plans of action for counter-piracy, qualified the Chinese approach as a disaster waiting to happen:

It would have been incredibly difficult and there would have been no coordination, so you would not have known where anyone was. There would have been no trust and even if you had managed to build some trust [...] it would not have been very effective, because if you put in fixed lines then the pirates will see that you are staying put in that box, whilst gaps are appearing because no one is covering that bit in the middle. This is the way of the wall: no one goes near the line, as you always sit in the middle and given that the boxes are quite big, this would not work (Interview 13).

A clear tactical schism had opened up between the two sides, reflective of the disparities between the coalitions and certain independent deployers to the benefit of the pirates who exploited the international community's lethargy in getting itself organised. Clearly, at that time, trust was lacking between the two sides.

\subsection{The PLAN's Tactical Sea Change}

In comparison to the inception of the PLAN's deployment, autumn 2009 began to mark a change of course in its tactical planning. From working in relative isolation and refusing to overly commit itself, the PLAN underwent somewhat of a u-turn in this context by suddenly wanting to play a leadership role within the SHADE as a co-chair - a position it genuinely sought for itself and actively lobbied for (BBC News 2010a). Although this change is far from earth-shattering and did not in any substantial way alter the trend of piracy attacks in its immediacy, the symbolism of China's "unprecedented" formal request for the cochairmanship of the CMF-inspired SHADE mechanism - when set against the traditional trends of Chinese foreign policy - should not be overlooked (SCMP 2009b). Indeed as one Chinese external relations expert attests: "in the area of global security, China's preferences can be summarised as 'following the majority': she does not take the initiative and never takes an international leadership role" (Song 2013: 478). This shift should be considered even more unprecedented given that: a) the Chinese military has - in the words of Major Ma Dingshing always been a "closed system," in which coordination and cooperation with other navies is not always favoured due to the risks of internal organisational secrets being revealed; $b$ ) when considering that almost a year earlier, voices from within the PLAN were dismissing the possibility of leading the SHADE due to China pertaining to its own codes of practice at sea 
thus making it making it "hard for China to restructure the existing naval presence and leading the coordination" (SCMP 2008, China Daily 2009b). ${ }^{146}$ In sum, this role reversal from being on the periphery to the heart of the counter-piracy effort demonstrates that the PLAN went, in a short space of time, from showing reluctance to the initiatives sponsored by NAVFOR and the coalitions to trusting that these initiatives could in fact be beneficial for China.

This was not the case, as seen in the previous chapter, during the conflict in Darfur when Beijing had refused to play the leadership role some in the West had hoped it would assume, while China only begrudgingly agreed to adopt a more proactive stance when put under pressure by Western civil society groups to do more. On counter-piracy, the evolution in its stance differed considerably in that not only was Beijing happy for the PLAN to figure among the lead actors but this decision seemed to have been taken out of its own volition. The "voluntary" nature was confirmed both by China's Deputy Permanent Representative to the UN, Wang Min (Xinhua News Agency 2012b) and via the following statement that was published at the time in one of the major English-language Chinese newspapers:

China has formally requested to take a lead role in coordinating international operations off Somalia - an unprecedented move that would be an expansion of its historic deployment of warships to the Indian Ocean. Beijing officials lodged the request during a closed-door meeting [sic] involving representatives of the key navies involved in protecting vital sea lanes between Asia and Europe (SCMP 2009b).

For those scholars that have taken an interest in this sudden and uncharacteristic transition, the explanations that have usually been attributed to this shift relate either to the PLAN's need to better protect Chinese interests or to the influence of exogenous material resources. In fact, the successful hijacking on 19 October 2009 of the MV De Xin Hai is generally referred to as the tipping point when the PLAN decided to break with its isolationist stance - which meant that China's shift in its tactical approach to counter-piracy came a little less than a year into its operation in the HoA. Carrying 76,000 metric tons of coal from South Africa to India, the MV De Xin Hai was attacked northeast of the Seychelles and held captive for two months before being released for a reported US\$ 4 million ransom (Al Jazeera 2009). This situation proved rather embarrassing for Chinese officials despite the PLAN's near perfect record in escorting Chinese vessels and mariners since the launch of its operation. Although the PLAN was no different to other naval forces in being unable to prevent all attacks against its citizens or commercial goods at any one time, the embarrassment and

\footnotetext{
${ }^{146}$ For example, one blog made the point that the PLAN did not - at the time - dispose of the communication gear needed to deal with a 40-nation strong maritime force (China Defense Blog 2010).
} 
frustration that emerged from this latest successful attack stemmed from the view within the Chinese camp that the attack could have been prevented if it had coordinated more closely with other naval forces - especially with the coalitions (Moore 2012). In a sense, this hijacking served as the tipping point which pushed the naval officers in charge to convince Beijing of the need for a rapprochement with the coalitions and other independent deployers, as a means of better protecting national self-interests. Not doing so would only lead to more such cases, simply because its two destroyers could not single-handedly patrol the entirety of the Indian Ocean. Whereas if Beijing wanted the PLAN to be better prepared in providing protection for Chinese interests transiting the area, then sharing the burden with others might be only a small price to pay. For Erik Lin-Greenberg, it was the MV De Xin Hai which triggered this adaptation from an exclusively inward-looking "escort mission" to a more integrative "presence mission" (2010: 214).

Another valid interpretation of this tactical shift posits instead that the PLAN made the decision to move closer to the work of the international community following the MV De Xin Hai incident, because it acted as the logical next step in the evolution of its counter-piracy experience. In other words, as China did not possess the necessary technological equipment or political will to better coordinate counter-piracy efforts, it had to accept to make the move closer towards those who could help it in this regard (Interview 2). The coalitions, and particularly NAVFOR, stood out in this respect as they had by this time put together the bulk of the technological devices and coordinative efforts that if applied earlier could most likely have prevented the pirates from seizing the MV De Xin Hai and its crew. Following the ratification of NAVFOR's initial mandate, budget and rules of engagement, the OHQ was presented with what they felt was a "unique opportunity to innovate" (Interview 26). This carte blanche originated not only from the urgency of the situation in the GoA but also from the fact that this represented the EU's first maritime CSDP operation, from which no prior institutional memory or experience could be drawn upon. The OHQ staff was able to exploit the novelty value of this situation, whilst also taking advantage of the short chain of command between Northwood and Brussels. For the first few months of the operation, the OHQ held a relatively free hand in terms of how it went about conducting NAVFOR's counter-piracy actions (Interview 22). As a result, it pragmatically set about applying creative solutions to help counteract the piracy phenomenon both directly and indirectly. Two specific innovations stand out in this respect: MSCHoA and the Mercury communication system. 
The MSCHoA, as presented earlier, consists in a web-based system used to organise Group Transits for interested shipowners (Muratore 2010: 98). ${ }^{147}$ As MSCHoA's conception rapidly received the backing of the shipping industry, who adopted it benevolently, the Northwood-based website soon found itself in a position to amass impressive volumes of data on the whereabouts and travel details of merchant ships transiting the GoA and Indian Ocean. It was further assisted in its task by the UKMTO office based in Dubai that partially served as the regional face to MSCHoA's data collection exercise. ${ }^{148}$ Eventually, NAVFOR found itself with a virtual monopoly over information and intelligence regarding counter-piracy, effectively allowing MSCHoA to act as the major: "[...] collection and coordination point and EU NAVFOR as the action point" (Ehrhart \& Pettreto 2012: 271). It naturally shared such information with CMF and NATO who, with their Maritime Liaison Office and Ocean Shipping Centre, were respectively in possession of their own data collecting instruments even if neither had specifically been designed to cater for counter-piracy initiatives in the same way MSCHoA had. Moreover, the centre proved particularly useful as an intermediary between the independent deployers and the shipping industry, as the former sought to organise their own escorts in an optimal fashion (Drossinos 2009: 41; Muratore 2010: 98).

A similarly large part of NAVFOR's initial budget was invested in the design of the Mercury communication system which could best be described as a "security, web-based communication platform" run by MSCHoA at Northwood, made available to any interested naval forces engaged in counter-piracy and distributed via the SHADE (Muratore 2010: 97). ${ }^{149}$ In order to holistically complement the technology produced for the shipping industry, NAVFOR purchased a custom-made chat system to facilitate communication and collaboration between the different naval forces. Those who were willing to adopt it onboard their vessels could use it to send alerts or share information on pirate activity to other forces through the virtual chat interface, in a cost-effective manner (Ibid: 97, 100). Although pioneering in the context of counter-piracy, similar interfaces between military forces have been applied elsewhere. For example, the US uses the CENTRIX platform to exchange intelligence with its very closest allies (Australia, Canada, New Zealand and the UK). The difference with Mercury quite prominently is that CENTRIX requires a security clearance clause from the US in order to be granted access - a highly complex procedure involving

\footnotetext{
${ }^{147}$ For more information, visit: http://www.mschoa.org/.

${ }^{148}$ In actuality, MSCHoA's task was greatly facilitated by its work in tandem with UKMTO because the latter collected the real-time details of commercial vessels featuring on MSCHoA's chart, allowing it to regularly update MSCHoA on the position and speed of the vessels under scrutiny (Muratore 2010: 98).

${ }^{149}$ Mercury's inspiration originated from a similar digital contraption used by the Royal Navy to distribute unclassified information during previous maritime operations (Gros-Verheyde 2010; Muratore 2010: 97).
} 
intelligence services and highly susceptible to protracted talks between parties seeking to adhere (Interview 22). For its part, Mercury required no such security clearances due to it being nothing more than a specialised internet forum in which naval forces could freely exchange intelligence, upload photographs and other information regarding pirate activity. In no way did adopting the Mercury system mean ceding to a predetermined chain of command given that adherence to it remained strictly voluntary (Gros-Verheyde 2010). After much reticence and careful examination, many of the independent deployers, including the PLAN, downloaded the software onto their onboard computers and began sharing information - with NAVFOR staff acting swiftly to ensure that no credible rival interface would emerge.

In short, the decision to invest in these technological devices is believed to have greatly benefited NAVFOR in terms of influencing the organisation of the international community's counter-piracy exercises in the GoA, mainly thanks to the leeway it had over collecting and disseminating vital information on pirate activity - data which was badly needed by independent deployers acting in relative isolation and more exposed to the activities of Somali pirates. In consequence, PLAN decision-makers are understood in this instance as having made the rational trade-off between improving the PRC's sources of information by buying into MSCHoA and Mercury in exchange for increasing its reliance on exogenous support platforms (Drossinos 2009: 55; Moore 2012). This entailed independent deployers implicitly moving further away from the periphery and closer to the centre in this context - a centre occupied by the coalitions and their vision for organising counter-piracy.

Finally, some have suggested that the PRC's progressive integration into the international community's counter-piracy effort was largely facilitated by the legitimacy of the counter-piracy exercise as a whole. As aforementioned, taking place predominantly in international waters - with the blessing of the TFG, the UNSC and the IMO - China did not have to overly concern itself about possible negative repercussions caused by its decision to deploy and coordinate with other naval forces, with regard to its core foreign policy principles of non-interference and territorial integrity (Erickson 2009; Weitz 2009: 31). As previously explained, most of the UNSCRs drafted on counter-piracy off the HoA expressly reiterated the need for concerned actors to: "[...] increase and coordinate their efforts to deter acts of piracy $[\ldots]$, share information $[\ldots]$, and to render assistance to vessels threatened by or under attack by pirates or armed robbers" (UNSC 2008a: 2). Moreover, as a critical mass of naval forces had already opted to send their maritime forces in a bid to deter the universally recognised enemy in this instance - the Somali pirate - Beijing again did not have to worry too much about dispatching its own warships. As a matter of fact, counter-piracy operations 
are usually associated with relative low intensity and low risk, so Chinese officials could be more relaxed about their decision to dispatch ships and fight pirates (Lin-Greenberg 2010: 222). All of this would suggest that the configuration of counter-piracy allowed the PLAN to demonstrate relative flexibility and leeway in the management of its own tactical approach. In turn, the decision to collaborate more firmly along the lines set by NAVFOR and others was possible due to the minimal chances of this decision backfiring on China. On the contrary, doing so could only be beneficial in terms of better protecting its national interests on top of showcasing its commitment in taking responsibility: "for an issue that affects the world" (Interview 25).

\subsection{NAVFOR, the PLAN and the Exercise of Building Trust}

\subsubsection{The Guiding Facets of NAVFOR's Identity}

These causalities make much sense but this thesis takes the view that these factors represent only the tip of the iceberg as far as explaining the shift from the PRC's initial position on counter-piracy. In fact it would not be misguided to ask at this juncture why it took Beijing so long to go down a more integrative and collaborative path if the trade-off between costs and benefits axiomatically outweighed in favour of the benefits? Why was Beijing relatively slow in giving its approval for the PLAN's tactical switch from the periphery to the centre if counter-piracy was such a risk-free and 'easy' enterprise? If the PLAN opted to coordinate its own tactical design more closely along the lines set by the coalitions as a means of avoiding first and foremost any future embarrassments as those caused by the seizure of the MV De Xin Hai, then how to explain China's decision to break with its unease for the international limelight by voluntarily requesting - in an "unprecedented" move - a leadership role in the SHADE? Rational explanations would seem to bring up as many questions as answers in this respect. As far as this thesis is concerned, it is the sufficient build-up of cognitive-based political trust between EU NAVFOR's (and the other coalitions) leading officers with the PLAN's own officers that constitutes the most prominent causal variable underpinning China's tactical u-turn. Without the process of partial negative identification observed in the early stages of their exchanges on counter-piracy, the chain reaction which ensued after the hijacking of the MV De Xin Hai may never have taken place since greater ensuing levels of trust may have fostered the cooperative spirit needed to diffuse the attack. Yet, at that stage, both sides were more inclined to exacerbate political divergences rather than strive to build trust. At face value, rational choice did appear to push the PLAN towards inclusiveness but in reality this shift was motivated by the trust it had that moving closer to the international 
community's efforts would not entail having to compromise upon the guiding facets of its foreign policy. Had PLAN officers not trusted its NAVFOR counterparts, it would have not undergone such an extensive shift in approach on counter-piracy, from displaying initial reluctance to eventually fully embracing the SHADE, in such a short space of time when acknowledging the traditional patterns of Chinese foreign policy. In the context of China's usual reticence in agreeing to Western initiatives on matters of security risk management, applying rational justifications for explaining this sudden shift is insufficient. In effect, PLAN officers had themselves been calling for this type of trusting relations in order to expand their coordination and cooperation with other naval forces in the region. This was evidenced in a statement retrospectively given to the Chinese state media by voices within the PLAN on this topic a few years after the launch of the latter's counter-piracy mission during China's first 'International Symposium on Counter-Piracy and Escort Cooperation': “naval forces involved in counter-piracy operations in the high-risk waters off the Somalia coast must expand trust and coordination" (CCTV 2012).

Earlier in this chapter, the hypothesis was raised that the coalitions negatively identified with certain independent deployers - such as China - in the counter-piracy environment, largely for their initial obduracy. Yet, as the data collected for the case study shows, this assumption would appear erroneous. Rather than negatively identifying with their PLAN counterparts, it should be argued that the coalitions considered the latter as part of their wider ingroup network and that those whom they did negatively identify with, held no connection whatsoever with China. In fact, those with whom NAVFOR OHQ staff did negatively identify with were: a) the Somali pirates; b) the "elements" (i.e. from being at sea); c) their political "masters" (Interview 25; Interview 26). Since they did not construct their identity against other naval forces, this would go a long way to shaping the realm of possibility that they would thereafter come to enjoy with the PLAN. ${ }^{150}$

The first to fill this identity void for the coalitions within the counter-piracy environment were the Somali pirates, due to the indiscriminate nature of their hijackings and greed for ever larger sums of 'easy money.' In contemporary Western thinking, pirates have always been castigated as outcasts. In the $16^{\text {th }}$ century, Dutch philosopher and legal scholar Hugo Grotius coined the term hostes humani generis (enemies of mankind) to describe pirates.

\footnotetext{
${ }^{150}$ With the possible exception of the Iranian naval forces, with whom the idea of closer collaboration was simply unthinkable for many in the West at that time, due to the political and historical baggage between the two sides (Interview 26). Some members of the OHQ did, however, seriously entertain the idea of integrating the Iranians into the international community's counter-piracy effort, principally as a means to open a conduit for communication with Iran, before having to abandon the initiative in the face of resistance from Western political and diplomatic actors (Ibid).
} 
Reference to this particular label is interesting not just for the fact that pirates are obviously pejoratively described but also because it provides an insight into the normative constitution of the (Western) naval cultural programme. Grotius applied this qualifier due to his belief that the principle of mare liberum (freedom of the High Seas) must remain inviolable so as to guarantee the safe and continuous passage of global trade, which subsequently serves the interests of all nations by helping to guarantee their survival (cited in ENA 2009: 3). This principle was perceived to be of universal benefit and to such an extent that sovereign states would deem it acceptable for their sovereignty to be encroached if it meant guaranteeing the freedom of the High Seas (Murphy 2008: 11-2; Till 2013: 19, 39, 40).

Pirates were thus condemned as "universal enemies" for threatening the benefits derived from the freedom of the seas and attacking ships of all states, while acts of piracy were categorised within the same class of crimes as genocide and the slave trade - which in the words of one specialist are: “[...] so heinous they invite universal condemnation” (Ibid: 12, 18). In fact:

before the anarchist and the slave trader, the pirate had already been singled out as the object of the first international or global war on terror. That is, the war on piracy was the first state-fought war against a non-state aggressor that was described as the enemy of humanity, and was treated and hunted as such (Thorup 2009: 402). ${ }^{151}$

For this reason, customary international law established the universal principle that state authorities had the right and responsibility to arrest pirates and arraign them under their own domestic law, regardless of the pirates' nationality or place of capture (Murphy 2008: 11-2; Russell 2010: 63; Marley 2011: 21). From this vantage point, pirates - as violators of the freedom of the Seas and the safe passage of trade and, in parallel, the sovereign existence of states - would naturally be negatively identified against by those ordered to protect this freedom. This interpretation of guardians of the freedom of the seas would come to represent a founding tenet of the Western mariner mindset in the context of counter-piracy off the HoA.

\footnotetext{
${ }^{151}$ Mikkel Thorup goes on to make an interesting analogy between the legal, political and moral rhetoric used at the height of the international crusade against piracy to what applied in contemporary times against Islamic terrorists in the West. Thorup's main argument posits that the moral high ground is adopted against pirates and terrorists as a means of devaluating and dehumanising the enemy as unlawful combatants who, through their own actions, have placed themselves outside the protection of legal and moral laws. Thorup goes on to argue that adopting this attitude against pirates and terrorists, above all, stems from the fact that these enemies represent serious threats because the sovereign entities do not have absolute control over them, since they do not operate in a physical space dominated by the sovereign entity. In turn, this leaves them vulnerable to attacks by these rogue elements at sea, in a similar way that recent terrorist attacks by groups promoting radical Islam have demonstrated that sovereign entities in the West are vulnerable to surprise outside attacks within the territories they control (Thorup 2009: 402-5).
} 
As stated earlier, NAVFOR staff put a premium on inclusiveness when initially reacting to the need to organise counter-piracy activity. In effect, the preference for an integrative response derives from the above recognition that the High Seas represent a global common, the benefits of which are to be shared by all on condition that they are conceived by all as a global common. As the sea cannot be regimented in the same way that land can and that no nation or other type of collective human entity can reign indefinitely and ubiquitously upon it, the seas and oceans cannot be treated as a jealously guarded territory but to the contrary it is their freedom and openness which need protecting - a message Grotius had attempted to convey in his writings (Russell 2010: 15-6). According to Roger Barnett, this creates a paradoxical situation - albeit one which is desired from a general legislative standpoint - whereby the freedom of the seas is not protected by elaborate international legislation, yet should this freedom come to be violated, the enforcement of such laws by those who abide by them tends to be unequivocal. ${ }^{152}$ This is because, the survival and progress of human civilisation may be jettisoned to the detriment of the global common if this concept of the freedom of the sea would repeatedly be violated, as highlighted by the European Commission's aforementioned quote on the (free) seas being a fundamental part of Europe's lifeblood. Since it is the duty of the naval officer and seafarer to uphold this conceptualisation, in the mindset of the coalitions' commanding officers an invisible bond is shared with those who live by this same code or who are perceived in the eyes of these seafarers as living by this code regardless of where they may come from. Indeed, negative identification was out of the question from the minute the coalition officers drew a parallel between the presence of independent deployers in the region with the desire to uphold the freedom of the seas, particularly, as in China's case, the protection of trade routes and flows of raw materials form part of its core foreign and security policy interests (Roell 2011: 3). Therefore, it is the principle of living by this conceptualisation which explains why leading NAVFOR staff opted for an integrative instead of a 'national' response to organising counterpiracy activity and why they held back from negatively identifying with more obstructive independent deployers, in spite of the temptation.

Another unifying factor in the mindset of these seafarers stemmed from their shared experience of life as professional women and men of the sea (Till 2013: 243). On top of fighting for a common cause, leading officers from the coalitions incorporated the

\footnotetext{
${ }^{152}$ He states: "having no effective supervening authority, and a comparatively small body of either treaty or case law, the legal regime for the ocean areas of the world is understandably weak. This, significantly, is by design" (2009: 34).
} 
independent deployers within their wider ingroup because of the belief that they were naturally bound by their experiences of life at sea and by the harsh physical conditions in which they all operate without exception (Interview 7). Seafarers may not always work for the same team or harbour the same objectives but the transversal nature of the harsh and rigorous climate in which they work provides them, for the most part, with a natural inclination to operate inclusively towards each other. As Barnett attests in his book on naval strategic culture: "the environment is inherently hostile, teamwork is required merely to survive. Outside help when problems arise is rarely available. This engenders a greater feeling of community" (2009: 13). ${ }^{153}$ Consequently, other naval forces working towards the resolution of a common problem at sea are usually unlikely to negatively identify with each other, instead increasing the chances of generating the levels of trust needed to overcome any broader political disagreements and adopt more cooperative patterns of behaviour - this is the case at least as far as the Western seafarer's lifeworld is concerned. Or in the words of Barnett: "military culture, and especially Navy culture, encompasses a community bound by trust. Trust must be as strong between leaders and subordinates as it is among equals in hierarchical organisations such as the military" (2009: 12).

The last noteworthy element concerning the constitution of the naval officers' identity in this context relates to the dyadic relationship they entertain with political actors. Over the course of the fieldwork undertaken for this case study, it became increasingly obvious that naval officers negatively identified with their political 'masters.' Military historians would most probably point to the Clausewitzian roots of this process of negative identification. As a pioneer of military strategy, Carl von Clausewitz posthumously rose to fame through the translation of his volumes which promulgated that war came to represent nothing more than the continuation of politics by other means (cited in Windsor 2002: 1). In brief, Clausewitz had attempted to summarise to the best of his abilities the relationship between political leaders and the military apparel, or to put it more bluntly, the usage that the former makes of the latter. One fleeting interpretation that can be extracted from this portrayal would tend towards the view that this hierarchical yet symbiotic relationship between the two levels masks a non-negligible degree of tension, emanating principally from the military side of the spectrum (Barnett 2009: 22, 32). As far as the naval officers were concerned, the importance of making the distinction between the realms of naval affairs and that of politics did not go

\footnotetext{
${ }^{153}$ Till made a similar in his book on seapower, by observing that: "there is, indeed, a kind of spiritual bond between sailors that derives perhaps from the fact that the medium on which they operate, the sea, is dangerous and pose them all the same risks [...]. There [sic] is a spontaneous camaraderie of the sea that can easily be turned to constructive political purpose" (2013: 243).
} 
understated. Naturally, it also flattered the former to the detriment of the latter (with the cue that political actors often failed to comprehend the dynamics of counter-piracy in the same way that naval officers did). This should not be considered as an ex-post reality only since it played a real part in driving a number of their actions when organising the counter-piracy response.

Indeed, the naval officers went to certain lengths to produce actions which they deemed to be legitimate in accordance with the normative repertoire underpinning their identity, but which they believed political actors would either not be capable of comprehending or would simply object to due to their different mindsets. An example mentioned earlier suggested that while political actors within the Council of the EU had already sounded out the need to protect European interests in the context of counter-piracy, naval officers from Northwood made it their priority to dismantle the myth of protecting national interests in an environment epitomising globalisation (Interview 22). ${ }^{154}$ They made this move in part to impose what they foresaw as appropriate action, as opposed to what their political 'masters' had deemed adequate. They were given added impetus to act in this fashion because doing so helped to emphasise the delineation between the military and the political, comforting their identity formation in the process.

According to some naval officers, this motivated them to perform what they considered to be the politically 'unaesthetic,' for example, by using counter-piracy as a conduit to better the EU/West's ties with the more problematic independent deployers regardless of how menial an impact this may have in the wider scheme of international affairs (Barnett 2009: 1). They deemed such actions to be important not simply because of its human virtues but also due to the fact that political actors would prefer not to overly give preference to flirting with distant rivals such as China, due to the risk of suffering a potential backlash in opinion polls (BBC World Service 2009). In his seminal work on naval strategic culture, Barnett argues that such behaviour does not come as a surprise to anyone with experience in the naval domain, as this demarcation reflects the diverse experiences and viewpoints that one has from operating at sea as opposed to operating from terra firma (2009: 22). In his view, the symbols and patterns that come to shape naval officers' cultural programmes and identities instinctively differ from those professionals with whom they have to interact who do pertain from the same lifeworld (mainly in reference to political actors but also to other components

\footnotetext{
${ }^{154}$ In the words of one expert: "[...] it is now common for beneficial ownership of maritime hulls to be vested in shifting multinational shipping alliances, the finance extended by one country, the cargo owned by another set of companies, the ship in transit from one state to another and crewed by people from a range of other countries" (Till 2013: 106).
} 
of the military such as territorial armies or the air forces with their own distinct lifeworlds). As Barnett affirms:

it seems that the ability of Navy officers to think strategically, to rise above the minutiae of the tactical battlefield, and to discern 'where the big picture fits in' renders [sic] them uniquely valuable as combat commanders. [...] 'Broadly speaking, sea power works slowly and subtly, whereas generals, politicians and the people at large are impatient for direct, immediately apparent results, as with armies on the march' (2009: 1-2).

On counter-piracy, the naval officers running EU NAVFOR and the other coalitions' operations indeed saw things differently. Put simply, viewing themselves largely in opposition to political actors, naval officers positively identified with the independent deployers because they did not deem it legitimate to seek political capital from politicising relations with certain independent deployers as they believed political actors might attempt to. ${ }^{155}$ As a case in point, one interviewee indicated that after a year of close interaction with the PLAN, as highlighted in the next section, the same political actors within the Council of the EU that had given carte blanche to the OHQ gradually began to exert greater control over this section of the counterpiracy file (Interview 22; Interview 26). In brief, the naval officers in question were open to working more closely with the independent deployers within a depoliticised setting as a way of proving to their political superiors that this was the appropriate way of conducting affairs with more distant international actors.

\subsubsection{Social Interaction in the Counter-Piracy Realm}

With the section above covering the process of identification undergone by officers working for NAVFOR and the coalitions, a number of hints have already been given about the prospects of the EU and Chinese naval officers building the levels of trust needed to reach the cooperative "threshold" in this context. Nonetheless, this only answers part of the picture drawn up by the conceptual framework in relation to bilateral trust in this particular environment, leaving a number of questions unanswered at this stage. For example: with the PLAN featuring in NAVFOR's wider ingroup network and with the latter tending to put a premium on "developing good, enduring and constructive maritime relations with others," how did this affect the shape of bilateral interaction on counter-piracy (Till 2013: 41)? What did it mean for trust-building? What would inclusiveness come to signify in practical terms? Understanding that the PRC was anything but a passive norm follower, staff at the OHQ were

\footnotetext{
${ }^{155}$ One interview made an interesting analogy to language in this respect, by claiming that contrary to political actors, naval officers did not tend to use the language of "spin" (Interview 7).
} 
of the belief that getting the PLAN to appreciate that it formed part of the coalition's ingroup would require persuading their Chinese counterparts of this reality, whilst making compromises as a show of proof. NAVFOR's strategy towards engaging the PLAN was built upon: a) directly and/or indirectly displaying cautious levels of empathetic behaviour and respect; b) consistent and intense communicative exchanges; c) encouraging - as far as possible - depoliticised forms of interaction, mostly via the SHADE mechanism. ${ }^{156}$ In the OHQ staff's mindsets, the characteristic of inclusiveness obviously held an important place and clearly shaped decision-making according. Yet, even though this mindset may have been shared by officers from non-Western naval forces as a result of their own experiences of being women and men of the sea, there was no guarantee that it constituted a definitive universal character trait in light of the obvious cultural differences. As stipulated in the thesis' conceptual framework, if positive identification constitutes the first and most vital step in the development of trusting relations it does not constitute the only step. This is why elements such as empathy and ideal-type communicative action are equally important in translating positive identification into actual cognitive-based political trust. As explained below, this process is what took place between the NAVFOR and PLAN naval officers.

This approach began as a matter of fact within the early stages of the counter-piracy effort, almost as soon as the PLAN's convoy had reached the region. NAVFOR staff's primary objective at that stage, working closely alongside the other coalitions, sought to sway the PLAN about the importance of collective action. Soon after the establishment of the SHADE and the realisation of the need for the independent deployers to partake, this objective was soon narrowed down to getting China to join this movement instead of letting it fight its own battles on the fringes of the international community's efforts. This task was made more arduous by the fact that those coalition naval officers responsible for setting up SHADE had taken the solemn vowel that participation in the mechanism would be entirely voluntary. With time pressing and rival bids being mooted, the coalitions had to act swiftly in order to formulate a convincing line of argumentation to convince Beijing that supporting a tactical shift would not simply lead the PLAN astray. Creating a common language which would resonate with PLAN officers would therefore prove vital - the language of depoliticisation held the key in this respect.

\footnotetext{
${ }^{156}$ More formal interactions did also take place in the UN's Contact Group on Piracy off the Coast of Somalia (CGPCS), which was mostly composed of diplomatic and political actors, rather than naval actors. The EU, its member states and the PRC were all represented in this forum but the focus in this instance is placed on the SHADE since the CGPCS largely provided the framework within which the SHADE could operate (Interview 25).
} 
In official terms, the SHADE has been described as a platform:

[...] designed to deconflict the activities of the various navies in the region, discuss the challenges of the ongoing military engagement off Somalia, the coordination of naval activities in general and group transits in particular, as well as force generation and best practice (Ehrhart \& Pettreto 2012: 271).

On the face of it, the mechanism's prerogative concerned the formulation of non-binding recommendations on coordination-related issues or resolving technicalities (such as using it as an intermediary to promulgate technological equipment or finalising the IRTC) (Larik \& Weiler 2011: 96). Deep down, however, the SHADE's constitution was grounded in attracting independent deployers through trust, which in the mariner belief system transpired as the only appropriate method of developing the cooperative spirit needed to collectively defeat piracy. They sought to promote the SHADE so that the independent deployers could rely upon the mechanism as well as have faith in those who had designed it.

For this reason, the coalitions were at pains to clarify to the independent deployers and the PLAN in particular - that the SHADE was neither an implicit command and control centre where eager participants would have to trade in a part of their sovereignty to adhere, nor did it imply a necessary chain of command (Larik \& Weiler 2011: 96). Meetings would deliberately take place at the Captain-level and not the Flag Officer-level so as to allow "mariners to talk as mariners" and avoid, to the furthest extent possible, the politicisation of the mechanism (Interview 25). For the creators of the SHADE, this principle of allowing women and men of the sea the freedom to speak their "language" was vital (Interview 7; Interview 25). In addition, where possible, they tried to promote the idea that the SHADE would come to stand for transparency and openness in a bid to create as "flat and democratic" a military structure as feasible (Interview 25; Interview 26). Such norms would become an integral part of the SHADE's being, so much so that if any of the participants got away with flouting these values then the coalitions' naval officers faced the possibility of the mechanism becoming redundant. They faced a tough challenge to balance impartiality with a need to get participants to adhere to basic protocol.

Naturally, the decision to construct the SHADE according to these principles was linked to the perception that distrustful others may hold of it. Fears of it being seen as an "American ploy" were as much a reality for some of the independent deployers as they were for its creators. The primary objective sought to allay any such fears, even to the extent that the initial SHADE meetings - held at the HQ of US Fifth Fleet - were strategically moved to a more neutral location in the shape of the 'British Club' in Bahrain (Interview 25; Interview 
26). At the time, the SHADE's legitimacy and credibility also received a boost thanks to the IMO's endorsement of it as the forum for tactical deconfliction (Interview 25). But beyond the fancy discourse designed to lure independent deployers, the SHADE's most appealing asset was the fact that it served as a veritable reflection of the identity and image which the coalition officers sought to portray of themselves within this environment. This allowed for a non-negligible dose of sincerity to accompany the fancy discourse, as these officers sought to project themselves as serious in terms of making trust happen, yet only doing so in a way that matched the independent deployers' ideals and expectations.

After all, the SHADE symbolised inclusive efficiency. It sought to attract the largest number of participating navies to join strictly of their own accord and contribute at their convenience. Notwithstanding, all navies were welcome to send a representative and do so strictly at their behest. They also exploited the value-added of their knowledge of the region and know-how of out-of-area naval operations when compared to many of the independent deployers, which meant that once the coalitions had joined forces they formed a mighty cog in the counter-piracy machinery. Yet, instead of imposing their value-added and ultimately their counter-piracy model as an 'in or out' last-chance saloon upon the independent deployers, they sold it as an alternative amongst others. Going round upsetting potential partners or stoking the fires of doubt by condemning those that sought alternative tactical preferences not only made little sense for these naval officers but simply went against their logic of appropriateness. For this reason, it is possible to assume that commanding officers from interdependent deployers such as the PLAN were receptive to the discourse behind the SHADE because NAVFOR, CMF and NATO officers had tried their best to prove the sincerity of their words and actions. As a case in point, when the first SHADE meeting took place, its original creators drew up a list of possible points for discussion on the agenda when taking the floor to open the first session. However, once this list had been read out, they held themselves back from intervening in discussions - and did so only if called upon - to the point of even leaving the room to let the participating navies get along with proceedings (Ibid).

Undoubtedly though, the SHADE's greatest asset was the attempt by the coalitions' naval officers in setting up this platform to prevent politics from entering the arena. Of course, such acts of depoliticisation constitute a major selling point in an environment where levels of trust are not running particularly high. The depoliticisation theme served primordially to attract those navies which, at first, may have felt as they had been negatively identified against. Yet again, the SHADE's creators configured the mechanism in such a way as to attract recalcitrant partners by allowing only Captains to partake in debates, thus barring 
participation from actors with politicised agendas. In some ways, SHADE's design was driven by the desire to show the political actors both the benefits of working in depoliticised settings with distrustful partners and, importantly, the futility of politicising interaction with these partners in a situation which required a rapid resolution. Clearly, the sincerity which the coalition officers displayed in making SHADE exactly into the kind of forum they had promised the independent deployers worked since rival proposals were soon dropped, turning it into the sole mechanism for tactical awareness, deconfliction and best-practice. SHADE worked because independent deployers could trust that NAVFOR and the other coalitions would make it work as they had promised to.

In China's case though, it took to SHADE and the overall efforts of NAVFOR and the coalitions with greater intent due to its gradual receptiveness to their approach to counterpiracy and also because the coalitions had placed particular emphasis on ensuring that PLAN officers fully understood this approach. The trust that the PLAN officers had in their NAVFOR counterparts was on the rise, while the latter's efforts at convincing their Chinese interlocutors of the trust-building benefits of the SHADE had not been in vain. As a case in point, the PLAN officers involved in these discussions eventually came to see the SHADE as a "confidence-building measure," a "good example" of an effective information communication mechanism and - in the opinion of Senior Naval Captain Hu Gangfeng - it constituted a means for the PLAN to "break the ice and improve communication with other navies" (China Daily 2009a, SCMP 2009a). Not only did this come across as a considerable change of approach and semantics when compared to the rhetoric emanating from the PLAN regarding the SHADE a year earlier, but it highlighted the extent to which the PLAN was buying into the integrative concept of the SHADE as a whole, as a reflection of their growing trust in the NAVFOR and coalition officers with whom they had to deal with. Consequently, these growing levels of trust were epitomised by China's "unprecedented" move for the SHADE leadership. This shift is in part justified by the emphasis placed upon language and intense exchanges, which served as the medium of choice for the OHQ staff in their attempts to persuade their Chinese counterparts. In fact, the establishment of the SHADE had provided the ideal platform for the naval officers to commence their quest to forge closer personal relations between the two sides, which evidently held the key to swaying PLAN officers about the merits of altering their tactics. The process was far from linear and required plenty of patience, with talks often getting bogged down by nitty-gritty interpretations of technical detail or simply getting lost in translation. As one insider recounted about his PLAN counterparts, they: "[...] came in saying that we needed a coordination organisation and it was 
not the SHADE, because the SHADE was deconfliction and deconfliction was not the same as coordination" (Ibid). Indeed, the term 'coordination' had explicitly been excluded from featuring within the SHADE acronym in order not to scare off potential participants (Ibid).

The OHQ staff did not shy away from the task at hand even if the PLAN's tentativeness and obsessive attention to detail could wear down even the most proven of negotiators. But their guiding norms, constitutive of their identity as Western naval officers, pushed them to interpret this challenge as an opportunity rather than a burden. Whereas NAVFOR officers believed political actors disapproved of wasting resources by engaging in protracted and intensive acts of persuasion with the Chinese, the OHQ staff saw the "gamechanging" potential of pursuing a "long dialogue" with the PLAN (Interview 25; Interview 26). In their view, this applied as much to increasing the efficiency of counter-piracy efforts as to improving the longer-term prospects of bilateral relations. Therefore, they launched into developing closer personal relations with the PLAN in parallel to negotiations surrounding the SHADE. As early as 16 December 2008, a 'Third Country Force Generation Conference' was held at Northwood with NAVFOR reportedly intent at the time on convincing actors such as Canada, Japan, Russia, Saudi Arabia and China to either consider direct contributions to the NAVFOR operation or to sign up to a bilateral Framework Agreement on counter-piracy (Interview 14). Neither initiative made it beyond the drawing board but they serve to highlight the extent to which NAVFOR coveted a closer working partnership with the PLAN amongst others - a fact that it itself was confirmed by the numerous fleet visits held between NAVFOR and PLAN Force Commanders (Xinhua News Agency 2011). ${ }^{157}$

To make these conduits of communication function adequately and produce results, however, entails the capacity to engage in discussions, listen and express cognitive empathy as explained in the cognitive-based conceptual framework on political trust. The expression of cognitive empathy by NAVFOR officers towards their PLAN counterparts was clearly detectable right from the inception of counter-piracy activities in the region and accrued in parallel with the intensity of negotiations surrounding the SHADE. As a matter of fact, the more experienced OHQ members of staff were both suitably impressed by the PLAN's contribution and capabilities, whilst showing appreciation for the size of the challenge with which they were faced - this being China's first out-of-area expedition for over 500 years. This was their way of showing them that although there may have been divergences in the

\footnotetext{
${ }^{157}$ In the Xinhua News Agency article referenced here, it is stated that between the launch of its operation and the year 2011, the PLAN exchanged 24 board visits of commanders with fleets from the EU, CMF, NATO, Russia, South Korea, the Netherlands and Japan.
} 
respective constitutions of their mindsets and there also being deeper cultural differences at stake, fundamentally in their capacity of seafarers they were able to relate to the struggles of their fellow naval force and thus that they positively identified with them. In fact, they showed particular empathy towards the "nervousness" felt by their Chinese colleagues in relation to the potential embarrassment the latter faced, should the decision to deploy backfire (Interview 22). As two Chinese foreign policy specialists have attested:

do not underestimate how intimidating the initiation of overseas operations can be for China if such operations are new to them [...]. The PLA has been a closed, inward-looking institution, with very little exposure to the outside world, which makes it more sensitive to exposing weaknesses in its force (Hirono \& Neill 2012: 20).

Such positive identification transpired in the way that NAVFOR naval officers showed their respect for the way with which the PLAN adapted to the hostile conditions, as well as to an environment in which it had little experience and few places to turn. As a case in point, reference was made during one interview to the fact that upon arrival in the GoA, the PLAN was unable to dock during the first four months of the operation due to its inability to enter ports in the region (Interview 26). This predicament left them suffering from a lack of adequate storage of food and fresh water, which for experienced Western seafarers constitutes an ill-advised practice (Roell 2011: 2; Interview 26). The fact that the PLAN did so unerringly garnered the respect of the coalitions' naval officers, instead of a situation where the former was ridiculed - as a member of the outgroup might have been - for such practices. As talks went on well into 2009, personal relationships were forged as a result of the constant stream of exchanges taking place. In turn, this led to a growing sense of mutual appreciation between the naval decision-makers on either side. ${ }^{158}$ Debates may at times have been heated or infused with a sense of passion and pride but this did not get in the way of NAVFOR staff's feelings evolving from doubt towards empathy and mutual respect. The following quote from one interlocutor working for the coalitions at the time, sums up this situation well: "I used to joke

\footnotetext{
${ }^{158}$ This mentality did not just apply to NAVFOR staff, but spread right across the other Western coalitions. During a 2013 joint Sino-American naval training exercise in the GoA, the Navy Captain participating on the American side had the following to say about that experience: "what my crew found out is they are sailors like we are, practising many of the same techniques as they confronted the same challenges." He was seconded in this train of thought by a Commander participating in the same exercise: "[...] we are all working towards that shared goal of freedom of movement in the maritime domain. So if we share the same goal, we ought to be working together, and that is what we are really trying to do. [...] We may come from different places and speak a different language, but at the end of the day, we all share a common interest in protecting the maritime environment" (cited in Miles 2013).
} 
that I had spent far too much time in overheated rooms, talking a language of detail and compromise with my Chinese counterparts, but actually it was fascinating" (Interview 25).

In truth, by this stage, there was nothing haphazard about this behaviour. Instead, it was simply the culminating effect of a generally positive attitude expressed in different shapes and forms by leading staff members from the three coalitions - to both assuage the fears of possibly recalcitrant partners and, more importantly, to make the most out of their shared predicament. In effect, this explains why the SHADE was conceived in the most depoliticised and 'no strings attached' manner possible; why Mercury was designed in such a user-friendly way; why NAVFOR sought to play upon the EU's supposed "neutrality" as a means of soothing the nerves of their Chinese counterparts with regard to dealing with the other coalitions (Ibid); why NAVFOR sought to engage PLAN staff as much as possible from a communicative perspective in intense bilateral and multilateral fora; why NAVFOR staff were keen to iterate over the course of these exchanges, as mentioned above, that both shared more in common than they could imagine despite not pertaining to identical 'lifeworlds'; why NAVFOR staff were willing to put in hours of dialogue with PLAN officers when some may have written this off as a waste of time; why NAVFOR pushed its Chinese counterparts to make a go of the co-chairmanship bid; why - in the words of an honorary fellow of the Centre for China-US defence relations of the Chinese Academy of Military Science - that "much more" had been achieved in collaboration between the PLAN and NAVFOR than with any of the other coalitions (Ibid; China Daily 2014). As the empirical evidence has highlighted throughout this chapter, NAVFOR staff clearly achieved the objectives they had set out at the outset of their mission in this regard, which in itself is testimony to the power of cognitivebased trust when developed adequately and applied intelligently.

\subsection{Concluding Remarks}

Chronologically, the bulk of this chapter has focused on a period stretching from the backend of 2007 until late 2009. As the sections above have highlighted, within this specific time period, strong evidence subsists that cognitive-based trust primarily triggered the PLAN's tactical shift from being a more peripheral contributor to a willing participant with its own leadership aspirations. In short, the PLAN had developed sufficient levels of trust in/with its counterparts from EU NAVFOR and with the two other coalitions' leading staff members that it held very few reservations about developing much closer cooperation with the international community's counter-piracy efforts (Xinhua News Agency 2010). In turn, it was able to convince concerned parties back in Beijing that integrating the international community's 
efforts would not constitute a costly venture for China, mainly because it could count on the sincerity of the promises made by leading NAVFOR naval officers. Of course, since the benefits of moving closer to the centre outweighed the risks of pursuing a marginalised approach, the PLAN's tactical u-turn was incentivised as well. Nevertheless, had it not been for the incremental build-up of concerted cognitive-based trust between the two sides, the PRC's shift would have been neither as comprehensive nor as far-reaching as its decision to actively seek out for the co-chairmanship of the SHADE. The PLAN was not initially encouraged by the SHADE, but uncharacteristically switched its position on the SHADE in such an "unprecedented" manner that rational explanations alone cannot sufficiently vindicate as to why the PLAN suddenly altered it tactical approach. As demonstrated by this chapter, the growing levels of trust that the PLAN officers placed in the SHADE mechanism - as a reflection of the state of their ties at that time with their NAVFOR counterparts - is what predominantly explains this shift away from the PRC's 'traditional' mindset when dealing with security risk management.

Indeed, the PLAN officers' receptiveness to the coalitions' trusting advances, which combined the process of positive identification from the latter towards the former - as well as with the latter courting the former through displays of empathy and ideal-type communicative action - is best reflected comparatively in its approach to the SHADE mechanism. In effect, because PLAN staff had fostered a considerable trust-based relationship with leading actors from NAVFOR and co, they paid heed to the coalitions' encouragement to take on a greater share of the counter-piracy burden by pushing for a leading seat at the SHADE. In comparison, although noteworthy independent deployers such as India and Russia participated in the SHADE too, their navies never harboured the same leadership ambitions as the PLAN. This is because they were not receptive, for various reasons, to the coalitions' trusting advances in the same way that their Chinese counterparts were, as demonstrated throughout this chapter. NAVFOR staff and naval officers from CMF and NATO had expended as much energy looking to forge closer partnerships with all the major counter-piracy actors as they had trying to convince the PLAN of the benefits of closer collaboration (Interview 25; Interview 26). Independent deployers responses' to these advances were far from unanimous, with some naval forces showing more promise than others. Generally speaking, however, the large majority of actors (including India and Russia) were happy to move closer to the coalitions' tactical design. They did so by participating in the SHADE, adopting the custommade counter-piracy software and by contributing to the Group Transit System. 
Most independent deployers did so because, rationally speaking, many benefits could be extracted from being involved with this tactical approach or because not doing so could potentially prove costly. Some may have adhered due to concerns about their international image - preferring to be part of the movement instead of being seen as an outcast - or went along with the coalitions' plans out of allegiance. But none of the more emerging powers that contributed to counter-piracy demonstrated such commitment to being an integral part of the international community's counter-piracy plans in the same way as the PLAN had by the end of 2009 (Ibid). In fact, if reports are accurate, other emerging powers were as much uncomfortable taking up a leadership role within the counter-piracy realm conceived by the coalitions, as they were allowing the PRC to do so and thus strove to curtail the latter's cochairmanship bid in the process (Deccan Herald 2010). ${ }^{159}$ Therefore, rationally accepting to move closer to the international community's efforts may have been acceptable for these naval forces but undertaking such a comprehensive tactical shift was not. Without the same levels of cognitive-based trust in/with the NAVFOR leadership at the time, they could not and did not replicate the behavioural pattern set by the PLAN in autumn 2009 against the backdrop of counter-piracy activities off the HoA. Whereas for China, the level of mutual trust needed had been attained - so much so that it was willing at the time to overlook Deng's precept of keeping a low profile. As one EU official attested, when looking at this interaction in retrospect: "our cooperation was made possible by the fact that we had built a certain amount of trust in our respective intentions there" (Interview 6).

Another argument also deserves to be brought up at this stage regarding the prevalence of cognitive-based trust between NAVFOR, the other coalitions and the PLAN in explaining their rapprochement in this context. Above all, what this shows is that the levels of trust garnered by the PLAN in the international counter-piracy effort had encouraged its officers to take China's overall contribution to this effort at sea a step further, especially when compared to the early reticence and fairly closed-minded attitude it had shown at the launch of its mission. Greater trust in the counter-piracy architecture that emanated for the most part from the PLAN's engagement with NAVFOR and the other coalition officers is what allowed the

\footnotetext{
${ }^{159}$ After formally submitting its bid for the role of co-chair, reports suggest that despite gaining the approval of 17 delegates, this proposal was rebuffed by the Indian delegation which objected on the grounds that no "terms of reference" had been set for the co-chairmanship position and therefore, it could not give its consent (Deccan Herald 2010). Reports also suggest that in July 2010, Catherine Ashton - the EU's former HR/Vice-President for CFSP - sought to keep China's co-chair bid alive by offering India a similar role in order to get New Delhi to retract its opposition (Mitra 2010). Had China been granted its wish to co-chair SHADE, this would also have implied its full recognition of the Group Transit System's tactical primacy within the counter-piracy environment, due to the requirement as co-chair to allocate at all times one of its warships to a 60 mile stretch of water within the IRTC (Zhu \& Xu 2009; Muratore 2010: 100; Moore 2012).
} 
PLAN to get further engaged in the fight against Somali pirates. Firstly, for example, the PLAN has provided a strong individual contribution as part of the overall effort. The statistics are impressive in this respect. Between 2008 and 2012, the PLAN reportedly escorted close to 5,000 commercial vessels with virtually no successful attacks recorded against it, which undoubtedly contributed to bringing down the number of pirate attacks (Xinhua News Agency 2012a). ${ }^{160}$ By the second half of 2012, pirate activity in the region appeared to have ground to a halt (BBC News 2012a).

Secondly, post-2010, the PLAN had reinforced its indirect contribution to the decline in these figures through its own activism. In 2011, following a number of bilateral meetings with NAVFOR staff at sea and after daily coordination activities with EU officials it was agreed that the PLAN would escort WFP shipments (SCMP 2011b). In accordance with this informal agreement, the PLAN substituted NAVFOR on four occasions, thus simultaneously freeing up the latter from a part of the obligations written into its mandate and allowing it to allocate resources towards other more pressing counter-piracy matters (People's Daily 2013; Interview 14). For the PLAN, this exchange was perceived as a further opportunity to build "trust," by supporting such initiatives for its warships to escort vessels other than those that are Chinese, while in continuation with of its empathic expression towards Chinese officers, an EU NAVFOR spokesperson declared being "hugely grateful" for this assistance (SCMP 2010; SCMP 2011a). Furthermore, in 2012 - alongside the Indian and Japanese navies present in the region - the PLAN surprisingly threw its support behind the implementation of a trilateral coordination mechanism as a supplementary means of enhancing their counterpiracy performances (Economic Times 2012). Whereas, as of 2015, the PLAN has carried out joint counter-piracy exercises with South Korean, Pakistani and US naval vessels while crossdeck exchanges and mutual information sharing sessions were held with naval representatives of EU NAVFOR, NATO, CMF, South Korea and Singapore (Zhang 2015).

Lastly, the fact alone that the PLAN did not revert back to its isolationist and even obstructionist stance but remained a focal part of the counter-piracy effort (as proven by its active participation within multilateral settings such as the CGPCS and SHADE mechanism to this very day) could be interpreted in itself as tacit proof that it assisted the international community in combating the Somali piracy phenomenon. ${ }^{161}$ This argument should not be taken lightly in light of past and current experiences when the West and the PRC have not

\footnotetext{
${ }^{160}$ In December 2014, China sent its nineteenth naval escort piracy task force to the GoA (Weening 2014).

${ }^{161}$ China has since co-chaired certain SHADE working groups meeting along with Russian naval representatives (Hopkins \& Rivasseau 2014).
} 
seen eye-to-eye on the resolution of crises situation, as seen in the case of the Darfur conflict. Beijing could have decided, especially after the failure of the SHADE co-chairmanship bid, to scale back on the PLAN's contribution to the overall counter-piracy effort. As a result, its resources could have been redirected back towards a more peripheral effort which although it may have not proved detrimental to the coalitions' plan of action, simply would have made life more complicated for the counter-piracy exercise as a whole both in terms of achieving objectives and for diplomatic purposes. Since Beijing appeared comfortable with its decision to go along with a more integrative stance, backtracking on the benefits of enhanced coordination and reneging on the trust fostered with the coalitions' staff seemingly never arose as viable option from 2010 onwards.

These examples notwithstanding, it can be argued that the intensity of exchanges between the PLAN and NAVFOR never quite reached the same heights during the post-2010 period as it had in the previous two years, which probably is the result of a natural evolution. But, here too, this is largely explained by the process of trust-building undergone between the two sides. In effect, some would say that the PRC and the coalitions had no need to push the boundaries of their dealings any further since what mattered most - the PLAN's tactical rapprochement - had been realised in more ways than one. China's co-chairmanship bid in a sense obviously came across as a significant compliment to the achievement of this succinct objective (regardless of the bid's eventual shortcoming). Others would argue that as the EU and China agreed to arrange biennial meetings between staff from the EU's Crisis Management and Planning Directorate with interlocutors from the Chinese Ministry of National Defence, as of 2011 onwards - for which counter-piracy would feature as an important component on the agenda - the legacy of these intense exchanges was preserved (Interview 14). ${ }^{162}$ This would especially appear to be the case given that this particular decision was taken during a high-level bilateral EU-China meeting conducted by Dai Bingguo (a leading member of China's State Council) and former High Representative Lady Ashton (Herald Tribune 2012).

On paper, evidence would suggest that both sides were content with maintaining the favourable status quo they had achieved over the course of the two first years of the counterpiracy struggle, rather than risk possible disappointment by over-extending the expectations of their bilateral interaction only for the outcomes to fall short. Hitherto, there have been little in the way of tangible outputs resulting from their bilateral discussions on counter-piracy

\footnotetext{
${ }^{162}$ On top of this, PLAN commanders made several ad hoc visits to the OHQ in Northwood (EU NAVFOR
} 2011). 
within the broader framework of the strategic partnership to contradict the idea that both sides are satisfied with maintaining the status quo - despite the handful of WFP escorts undertaken by the PLAN, the odd case of bilateral assistance to release a hijacked ship and a joint orientation seminar focused on counter-piracy (EEAS 2013). ${ }^{163}$ Perhaps both sides had already over-exceeded their natural propensity for cooperation, thereby explaining the slowdown in activity once the bilateral interactive threshold had been reached. A more credible line of thought would posit that the relaxation in the intensity of their exchanges relative to counter-piracy was most likely caused by the turnover of leading naval officers within all of the coalitions, in and around winter 2010 (Interview 25; Interview 26). This turnover, which was expected to take place, would have had an immediate impact on the conduct of bilateral interaction due to the fact that PLAN staff had entrusted officers within the coalitions who had just moved to pastures new. A new assembly of officers were chosen to succeed those initially appointed, which entailed that the entire process of trust-building as witnessed between early 2008 and late 2009 would need rekindling if both sides were intent on reinforcing the success of their earlier interaction.

This partly confirms the assumptions put forward in chapter 4 about the institutional memory of trust in the context of Sino-European relations which demands considerable continuous investment to cultivate and maintain and the argument put forward throughout this thesis concerning the primordial importance of cognitive-based political trust in shaping the outcome of bilateral interaction. Yet given the lack of any form of bilateral mechanism to maintain and develop these levels of trust with an eye on the bigger picture of the strategic partnership, they easily stagnate and disintegrate without seemingly leaving any imprints on the long-term future of Sino-European ties. It would thus appear that, in the context of the broader picture of the interaction between the EU and China on security risk management in Africa, cognitive-based political trust - when it is detectable - cannot be transferred across contexts as the lack of a form of bilateral institutional memory implies that such trust cannot be reignited when needed. Once the individuals who have fostered trust are no longer responsible for bilateral interaction, the trust they helped to foster disappears along with them, with the wider bilateral political divide re-emerging to set the backdrop to any future interaction. Newcomers and replacement actors are then obliged to start the process anew if they desire to attain levels of trust parallel to those developed by their predecessors on either

\footnotetext{
${ }^{163}$ With regard to the case of bilateral assistance, EU NAVFOR played the role of intermediary between a Taiwanese delegation and the PLAN in June 2012 to help release a hijacked ship (FV Shiuh Fu $\left.n^{\circ} 1\right)$ and crew (made up of Chinese, Filipino and Vietnamese seafarers). NAVFOR then assisted the Chinese navy to locate and eventually rescue the captured vessel (see: Gros-Verheyde 2012b; Interview 9).
} 
side of the spectrum. This was the case for Sino-European cooperation on counter-piracy as of January 2010 onwards.

Naturally though, the objectives and needs for the latest arrivals at the OHQ were dissimilar to those of their predecessors. The PLAN was not by that stage an obstacle to counter-piracy by any stretch of the imagination, whilst the newcomers were not faced with the pressures which their predecessors had faced in terms of devising a counter-piracy plan of action, such as having to make optimal use of the slim resources available to the international community to fight piracy in an environment dominated by suspicion. By the time they had taken up their roles, the wheels of the counter-piracy efforts had well and truly been set in motion. Other than keeping up the momentum or tweaking the tactical design to improve operational efficiency, no such groundbreaking efforts were required. It was more a case of taking the counter-piracy effort to the next level in the hope of finishing off the job sooner rather than later. With trust-building demanding a fairly long-term and labour-intensive approach, the successors would simply not have seen the necessity of starting over from scratch even if maintaining the positive levels of cooperation achieved with the PLAN would still have featured on their list of priorities. Nevertheless, the turnover in staff may well have slightly eroded the confidence PLAN officers had in the coalitions, as familiar faces were replaced by unknown quantities. This does not imply that mistrust was automatically generated between the two sides. The good impression made by the original OHQ staff, as well as a similar process of general positive identification, would have naturally mitigated any such misgivings.

But both sides had virtually receded back to square one - of a more harmonious drawing board - and would need to undertake their own trust-building process to match the heights observed during the first phase of counter-piracy. The futility for either side to go through this process once more undoubtedly goes some distance to clarifying as to why the onus was on maintaining the status quo and not on substantially upgrading the nature of their bilateral interaction. It could be argued that since bilateral interaction did not recede back to the more strained state of affairs witnessed at the start of the counter-piracy effort, cognitivebased trust had institutionalised itself to a limited extent. But with no mechanism - other than the odd dialogue and meeting, whether in Brussels, Beijing or at sea - to maintain and build upon the momentum generated in this particular instance, the degree of institutionalisation and transferability remains questionable because cognitive-based trust only pertains to this particular case and period in time. In light of the paucity of concrete developments since January 2010, especially when it has come to taking the fight against pirates on land as part of 
the natural evolution of the fight against piracy, China and the EU seem to be back where they started with the PRC preferring to act unilaterally as opposed to showing more wholehearted commitment to the integrated counter-piracy endeavours promulgated by the EU.

For all the highly-publicised confidence-building activities held with NAVFOR and the other naval forces mentioned above, the PLAN has preferred to maintain a certain distance with other international efforts, treating such exchanges more as: "[...] bilateral diplomatic sweeteners, added bonuses to its core piracy responsibilities" (Erickson \& Strange 2013). This is particularly true when highlighted against the patterns and trends witnessed as part of other relevant independent deployers' interactions with NAVFOR and the other coalitions. For example, although Japan dispatched warships to the region at a slightly later date than the PLAN, escorted fewer vessels in absolute terms and engaged in similar training exercises with NAVFOR and NATO in and around 2014, its overall contribution to the international fight against counter-piracy has been more comprehensive and more in line with the expectations of its European counterparts (MOFA 2015; Rider 2015). Not only did the Japanese navy participate in CMF in the same way that the South Korean navy did, but it even took temporary command of CMF's counter-piracy operations out of its own free will and played an active role within multilateral settings (FCO 2014; MOFA 2015). ${ }^{164}$ Throughout the entire counter-piracy context, the Japanese navy - whether at sea or through its naval diplomacy on land - has shown an incremental propensity to immerse itself in the international community's efforts and doing so from a holistic perspective rather than simply limiting itself to a fairly narrow naval contribution.

The Chinese and Japanese cases are comparable to the extent that they both started out in similar positions as independent deployers. Yet, for all the PLAN's exchanges of goodwill and the consistency it has shown in its efforts to bring down successful pirate attacks in the GoA, its trajectory in the post-2010 period has not been on the same upward curve as it was from the latter stages of 2009, especially when compared to the performance of other independent deployers such as the Japanese case. This is undoubtedly connected to the unsuccessful attempt at seeking out the co-chairmanship of the SHADE, but there clearly also exists a strong correlation between the changeover of staff at NAVFOR (and within the other coalitions), the evolution of the urgency of the counter-piracy context and the need to rekindle strong levels of trust in order to get the PLAN to take that extra step of committing to the fight against piracy on land. As a case in point, although efforts were made by European actors to

\footnotetext{
${ }^{164}$ Japan has served as chair for certain CGPCS meetings.
} 
transfer the interaction witnessed between both sides at the SHADE to discussions about solutions for tackling the root causes of piracy on land, the Chinese simply refused to assist EU officials responsible for the latter's operations in this regard - EUTM Somalia and EUCAP NESTOR (Interview 11; Interview 13; Interview 14). ${ }^{165}$ In comparison, Japan initiated the IMO's Djibouti Code of Conduct multi-donor trust fund, donating around US\$ 15 million in the process towards capacity-building exercises for authorities in Somalia and in neighbouring countries, so as to improve their endogenous capabilities to prevent and suppress acts on piracy by taking the necessary steps on land (MOFA 2015). In effect, the Chinese government's decision to turn down the EU's offer speaks volumes both about the limitations underpinning the institutionalisation and transferability of cognitive-based political trust between the EU and the PRC within the counter-piracy context, as well as the longerterm impact this had on the nature of China's overall contribution to the international counterpiracy effort. It also says a lot about the potentially divisive role that local third parties and the social environment can have on bilateral cooperative endeavours on this theme, especially when one compares the outcome of this interaction in international waters as opposed to the opportunity to pursue cooperation on land. Had such levels of cognitive-based political trust persisted between the two sides, there are strong chances that the qualitative impact and depth of the PLAN's contribution could have taken on attributes as impressive as its quantitative impact (Erickson \& Strange 2013). Yet, as NAVFOR officers and EU officials may have come to realise over the past few years, to ask that much of their Chinese counterparts in this type of context is still somewhat premature. This just goes to show that it is above all cognitive-based political trust (or the lack of) which predominantly shapes the outcome of bilateral relations on the topic of security risk management in Africa, regardless of the impact that other variables can have, particularly rational variables. As seen throughout this chapter, it is the detection of cognitive-based political trust that allowed favourable rational variables to be converted from the theoretical idea of coordination and cooperation to the practical implementation of coordination and cooperation between NAVFOR and the PLAN, as epitomised by the role played by the latter in impacting the latter's approach towards the SHADE. Cognitive-based political trust between the officers from both sides largely contributed to the evolution of the PLAN counter-piracy approach from its traditional tactical

\footnotetext{
${ }^{165}$ EUTM Somalia, launched in 2010, is designed: "to contribute to strengthening the TFG and the institutions of Somalia" (see: http://www.eeas.europa.eu/csdp/missions-and-operations/eutm-somalia/), while EUCAP NESTOR: "is a civilian mission which assists host countries in developing a self-sustainable capacity for continued enhancement of the maritime security, including counter-piracy and maritime governance" (see: http://www.eeas.europa.eu/csdp/missions-and-operations/eucap-nestor/mission-description/index_en.htm).
} 
stance towards a more integrative one, which contributed in part to China becoming one of the leading actors within the counter-piracy realm rather than just a peripheral actor. 


\section{Thesis Conclusions}

\subsection{Trust and the Failing of the Bilateral Institutional Memory}

The cases of bilateral interaction in Darfur and on counter-piracy were selected in part because - with the possible exception of Zimbabwe - they figured as the first real instances where China and the EU needed to seriously acknowledge each other on the theme of security risk management in Africa. Both cases were also selected because of their chronological proximity, having both taken place in the first decade of the $21^{\text {st }}$ century and thus making for a more salient comparative analysis. But with parts of the African continent coping with bouts of instability caused by the side-effects of the Arab Spring movements in the Maghreb and Mashriq regions, the bilateral agenda on this particular theme has been confronted with a new series of problematic items. An overview of these latest developments is key not only to fulfilling one of the main objectives behind this thesis (i.e. providing an assessment of the bilateral state of affairs on the continent when it comes to security risk management), but also in terms of looking into the idea of the institutionalisation of trust as explored in the conceptual framework and fleetingly across chapters 5 and 6 . Indeed, the verdict thus far contends that cognitive-based trust would appear to be difficult to transfer even between agents working on a case where both sides have instilled a degree of cooperation, as predicted by the initial thinking on this point raised in chapter 4. As aforementioned, despite the existence of bilateral institutional mechanisms (bilateral dialogue on Africa) to facilitate the transfer of trust amongst officials on both sides of the spectrum, it would appear that the mechanisms in question are ill-suited to institutionalise trust, have not received adequate backing, have not been sufficiently exploited or necessitate more time in order to produce more tangible outputs.

Nonetheless, when assessing cases of bilateral interaction from a very general standpoint, the collaborative endeavours to help fend off the Somali piracy threat could be interpreted as a turning point with regard to the state of affairs when it comes to security risk management in Africa. At the very least, their ability to work side by side on that specific case could be seen as setting the tone for any ensuing interaction, allowing them to deal with one another on a more level footing should the need arise. For both sides to have developed such linearity and continuity in their dealings would require that they utilise the mechanisms for the institutionalisation of trust explained in the previous paragraph. As the contrasting outcomes of their interaction over the course of the following examples will show (on events in Libya and Mali), since cognitive-based trust (or the lack of it) serves as the primary explanatory variable determining the nature of their dealings in this respect, its 
institutionalisation remains a non-issue. For as long as the nature of bilateral interaction is characterised by the absence of linearity but characterised instead by susceptibility and volatility, it will be nonsensical to give credence to the idea of institutionalised trust. Perhaps for a host of various reasons it might be premature to pass judgement on the institutionalisation of bilateral trust solely on the basis of these two examples, given that it may be asking for too much too soon. Neither events in Libya nor Mali figure as perfect follow-up examples in the sense that the EU and China were not directly confronted with these issues as part of a bilateral agenda, even if they do both fall within the wider realm of Sino-European ties. In the short-term at least, these examples should offer clarification to the following questions: have both sides been able to build upon the success of their counterpiracy cooperation? Have bilateral mechanisms made a difference by helping to transfer consolidated trust from one case to another? Have the conditions been permissive for the transfer of trust in this regard? Can we speak of trust having been institutionalised? What impact did local/regional actors have? As this part of the concluding section to this thesis will now elaborate, the evidence would tend to raise more questions than answers when it comes to assessing the institutionalisation of bilateral trust on this theme.

\subsubsection{The Libyan Revolution}

If there is one example which belies the existence of any institutionalised form of bilateral cognitive-based political trust it is developments on the matter of the Libyan revolution, which saw Chinese and European actors somewhat re-enacting their behaviour over the resolution of the Darfur crisis. Counter-piracy may well have been trumpeted as a possible watershed moment for the EU and China following previous fallouts over Zimbabwe and Darfur but when faced with the nature of the problem in Libya, it was almost as if this step forward had never taken place. Instead, in terms of bilateral interaction on security risk management in Africa, Libya was a case of going back to square one. On paper, the argument could be made that up until the NATO bombing campaign over Libya - spearheaded by a number of EU member states - had commenced, the EU and China unexpectedly found themselves in agreement on how to handle this situation. To begin with, the Chinese government voted in favour of Resolution 1970 imposing sanctions upon the Gaddafi regime (in the shape of an international asset freeze, travel ban and arms embargo), which was significant for this was the first time in modern Chinese history that Beijing had voted to sanction a fellow sovereign government (Hirono \& Neill 2012: 6). Thereafter, China consented to the second major UNSCR relating to the situation in Libya (1973) by refusing to 
veto the proposal and thereby tolerating: "[...] interventionist action purely based on humanitarian reasons" (Richardson 2012: 10). Through its abstention, China (as well as the other four abstainees) allowed other members of the international community to use this Resolution as the legal basis to their subsequent military action in Libya, since the Resolution had granted UN member states the authorisation: "[...] to take all necessary measures [...], to protect civilians and civilian populated areas under threat of attack in the Libyan Arab Jamahiriya, including Benghazi, while excluding a foreign occupation force of any form on any part of Libyan territory" (UNSC 2011a: 3).

In the same way that Chinese activism in Darfur had been the cause of intrigue for Chinese foreign policy experts, the decision to not veto a foreign intervention into a sovereign territory occupied by a seating government - itself naturally opposed to any form of external meddling - came across as a surprise since it defied the PRC's usual stance on state sovereignty. This gave the impression once more that the tide may finally have been turning in relation to the modernisation of Chinese foreign policy, with officials in Beijing seemingly re-evaluating the feasibility of continuously holding firm to the principles of state sovereignty and territorial integrity. However, any impressions that China was siding with the EU and European members of Security Council (with the possible exception of Germany) were soon dispelled when it came to the best way of solving the Libyan crisis. Whereas the EU (for the most part) believed that the source of all wrongs in the crisis resided exclusively with the Gaddafi regime - and thus the solution to this problem consisted of accelerating regime change through the implementation of Resolution 1973 - the PRC's take on events could not have been any further apart. In fact, along with the Russian representation at the UNSC, it called for an "immediate ceasefire" of the NATO bombing campaign as it saw these attacks as disproportionate, careless of civilians and extending beyond the no-fly zone which the Resolution had made clear needed enforcing so as to protect civilians (Bellamy \& Williams 2011: 845; Tisdall 2011; Hirono \& Neill 2012: 7; Richardson 2012: 12).

European leaders may have justified the NATO-led military intervention in Libya on the basis that they felt a "moral duty" to avoid another humanitarian disaster similar to that witnessed in Rwanda or Srebrenica - in light of the Libyan army marching on the rebels' final stronghold in Benghazi whilst the Gaddafi family promised drastic retaliatory action against the rebels (Hirono \& Neill 2012: 7; Interview 5). Inter alia, Gaddafi had made repeated threats of wanting his armed forces to show "no mercy" with the rebels in Benghazi in what was supposed to be the final showdown of the revolution, even granting his troops the freedom to "cleanse" every house in the country of rebels if need be (BBC News 2011; Huffington Post 
2011). With a UNSCR in hand and with regional actors unwilling or unable to take on the responsibility to intervene alone in Libya, EU member states led by France and the UK believed that the veil of constricted activism had sufficiently been lifted for them to orchestrate a bombing campaign to enforce the no-fly zone and prevent the supposedly pending humanitarian disaster. Yet, as aforementioned, they also took it as their best chance of indirectly supporting the rebel movement to enact regime change upon Gaddafi - who for long periods in the 1980s and 1990s had been a thorn in the West's struggle with international terrorism.

Naturally, Chinese officials opposed what they interpreted as a blatant violation of Libya's sovereignty and of the Resolution, since this type of orchestrated manoeuvre to oust a sitting authoritarian government - and one with virtually no standing in the West - triggered concern among these officials. Indeed, these are exactly the kind of scenarios which cause concern in Beijing for the fear that the West could attempt to bring the Chinese government's sovereign control into disrepute by concocting a similar approach to domestic affairs in the PRC. As a result, Beijing was obliged to respond in a critical manner to the generous interpretation European actors had of the Resolution, in order to sound its own warning shot to those parties harbouring ambitions to plot a similar scheme against the Chinese government. In actuality though, the PRC had never really supported the international community's overall approach to the Libyan question in the first place, but only went along with the initiatives passed through the UNSC because it could not afford to alienate itself by single-handedly going against the wishes of the international community. Its vote in favour of Resolution 1970 was mostly justified on the grounds that it took its cues from local and regional actors such as the AU, LAS, OIC and Gulf Cooperation Council (GCC) who all supported the sanctions on the Gaddafi regime (Marlier \& Kao 2011: 18-9). Similarly, China retracted from its initial opposition to Resolution 1973 mainly because the AU, GCC and LAS had actively supported the enforcement of the no-fly zone, with the Kingdom of Jordan, Qatar and the UAE all contributing to the eventual NATO mission (Bellamy \& Williams 2011: 841; The Economist 2011; Kingah \& van Langenhove 2012: 215). ${ }^{166}$ Without such support from these regional parties, the proposal for military intervention would never have made it through the Security Council.

\footnotetext{
166 The AU may have voted in favour of enforcing a no-fly zone following South Africa's vote in favour at the UNSC (in its role of non-permanent member at the time), but contrary to its Middle Eastern counterparts the AU did not rousingly endorse military intervention or the use of force (van Hoeymissen 2011: 96-7; Omorogbe 2012: 143).
} 
For its part, China had opposed the use of force in Libya as it felt the specificities of enforcing the no-fly zone remained unclear and did not believe that this would help bring peace and stability to the country, as alternatives had yet to have been given serious consideration (Bellamy \& Williams 2011: 843; Richardson 2012: 9; Yun 2013). In reality, it never wanted to adopt more coercive measures than those already sanctioned by UNSCR 1970 (Bellamy \& Williams 2011: 840). As China's Permanent Representative to the UN Li Baodong said at the time:

the continuing deterioration of the situation in Libya was of great concern to China. However, the UN Charter must be respected and the current crisis must be ended through peaceful means. China was always against the use of force when those means were not exhausted (cited in Marlier \& Kao 2011: 2).

Nevertheless, it was not willing to upset the looming regional consensus which also believed in the notion that Gaddafi's day of reckoning had arrived and needed to be seen through, due to the latter's unpopularity with other key regional actors (Bellamy \& Williams 2011: 825). ${ }^{167}$ Unwilling to tip this balance, the PRC opted for the consensual approach of abstaining, thus permitting it to tacitly support the preferences of those regional voices (which Beijing perceived as being legitimate in this context) all the while demarcating itself from the Western position by creating the space with which to criticise the intervention.

The lack of convergence about what to do to solve the crisis between China, the EU and the large majority of EU member states meant that there was no common source of identification which officials on both sides could use to foster cognitive-based political trust. Clearly, the institutionalisation of trust from the counter-piracy experience had become a redundant concept by this stage of this crisis. This situation was compounded by the fact that the EU and China found themselves rooting for opposing sides of the conflict, even if contrary to the situation in Darfur, the PRC's relationship with the host state was nowhere near as close. Over the course of the crisis, commentators have often made reference to the fact that Chinese companies in Libya had seen sizeable investments go up in smoke due to the rebel uprising, NATO airstrikes and the government's heavy-handed response, with financial losses estimated close to the US\$ 20 billion mark (Stahl 2011: 162; Ferdinand 2013: 8). Reference has also been made about Beijing having to order a PLAN vessel out of its mission

\footnotetext{
${ }^{167}$ Gaddafi's regime was widely distrusted across Africa and the Middle East: "[...] not least for its role in fuelling conflicts in Liberia, Sierra Leone and Chad, as well as the radical Republican Front of the Liberation of Palestine. Gaddafi was also a prominent rival for regional influence with Saudi Arabia and other Gulf states" (Bellamy \& Williams 2011: 842). As a case in point, the LAS did not hesitate to suspend Libya's participation in February 2011 until the violence had ceased - which showed how highly members of that organisation thought of Gaddafi's regime (Ibid: 839).
} 
in the GoA to redirect it to the Mediterranean to help evacuate a large part of the 36,000 Chinese guest workers based in Libya at the outbreak of the crisis as part of the 75 Chinese companies involved in the Libyan oil sector, network development, railway and irrigation construction industries (Richardson 2012: 10-1; Lanteigne 2013: 12-3). This being so, its ties to the Gaddafi regime were quite poor especially when compared to its dealings with alBashir and his respective entourage. When Gaddafi was still in power, Libya did not make it into China's five most important oil-producing partners in Africa and the former had even disapproved of the sale of a Canadian-based oil exploring firm (well known to the Libyan regime) to CNPC in 2009 (Escobar 2011; Lee et al. 2012: 433; Sotloff 2012). Consequently, Libya did not feature as a top priority as far as China's African diplomacy was concerned. As a case in point, Jiang Zemin was the last Chinese President to pay a state visit to Libya all the way back in April 2002 (Hirono \& Neill 2012: 6; Lee et al. 2012: 433).

Notwithstanding the PRC's bilateral relations with Libya having taken a similar course to that of many other members of the international community, the leadership in Beijing refused to let this factor detract them from their core foreign policy mindset of state sovereignty. In other words, just because European actors had decided that the revolutionary movement in Libya signified the end of Gaddafi's rule, the Chinese government did not follow suit by taking the side of the rebels but stuck to its habitual stance of looking for a solution by working through the sovereign authority in place, rather than work around it. China may have voted in favour of sanctioning the regime by supporting UNSCR 1970 but it had no intention of seeing Gaddafi dethroned and certainly did not envisage seeing the regime collapse into the hands of the rebels, following Western interference. According to one author, the PRC wanted: "[...] for the rebels to collapse, with Gaddafi back in charge of the whole country and no "regime change" (Escobar 2011). This thinking characterised the Chinese approach to the crisis even until the latter stages and could not have been further apart from the approach of most European countries who strove to get behind the revolutionary movement almost from the very start of clashes with the regime.

In fact, it took only a matter of weeks for EU member states such as France and Italy but also for Ashton herself to open talks with the NTC about the transition of power in Libya (Bellamy \& Williams 2011: 841). Incredibly: "Sarkozy agreed to officially recognise the NTC as Libya's legitimate government when the rebellion was barely three weeks old and when the rebels had lost most of their initial territorial gains" (Kuperman 2013: 124). As previously explained, the EU had made it clear from the off whose corner it was willing to fight and the rhetoric employed in Brussels and across member state capitals to make sense of events on the 
ground soon began to confuse government retaliation against the rebels for possible widespread strikes against innocent civilians - despite there being insufficient evidence to this day that Gaddafi had ordered vengeful attacks on ordinary Libyans (Ibid: 110). Notwithstanding this crucial detail, the possibility of strikes against the civilian population as misinterpreted through the threatening language employed by Gaddafi targeting the rebels, led to civilians and rebels being purposefully placed into the same bracket by European actors as needing assistance to prevent them suffering Gaddafi's wrath. Basically though, this simplification was undertaken because a number of European political leaders had a bone to pick with the Libyan leader himself, which transcended down to the level of European officials involved in the management of the crisis.

Therefore, from early statements condemning "the violence and use of force against civilians" and deploring "the repression against peaceful demonstrators," the EU's rhetoric rapidly escalated to the point where demands were being made in Brussels for Gaddafi to "relinquish power immediately" (Ashton 2011: 1; EU Council 2011a: 8). It even went so far as to give "those working with the regime" an ultimatum as early as April 2011:

to continue to associate themselves with the brutal repression of the Libyan people by Colonel Gaddafi or work to support an orderly and Libyan-led transition to democracy through a broad-based dialogue in the interests of the security and prosperity of all the Libyan people (EU Council 2011b: 7).

The EU's identification with the anti-Gaddafi movement in Libya could not have been any more stark or evident from that moment onwards. In fact, beyond the diplomatic recognition of the NTC as the preferred partner of choice for what the EU considered as the preparatory steps for a post-Gaddafi Libya, the EU member states participating in the NATO campaign went beyond the call of duty to assist the rebel movement and the downfall of the regime (Kuperman 2013: 112). They subsequently interpreted Resolution 1973 as providing the basis for a wide range of military activity including the suppression of the Libyan air force and other components of its field forces, facilitating the path to regime change (Bellamy \& Williams 2011: 845). The bombing campaign targeted tanks, APCs, air defences and military command and control centres to degrade the regime's military capabilities, while repeatedly targeting Gaddafi's residences in a: "[...] presumed attempt to assassinate the Libyan leader" (Omorogbe 2012: 160; Faligot et al. 2012: 645). The French and British governments supported covert attempts made by their military personnel to help the rebels by providing training to their forces, guidance in their command and control centres and in going against 
the arms embargo outlined in UNSCR 1970 by airdropping weapons to the rebels (Ibid; Kuperman 2013: 114; Ulfstein \& Føsund Christiansen 2013: 168).

All of this was a far cry from the stipulations of Resolution 1973 calling for the protection of civilians via the enforcement of a no-fly zone. Two scholars have put forward an interesting synopsis in this respect about the extent to which European actors decided to empathise with the objectives of the rebel movement in wanting to take down the selfproclaimed 'Guide' and his regime:

the coordination between the rebels and NATO while the rebels advanced on Gaddafiheld territories, witnessed NATO taking sides in the conflict. The traditional UN principle of impartiality implies that when the Security Council authorises the use of force in situations of armed conflict, unless otherwise specified, the intervening states should remain neutral towards the political aims of the parties of the conflict. Evidently, during the Libyan conflict, NATO and its allies acted solely on the part of the rebels, although the mandate did not take sides in the conflict (Ulfstein \& Føsund Christiansen 2013: 169).

Unsurprisingly, when the first signs began to emerge of the bombing campaign bearing fruit as far as the advances of the rebel movement on Gaddafi strongholds were concerned, the EU made sure it was first in line to lead the congratulatory announcements of the rebels having taken Gaddafi's hometown of Sirte, where the latter's death was simultaneously pronounced: "after ten months of extraordinary sacrifices, the Libyan people can say with pride and confidence that they have shaken off a regime that terrorised and oppressed for more than 40 years" (EU Delegation to the UN 2011). A declaration of this order raises eyebrows in the sense that European actors seemed as much relieved as the rebels to see the back of Gaddafi, which only confirms that they were right behind the rebel cause for as long as it involved deposing the former Libyan leader.

For its part, China only made contact with the NTC in June 2011 (Richardson 2012: 13). ${ }^{168}$ During the same month though, Beijing had continued to engage with the ruling regime as its officials agreed to meet with the then Libyan Foreign Minister (The Economist 2011). Furthermore, Chinese representatives remained aloof from the international meeting held in Turkey in July 2011 where Western governments, Middle Eastern governments and the NTC met to discuss Libya's future (Richardson 2012: 12-3). Such seeming disinterest is probably explained by the fact that Chinese officials may still have been hedging their bets on the survival of the regime instead of making plans for its anticipated downfall. Documents

\footnotetext{
${ }^{168}$ During the earlier stages of the conflict, the Chinese government had also thrown its weight behind Gaddafi's reign by opposing Libya's suspension from the UN Human Rights Council (Xinhua News Agency 2011). The PRC was nevertheless powerless in preventing Libya from seeing its membership suspended at the time.
} 
found by The Globe and Mail provide evidence of this pro-Gaddafi attitude within the halls of power in Beijing, as they report that members of Gaddafi's entourage travelled to Beijing in July 2011 to meet with representatives of state-controlled arms manufacturers to discuss the possibility of a US\$ 200 million arms deal (Sotloff 2012). Had such a deal been sanctioned by the Chinese government this would have implied contravening the same UN arms embargo on Libya which China had voted in favour of. Regardless of whether this deal was concluded or not, the fact that talks went ahead is testimony to the Chinese commitment to maintaining Gaddafi in power. It was only until the writing was well and truly on the wall for the Gaddafi regime in September 2011 that the PRC went through with its own official recognition of the NTC as the legitimate authority in Libya - well after the rest of the international community had done so (Richardson 2012: 12-3).

If the absence of converge and commonality between the EU and China - at the highest levels of government - regarding Libya entailed that trust between their respective officials on the ground was always likely to be non-existent (and thus clearly not successfully institutionalised), then the social context in which the crisis unfolded was not particularly promising in terms of bringing the two sides together in this respect - a situation undoubtedly unaided by the unwillingness of the Libyan regime to see the international community conspiring in unison against his regime and thus doing its best to derail potential cooperation between actors such as the EU and Chinese officials. In effect, as the situation in Libya deteriorated and degenerated rapidly the entire ordeal was dealt with at a speed which did not allow much room for negotiations or discussion on alternative proposals. The protests had begun in February 2011 while the UNSC had already ruled on Resolution 1973 by the following month, at which point Gaddafi's fate was sealed. From the moment NATO and its allies were given the go-ahead to enforce the no-fly zone there would be no turning back since there was nothing to impede these actors from following through in their determination to overcome the regime. Those against regime change had to take responsibility for not having vetoed the no-fly zone proposal regardless of the ethical debates surrounding the ensuing campaign to oust Gaddafi, while the latter was too isolated politically to be able to call upon allies to robustly counter the NATO-led aerial support to the rebel advances on the ground. As a result, the only window of opportunity in which noteworthy international talks on approaching the Libya crisis could take place barely lasted a month, leaving little opportunity for officials assigned to this case to work on exploring different options with the other main interlocutors (Bellamy \& Williams 2011: 825, 845; Richardson 2012: 11). 
Whatever suggestions were put forward for mediation between the Libyan government, the rebels and the concerned third parties were either lacking in credibility or rejected out of hand (Jones 2011: 55). For example, the AU's Peace and Security Council wanted a powersharing agreement in Libya between the regime and the NTC similar to that which regiments current-day politics in Zimbabwe, with South Africa's Jacob Zuma (for the AU) and the Venezuelan government both offering to play the part of peace broker (Omorogbe 2012: 162; Kuperman 2013: 115; Ulfstein \& Føsund Christiansen 2013: 165). This initiative for a peaceful settlement had been preferred all along by the AU, received support from Russia and China amongst others at the UNSC level and even apparently appealed to the regime (Kuperman 2013: 115; Ulfstein \& Føsund Christiansen 2013: 165). However, the rebels were never serious about mediation and set as an initial condition for negotiations that Gaddafi first step down before any such peace talks could be engaged (Omorogbe 2012: 162). At the same time, European actors did not appear to encourage the rebels and NTC to take up the offer of a peaceful settlement given that they remained adamant that Gaddafi's army was on the cusp of committing grave crimes against humanity in Benghazi and thus needed to be stopped rather than engaged in talks. As Alan Kupermans argues, there has hitherto not been any counterfactual evidence presented which would suggest that those parties involved in the bombing campaign attempted to use their leverage over the rebels to get the latter to explore the advances of the regime, as sponsored by certain regional parties (2013: 115). The reality was that the Libya vote at the USNC was all about mistrust, with "real ambivalence and real cynicism" clearly playing an important part in this instance (Jones 2011: 55).

Hypothetically speaking, even if a more extensive window of opportunity had opened in which the EU could have attempted to reconcile its stance with the more cautious members of the UNSC, including the PRC, it lacked the political authority to do so. Quite simply, to tackle matters on the ground NATO had been preferred for it possessed a number of advantages that the EU could not offer such as: a functioning operational procedure (including a command and control structure in Naples); a framework allowing for considerable US military support during the operation; and a flexible political framework allowing for unity in action despite differences amongst NATO member states (due to the principle of constructive abstention) (Techau 2013: 270). ${ }^{169}$ Diplomatically, any critical negotiations on Libya took place in New York where the EU's lack of an actual seat continuously leaves it exposed to the

\footnotetext{
${ }^{169}$ According to information gathered during interviews, Sarkozy and his team preferred using NATO over the EU this time around to mark France's return to the NATO Command Structure, engineered under Sarkozy's presidency (Interview 1; Interview 5).
} 
political calculations of its member states. Since the two key member states in this context, France and the UK, had opted to intervene and decided that the best course of action came in the shape of a NATO-led mission, the EU was soon left to play a bit part role which entailed using strong rhetoric but only really being able to impact the humanitarian side of the crisis through important donations and a civilian CSDP mission (Menon 2011: 75; Coelmont 2012: 4). ${ }^{170}$ Libya soon brought back memories of Darfur for the EU which undoubtedly explains why bilateral cognitive-based political trust was unlikely ever to be transferred, which left its officials empty-handed in terms of credibility or when it came to acting at the forefront of this particular case of security-risk management. Perhaps the EU's greatest shortcoming was its inability to come to a common internal understanding on how to approach the crisis (as epitomised by the German abstention on Resolution on 1973 despite France, the UK and Portugal voting in favour), leaving it to be bypassed by other venues and leaving member states unconvinced about granting it a credible role and mandate for action on the ground. Even the newly implemented Lisbon Treaty was unable to prevent the EU's internal implosion in the light of member states' seemingly irreconcilable differences and this as early as March 2011, at which time the Libya issue was moved out of the remit of the EU institutions (Helwig 2013: 247).

In turn, this factor only served to compound an already tricky situation in terms of bilateral interaction on this particular crisis. Miwa Hirono and Alexander Neill are correct in their fairly generous assessment that the differences in interpretation of the situation in Libya led to a lack of trust and confidence between the two sides, which only hampered "deepening military cooperation" (2012: 7). Unfortunately, the repercussions of this competitive bilateral outcome go beyond what would appear to be another missed opportunity, as was the case for Darfur. However, the similarities between these cases stop here given that the international fallout over what to do in Libya, conjoined with the unforeseen regional ramifications of the collapse of the Gaddafi regime, have only helped contribute to the development of new civil conflicts to which the international community has found itself stuck in a stalemate. More specifically, evidence has shown that the NATO intervention in Libya has caused collateral damage in the wider region by "encouraging the militarisation of Syria's uprising" and, as explained in the section below on Mali, by creating a more favourable climate for the insurgency which took hold of the north of that country throughout 2012 (Kuperman 2013:

\footnotetext{
${ }^{170}$ The EU provided more than $€ 156.5$ million in humanitarian support, with $€ 80.5$ million coming from the EU budget, which was used to help to mobilise EU civil protection teams and the European Commission's humanitarian teams (EU Delegation to the UN 2011).
} 
132). To make matters worse, from the mistrust created by NATO's broad interpretation of Resolution 1973, the short-sightedness of wanting to overthrow Gaddafi by all means only stiffened the resolve of the abstainees. In other words, since the developments that unfolded in the wake of UNSCR 1973, the veto-wielding non-Western members of the UNSC have blocked any Western initiatives they see as being comparable to what happened over Libya. Syria has been the most prominent casualty of this fallout, leaving the rebel movement to take on (with covert support from certain parts of the international community) Bashar al-Assad's forces with many Syrian civilians being caught in the crossfire (Ferdinand 2013: 6). ${ }^{171}$ Two scholars have accurately summarised the repercussions of this chain reaction, as triggered by the international debacle over Libya:

Russia, China as well as Brazil, India and South Africa have been opposed or reluctant to adopt strong Security Council Resolutions against Syria [...], the representative of Russia stated that the Syrian situation cannot be considered separately from the Libyan experience. [...] Due to fear by some countries of military intervention, the Council has not even been able to adopt non-military sanctions, such as an arms embargo or reference to the ICC. [...] The responsibility to protect is a fragile creation. The overstepping of the UN mandate in Libya may have the unfortunate effect, as the current Syrian conflict appears to underscore, that the first use of this principle may also be the last (Ulfstein \& Føsund Christiansen 2013: 171).

\subsubsection{Insurgency and Counterinsurgency in Mali}

The lessons to be drawn from the example of Libya indicate that: a) there was no bilateral cognitive-based political trust between officials from either side on the ground, which in large part stemmed from higher-level governmental differences on this issue that in part contributed to the eventual competitive outcome; b) as a result, bilateral trust showed no signs of having been institutionalised in any shape or form, with the mechanisms in place to help institutionalise trust proving ineffectual. Furthermore, if we draw Sino-European interaction on Mali into the context of this study of political trust and its possible institutionalisation, the findings are inconclusive. This is despite the fact that the outcome of this case of bilateral interaction was certainly more cooperative, with cognitive-based political trust between officials from both sides - predicated on a relatively convergent source of identification certainly playing an important part in this rapprochement. Yet, as this section will outline, it is unlikely that institutionalisation had much to do with it.

The insurgency in Mali took place in a nonlinear fashion and involved different phases culminating in the French government sending troops to the country to counteract the final

\footnotetext{
${ }^{171}$ As well as allowing groups of radical Islamists to wreak further havoc through participating in the conflict.
} 
phase of the insurgency, whereby radical Islamist groups were making a siege on strategic parts of southern Mali. Scholars knowledgeable of the dynamics behind events in Mali throughout the past few years have concurred that a large explanatory factor in the rise of instability affecting the country stemmed from, on the one hand, "the outflow of weapons from Gaddafi's arsenal" exacerbating the structural instability of the regional environment (caused by elements such as organised crime and environmental degradation) (Cristiani \& Fabiani 2013: 80,93). On the other hand, Malian security and economic dependence on the Gaddafi regime was substantial: from his instrumental patronage of local Tuareg groups to investments being injected into the weak Malian economy (Ibid). Thus, to a large extent, the collateral damage created by Gaddafi's demise exposed the weak social and political structures of the Malian nation-state, thus helping to offset the first phase of the insurgency. Fresh from having attempted to aid the survival of the Gaddafi regime, the 1,500 Tuareg fighters based in Mali - with whom the Libyan leader enjoyed close affiliations - returned to their home country: "[...] with money, weapons and the political will to change the status quo" (Ibid: 83; Lacher 2013: 2).

In response to the unrest caused by the Tuareg fighters' strive for greater political recognition, the Malian army was sent to put these protestors back in their place. When doing so, they found themselves outgunned and suffered badly as a result. This situation led to the following phase in the insurgency when the democratically elected leadership in Bamako was overturned by a military coup in March 2012 from members of the armed forces upset at having been sent to fight a battle they knew in advance they could not win (Kuperman 2013: 129). The coup severely disrupted Mali's political scenery allowing for the northern half of the country to be left virtually lawless and beyond the control of Mali's already weakened state apparatus. Tuareg groups and, most worryingly, radical Islamist organisations such as AQIM were handed a free rein with which to pursue their activities and plot their next move the latter of whom has also been busy stocking up on weapons released in the wake of the collapse of the Gaddafi regime (Ibid: 131). In fact, this allowed AQIM to mobilise other likeminded groups to capitalise on the gains made by the Tuareg movement so as to launch a raid on the southern part of the country, which they believed was vulnerable. Thence commenced the final phase of the insurgency as jihadists - after having defeated the Touaregs, imposed Sharia law and declared the north of the country independent - began moving southwards with the aim of capturing strategic posts that would have made it far more difficult for Bamako to receive overseas military assistance and ultimately would have created ideal conditions for the country to fall into the hands of these terrorist organisations (Ibid: 
129). It was by this stage that the interim Malian President began raising awareness of the gravity of the situation to the Economic Community of West African States (ECOWAS), the AU, the UNSC and other international allies.

For as long as the situation in the north of Mali was interpreted as an internal problem between the centre in Bamako and nomadic actors in the northern periphery, the international community's detailed attention to this problem was not deemed worthy enough. Yet, from the moment when political actors in Bamako began emitting distress calls about the incursion of Islamic terrorist groups from the northern boundaries of the Sahara right across key cities in the Southwest of the country, the mood changed: "it was not the Tuareg rebellion per se that turned northern Mali into an international concern, but the 'ghost' of militant Salafism” (Bøas \& Torheim 2013: 420). Upon learning of this development, the French government took it upon itself to act in the light of what it saw as a grave menace not only to the fate of the Malian state but as a direct threat to the 6,000 French citizens based in Mali and in the surrounding countries (Arieff 2013: 1; Interview 1). ${ }^{172}$ The timing of the French-led intervention was crucial because had it come any earlier, when the threat of AQIM's territorial advances was only in its inception, it may have struggled to smoothly overcome the conditions of constricted activism and would probably have been criticised by all parts for being a remnant of the Françafrique phenomenon. This being said, had the French government decided to hold back from intervening only to do so at a later stage, it may well have been a case of 'too little, too late.' Although such thinking remains purely speculative, the insurgents may well have swept through to Bamako which only would have amplified the scale of the problem - at which point the international community would have been blamed for not having moved with sufficient haste.

In effect, the Malian government had been pleading for over a year with its regional and international interlocutors for military assistance and particularly with the French government, first with Sarkozy (whose hands were tied by the 2012 Presidential election) and then with Hollande (Whitehouse 2013). The latter had also postponed any decision due to the situation not being critical to the point of expediting a contingent of French armed forces back into what previously was a French colony. In the meantime, ECOWAS had been approached by Bamako for help with the former looking both at the military and political dimensions of the crisis. The EU too had supported ECOWAS' early initiatives and had even envisaged

\footnotetext{
${ }^{172}$ A couple of articles written on the rationale of the French government to intervene in Mali mention that Paris had "declared war" on AQIM in 2010 following a failed attempt to rescue French hostages held by the terrorist group, but also because AQIM reportedly had the capacity of attracting French citizens of African origin to fight alongside it against the French (Arieff 2013: 9; Tertrais 2013: 53).
} 
assisting with the financing of its activities, all the while calling for a response to be formulated within the framework of a UNSC mandate (EU Council 2012a: 2, 3). But the reality of the situation on the ground created a disconnect between the time and resources needed to foster a regional response on both fronts and the momentum generated by the progress of the insurgency. For one expert:

[...] regional deployment was widely seen as requiring many months to prepare, pending anticipated internationally assisted training and restructuring of the Malian military, which was expected to lead operations to retake the north. Serious questions were also raised [sic] concerning troops' military capacity, commitment and human rights records, as well as the potential cost and human consequences of such an operation (Arieff 2013: 2).

In terms of needing to deal with constricted activism, this situation actually benefited the French government. When it became clear that it was the only actor willing and able to deploy troops on the ground, it did not have to expend too much political energy to justify the rationale of its efforts to the watching world. Indeed, African ownership had been tried and could not come up with the necessary goods; the French had received an explicit written intervention by the authorities in Bamako (which goes to show how much of a difference local/regional support can make); the UNSC was already poised to draw up a mandate without much fuss being made; the threat of the insurgency was obviously increasing by the day (EU Council 2013; ICG 2013: 6; Interview 19). Still, the French government did make sure that its intervention was perceived by all to be as legitimate as possible. Hollande used the rhetoric of last resort claiming to have had no other choice but to intervene following the request of the Malian government, portraying the intervention as necessary to prevent the Malian capital from falling into the hands of terrorists, to protect French citizens, help rescue French hostages held captive in the North and provide assistance to the 300,000 Malian IDPs (Ibid: 1, 12; ICG 2013: 7, 12; Interview 10). ${ }^{173}$ French Foreign Minister Laurent Fabius was dispatched to explain France's intentions in front of ECOWAS' heads of state while the French and the EU had consulted with the AU's Commission Chairperson Nkosazana Dlamini-Zuma beforehand (Interview 19).

Troops from other African armed forces were invited to participate (mainly from Chad and Niger for their expertise in leading combat operations in arid environments), with the Malian army expected to be thoroughly integrated as part of Opération Serval (Bøas \&

\footnotetext{
${ }^{173}$ The total number of IDPs both in Mali and in neighbouring countries would rise to 467,000 as a result of the conflict (Vilanova \& de Castro 2013: 220).
} 
Torheim 2013: 417; Kuperman 2013: 130). ${ }^{174}$ Once the intervention was under way, the French government also became the most vocal supporter for the African-led Support Mission in Mali (AFISMA) and from the very start had made plans for its mission to be of short length so as to allow an endogenous contingent to take over the reins once the French forces were due to withdraw (ICG 2013: 7; Interview 12). ${ }^{175}$ This meant that all the necessary conditions for legitimacy had been met as far as an intervention led by European actors on the African continent was concerned, albeit with the exception of the multilateralisation of the mission. Yet again though, the French came up against strong resistance in Brussels for turning its plan for intervention into a CSDP operation, with the idea not even making it onto the EU's agenda (Cristiani \& Fabiani 2013: 79, 93). ${ }^{176} 177$ Once again, the EU was left to play the part of emergency humanitarian aid donor. ${ }^{178}$

In the light of the urgency of the situation in Mali, Paris bypassed this glitch by acting alone in the knowledge that the risks may have been greater in doing so but that the insurgents would only benefit from possible squabbling in Brussels about the virtues of working within an EU framework. This glitch aside, the decision to send troops to fight the insurgents had been by this stage unanimously acclaimed by key voices within the international community, from the African diplomatic community to the UNSC, which naturally facilitated the mission of the French army (ICG 2013: 7, 13; Interview 19). Even Chinese officials could be heard lauding the approach of the French government for its "necessary intervention" and for having brought much needed stability to the situation inside the country (Bhadrakumar 2013). He Wenping, director of African studies at the Chinese Academy of Social Sciences, translated

\footnotetext{
${ }^{174}$ The EU put on an additional training mission to reorganise the Malian military in order to enable them to engage in combat operations. The objective of EUTM Mali is to: "[...] advise on issues pertaining to command and control, logistical chains and human resources, as well as on international humanitarian law, the protection of civilians and human rights" (Cristiani \& Fabiani 2013: 94).

${ }^{175}$ AFISMA, generated through UNSCR 2085, consists of an ECOWAS/AU proposal to launch an endogenous mission designed to support Opération Serval and supersede it (in parallel with a UNPKO for Mali) once the French mission would come to an end. AFISMA would regroup 3,300 troops from ECOWAS and AU member states on top of 5,500 Malian troops (to have received training via the EUTM mission) (Arieff 2013: 11).

${ }^{176}$ One interviewee put this resistance to collective action down to other member states fearing that the French government was attempting to drag the EU into an operation similar to EUFOR Tchad/RCA which - as explained during the first case study - was perceived as an attempt by the French government under Sarkozy to disguise an attempt to prop up the Déby leadership in Chad in the face of rebels incursions from Darfur into the eastern part of the country, under the pretence of a humanitarian mission (Interview 8).

${ }^{177}$ No Western country contributed to forces on the ground and US support was strong only on intelligence, refueling and airlift assistance. Seven European nations gave airlift and refueling support but the EU generally suffered from a paucity of commitments for training African troops and of force protection needed for EUTM Mali (Tertrais 2013: 52).

${ }^{178}$ The EU's overall humanitarian support for Mali stood at $€ 115$ million after eruption of the crisis in 2012 including an allocation of $€ 20$ million in January 2013 and an additional $€ 22$ million to assist victims of the conflict in the north. A total of $€ 100$ million in European Commission Humanitarian Office (ECHO) funding has been provided since the beginning of the crisis, along with $€ 15$ million in emergency food assistance (Cristiani \& Fabiani 2013: 94).
} 
the thinking from within the halls of power in Beijing about the French intervention: "I think the French military intervention was necessary. It was necessary because the situation was very urgent: militias in the north of Mali were attacking strategic strongholds not far from the capital city of Bamako" (cited in Musakwa 2013).

In reality though, China's position had not always been so forthcoming. Following the coup, the instinctive reaction of Chinese officials was to: "[...] call on all parties in Mali to return to normal order and to uphold national unity and stability" (Shinn 2013a). Following tradition, the emphasis was placed on the need for an internal solution with the objective being to maintain stability and preserve the status quo. As matters worsened, the PRC was again found sticking to its customary stance of wanting a peaceful solution to the detriment of any form of military intervention, regardless of the state of affairs on the ground. For that matter, it was happy to endorse the endeavours of a regional actor (in this case ECOWAS) but only so long as the latter was involved in efforts to mediate the warring parties rather than engage in any form of military action (Musakwa 2013; Shinn 2013a). By September 2012, the views of the Chinese leadership on the evolving situation in Mali changed to the extent that they were now willing to consider and support military action against Islamic rebels for as long as it was conducted by the Malian army (Shinn 2013b). China thus played an important role during the negotiations at the UNSC in the autumn of 2012 which paved the way for a military intervention against the Islamists (Anthony 2012: 1). As a matter of fact, the chargé d'affaires at the Chinese embassy in Bamako even went so far as claiming that his government stood ready to bring military assistance and rekindle military cooperation with the Malian army against this backdrop (Dembele 2012).

Whether or not this statement actually came to fruition is questionable but what it did guarantee was that any talk of any form of foreign military (European or American) assistance would be looked upon unfavourably by Beijing - since the latter wanted Mali to be in control of Malian affairs. As the above section made clear, China was in no mood to sanction a "heavy foreign military presence" led by Western powers in another non-Western country following the ordeal in Libya (Musakwa 2013). The message it delivered on Syria at the Security Council did not warrant any further explanation, whilst the PRC needed to recapture some of its non-conformism to regain the respect of non-Western states after its abstention on UNSCR 1973. For this reason, when the first signs emerged that Mali's former colonial ruler was about to embark on a mission whereby French boots would be placed on Malian soil, the Chinese reaction (leaked through unofficial channels) took a rather disdainful turn. Some Chinese scholars argued - similarly to the case of Darfur - that Mali would become France's 
Afghanistan but the more common criticism lamented France's supposed neo-colonial ambitions and desire to "bring back colonial memories" (cited in Shinn 2013b; Yun 2013). Some simply took the self-interested view that such acts of neo-colonialism were undertaken by the French as a means of accessing greater reserves of oil, even if Mali in itself has few resources beyond gold or uranium and low quantities of diamonds and bauxite (Farhaoui 2013: 37; Li \& Jin 2013; Tertrais 2013: 53).

How is it then that Chinese officials underwent a change of approach by opting to throw their support behind the French intervention when all the indicators were pointing towards this being yet another case of clashing interpretations between the two sides? Three main reasons are given here. Firstly, for all the talk about the need to play by the rules of the UN Charter regarding non-interference and territorial integrity, the Chinese government could not completely remain immune to the fact that the central authority in Bamako was clearly at risk of succumbing to the sweeping advances of the insurgency, with the latter benefiting from the general political turmoil undermining the country. In addition, Beijing could not remain immune from the fact that neither the Malian army - due to its poor track record, low morale and internal divisions - nor a regional collaborative effort were up to the job of putting together an immediate response to keep the insurgents at bay. As President Hollande reiterated, since there were no takers the international community had no choice but to support the efforts of the French in this instance. Secondly, what really convinced the Chinese leadership about the necessity of this intervention was that by constantly displaying its opposition, it actually undermined its own domestic battle with terrorism in mainland China where the government's authority is regularly tested by groups making separatist claims (as explained in chapter 2). All the above transcended to Chinese officials on the ground.

It was this point of convergence, knowing that the French army had been sent to consolidate the Malian government's state sovereignty and the safety of citizens in that country against the jihadist threat, which allowed Chinese officials to take a more relaxed view of events. As it was able to identify with the motives of the French government in this context and since this created an overlap with its own domestic governance prerogatives, the PRC was more willing to trust in very general terms the actions of the French. Moreover, the social environment surrounding the Mali issue gave the Chinese officials no reason to mistrust the French. After all, as previously highlighted, they went out of their way to ensure that the all the boxes on the checklist for overcoming constricted activism had been ticked. One vital criterion for Chinese officials in this instance relates to the need for the host state (and preferably regional actors) to expressly demand a foreign intervention. The interim Malian 
President unequivocally gave his blessing to Opération Serval by presenting an invitation letter to Paris and also to Brussels in the framework of EUTM Mali (EU Council 2013). Given that France had convinced all of those who in Beijing's eyes constituted key actors, there was no reason for its own officials to harbour mistrust. To the contrary, they quickly retracted their reservations about French-led intervention, gave diplomatic support to it and even reportedly agreed - for the first time in its contemporary history - to dispatch combat troops in July 2013 to MINUSMA, thus breaking with China's tradition of only contributing civilian contingents to UNPKOs (Sisk 2013).

Such distant cooperation between the two sides on this matter can indeed be made sense of primarily by applying the concept of trust and a common/convergent source of identification (coupled to a permissive social environment) to their respective officials on the ground. This being said, the brief analytical overview of insurgency and counterinsurgency in Mali does little to convince that cognitive-based trust between these officials can be replicated across contexts with regard to the security risk management in Africa. If the PRC could eventually bring itself round to agreeing and indirectly contributing to the French-led efforts to stabilise Mali in the short-term, it certainly had little to do with any form of institutionalisation of bilateral trust at the level of EU-China relations. The EU may have contributed to the stabilisation of Mali in its own way but similar to its role in Libya, Brussels provided a far more pragmatic contribution to the situation on the ground than was expected of it. Even if the bilateral institutional mechanisms could have played a part in bridging both sides' political divergences, it is highly doubtful whether they did given that the interaction on Mali was far from linear between their respective set of officials. Beijing eventually came round to supporting the French approach but only tentatively so, following a period of hesitancy where it kept its distances.

In short, both the Libya and Mali cases have come to show that although bilateral trust between officials plays a decisive factor in determining the nature of Sino-European interaction on security risk management in Africa, discussions concerning the institutionalisation of trust may be somewhat premature. This does not signify that this discussion is irrelevant but it is perhaps too nascent to permit a more thorough assessment of this phenomenon of institutionalisation and may be more relevant should future cases emerge where the EU and China are both directly confronted with a security threat on the continent, as was the case with the piracy phenomenon off the HoA. Even then, there is no guarantee that institutionalisation may be observed as it requires the kind of consistency and solid support mechanisms which are far beyond the current reach of the EU's ties with Beijing. 
Furthermore, officials on either side would have to make purposeful use of the instruments available to help institutionalise bilateral cognitive-based political trust. Up until now, it remains difficult to see how the current instruments have produced any effect and there is yet nothing to suggest that they will have any value in terms of the longer-term perspective of the EU and China's bilateral dealings on the topic of security risk management in Africa.

\subsection{Thesis Summary and Guidelines for a Future Research Agenda}

Political trust and specifically the cognitive-based understanding of it analysed throughout this thesis is a powerful tool in the context of relations between two distant partners such as the EU and China - whether its presence can be deciphered or not. When detectable, it has shown to help push the boundaries of bilateral expectations which are usually kept low as a result of the endemic political divide between the two sides. When undetectable, its absence widens the bilateral political gulf between officials on the ground to the extent that the chances of bridging the gap become virtually non-existent. Its presence or absence - as this research project has demonstrated in relation to the theme of security risk management in Africa - is what largely determines the nature of bilateral interaction on the continent in terms of the EU and China choosing to collaborate or setting off down the path of conflict and rivalry. As we have seen, the nature of the bilateral relationship on this particular theme has shown a tendency to alternate in a nonlinear fashion between scenarios of diplomatic rapprochement and scenarios of outright opposition when attempting to resolve a given security dilemma. But in each of the cases, a similar pattern emerges in that the absence or presence of cognitive-based trust appears to be the defining element in deciding upon the outcome of their eventual interaction and thus plays the pivotal role in shaping the bilateral state of affairs in Africa on this issue. At this juncture, one could even go so far as to predict that the next case of bilateral interaction on this particular theme will be predominantly decided by the presence or absence of cognitive-based political trust between groups of European and Chinese officials appointed to represent their side in negotiations on the ground.

To bring this thesis to a close, this final section will ask empirically what lessons have been learnt about the relationship between cognitive-based trust and bilateral interaction regarding security risk management in Africa in the light of the comparative case studies. What do the two case studies tell us about the conceptual framework on cognitive-based trust outlined in chapter 4 ? What about the hypotheses underpinning the conceptual framework? Overall, the secondary hypotheses regarding the impact of positive/negative identification and the importance of expressing empathy/striving for ideal-type communicative action have been 
confirmed by the empirical evidence put forward across the two case studies. More specifically, what we find is that: a) cognitive-based trust is likely to take hold between officials from both sides when actors pertain to a common or overlapping source of identification as part of their respective worldviews in a given context (and vice versa); b) cognitive-based trust is likely to take hold in a social environment conducive to the expression of empathy and to the fulfilment of ideal-type communicative action (and vice versa). In turn, with these secondary hypotheses having been validated, this means that the primary hypothesis - detectable cognitive-based trust being understood as the primary variable for greasing the wheels of cooperative behaviour between European and Chinese officials in this context (and likely to reinforce patterns of uncooperative behaviour when undetectable) would equally appear to have been confirmed by the research carried out for this thesis.

This being so, what the findings of this thesis have also shown is that there are a handful of hypotheses-come-variables of importance to the design of the conceptual framework whose importance were understated or which were simply overlooked during chapter 4. Since it would be inappropriate at this stage of the thesis to return to an in-depth discussion regarding the structure of the conceptual framework, the other important lessons to be taken from this thesis will only be discussed on the basis of their individual merits but will not involve a more thorough analytical rerun of the conceptual framework. Nevertheless, this summary section will outline the grounds upon which to possibly improve the design of the conceptual framework as part of a future research agenda, with the overall aim to improve the scholarly understanding linking cognitive-based political trust to the dynamics of contemporary international affairs. There are three lessons exposed by the comparative case studies to be taken into consideration for the conceptual framework (as summarised below in Table 8). These are:

c) cognitive-based political trust between European and Chinese officials is likely to be generated in environments characterised by well-defined centres of leadership (preferably assumed by either one or by both interacting parties) and unlikely in cases where centres of leadership are weakly defined or dispersed;

d) cognitive-based political trust is much likelier to be generated when European and/or Chinese officials appointed to deal with the matter at hand are experts in the domain or at least very familiar with the portfolio they have been appointed to handle, 
and far more unlikely when they are originally less familiar with the dynamics of the situation at hand;

e) cognitive-based political trust is more likely to take hold if the EU can trust itself, can put trust in its traditionally close allies and its officials can be trusted by the latter to make a difference with regards to a given crisis situation in a meaningful way and less likely when there is no trust in the EU from within and without.

In the most basic sense, point (a) was confirmed by the fact that in the Darfur case no common source of identification could bind European and Chinese officials and thus reconcile the political divide, but instead they respectively tended to negatively identify with one another through the prism of the GoS - which confirms the pivotal impact that local/regional actors can have on this trust-building process. From the perspective of EU officials, this corrupted their vision of their Chinese interlocutors as being guilty by association with Khartoum whereas for these same Chinese actors, standing up to the Western diplomatic assault on al-Bashir served as a meaningful exercise. The PRC's leadership took the side of al-Bashir for multiple reasons (economic, historical, ideological) and spent considerable energy trying to undermine the European approach to the crisis, even if the Chinese government did appear to have adopted a more conciliatory position towards the later stages of the crisis. Since the EU and EU member states mostly pointed the finger at Khartoum over the causes and consequences of the violence in Darfur, a psychological wall had been erected between the two sides' identification processes. To add to this, evidence of Beijing's negative identification with the EU (regardless of it being only indirect) was compounded by its apparent proximity with regional actors such as the AU and LAS, who for the most part stood up for the GoS especially in the face of accusations made by Western governments and civil society actors about the regime's behaviour.

In parallel, European actors could be found to a certain extent identifying with the cause of those who had fallen victim to Khartoum's tyranny: the IDPs, neighbouring states and at times the rebel groups. The identity wedge between actors from the two sides could not have been any more pronounced. On counter-piracy, actors on both sides were able to bridge the political divide because they built cognitive-based trust on the premise that they shared the notion of identifying against a common outgroup member. Simply put, with the Somali pirate playing the part of the universal figure of enmity, those intent on putting an end to the latter's winning streak were all seen as being on the right side of a legitimate fight. Consequently, the 
development of cognitive-based trust was facilitated since all actors contributing to counterpiracy shared this sense of positive identification of being united against the Somali pirates almost in the same way that terrorist groups leading the insurgency in Mali were widely condemned by the international community, paving the way for the Chinese officials to establish common grounds for identification with their European contemporaries on this issue.

As the comparative case studies also highlighted, it is not just a matter of whether groups of officials shared a common sense of identification or not but as Hopf made clear, the source(s) behind two groups' respective identification processes determines the probability of them sharing or not a common source of identification. On Darfur, with so much of the focus revolved around trying to separate the good guys from the bad, the process of identification (whether positive or negative) for both representatives of the EU and China, in this context, were foreign (the al-Bashir regime, the rebels and the IDPs). Yet on counter-piracy, at least from the vantage point of EU NAVFOR officers, the sources of identification were channelled in a less narrow and intense manner, originating instead from multiple sources. Indeed, Somali pirates did constitute a recurrent external source of identification for those contributing to the counter-piracy effort but as chapter 6 made clear, leading NAVFOR staff confidently drew upon other sources to form the basis of their identity. The respective sources of their identification were not just foreign (i.e. the pirates) but equally domestic (political masters), conceptual (the freedom of the seas) and physical (the rigours of life at sea). The message coming across in the comparative analysis would seem to support the suggestion formulated by Hopf that European and Chinese officials are likely to engage in trusting relations when the identities of one or both groups are framed against multiple sources and/or sources that are not exclusively foreign but also domestic and/or non-material. This is so because if their respective sources of identification are foreign, the chances that they will eventually utilise one another to construct their own identity in a given context (in view of their endemic political differences) are only likely to increase. Ironically, it would seem that when the process of identification for either side does not rely exclusively upon a direct/indirect foreign source, their judgements of one another become less clouded and appear to open their eyes to a more pragmatic appreciation between the two sets of officials. The case study on counter-piracy constitutes living proof that other non-foreign sources of identification for European officials provided extra incentive for them to trust their Chinese counterparts and vice versa.

Thanks to the comparison established between bilateral interaction on Darfur and counter-piracy, the second major hypothetical tenet (b) supporting the conceptual framework 
also received empirical confirmation. In other words, cognitive-based trust prospered in a social environment conducive to the expression of empathy and to the application (to the furthest extent possible) of ideal-type communicative action, which was the case for bilateral interaction on counter-piracy but not on Darfur. Instances of cognitive empathy being detectable between European and Chinese officials clearly occurred on counter-piracy, particularly over the course of discussions in the SHADE mechanism. On resolving the situation in Darfur, not only was empathy between officials hard to come by but dyspathy was a more common and logical occurrence given the propensity for indirect negative identification being more acute. Naturally, this limited the scope for expressing empathy and simultaneously rendered it somewhat obsolete.

Bilateral talks on counter-piracy between EU NAVFOR officers and their PLAN counterparts during the first phase of counter-piracy, whether held as part of the SHADE or beyond, ticked many of the criteria presented in the cognitivist literature review on trust constitutive of ideal-type communication. Particularly on the European (and Western) side informality, depoliticisation, humility, sacrifice, commitment and voluntarism were all qualities put on display by these officers as part of their overall attitude to working with the independent deployers on defeating the pirates. But very few of these qualities, if any, could be detected over the course of the EU's attempts to find a suitable exit from the fighting in Darfur. This is because the situation on the ground in this western region of Sudan was characterised by severe intensity and a high degree of politicisation, especially when compared in relative terms to the environment encapsulating counter-piracy. ${ }^{179}$ For one, the body count and other human costs of the conflict were far superior to the fewer number of victims and other forms of violent ordeals witnessed during the entirety of the fight against piracy (with the exception of a few noteworthy hijackings and unfortunate deaths). In Darfur, rebel groups had a political vocation to unseat the al-Bashir regime or at the very least coax greater political freedoms and rights out of Khartoum against the latter's will. What's more, on Darfur, many actors constitutive of this social environment were simply uninterested in seeing an end to the violence and destruction via cooperative endeavours and thus actively and/or passively derailed any attempts from others to do so.

To summarise briefly on the social environment, the international community arrived too late to the scene and when its constituent parts did finally turn up, the first noises some

\footnotetext{
${ }^{179}$ As Annan recounts in his memoirs: "Two days after my meeting with Straw, on September 9, 2004, Colin Powell referred to the conflict as 'genocide.' Rather than ending the debate on the label and moving on to the question of action, this move only stoked it" (Annan \& Mousavizadeh 2013: 130).
} 
actors began to make concerned the possibility of a genocide unfolding under the world's eyes at a time when many were leading commemorations to mark the tenth year anniversary of the Rwandan tragedy. The hype did not stop there. Against the backdrop of the WoT, the early interpretations of the violence in Darfur were erroneously portrayed by some (mostly in Western political, media and civil society circles) as falling into the category of a clash of civilisations, of yet another chapter in the lengthy book of clashes between Christians and Muslims. Although it soon became clear that the situation in Darfur was ill served by using the religious and racial heuristics of the conflict in South Sudan as a prism through which to comprehend developments, the damage had already been done. Notwithstanding the weak connection between events in Darfur and the WoT, the fact alone that Darfur was drafted into the wider debate on the fight against worldwide Islamic fanaticism only served to up the ante further. Since the voices of reason were too often being drowned out by more radical interpretations, Darfur soon took on the allure of a highly sensitive conflict and an environment steeped in politicised moralisation, as best epitomised by the ICC's decision to produce the 2008 arrest warrant for al-Bashir: it constituted a highly contentious and disputed decision which only further exacerbated the differences between the various sides of the conflict and ended up doing more harm than good. Thus, the more the conflict dragged on, the more difficult it became for the various stakeholders to disengage from the intensity of the situation (towards which they may have contributed) and to backtrack on the need to pick sides, as mentalities became engrained especially with no end to the conflict in sight.

On the contrary, the pirates never gave the impression of supporting any kind of political agenda, notwithstanding the potential which existed for them to make a stand about the desolation and hardship they faced in their hometowns - misery that was only compounded by tales of widespread corruption and commonplace illegal activities (fishing and dumping of nuclear waste in nearby waters). This is not to say that the pirates' complaints would necessarily have been acknowledged by the international community or would have made any difference to their depiction as hostes humani generis had they sought to use acts of piracy as a means to raise awareness of the plight they endured in Somalia. With the media spotlight scrutinising the pirates, the stage was set for those accustomed to being voiceless to air their grievances to the world about the country's perpetual state of crisis. But since the pirates did not overwhelmingly exploit this unique opportunity to make themselves heard, reports on piratical acts mostly toned down any of the political dimensions in favour of promoting the image of the sea bandit. Additionally, as links between those groups benefiting the most from the hijacking of ships off the HoA with al-Qaeda (via al-Shabaab) remained 
elusive, the idea of this phenomenon being nothing more than a commercial enterprise gained traction. ${ }^{180}$ Whereas the uprising in Darfur stemmed amongst others from long-standing tribal grievances, Somali piracy could hardly be considered as anything beyond a business model. Pirates targeted transiting vessels indiscriminately and held little regard for the origin, destination and contents of the vessels crossing the Indian Ocean. Crews aboard ships were objectified purely as commodities which could be used for bartering with concerned third parties willing to pay a price in return for the safe delivery of their crew, equipment and goods. The intensity of the counter-piracy context does not stand up in any shape or form to the intensity of the situation in Darfur, as the source of the problem (Somali pirates) could easily be identified by those affected by the rise in attacks. If contention did briefly reign in this regard, it involved debates about how to cure the symptoms of this problem rather than trying to put to bed arguments about its root causes. But the need for a collective response never resulted in the development of an intensive social ambiance like that characteristic of Darfur.

Part of the problem on Darfur was that EU and Chinese officials were not able and willing to channel their bilateral communication through platforms inspired by ideal-type communicative action. As observed in chapter 5, the resolution to the crisis became overrun by competing platforms for mediation which one after the other unsuccessfully endeavoured to create a credible formula to help put a definitive end to the conflict. Counter-intuitively, the establishment of overlapping or disconnected fora, as summarised in Table 4, only managed to reinforce and institutionalise ambient mistrust among the various stakeholders. These fora were ineffective for the most part because they did not tick enough of the boxes needed to strive towards ideal-type communicative action, while lessons that should have been learnt from the failure of prior platforms went missing when new initiatives were instigated to get the warring actors and concerned third parties to sit at the same table to negotiate. This was not the case for the SHADE mechanism which displayed many of the qualities needed to put into practice the theory of communicative action with its emphasis on depoliticisation, voluntarism and relative informality. SHADE constitutes a real eye-opener - if not somewhat of a paradox - for it shows the extent to which cognitive-based political trust between intrinsically distant actors is most potent within a depoliticised setting.

As the evolution of China's stance on Darfur testified, the social environment as well as the various platforms constituting it did not exactly encourage voluntarism either, with the EU and other Western actors preferring to resort to coercive methods to get Chinese officials

\footnotetext{
${ }^{180}$ Especially if one adds to the equation the fact that the ICU had declared war on piracy when it briefly reigned over Somalia.
} 
to adopt a more supportive approach. If coercion epitomised bilateral interaction on Darfur then free will was emblematic of bilateral interaction on counter-piracy, which says a lot about why cognitive-based political trust between EU and Chinese officials was undetectable in the first case study but very much a fixture in the second. Since the platforms set up in the context of the crisis in Darfur did not credibly come anywhere close to the expectations laid out in the theory of communicative action, the concerned actors never embodied the qualities required to aspire to this ideal. In fact, the social environment in Darfur seemed to bring out the worse in officials irrespective of their origins with aggressiveness, defensiveness, competitiveness and jealousy superseding the positive connotations demanded by the theory of communicative action. With the counter-piracy case turning out differently, the explanation lies in the fact that the lower intensity of the social environment encouraged all of the actors involved to progressively adopt a more relaxed attitude about staying true to the guiding facets of their identity. This was undoubtedly facilitated by the absence, in this case, of local/regional with the power to surreptitiously meddle in these bilateral cooperative endeavours. There was markedly more open-mindedness than that engulfing talks on Darfur, as caused by the overall progressively lower levels of intensity which helped NAVFOR's attempts to assuage the fears of the independent deployers about the former's intention in wanting to build more trusting relations.

In sum, all of this implied that from the moment when European and Chinese officials acknowledged the disparities in their respective approaches to solving the crisis in Darfur, they were never able to accept and iron out these differences through communicative endeavours due to the mentalities and processes making up the social environment. The longer this inability to undergo a thorough exchange lasted, the more complex it would be to reverse the course of this mutual disapproval. As indicated, the ties between their officials on the matter of counter-piracy did not suffer from a similar fate. Although early divergences and disagreements could have potentially derailed the eventual cooperative outcome, once again, the mentalities and processes constitutive of the counter-piracy environment meant that they would be in a position to work through their fundamental differences. Therefore, the comparative case studies confirm the suppositions put forward as part of this thesis' conceptual framework which posits that common sources of identification - on top of a social context conducive to the expression of empathy and ideal-type communicative action - are vital for the development of cognitive-based political trust. In turn, it is the presence of cognitive-based trust between officials on the ground which determines whether actors such 
as the EU and China are likely to enter into a relationship coloured by partnership or rivalry on a given concern relating to the theme of security risk management in Africa.

The conceptual framework on cognitive-based trust applied in this thesis does help to explain the bulk of the bilateral cooperative/competitive dynamics at play in this respect but as explained at the beginning of this section, the comparative analysis helped shed light on three other variables of relevance overlooked by this conceptual framework. As a consequence, their acknowledgement is important at this stage in order both to render the conceptual framework more complete and to outline areas requiring further exploration as part of a future research agenda on this topic. What the comparative case studies teach us (across points (c), (d), (e)) is that the probability of cognitive-based trust being built between politically distant officials would appear to go hand in hand with a strong sense of leadership on the issue-area under study. That is, this affirmative leadership does not have to be directly related to the EU, to China or to Sino-European relations. However, in cases where both actors find themselves directly dealing with one another on a common concern in Africa, their respective officials on the ground are more likely to generate trust among one another if they are interacting within an environment demarcated by a clear centre of leadership. Should they find themselves dealing with one another in a setting characterised by a well-defined centre of leadership, capable of channelling the energies of others towards the resolution of the issue at hand, then the chances of both sides fostering cognitive-based trust are likely to accrue significantly. At least if we do limit our analysis of the resolution of crisis situations on the African continent exclusively to the bilateral interaction between the EU and China's respective officials, it would appear that in cases marked by distinctively strong international leadership, actors on both sides are more inclined to engage in trusting relations (and vice versa). Of course, this hypothesis leaves much to be desired since it says nothing of the parameters for studying leadership or about the conditions under which leadership is likely to emerge or not in this context. Much more investment would be needed to incorporate the notion of leadership into the conceptual framework but this would represent the most pressing addition since there is an obvious association between leadership, identification, the social environment and the development of cognitive-based political trust between distant officials.

After a period of uncertainty at the very start of the counter-piracy activity, the international effort eventually organised itself around the leadership exercised by EU NAVFOR and the other two coalitions. As shown during chapter 6 , the coalitions possessed a comparative advantage when it came to structuring the optimal response to fighting pirates for a number of reasons. Indeed, their expertise and experience on such matters naturally granted 
them the added-value other 'younger' and less experienced naval forces lacked, making it easier for them to garner authority in the fight against the pirates. The good rapport among the coalitions nurtured through years of previous exchanges and shared cultural strategy between Western navies meant that they were not hampered in their efforts by problems related to material or tactical interoperability, while many officers had acquaintances working with them as part of the same coalition or in one of the two others. Naval forces participating in EU NAVFOR knew the region well due to institutional memory - with some of the regional states having been former colonies - and as a result of more recent WoT activities taking place in nearby countries and adjacent stretches of water. Prepositioned naval assets and preestablished access to regional ports allowed these naval forces to respond with haste and efficiency. In the case of EU NAVFOR, the Council of the EU agreed to grant the former a solid mandate and pooled together impressive material and financial means to support the mission. Crucially, each of the coalitions entertained close and long-standing ties with the shipping industry, which they understood well and therefore could anticipate the likely behavioural response of commercial actors to this particular threat. All in all, when ranked in comparison to many of the independent deployers, the naval forces working for EU NAVFOR, NATO and CMF had everything they needed to serve as de facto leaders of the international response to the Somali piracy phenomenon. As testimony to their natural leadership capabilities, they never felt the need to impose their know-how upon others or coerce the independent deployers into adhering to their modus operandi. Instead, they persuaded them of the benefits of exploiting their tried and tested blueprint for fighting pirates in a collective fashion for the greater good of the international community.

Darfur could not have been any further apart from this scenario. Because of the polarisation triggered by the crisis that drove concerned parties into divisive pro- and anti-al Bashir camps, competing strands of leadership emerged in an attempt to influence the course of events in a way that they saw fit. ${ }^{181}$ There was never one actor or a consortium of actors consistently looking to, or willing to, exercise leadership to bring an end to the conflict - a fact that may well have satisfied certain local/regional actors. The AU and LAS, as well as neighbouring countries could have upheld this position but internal wrangling coupled to a lack of resources eventually put an end to their aspirations, with the possible exception of the role played by the Qatari government. Brussels might have been well placed to do more if it was not for the need to respect constricted activism - which was not really the case on

\footnotetext{
${ }^{181}$ Or pro- and anti-rebel camps depending on who these third parties pledged their allegiance to.
} 
counter-piracy - and its subsequent inability to mount a sizeable presence on the ground in the shape of a credible CSDP mission, which in turn would come to hamper the efforts of this officials on the ground. ${ }^{182}$ Other Western actors faded in and out of the resolution of the crisis given their prior commitments elsewhere, so much so that this created space for nongovernmental and civil society groups to help fill the void - which in retrospect only resulted in their being one more set of competing interests to deal with. China's evolution from passive follower to active participant should not be interpreted as equating to the expression of international leadership.

In the end, finding a way out of the situation in Darfur was undermined by the cacophony of voices and concomitant initiatives that competed with one another often out of spite, without ever leading the international efforts in a coherent manner. As explained earlier, the social environment in Darfur was left cluttered with a critical mass of competing actors, platforms for mediation and initiatives creating a vicious circle which would overcome any newcomer hoping to bring change, leaving them to lose faith and eventually to renege on looking for a viable solution to end the region's circle of violence. The supposed resolution of the conflict only took place under the well-financed auspices of Qatari oversight but here too, Doha's efforts came at a time when Darfur was suffering from conflict fatigue. But over the course of the entire crisis, irrespective of where peace talks were held, at no point did one actor or a group of actors demonstrate the ability to convince those concerned by the conflict - whether the warring parties or third parties - to stick to a specific roadmap. For third parties such as the EU and China, their representatives rarely received the outside stimulus needed in the shape of carrots or sticks to encourage them to move closer towards one another and overcome the barrier of mistrust.

Had a credible source of leadership exogenous to the conflict assumed this position, there is no saying whether it would have made a difference as far as the EU and China's bilateral dealings on Darfur were concerned. It does not seem too far-fetched to imagine that this source of leadership could have pushed both sides to work together at an earlier stage of the conflict and without having to resort to indirect coercion. If this other source of leadership had shown proof of a tried and tested game plan as well as the ability to whip the warring parties into shape, other third parties would probably have fallen into line. In so doing, they may have found that operating in a less politicised environment (as triggered by the presence

\footnotetext{
${ }^{182}$ Although given the scale of the problem in Darfur, it would probably have come too soon for the EU to put together such a large and complex operation in view of its general inexperience at the time in managing overseas peacekeeping operations.
} 
of a leader and a sense of direction) would have put them in a better position to build cognitive-based trust with more distant partners, in the aim of coming up with a faster solution to the problem at hand. This discussion remains purely speculative but the association between the absence of a well-defined centre of international leadership with the inability of distant third parties' representatives to build cognitive-based political trust is clearly obvious when comparing the findings from the two case studies. Certainly, this is what happened as far as European and Chinese officials were concerned.

Leadership, however, is not just a matter of factors exogenous to the agents who come to embody it. It is also the fruit of a personal effort. On counter-piracy, those put in charge both on the European and Chinese side would simply appear to have been better placed to assume international leadership than those assigned to oversee the Darfur portfolio (d). ${ }^{183}$ This is probably explained by the fact that mariners were appointed to deal with the political aspects of the counter-piracy threat (a thematic which they knew well as men and women of the sea) whereas from the EU and China's perspective, those sent to help find a way out of the crisis on Darfur often had very little prior knowledge of the intricacies behind this particular conflict or of the dynamics in the Darfur region as a whole. Being briefed by policy experts, assigned to support the work of the political actors representing the EU and its member states during talks on Darfur, may not have always sufficed to reduce the asymmetry of knowledge about the background to the conflict and about each of the key participants.

To the contrary, NAVFOR could rely upon officers trained within some of the most competent naval academies in the world to deal with maritime threats of one kind or another. Not only could NAVFOR access the capabilities of these different navies themselves (such as the Royal Navy) but it could also rely upon the expertise and know-how embodied by the officers in command of the operation. As aforementioned, this implicitly granted NAVFOR a certain authority in the international maritime realm but equally guaranteed - since the UK served as the framework nation for the operation - that the leading members of the operation would pertain to a similar profile. At the very least, new staff would be cloned from a similar mould, ensuring continuity in NAVFOR's approach to tackling counter-piracy and helping to reinforce this authority. Very quickly though, the leading officers were able to set out the

\footnotetext{
${ }^{183}$ According to one well-placed observer, when analysing the international community's failings on the Rwandan genocide, he argues that one of the main problems was the international community's: "[...] thin appreciation of Rwanda's society and history and the forces at play there" (Annan \& Mousavizadeh 2013: 51). The author delves deeper into his claim by using the example of one Central Intelligence Agency officer who admitted only after the genocide had taken place that: "[...] when he was assigned to Rwanda in 1990, his first task was to locate the country on a map. At DPKO, we certainly had no genuine, deep expertise on the country. [...] A limited knowledge of the countries in which our operations were taking place had simply become a necessary way of life at DPKO" (Ibid).
} 
principles guiding their response to the piracy threat and displayed confidence in their ability to stick to these principles for the duration of their assignment. With such self-assuredness, they were naturally well placed to position themselves as reference points in the fight against Somali pirates and as chapter 6 outlined, other naval forces did gravitate somewhat towards them during the crucial junctures of the counter-piracy effort.

This is not to say that when it came to tackling problems in Darfur, the EU was not blessed with competent individuals but too often they were career diplomats or political actors who were not necessarily specialists on Sudan, Darfur or on the region's history. Too often, they were posted and assigned for a fixed time period before moving on to a completely different calling whilst the conflict rumbled on, and in some cases they tried to rush through results for political gain instead of playing the game with a longer-term frame of mind. From the interviews conducted on the piracy case, the naval officers seemed to have a greater understanding about the importance of working with one eye on the need to curtail the piracy threat and the other on making strategic moves with a longer-term remit - after all, they did not prioritise the policy of inclusiveness for no reason. Yet, this is not the impression one takes from studying developments in Darfur, where envoys were parachuted with the objective of breaking the general catharsis and thereafter claimed to have scored points of value only to their respective domestic political realms. Longer-term interests did not seem to be a salient concern, at least as far as European actors were concerned.

Where specialists could be found, their views were frequently contradicted by the actions of political actors who preferred to move Darfur to the centre stage out of expectation that doing so would bring fresh impetus and produce tangible results to move the process forward. When the rewards for making Darfur a priority began to stall or backfire, the file was duly moved down the pecking order and left for others to assume the responsibility. Although this strategy was not entirely flawed - since drafting in senior political figures into the resolution of a crisis can act as a catalyst - the real mistake was not giving more responsibility and influence to those stationed on the ground representing the EU and the member states, working on the crisis on a daily basis with a bona fide understanding of goings-on. With member states opting not to pursue a collective response, this left the EU with a small team and few resources to convince others that it could help channel the energies of the international community. How could the EUSR play such a leading role with such small support (quantitatively speaking) and such a narrow mandate? How was this possible when member states had their own teams in Khartoum working in relative isolation with no apparent system of coordination? 
As the crisis endured, the EU's overall response developed in an increasingly ad hoc manner and the lack of a clear mediation methodology signified that the agents representing the EU were never going to be looked upon as being able to provide the necessary inspiration to enlighten and lead others. On the contrary, the longer the status quo reigned over the conflict, the more European actors felt pressed into elaborating quick fix remedies for the symptoms of the conflict. This preference for quick fixes conceals an obvious deficit in terms of knowledge about the root causes behind the conflict and this lack of expertise clearly impacted the ability of European actors to fully assess all the options available to them to help stop the fighting - including striking up unconventional partnerships with distant third parties capable of making a telling contribution on the ground. Had they made a greater investment to explore these alternative options (by relying more heavily upon their agents in Sudan) and had they displayed a greater grasp of the dynamics in Darfur, European actors would clearly have been in a much stronger position to develop a more trusting relationship with their Chinese counterparts.

In turn, since the EU became less and less trusted as the crisis evolved to be able to make a significant contribution, the expectations of other third parties and even from some of its traditional allies progressively plummeted - leaving those representing the EU with the feeling that they themselves could not be trusted to make a difference (e). Brussels was not the only one which began losing faith in its capacity to live up to its rhetoric on Darfur and this sense of frustration was widespread among the other third parties too. But those representing the EU during the most crucial period of the conflict were some of the most worse off in terms of being capable of living up to the lofty expectation of helping to put an end to the violence and finding a way out of the conflict. Since the EU was never handed a strong mandate by its member states in conjunction to the fact that it had very little direct leverage over the GoS and no seat at the UNSC, it was unsurprising that an air of despondency came across from those who were the direct representatives for the Union on the ground. Clearly, for all the criticism directed at the EU for its performance on Darfur, only a small part of that can be attributed to the performance of these specific representatives.

Constraining them and preventing them from making any significant impact by failing to provide sufficient resources or by resisting the urge to pool forces under the EU flag only added to the sense of frustration explained above. Consequently, after a relatively strong start the EU's impact dwindled as its hands were increasingly tied, leaving others to doubt its capacity to do something meaningful. A hesitant and introspective actor is unlikely to inspire confidence and trust from those around it especially among traditionally more reticent 
partners, and it was the case on Darfur that the EU progressively began to lose trust in itself as others (including its own member states) began to lose faith in it too. How, in these conditions, could EU officials possibly be in a position to build cognitive-based political trust with a distant partner like China when it was not trusted even within its own circle of members and allies? Being trusted and being able to trust clearly go hand in hand and this naturally applies to the conceptual framework developed for this thesis.

For matters relative to counter-piracy, EU officials did not have to concern themselves so much with the opinions of their closest allies because they had already received a resounding vote of confidence by the member states' heads of state, who had decided to act collectively to defy the pirates. Additionally, the personal relations that members of NAVFOR staff entertained with colleagues and friends working for NATO and CMF guaranteed that trust featured prominently within this triumvirate. Unlike officials working on Darfur, their trusting foundations were already well placed before they even began to make moves targeting the independent deployers and were confident in their ability that they could bring as many stakeholders together on counter-piracy notwithstanding endemic political differences. Such self-confidence would undoubtedly have mattered as far as Chinese officials were concerned in terms of the intentions professed by NAVFOR staff were not in any way harmful for China, but instead could be beneficial. Following this reassuring assessment, the Chinese actors were happy to put their trust in the counter-piracy blueprint promoted by the coalitions.

At this point, it is not unreasonable - taking into account the results produced by the comparative analysis - to make the assumption that if by displaying leadership when tackling international affairs EU officials are likely to build more trusting relations with distant partners in the international community, then a correlation might also exist between collective action under an EU banner and the ability to foster trusting relations with others. By proposing such a hypothesis at this stage of the conclusion we are treading into precarious scholarly ground, for the merits and drawbacks of European foreign and security policy has only featured as a backdrop to this doctoral research project. But since this part of the thesis' concluding section is designed to outline areas for improvement of the conceptual framework with an eye on a possible future research agenda built around the idea of cognitive-based trust, this correlation deserves not to be overlooked at this stage. The idea here, as proven across the comparative case studies would contend that when the EU acts collectively as it did on counter-piracy it stands a better chance of playing a leading international role, of engaging in trusting relations with other global players and promoting cooperation rather than competition 
within the international community. Naturally, it is difficult to make a definitive case for this particular supposition exclusively on the basis of this thesis since it covers only a minor part of the broad spectrum of European foreign policy, leaving too many unknowns up for debate to be able to develop a solid argument in this regard. The evidence produced by the case studies does though make for interesting reading.

When a comparison is drawn up between the responsibilities and capabilities handed to NAVFOR in the shape of its mandate with those assigned to the EUSR on Darfur (if we are talking strictly speaking about the EU's actorness in this instance), and then a subsequent comparison is made between the respective levels of success across each case study in terms of successful collaboration with China, there exists a clear correlation. The mandate and resources in themselves all obviously depend upon how they are exploited by the actors appointed to implement the EU's objectives. Sometimes actors can produce impressive results without needing to resort to vast material resources. But on a purely comparative note, if we weigh up the respective qualities of the two mandates on top of weighing up the resources made available by the member states and supranational institutions to those officials working under the EU flag towards the end result of bilateral interaction on these two cases, then it could be argued that when the EU chooses to act collectively on foreign policy matters it stands a greater chance of building politically trusting relations with others. On Darfur, as aforementioned, the EU per se was never entrusted by the member states to carry the flame and since it is the member states who have the final say on military matters, there were no supranational EU competences with which to entice or coerce member states to act collectively. For this reason, its officials on the ground were left playing a minor diplomatic role. Whereas on counter-piracy, not only did the consensus shift very rapidly towards a collective solution in light of the EU's wider array of relevant foreign policy instruments (and its greater relevance for tackling the piracy phenomenon) but the European Commission could possibly have utilised its supranational competences in the realm of trade, maritime affairs and fisheries to coax a common response out of the member states - which it could not do on Darfur. Whatever the case, the EU collectively sought to get to the bottom of the piracy case and gave itself the means to do so and despite its rhetoric on Darfur giving out a similar impression of a collective desire to bring peace, the political will to unanimously implement this desire was lacking. Generally speaking, a direct link can be established between collective action at the EU level with the ability of European officials to build trusting relations with their Chinese counterparts on the theme of security risk management in Africa (and vice versa). To provide a more thorough assessment of the association between 
collective EU action in the context of bilateral interaction with the PRC and the ability for the former to develop cognitive-based political trust with the latter requires a research agenda going beyond the scope of this thesis. Nevertheless, the work provided by the comparative case studies show that there may be reason to explore this correlation in greater depth.

As a final comment on this conceptual framework related to cognitive-based political trust, the comparative case studies do also reveal other important variables which come into play to either facilitate cooperative tendencies or hinder them. For example, interaction on counter-piracy points to the importance of there being an overlap between the EU's need to respect constricted activism with the PRC's own satisfaction that any form of outside intervention in the affairs of African states fully respects the latter's state sovereignty. On counter-piracy, the lack of a credible form of state authority over the entirety of the Somali territory, the tacit agreement of the TFG to allow an international intervention against the pirates and the fact that piratical acts took place in international waters - the "neutral medium" (Till 2013: 228) - conjointly facilitated the need to accommodate constricted activism and the respect for state sovereignty. On Darfur, the EU struggled with constricted activism while the PRC reverted to its usual stance on the prospect of a foreign intervention on land belonging to a sovereign government. This configuration mattered as far as the odds of potential collaboration or rivalry between the two sides are concerned. So does the existence of shared rational interests. Indeed, a shared set of rational interests increased the attractiveness of bilateral cooperation for the PLAN in the context of counter-piracy (protecting the free flow of commercial goods). Although the EU and China both strove for stability in Darfur, the protection of Chinese national interests did not induce the PRC to seek a rapprochement with Brussels and member state capitals on this issue. Both the EU and China were also directly concerned by acts of piracy off the HoA and in the same way, which was not the case for Darfur where they were both only indirectly implicated as concerned third parties (with the PRC more affected than the EU when seen from a rationalist perspective).

These factors clearly played their part in terms of defining the nature of their interaction but what these case studies also show is that they should only be interpreted as setting the basis for eventual competition or cooperation. Should their interests and underlying principles overlap in relation to a crisis situation on the African continent, the chances that both sides will engage in a partnership may indeed be higher. However, the case studies demonstrate that more is needed than just rational interests to help bridge the political divide between the EU and China when it comes to their bilateral dealings on this theme. It is necessary for officials to build political trust both to avoid possible divergences turning into 
irreconcilable differences (as in the case of Darfur) and to convert mere diplomatic agreement into outright practical cooperation between the two sides (as observed on counter-piracy). This thesis has demonstrated that for cognitive-based trust to take hold, the existence of a common source of identification as well as a conducive social environment are primordial otherwise effective bilateral cooperation no longer becomes a possibility. We have shown throughout this concluding section that trust is unlikely to become institutionalised as things stand in the context of contemporary EU-China relations within the field of security risk management pertaining to the African continent. What is certain though is that cognitivebased political trust and these specific variables hold the key to gauging the bilateral state of affairs regarding interaction in Africa on this theme whether past, present or future.

Table 8 - Variables for Cognitive-Based Political Trust

\begin{tabular}{|c|c|c|}
\hline Variables Cases & Darfur & Counter-Piracy \\
\hline $\begin{array}{l}\text { Common Positive Sources of } \\
\text { Identification }\end{array}$ & No & Yes \\
\hline $\begin{array}{l}\text { Principle Source(s) of } \\
\text { Identification }\end{array}$ & Foreign & Foreign, Domestic \& Immaterial \\
\hline "Guilty by Association?" & Yes & No \\
\hline $\begin{array}{l}\text { Flexibility of Cultural } \\
\text { Programme }\end{array}$ & Less flexible & More flexible \\
\hline $\begin{array}{l}\text { Comparative Contextual } \\
\text { Intensity }\end{array}$ & More politically intense & Less politically intense \\
\hline Cognitive Empathy & Undetectable & Detectable \\
\hline $\begin{array}{l}\text { Ideal-Type Communicative } \\
\text { Action }\end{array}$ & Far from the ideal-type & Close to the ideal-type \\
\hline $\begin{array}{l}\text { Platforms for Social } \\
\text { Interaction }\end{array}$ & Multiple & Few \\
\hline $\begin{array}{l}\text { Regularity of Social } \\
\text { Interaction }\end{array}$ & Inconsistent & Consistent \\
\hline $\begin{array}{l}\text { Mechanism for } \\
\text { Institutionalising Trust }\end{array}$ & Inexistent & Existent \\
\hline Centre of Leadership & Poorly demarcated & Clearly demarcated \\
\hline Decision-Maker Expertise & Mostly unproven & Mostly proven \\
\hline $\begin{array}{l}\text { EU Mandate for Collective } \\
\text { Action }\end{array}$ & Weak & Strong \\
\hline Concept of Sovereignty & More problematic & Less problematic \\
\hline Implication in the Crisis & Indirect & Direct \\
\hline Common Rational Interests & Weak & Strong \\
\hline $\begin{array}{l}\text { Level of Cognitive-Based } \\
\text { Trust }\end{array}$ & Untrusting & Trusting \\
\hline $\begin{array}{l}\text { Outcome of Bilateral } \\
\text { Interaction }\end{array}$ & Uncooperative & Cooperative \\
\hline
\end{tabular}




\section{Bibliography}

\section{CHAPTER 1}

\section{Book References}

Alden, C., 2009, China in Africa, London: Zed Books.

Booth, K. \& Wheeler, N., 2007, The Security Dilemma: Fear, Cooperation and Trust in World Politics, Basingstoke: Palgrave Macmillan.

Deutsch, M., 1973, The Resolution of Conflict: Constructive and Destructive Processes, New Haven, CT: Yale University Press.

Glaser, C., 2010, Rational Theory of International Politics: The Logic of Competition and Cooperation, Princeton: Princeton University Press.

Solomon, R. \& Flores, F., 2003, Building Trust: In Business, Politics, Relationships, and Life, Oxford: Oxford University Press.

Taylor, I., 2009, China's New Role in Africa, Boulder, CO: Lynne Rienner.

Welch Larson, D., 2000, Anatomy of Mistrust: US-Soviet Relations during the Cold War, Ithaca, NY: Cornell University Press.

\section{Book Chapters}

Feger, H., 1991, 'Cooperation between groups', in Hinde, R. \& Groebel, J. (eds.), Cooperation and Prosocial Behaviour, Cambridge: Cambridge University Press, pp. 281300.

Gambetta, D., 1988, 'Can we trust trust?', in Gambetta, D. (ed.), Trust: Making and Breaking Cooperative Relations, Oxford: Basil Blackwell, pp. 213-235.

Tyler, T., 2001, 'Why do people rely on others? Social identity and the social aspects of trust', in Cook, K. (ed.), Trust in Society, New York, NY: Russell Sage Foundation, pp. 285-306.

Xiang, H. \& Zaborowski, M., 2007, 'Security issues', in Crossick, S. \& Reuter, E. (eds.), China-EU: A Common Future, Singapore: World Scientific, pp. 41-56.

\section{Journal and Electronic Articles}

Berger, B., 2006, 'China's engagement in Africa: Can the EU sit back?', South African Journal of International Affairs, 13:1, pp. 115-127.

Bleiker, R. \& Hutchinson, E., 2008, 'Fear no more: emotions and world politics', Review of International Studies, 34, pp. 115-135.

Hoffman, A., 2002, 'A conceptualisation of trust in international relations', European Journal of International Relations, 8:3, pp. 375-401.

Kramer, R., 2010, 'Collective trust within organizations: Conceptual foundations and empirical insight', Corporate Trust Review, 13:2, pp. 82-97.

Schoeman, M., 2008, 'China and Africa: Whose challenge and whose opportunity?', Afrika Spectrum, 43, pp. 403-413.

Stahl, A., 2011, 'Contrasting rhetoric and converging security interests of the European Union and China in Africa', Journal of Current Chinese Affairs, 40:4, pp. 147-173.

\section{Websites and Newspaper Articles}

People's Daily, 2002, China offers new security concept at ASEAN meeting, retrieved at: http://www.china.org.cn/english/international/38502.htm, on 02/06/2014. 


\section{CHAPTER 2}

\section{Book References}

Alden, C., 2009, China in Africa, London: Zed Books.

Annan, K. \& Mousavizadeh, N., 2013, Interventions: A Life in War and Peace, London: Penguin Books.

Beuret, M. \& Michel, S., 2009, La Chinafrique : Pékin à la Conquête du Continent Noir, Paris : Hachette.

Bokilo, J., 2011, La Chine en Afrique : La Chine en Concurrence avec les Anciens Partenaires de l'Afrique et les Pays BRICs, Paris : L'Harmattan.

Charbonneau, B., 2008, France and the New Imperialism: Security Policy in Sub-Saharan Africa, Farnham: Ashgate.

Duffield, M., 2001, Global Governance and the New Wars: The Merging of Development and Security, London: Zed Books.

Eberling, G., 2011, Chinese Energy Futures and their Implications for the United States, Lanham, MD: Lexington Books.

Gounin, Y., 2009, La France en Afrique : Le Combat des Anciens et des Modernes, Bruxelles : Groupe De Boeck.

Grant, C. \& Barysch, K., 2008, Can Europe and China Shape a New World Order?, London: Centre for European Reform.

Granvaud, R., 2009, Que fait l'armée française en Afrique ?, Marseilles: Agone.

Huntington, S., 1996, The Clash of Civilisations and the Remaking of World Order, New York, NY: Simon Schuster.

Kaldor, M., 2007, Human Security: Reflections on Globalization and Intervention, Cambridge: Polity.

Mamdani, M., 2009, Saviours and Survivors: Darfur, Politics, and the War on Terror, New York, NY: Pantheon Books.

Raine, S., 2009, China's African Challenges, Abingdon: Routledge.

Shambaugh, D., 2013, China Goes Global: The Partial Power, New York, NY: Oxford University Press.

Shinn, D. \& Eisenman, J., 2012, China and Africa: A Century of Engagement, Philadelphia, PA: University of Pennsylvania Press.

Sicurelli, D., 2010, The European Union's Africa Policies: Norms, Interests and Impact, Farnham: Ashgate.

Steiler, I., 2009, The European Union and China in Africa: Explaining Conflict and Cooperation with IR Theory, Hamburg: Verlag Dr. Kovač.

Taylor, I., 2009, China's New Role in Africa, Boulder, CO: Lynne Rienner.

\section{Book Chapters}

Abrahamsen, R., 2013, 'Introduction: Conflict and security in Africa', in Abrahamsen, R. (ed.), Conflict and Security in Africa, Woodbridge: James Currey, pp. 1-12.

Alden, C., Large, D. \& Soares de Oliveira, R., 2008, 'Introduction: China returns to Africa', in Alden, C., Large, D. \& Soares de Oliveira, R. (eds.), China Returns to Africa: A Rising Power and a Continent Embrace, New York, NY: Columbia University Press, pp. 1-25. 
Curtis, M. \& Hickson, C., 2006, 'Arming and alarming? Arms exports, peace and security', in Wild, L. \& Mepham, D. (eds.), The New Sinosphere: China in Africa, London: The Institute for Public Policy Research, pp. 37-46.

Dehéz, D., 'Crisis region East Africa: The IGAD in an environment of latent conflict', in Gebrewold, B. (ed.), Africa and Fortress Europe: Threats and Opportunities, Farnham: Ashgate, pp. 21-36.

Freire, M., 2008, 'The European Security and Defence Policy: History, structures and capabilities', in Merlingen, M. \& Ostrauskaite, R. (eds.), European Security and Defence Policy: An Implementation Perspective, Abingdon: Routledge, pp. 9-24.

Gegout, C., 2010, 'EU conflict management in Africa: The limits of an institutional actor', in Hughes, J. (ed.), EU Conflict Management, Abingdon: Routledge, pp. 125-137.

Lam, W., 2008, 'China's petroleum diplomacy: Hu Jintao's biggest challenge in foreign and security policy', in Wu, G. \& Landsdowne, H. (eds.), China Turns to Multilateralism: Foreign Policy and Regional Security, Abingdon: Routledge, pp. 222-240.

Mangala, J., 2010a, 'Introduction: Evolving security discourse and crises in Africa Conceptual, policy, and practical relevance', in Mangala, J. (ed.), New Security Crises in Africa: Regional and International Perspectives, Basingstoke: Palgrave Macmillan, pp. $1-15$.

Mangala, J., 2010b, 'The European Union and Africa: Old partners in a changing world', in Mangala, J. (ed.), Africa and the New World Era: From Humanitarianism to a Strategic View, Basingstoke: Palgrave Macmillan, pp. 167-192.

Rye Olsen, G., 2009, 'The EU: 'European interests', bureaucratic interests and international options', in Engel, U. \& Rye Olsen, G. (eds.), Africa and the North: Between Globalisation and Marginalisation, Abingdon: Routledge, pp. 94-106.

Smith, M., 2009, 'Terrorism thinking: '9/11 changed everything', in Smith, M. (ed.), Securing Africa: Post-9/11 Discourses on Terrorism, Farnham: Ashgate, pp. 1-30.

Soares de Oliveira, R., 2008, 'Making sense of Chinese oil investment in Africa', in Alden, C., Large, D. \& Soares de Oliveira, R. (eds.), China Returns to Africa: A Rising Power and a Continent Embrace, New York, NY: Columbia University Press, pp. 83-109.

Suzuki, S., 2011, 'Chinese soft power, insecurity studies, myopia and fantasy', in Dent, C. (ed.), China and Africa Development Relations, Abingdon: Routledge, pp. 68-84.

Tull, D., 2008, 'The political consequences of China's return to Africa', in Alden, C., Large, D. \& Soares de Oliveira, R. (eds.), China Returns to Africa: A Rising Power and a Continent Embrace, New York, NY: Columbia University Press, pp. 111-128.

Wheeler, T., 2011, 'Tackling proliferation of Small Arms and Light Weapons: An opportunity for EU-China cooperation', in Men, J. \& Barton, B. (eds.), China and the European Union in Africa: Partners or Competitors?, Farnham: Ashgate, pp. 105-126.

Zhao, H., 2010, 'China's energy relations with Africa', in Liu Currier, C. \& Dorraj, M. (eds.), China's Energy Relations with the Developing World, New York, NY: Continuum, pp. 101-125.

\section{Journal and Electronic Articles}

Abrahamsen, R., 2004, 'A breeding ground for terrorists? Africa and Britain's 'War on Terrorism', Review of African Political Economy, 31:102, pp. 677-684.

Bergeron, S., 2007, 'Vers une européanisation de la politique de sécurité et de défense de la France en Afrique ?', Défense Nationale et Sécurité Collective, 63:1, pp. 55-62.

Chafer, T. \& Cumming, G., 2010, 'Beyond Fashoda: Anglo-French security cooperation in Africa since Saint-Malo', International Affairs, 86:5, pp. 1129-1147. 
Ero, C., 2001, ‘A critical assessment of Britain's Africa policy', Conflict, Security and Development, 1:2, pp. 51-71.

Esmenjaud, R. \& Franke B., 2009, 'Who owns African ownership? The africanisation of security and its limits', Working Papers in International History and Politics, 1.

Faria, F., 2004, 'Crisis management in Sub-Saharan Africa: The role of the European Union', EU Institute of Security Studies Occasional Paper, 51.

Gallagher, J., 2011, 'Ruthless player or development partner? Britain's ambiguous reaction to China in Africa', Review of International Studies, 37, pp. 2293-2310.

Geoxavier, B., 2012, 'China as peacekeeper: An updated perspective on humanitarian intervention', Yale Journal of International Affairs, 7:2, pp. 98-101.

Herman, H. \& Davies, M., 2009, The EU and China: Prospects for Partnerships in Democracy Building in Africa, Stockholm: International Institute for Democracy and Electoral Assistance.

Holslag, J. \& van Hoeymissen, S., 2010, The Limits of Socialisation: The Search for EUChina Cooperation towards Security Challenges in Africa, Brussels: Brussels Institute of Contemporary China.

Holslag, J., 2008, 'China's next security strategy for Africa', BICCS Asia Paper, 3:6.

Huliaras, A. \& Magliveras, K., 2008, 'In search of a policy: EU and US reaction to the growing Chinese presence in Africa', European Foreign Affairs Review, 13, pp. 399-420.

ICG, 2008, China's Thirst for Oil, Brussels.

Lee, K., Chan, G. \& Chan, L., 2012, 'China in Darfur: Humanitarian rule-maker or ruletaker?', Review of International Studies, 38, pp. 423-444.

Pirozzi, N., 2009, 'EU support to African security architecture: Funding and training components', EU Institute of Security Studies Occasional Paper, 76.

Renard, T., 2011, 'The treachery of strategies: A call for true EU strategic partnerships', Egmont Paper, 45.

Saferworld, 2011, China's Growing Role in African Peace and Security, London.

Steiler, I., 2010, 'The best of both worlds: Some lessons the European Union should learn from China in Africa', Das Forum Regensburger Politikwissenschaftler Working Paper, 3.

Stumbaum, M-B., 2007, 'Opportunities and limits of EU-China security cooperation', The International Spectator: Italian Journal of International Affairs, 42:3, pp. 351-370.

Taylor, I., 2007, 'China's arms sales to Africa: Beijing's reputation at risk', China Brief, 7:5, pp. 10-11.

van der Meulen, E. \& van der Putten, F-P., 2009, Great Powers and International Conflict Management: European and Chinese Involvement in the Darfur and Iran Crises, The Hague: Netherlands Institute of International Relations Clingendael.

Vines, A., Wong, L., Weimer, M. \& Campos, I., 2009, Thirst for African Oil: Asian National Oil Companies in Nigeria and Angola, London: Chatham House.

Wennerholm, P., Brattberg, E. \& Rhinard, M., 2010, 'The EU as a counter-terrorism actor abroad: Finding opportunities, overcoming constraints', European Policy Centre Issue Paper, 60.

\section{Websites and Newspaper Articles}

BBC News, 2007b, Scores die in Ethiopia oil attack, retrieved at: http://news.bbc.co.uk/2/hi/6588055.stm, on 12/03/2014.

Branigan, T., 2013, 'Tiananmen Square crash: Five held over 'terrorist' incident', The Guardian, retrieved at: http://www.theguardian.com/world/2013/oct/30/tiananmensquare-crash-five-held-beijing, on 07/11/2013. 
Chrisafis, A., 2011, 'Sarkozy hopes Libya can boost France's reputation - as well as his own', The Guardian, retrieved at: http://www.theguardian.com/world/2011/sep/01/sarkozylibya-france-reputation-reelection, on 07/11/2013.

Chrisafis, A., 2013, 'Mali: High stakes in 'Hollande's war', The Guardian, retrieved at: http://www.theguardian.com/world/2013/jan/13/mali-high-stakes-francois-hollande, on $07 / 11 / 2013$.

FMPRC, 2007, Forum on China-Africa Cooperation Beijing Action Plan (2007-2009), retrieved at: http://www.fmprc.gov.cn/zflt/eng/zyzl/hywj/t280369.htm, on 02/06/2014.

FOCAC, 2000, Beijing Declaration of the Forum on China-Africa Cooperation, retrieved at: http://www.focac.org/eng/ltda/dyjbzjhy/DOC12009/t606796.htm (published on 25/09/2009), on 10/01/2015.

Holslag, J., 2009, China's vulnerability in Africa and options for security cooperation with Europe, retrieved at: http://www.clingendael.nl/publication/chinas-vulnerability-africaand-options-security-cooperation-europe, on 28/05/2014.

Kaiman, J. \& Branigan, T., 2014, 'Kunming knife attack: Xinjiang separatists blamed for 'Chinese 9/11', The Guardian, retrieved at: http://www.theguardian.com/world/2014/mar/02/kunming-knife-attack-muslimseparatists-xinjiang-china, on 07/03/2014.

Kristof, N., 2008, 'China's Genocide Olympics', The New York Times, retrieved at: http://www.nytimes.com/2008/01/24/opinion/24kristof.html, on 29/02/2012.

Le Nouvel Observateur, 2013, MALI. Le président demande l'aide militaire de la France, retrieved at: http://tempsreel.nouvelobs.com/monde/20130111.OBS5088/mali-lepresident-demande-l-aide-militaire-de-la-france.html, on 29/04/2014.

Oberlé, T., 2013, 'Pourquoi la France a passé la vitesse supérieure au Mali', Le Figaro, retrieved at: http://www.lefigaro.fr/international/2013/01/13/0100320130113ARTFIG00184-pourquoi-la-france-a-passela-vitesse-superieure-au-mali.php, on $29 / 04 / 2014$.

People's Daily, 2006, Full text: China's African policy, retrieved at: http://english.peopledaily.com.cn/200601/12/eng20060112_234894.html, on 02/06/2014.

Shichor, Y., 2007, China's Darfur policy, retrieved at: http://www.asianresearch.org/articles/3039.html, on 26/02/2014.

Shinn, D., 2009, China's involvement in African conflict zones, retrieved at: https://sites.google.com/site/davidhshinn/china-s-involvement-in-african-conflict-zones, on $07 / 11 / 2013$.

Smith, G., 2011, 'China offered Gaddafi huge stockpile of arms: Libyan memos', The Globe and Mail, retrieved at: http://www.theglobeandmail.com/news/world/china-offeredgadhafi-huge-stockpiles-of-arms-libyan-memos/article1363316/, on 08/11/2013.

Solana, J., 2007, 'Challenges for EU-China cooperation in Africa', China Daily, 7 February, p. 3.

The Economist, 2011, China's evolving foreign policy: The Libyan dilemma, retrieved at: http://www.economist.com/node/21528664, on 08/11/2013.

Tran, M., 2008, 'Zimbabwe arms shipment returns to China', The Guardian, retrieved at: http://www.theguardian.com/world/2008/apr/24/zimbabwe.china, on 03/09/2013.

Wade, A., 2008, 'Time for the West to practice what it preaches', Financial Times, retrieved at: http://www.ft.com/intl/cms/s/0/5d347f88-c897-11dc-94a60000779fd2ac.html\#axzz1nm5WiPwj, on 29/02/2012.

Zheng, B., 2005, 'China's 'peaceful rise' to great power status', Foreign Affairs, retrieved at: http://www.foreignaffairs.com/articles/61015/zheng-bijian/chinas-peaceful-rise-to-greatpower-status, on 06/03/2014. 
Zoellick, R., 2005, Whither China: From membership to responsibility?, retrieved at: http://2001-2009.state.gov/s/d/former/zoellick/rem/53682.htm, on 07/11/2013.

\section{Command Documents}

EU Council, 2004e, Joint Declaration of the People's Republic of China and the European Union on Non-Proliferation and Arms Control, 15854/04 (Presse 348), Brussels.

EU Council, 2005b, The EU and Africa: Towards a Strategic Partnership, 15961/05 (Presse 367), Brussels.

EU Council, 2006a, Declaration by the Presidency on behalf of the European Union Concerning the Darfur Talks, 8989/1/06 REV 1 (Presse 124), Brussels.

EU Council, 2006d, Plenary Session of the European Parliament, Strasbourg, 27 September 2006: Council and Commission Statements - Situation in Darfur, 13429/06, Brussels.

European Commission \& Council Secretariat, 2007, Beyond Lisbon: Making the EU-Africa Strategic Partnership Work, COM(2007) 357, Brussels.

European Commission, 2008, The EU, Africa and China: Towards Trilateral Dialogue and Cooperation, COM(2008) 654, Brussels.

European Parliament, 2007, Draft Report on China's Policy and Its Effects on Africa, 2007/XXXX(INI), Brussels.

Ministère de la Défense, 2008, Livre Blanc sur la Défense et la Sécurité Nationale, Paris : Odile Jacob.

\section{Miscellaneous}

Lawson, B., 2011, The Price of Peace: A Quantitative Analysis of Economic Interests and China's Involvement in United Nations Peacekeeping Operations, Master's Thesis, Georgetown University.

\section{CHAPTER 3}

\section{Book References}

Axelrod, R., 1984, The Evolution of Cooperation, New York, NY: Basic Books.

Booth, K. \& Wheeler, N., 2007, The Security Dilemma: Fear, Cooperation and Trust in World Politics, Basingstoke: Palgrave Macmillan.

Brown, R., 2000, Group Processes: Dynamics Within and Between Groups, $2^{\text {nd }}$ Edition, Chichester: Wiley.

Connolly, W., 1991, Identity/Difference: Democratic Negotiations of Political Paradox, Ithaca, NY: Cornell University Press.

de Waal, F., 2009, The Age of Empathy: Nature's Lessons for a Kinder Society, New York, NY: Harmony Books.

Fisher, G., 1997, Mindsets: The Role of Culture and Perceptions in International Relations, Yarmouth, ME: Intercultural Press.

Hopf, T., 2002, Social Construction of International Politics: Identities and Foreign Policies, Moscow, 1955 \& 1999, Ithaca, NY: Cornell University Press.

Jervis, R., 1976, Perceptions and Misperception in International Politics, Princeton, NJ: Princeton University Press.

Keohane, R. \& Nye, J., 2012, Power and Interdependence, $4^{\text {th }}$ Edition, Boston, MA: Pearson. 
Kydd, A., 2005, Trust and Mistrust in International Relations, Princeton, NJ: Princeton University Press.

Luhmann, N., 1979, Trust and Power, Chichester: Wiley.

Möllering, G., 2006, Trust: Reason, Routine, Reflexivity, Oxford: Elsevier.

Neumann, I., 1999, Uses of the Other: 'The East' in European Identity Formation, Manchester: Manchester University Press.

Nooteboom, B., 2002, Trust: Forms, Foundations, Functions and Figures, Cheltenham: Edward Elgar.

Peters, D., 2010, Constrained Balancing: The EU's Security Policy, Basingstoke: Palgrave Macmillan.

Shambaugh, D., 2013, China Goes Global: The Partial Power, New York, NY: Oxford University Press.

Sherif, M., 1966, Group Conflict and Co-operation: Their Social Psychology, Abingdon: Routledge.

Solomon, R. \& Flores, F., 2003, Building Trust: In Business, Politics, Relationships, and Life, Oxford: Oxford University Press.

Stumbaum, M-B., 2009, The EU and China: Decision-Making in EU Foreign and Security Policy towards the PRC, Baden-Baden: Nomos.

Vertzberger, Y., 1990, The World in their Minds: Information Processing, Cognition and Perception in Foreign Policy Decision-making, Stanford, CA: Stanford University Press.

Welch Larson, D., 2000, Anatomy of Mistrust: US-Soviet Relations during the Cold War, Ithaca, NY: Cornell University Press.

\section{Book Chapters}

Algieri, F., 2007, 'It's the system that matters: Institutions and making EU policy towards China', in Shambaugh, D., Sandschneider, E. \& Zhou, H. (eds.), China-Europe Relations: Perceptions, Policies and Prospects, Abingdon: Routledge, pp. 65-83.

Avuch, K., 2008, 'Culture theory, culture clash and the practice of conflict resolution', in Sandole, D., Byrne, S., Sandole-Staroste, I. \& Senehi, J. (eds.), Handbook of Conflict Analysis and Resolution, Abingdon: Routledge, pp. 241-255.

Bachmann, R., 2006, 'Trust and/or power: Towards a sociological theory of organizational relationships', in Bachmann, R. \& Zaheer, A. (eds.), Handbook of Trust Research, Cheltenham: Edward Elgar, pp. 393-407.

Balme, R., 2008, 'A European strategy towards China? The limits of integration in foreignpolicy making', in Balme, R. \& Bridges, B. (eds.), Europe-Asia Relations: Building Multilateralisms, Basingstoke: Palgrave Macmillan, pp. 125-144.

Boon, S. \& Holmes, J., 1991, 'The dynamics of interpersonal trust: resolving uncertainty in the face of risk', in Hinde, R. \& Groebel, J. (eds.), Cooperation and Prosocial Behaviour, Cambridge: Cambridge University Press, pp. 190-211.

Broome, B., 2008, 'Building relational empathy through an interaction design process', in Sandole, D., Byrne, S., Sandole-Staroste, I. \& Senehi, J. (eds.), Handbook of Conflict Analysis and Resolution, Abingdon: Routledge, pp. 184-200.

Brown, R. \& Turner, J., 1981, 'Interpersonal and intergroup behaviour', in Turner, J. \& Giles, H. (eds.), Intergroup Behaviour, Chicago, IL: University of Chicago Press, pp. 33-65.

Cook, K., Hardin, R. \& Levi, M., 2007, 'The significance of trust', in Cook, K., Hardin, R. \& Levi, M. (eds.), Cooperation Without Trust?, New York, NY: Russell Sage Foundation, pp. 1-20. 
Cook-Huffman, C., 2008, 'The role of identity in conflict', in Sandole, D., Byrne, S., SandoleStaroste, I. \& Senehi, J. (eds.), Handbook of Conflict Analysis and Resolution, Abingdon: Routledge, pp. 19-31.

Dunn, J., 1988, 'Trust and political agency', in Gambetta, D. (ed.), Trust: Making and Breaking Cooperative Relations, Oxford: Basil Blackwell, pp. 73-93.

Feger, H., 1991, 'Cooperation between groups', in Hinde, R. \& Groebel, J. (eds.), Cooperation and Prosocial Behaviour, Cambridge: Cambridge University Press, pp. 281300.

Gambetta, D., 1988, 'Can we trust trust?', in Gambetta, D. (ed.), Trust: Making and Breaking Cooperative Relations, Oxford: Basil Blackwell, pp. 213-235.

Good, D., 1988, 'Individuals, interpersonal relations, and trust', in Gambetta, D. (ed.), Trust: Making and Breaking Cooperative Relations, Oxford: Basil Blackwell, pp. 31-48.

Hardin, R., 2007, 'Conceptions and explanations of trust', in Cook, K., Hardin, R. \& Levi, M. (eds.), Cooperation Without Trust?, New York, NY: Russell Sage Foundation, pp. 3-33.

Heimer, C., 2007, 'Solving the problem of trust', in Cook, K., Hardin, R. \& Levi, M. (eds.), Cooperation Without Trust?, New York, NY: Russell Sage Foundation, pp. 40-88.

Herrmann, R., 2002, 'Linking theory to evidence in IR', in Carlsnaes, W., Risse, T. \& Simmons, B. (eds.), Handbook of International Relations, London: Sage, pp. 119-136.

Jepperson, R., Wendt, A. \& Katzenstein, P., 1996, 'Norms, identity, and culture in national security', in Katzenstein, P. (ed.), The Culture of National Security: Norms and Identity in World Politics, New York, NY: Columbia University Press, pp. 33-75.

Katzenstein, P., 1996, 'Introduction: Alternative perspectives on national security', in Katzenstein, P. (ed.), The Culture of National Security: Norms and Identity in World Politics, New York, NY: Columbia University Press, pp. 1-32.

Kelman, H., 2008, 'A social-psychological approach to conflict analysis and resolution', in Sandole, D., Byrne, S., Sandole-Staroste, I. \& Senehi, J. (eds.), Handbook of Conflict Analysis and Resolution, Abingdon: Routledge, pp. 170-183.

Keohane, R. \& Ostrom, E., 1995, 'Introduction', in Keohane, R. \& Ostrom E. (eds.), Local Commons and Global Interdependence, London: Sage, pp. 1-26.

Keohane, R., 1990, 'Empathy and international regimes', in Mansbridge, J. (ed.), Beyond SelfInterest, Chicago, IL: Chicago University Press, pp. 227-238.

Kowert, P. \& Legro, J., 1996, 'Norms, identity and their limits: A theoretical reprise', in Katzenstein, P. (ed.), The Culture of National Security: Norms and Identity in World Politics, New York, NY: Columbia University Press, pp. 451-497.

Lemaine, G., Katzenstein, J. \& Personnaz, B., 1978, 'Social differentiation', in Tajfel, H. (ed.), Differentiation between Social Groups: Studies in Social Psychology of Intergroup Relations, London: Academic Press, pp. 269-300.

Lose, L., 2001, 'Communicative action and the world of diplomacy', in Fierke, K. \& Jørgensen, K. (eds.), Constructing International Relations: The Next Generation, Amonk, NY: M.E. Sharpe, pp. 179-199.

McClintock, C., Stech, F. \& Keil, L., 1983, 'The influence of communication upon bargaining', in Paulus, P. (ed.), Basic Group Processes, New York, NY: Springer-Verlag, pp. 205-233.

McEvily, B., Weber, R., Bicchieri, C. \& Ho, V., 2006, 'Can groups be trusted? An experimental study of trust in collective entities', in Bachmann, R. \& Zaheer, A. (eds.), Handbook of Trust Research, Cheltenham: Edward Elgar, pp. 52-67.

McKnight, D. \& Chervany, N., 2006, 'Reflection on an initial trust-building model', in Bachmann, R. \& Zaheer, A. (eds.), Handbook of Trust Research, Cheltenham: Edward Elgar, pp. 29-51. 
Miller, P., Bernzweig, J., Eisenberg, N. \& Fabes, R., 1991, 'The development and socialisation of prosocial behavior', in Hinde, R. \& Groebel, J. (eds.), Cooperation and Prosocial Behaviour, Cambridge: Cambridge University Press, pp. 54-77.

Müller, H., 2001, 'International relations as communicative action', in Fierke, K. \& Jørgensen, K. (eds.), Constructing International Relations: The Next Generation, Amonk, NY: M.E. Sharpe, pp. 160-178.

Nooteboom, B., 2006, 'Forms, sources and processes of trust', in Bachmann, R. \& Zaheer, A. (eds.), Handbook of Trust Research, Cheltenham: Edward Elgar, pp. 247-263.

Pan, C., 2012, 'Problematising 'constructive engagement' in EU-China policy', in Vogt, R. (ed.), Europe and China: Strategic Partners or Rivals?, Hong Kong: Hong Kong University Press, pp. 38-57.

Riker, W, 1974, 'The nature of trust', in Tedeschi, J. (ed.), Perspectives on Social Power, Chicago, IL: Aldine, pp. 63-81.

Rosati, J., 1995, 'A cognitive approach to the study of foreign policy', in Neack, L., Hey, J. \& Haney, P. (eds.), Foreign Policy Analysis: Continuity and Change in Its Second Generation, Upper Saddle River, NJ: Prentice Hall, pp. 49-70.

Tajfel, H., 1978a, 'Interindividual behaviour and intergroup behaviour', in Tajfel, H. (ed.), Differentiation between Social Groups: Studies in Social Psychology of Intergroup Relations, London: Academic Press, pp. 27-60.

Tajfel, H., 1978b, 'Social categorization, social identity and social comparison', in Tajfel, H. (ed.), Differentiation between Social Groups: Studies in Social Psychology of Intergroup Relations, London: Academic Press, pp. 61-76.

Triandis, H., 1991, 'Cross-cultural differences in assertiveness/competition vs. group loyalty/cooperation', in Hinde, R. \& Groebel, J. (eds.), Cooperation and Prosocial Behaviour, Cambridge: Cambridge University Press, pp. 78-88.

Turner, J. \& Giles, H., 1981, 'Introduction: The social psychology of intergroup behaviour', in Turner, J. \& Giles, H. (eds.), Intergroup Behaviour, Chicago, IL: University of Chicago Press, pp. 1-32.

Turner, J., 1981, 'The experimental social psychology of intergroup behaviour', in Turner, J. \& Giles, H. (eds.), Intergroup Behaviour, Chicago, IL: University of Chicago Press, pp. 66-101.

Tyler, T., 2001, 'Why do people rely on others? Social identity and the social aspects of trust', in Cook, K. (ed.), Trust in Society, New York, NY: Russell Sage Foundation, pp. 285-306.

van Knippenberg, A., 1978, 'Status differences, comparative relevance and intergroup differentiation', in Tajfel, H. (ed.), Differentiation between Social Groups: Studies in Social Psychology of Intergroup Relations, London: Academic Press, pp. 171-199.

Vogt, R., 2012a, 'Europe and China: A maturing relationship?', in Vogt, R. (ed.), Europe and China: Strategic Partners or Rivals?, Hong Kong: Hong Kong University Press, pp. 1-16.

Vogt, R., 2012b, 'Limitations to Europe's partnership with China', in Vogt, R. (ed.), Europe and China: Strategic Partners or Rivals?, Hong Kong: Hong Kong University Press, pp. 59-80.

Zhu, L., 2007, 'Chinese perceptions of the EU and the Sino-European relationship', in Shambaugh, D., Sandschneider, E. \& Zhou, H. (eds.), China-Europe Relations: Perceptions, Policies and Prospects, Abingdon: Routledge, pp. 148-173.

\section{Journal and Electronic Articles}

Abdelal, R., Herrera, Y., Johnston, A. \& McDermott, R., 2006, 'Identity as a variable', Perspectives on Politics, 4:4, pp. 695-711. 
Alexander, M., Brewer, M. \& Hermann, R., 1999, 'Images and affect: A functional analysis of out-group stereotypes', Journal of Personality and Social Psychology, 77:1, pp. 7893.

Axelrod, R. \& Keohane, R., 1985, 'Achieving cooperation under anarchy: Strategy and institutions', World Politics, 38:1, pp. 226-254.

Baier, A., 1986, 'Trust and antitrust', Ethics, 96:2, pp. 231-260.

Burt, R. \& Knez, M., 1995, 'Kinds of third-party effects on trust', Rationality and Society, 7:3, pp. 255-292.

Casarini, N., 2006, 'The evolution of the EU-China relationship: From constructive engagement to strategic partnership', EU Institute of Security Studies Occasional Paper, 64.

Checkel, J., 2004, 'Social constructivisms in global and European politics: A review essay', Review of International Studies, 30:2, pp. 229-244.

Cheney, J., Harford, T. \& Solomon, L., 1972, 'The effects of communicating threats and promises upon the bargaining process', Journal of Conflict Resolution, 16:1, pp. 99-107.

Chilton, S., Stalzer, M. \& Cuzzo, W., 2005, 'Habermas' theory of communicative action as a theoretical framework for mediation practice', Conflict Resolution Quarterly, 22:3, pp. 325-348.

Dessler, D. \& Owen, J., 2005, 'Constructivism and the problem of explanation: A review article', Perspectives on Politics, 3:3, pp. 597-610.

Deutsch, M., 1958, 'Trust and suspicion', Journal of Conflict Resolution, 2:4, pp. 265-279.

Engelen, E-M. \& Röttger-Rössler, B., 2012, 'Current disciplinary and interdisciplinary debates on empathy', Emotion Review, 4:3, pp. 3-8.

Farrell, T., 2002, 'Constructivist security studies: Portrait of a research programme', International Studies Review, 4:1, pp. 49-72.

Finnemore, M. \& Sikkink, K., 1998, 'International norm dynamics and political change', International Organization, 52:4, pp. 887-917.

Fiske, S., Cuddy, A. \& Glick, P., 2006, 'Universal dimensions of social cognition: Warmth and competence', TRENDS in Cognitive Sciences, 11:2, pp. 77-83.

Grobe, C., 2010, 'The power of words: Argumentative persuasion in international negotiations', European Journal of International Relations, 16:1, pp. 5-29.

Halpern, J. \& Weinstein, H., 2004, 'Rehumanizing the other: Empathy and reconciliation', Human Rights Quarterly, 26:3, pp. 561-583.

Head, N., 2012, 'Transforming conflict: Trust, empathy, and dialogue', International Journal of Peace Studies, 17:2, pp. 33-55.

Hoffman, A., 2002, 'A conceptualisation of trust in international relations', European Journal of International Relations, 8:3, pp. 375-401.

Hollan, D., 2012, 'Emerging issues in the cross-cultural study of empathy', Emotion Review, 4:1, pp. 70-78.

Holslag, J., 2006, 'The European Union and China: The great disillusion', European Foreign Affairs Review, 11, pp. 555-580.

Holsti, O., 1962, 'The belief system and national images: A case study', The Journal of Conflict Resolution, 6:3, pp. 244-252.

Houghton, D., 2007, 'Reinvigorating the study of foreign policy decision making: Towards a constructivist approach', Foreign Policy Analysis, 3:1, pp. 24-45.

Johnson, J., 1991, 'Habermas on strategic and communicative action', Political Theory, 19:2, pp. 181-201.

Jones, K., 1996, 'Trust and affective attitude', Ethics, 107:1, pp. 4-25.

Krauss, R. \& Deutsch, M., 1966, 'Communication in interpersonal bargaining', Journal of Personality and Social Psychology, 4:5, pp. 572-577. 
Lindskold, S., 1978, 'Trust development, the GRIT proposal and the effects of conciliatory acts on conflict and cooperation', Psychology Bulletin, 85:4, pp. 772-793.

Loomis, J., 1959, 'Communication, the development of trust, and cooperative behaviour', Human Relations, 12:4, pp. 305-315.

Lorenz, E., 1993, 'Flexible production systems and the social construction of trust', Politics Society, 21:3, pp. 307-324.

Maoz, Z. \& Felsenthal, D., 1987, 'Self-binding commitments, the inducement of trust, social choice, and the theory of international cooperation', International Studies Quarterly, 31:2, pp. 177-200.

McAllister, D., 1995, 'Affect- and cognition-based trust as foundations for interpersonal cooperation in organization', The Academy of Management Journal, 38:1, pp. 24-59.

Mercer, J., 2010, 'Emotional beliefs', International Organization, 64:1, pp. 1-31.

Moller Okin, S., 1989, 'Reason and feeling in thinking about justice', Ethics, 99:2, pp. 229249.

Moravcsik, A., 1997, 'Taking preferences seriously: A liberal theory of international politics', International Organization, 51:4, pp. 513-553.

Neumann, I., 1996, 'Self and other in international relations', European Journal of International Relations, 2:2, pp. 139-174.

Nicholson, C., Compeau, L. \& Sethi, R., 2001, 'The role of interpersonal liking in building trust in long-term channel relationships', Journal of the Academy of Marketing Science, 29:1, pp. 3-15.

Risse, T., 2000, 'Let's argue!': Communicative action in world politics', International Organization, 54:1, pp. 1-39.

Rotter, J., 1971, 'Generalized expectancies for interpersonal trust', American Psychologist, 26:5, pp. 443-452.

Ruggie, J., 1998, 'What makes the world hang together? Neo-utilitarianism and the social constructivist challenge', International Organization, 52:4, pp. 855-885.

Shambaugh, D., 2004, 'China and Europe: The emerging axis', Current History, September Issue.

Shapiro, M. \& Bonham, G., 1973, 'Cognitive process and foreign policy decision-making', International Studies Quarterly, 17:2, pp. 147-174.

Sterling-Faulker, J., 2000, 'Competing paradigms or birds of a feather? Constructivism and neoliberal institutionalism compared', International Studies Quarterly, 44:1, pp. 97-119.

Swinth, R., 1967, 'The establishment of the trust relationship', Journal of Conflict Resolution, 11: 3, pp. 335-344.

Wendt, A., 1992, 'Anarchy is what states make of it: The social construction of power politics', International Organisation, 46:2, pp. 391-425.

Wheeler, N., 2012, 'Trust-building in international relations', Peace Prints: South Asian Journal of Peacebuilding, 4:2, pp. 1-13.

White, R., 1991, 'Empathising with Saddam Hussein', Political Psychology, 12:2, pp. 291308.

Williamson, O., 1993, 'Calculativeness, trust, and economic organization', Journal of Law and Economics, 36:1, pp. 453-486.

Zyla, B., 2008, 'Riding the Asian tiger? How the EU engaged China since the end of the Cold War', Current Politics and Economics of Asia, 17:1, pp. 83-106.

\section{Website and Newspaper Articles}


Cameron, L., 2011a, 'Empathy: A review', Working paper from the research project: "Living with uncertainty: Metaphor and the dynamics of empathy in discourse", 1, retrieved at: http://www.open.ac.uk/researchprojects/livingwithuncertainty/, on 12/02/2014.

Cameron, L., 2011b, 'Empathy in talk: A model and some methodological considerations', Working paper from the research project: "Living with uncertainty: Metaphor and the dynamics of empathy in discourse", 3, retrieved at: http://www.open.ac.uk/researchprojects/livingwithuncertainty/, on 13/02/2014.

Cameron, L., 2012, 'Dyspathy: The dynamic complement of empathy', Working paper from the research project: "Living with uncertainty: Metaphor and the dynamics of empathy in discourse”, 5, retrieved at: http://www.open.ac.uk/researchprojects/livingwithuncertainty/, on $13 / 02 / 2014$.

EEAS, 2012, Information note: Sectoral Cooperation between the EU and China, retrieved at http://eeas.europa.eu/china/docs/sectoraldialogues_en.pdf, on 22/02/2012.

European Commission, 2013, China, retrieved at: http://ec.europa.eu/trade/policy/countriesand-regions/countries/china/, on 16/09/2013.

\section{CHAPTER 4}

\section{Book References}

Allport, G., 1954, The Nature of Prejudice, Cambridge, MA: Addison-Wesley.

Deutsch, M., 1973, The Resolution of Conflict: Constructive and Destructive Processes, New Haven, CT: Yale University Press.

Fisher, G., 1997, Mindsets: The Role of Culture and Perceptions in International Relations, Yarmouth, ME: Intercultural Press.

Ginsberg, R., 2001, The European Union in International Politics: Baptism by Fire, Lanham: Rowman \& Littlefield.

Haaland Matláry, J., 2009, European Union Security Dynamics: In the New National Interest, Basingstoke: Palgrave Macmillan.

Hopf, T., 2002, Social Construction of International Politics: Identities and Foreign Policies, Moscow, 1955 \& 1999, Ithaca, NY: Cornell University Press.

Vertzberger, Y., 1990, The World in their Minds: Information Processing, Cognition and Perception in Foreign Policy Decision-making, Stanford, CA: Stanford University Press.

\section{Book Chapters}

Adler, E., 2002, 'Constructivism and IR', in Carlsnaes, W., Risse, T. \& Simmons, B. (eds.), Handbook of International Relations, London: Sage, pp. 95-119.

Boon, S. \& Holmes, J., 1991, 'The dynamics of interpersonal trust: Resolving uncertainty in the face of risk', in Hinde, R. \& Groebel, J. (eds.), Cooperation and Prosocial Behaviour, Cambridge: Cambridge University Press, pp. 190-211.

Clarke, M. \& Smith, S., 1989, 'Perspectives on the foreign policy system: Implementation approaches', in Clarke, M. \& White, B. (eds.), Understanding Foreign Policy: The Foreign Policy Systems Approach, Cheltenham: Edward Elgar, pp. 163-184.

Cook, K., Hardin, R. \& Levi, M., 2007, 'The significance of trust', in Cook, K., Hardin, R. \& Levi, M. (eds.), Cooperation Without Trust?, New York, NY: Russell Sage Foundation, pp. 1-20. 
Cook-Huffman, C., 2008, 'The role of identity in conflict', in Sandole, D., Byrne, S., SandoleStaroste, I. \& Senehi, J. (eds.), Handbook of Conflict Analysis and Resolution, Abingdon: Routledge, pp. 19-31.

Gebhard, C., 2011, 'Coherence', in Hill, C. \& Smith, M. (eds.), International Relations and the European Union, $2^{\text {nd }}$ Edition, Oxford: Oxford University Press, pp. 101-127.

Katzenstein, P., 1996, 'Conclusion: National security in a changing world', in Katzenstein, P. (ed.), The Culture of National Security: Norms and Identity in World Politics, New York, NY: Columbia University Press, pp. 498-537.

Major, C., 2011, 'Pulling the strings behind the scenes - But never against the member states: Solana's role in the launch of EU military operations', in Müller-Brandeck, G. \& Rüger, C. (eds.), The High Representative for the EU Foreign and Security Policy: Review and Prospects, Baden-Baden: Nomos, pp. 175-199.

McClintock, C., Stech, F. \& Keil, L., 1983, 'The influence of communication upon bargaining', in Paulus, P. (ed.), Basic Group Processes, New York, NY: Springer-Verlag, pp. 205-233.

Peclow, V., 2008, 'Le Conseil et la gestion de crises', in Delcourt, B., Martinelli, M. \& Klimis, E. (eds.), L’Union européenne et la Gestion des Crises, Bruxelles : Ed. de l'Université Libre de Bruxelles, pp. 25-46.

Quille, G., 2008, 'La place du Parlement européen dans le processus de gestion de crise', in Delcourt, B., Martinelli, M. \& Klimis, E. (eds.), L'Union européenne et la Gestion des Crises, Bruxelles : Ed. de l'Université Libre de Bruxelles, pp. 65-80.

Reinke de Buitrago, S., 2012, 'Othering in international relations: Significance and implications', in Reinke de Buitrago, S. (ed.), Portraying the Other in International Relations, Newcastle-upon-Tyne: Cambridge Scholars Publishing, pp. xiii-2.

\section{Journal and Electronic Articles}

Abdelal, R., Herrera, Y., Johnston, A. \& McDermott, R., 2006, 'Identity as a variable', Perspectives on Politics, 4:4, pp. 695-711.

Alexander, M., Brewer, M. \& Hermann, R., 1999, 'Images and affect: A functional analysis of out-group stereotypes', Journal of Personality and Social Psychology, 77:1, pp. 78-93.

Brubaker, R. \& Cooper, F., 2000, 'Beyond identity', Theory and Society, 29:1, pp. 1-47.

Checkel, J., 2004, 'Social constructivisms in global and European politics: A review essay', Review of International Studies, 30:2, pp. 229-244.

Farrell, T., 2002, 'Constructivist security studies: Portrait of a research programme', International Studies Review, 4:1, pp. 49-72.

Finnemore, M. \& Sikkink, K., 1998, 'International norm dynamics and political change', International Organization, 52:4, pp. 887-917.

Lebow, R., 2008, 'Identity and international relations', International Relations, 22:4, pp. 473492.

Mitrović, L., 1999, 'New social paradigm: Habermas' theory of communicative action', Philosophy and Sociology, 2:6/2, pp. 217-223.

Risse, T., 2000, 'Let's argue!': Communicative action in world politics', International Organization, 54:1, pp. 1-39.

Smith, M., 2000, 'Conforming to Europe: The domestic impact of EU foreign policy cooperation', Journal of European Public Policy, 7:4, pp. 613-631.

Smith, M., 2004, 'Institutionalization, policy adaptation and European foreign policy cooperation', European Journal of International Relations, 10:1, pp. 95-136.

Steinberg, P., 2007, 'Causal assessment in small-N policy studies', The Policy Studies Journal, 35:2, pp. 181-204. 
Wendt, A., 1992, 'Anarchy is what states make of it: The social construction of power politics', International Organization, 46:2, pp. 391-425.

\section{CHAPTER 5}

\section{Book References}

Annan, K. \& Mousavizadeh, N., 2013, Interventions: A Life in War and Peace, London: Penguin Books.

Barltrop, R., 2011, Darfur and the International Community: The Challenges of Conflict Resolution in Sudan, New York, NY: I.B. Tauris.

Cockett, R., 2010, Sudan: Darfur and the Failure of an African State, New Haven and London: Yale University Press.

Collins, R., 2008, A History of Modern Sudan, Cambridge: Cambridge University Press.

Crilly, R., 2010, Saving Darfur: Everyone's Favourite African War, London: Reportage.

Deutsch, M., 1973, The Resolution of Conflict: Constructive and Destructive Processes, New Haven, CT: Yale University Press.

Flint, J. \& De Waal, A., 2008, Darfur: A New History of a Long War, London: Zed Books.

Granvaud, R., 2009, Que fait l'armée française en Afrique ?, Marseilles: Agone.

Howorth, J., 2007, Security and Defence Policy in the European Union, Basingstoke: Palgrave Macmillan.

Kaldor, M., 2007, Human Security: Reflections on Globalization and Intervention, Cambridge: Polity.

Kerr, D. \& Liu, F., 2007, The International Politics of EU-China Relations, Oxford: Oxford University Press.

Mamdani, M., 2009, Saviours and Survivors: Darfur, Politics, and the War on Terror, New York, NY: Pantheon Books.

Natsios, A., 2012, Sudan, South Sudan and Darfur: What Everyone Needs To Know, New York, NY: Oxford University Press.

Prunier, G., 2008, Darfur: A $21^{\text {st }}$ Century Genocide, Ithaca, NY: Cornell University Press.

\section{Book Chapters}

He, W., 2010, 'The Darfur issue: A new test for China's Africa policy', in Cheru, F. \& Obi, C. (eds.), The Rise of China and India in Africa: Challenges, Opportunities and Critical Interventions, London: Zed Books, pp. 155-166.

Keane, R. \& Wee, A., 2010, 'The European Union', in Black, D. \& Williams, P. (eds.), The International Politics of Mass Atrocities: The Case of Darfur, Abingdon: Routledge, pp. 119-133.

Richardson, S., 2008, 'Challenges for a 'responsible power', in Worden, M. (ed.), China's Great Leap: The Beijing Games and Olympian Human Rights Challenges, New York, NY: Seven Stories Press, pp. 283-296.

Srinivasan, S., 2008, 'A marriage less convenient: China, Sudan and Darfur', in Ampiah, K. \& Naidu, S. (eds.), Crouching Tiger, Hidden Dragon? Africa and China, Scottsville: University of KwaZulu-Natal Press, pp. 55-85.

Stedjan, S. \& Thomas-Jensen, C., 2010, 'The United States', in Black, D. \& Williams, P. (eds.), The International Politics of Mass Atrocities: The Case of Darfur, Abingdon: Routledge, pp. 157-175. 
Taylor, I., 2010, 'The People's Republic of China', in Black, D. \& Williams, P. (eds.), The International Politics of Mass Atrocities: The Case of Darfur, Abingdon: Routledge, pp. 176-194.

van Dijk, M.P., 2009, 'The political impact of the Chinese in Sudan', in van Dijk, M.P. (ed.), The New Presence of China in Africa, Amsterdam: Amsterdam University Press, pp. 141156.

Williams, P., 2010, 'Britain and Africa in the twenty-first century', in Mangala, J. (ed.), Africa and the New World Era: From Humanitarianism to a Strategic View, Basingstoke: Palgrave Macmillan, pp. 37-51.

Zhao, H., 2010, 'China's energy relations with Africa', in Liu Currier, C. \& Dorraj, M. (eds.), China's Energy Relations with the Developing World, New York, NY: Continuum, pp. 101-125.

\section{Journal and Electronic Articles}

Ahmed, G.K., 2010, 'The Chinese stance on the Darfur conflict', South Africa Institute of International Affairs Occasional Paper, 67.

Aning, K. \& Lecoutre, D., 2008, 'China's ventures in Africa', African Security Review, 17:1, pp. 39-50.

Appiah-Mensah, S., 2005, 'AU's critical assignment in Darfur', African Security Review, 14:2, pp. 7-21.

Badescu, C. \& Bergholm, L., 2009, 'The Responsibility to Protect and the conflict in Darfur: The big let-down', Security Dialogue, 40:3, pp. 287-309.

Berg, P., 2009, 'EUFOR Tchad/RCA: The EU serving French interests', in Asseburg, M. \& Kemplin, R. (eds.), 'The EU as a strategic actor in the realm of security and defence? A systematic assessment of ESDP missions and operations', Stiftung Wissenschaft und Politik Research Paper, 14, pp. 57-69.

Bradbury, R., 2012, 'Sudan - The hollow state: What challenges to Chinese policy?', Journal of Politics and International Studies, 8, pp. 362-410.

Brosché, J., 2008, 'Darfur - Dimensions and dilemmas of a complex situation', Uppsala Conflict Data Program Paper, 2.

Carmody, P. \& Taylor, I., 2010, 'Flexigemony and force in China's resource diplomacy in Africa: Sudan and Zambia compared', Geopolitics, 15:3, pp. 495-515.

Crisis Action, 2011, Darfur: No Peace in Sight, London.

Dagne, T., 2010, Sudan: The Crisis in Darfur and Status of the North-South Peace Agreement, Washington, DC: Congressional Research Service.

El-Tom, E., 2003, 'The Black Book of Sudan: Imbalance of power and wealth in Sudan', Journal of African National Affairs, 1:2, pp. 25-35.

Gya, G., 2010, 'The EU's role in the Darfur crisis from 2003 until today', in FRIDE (ed.), The Gap Between Narratives and Practices - Darfur: The Responses From the Arab World, Madrid: Fundación para los Relaciones Internacionales y el Diálogo (FRIDE).

Hagan, J. \& Polloni, A., 2006, 'Death in Darfur', Science Magazine, 313, pp. 1578-1579.

Holslag, J., 2007a, 'China's diplomatic manoeuvring on the question of Darfur', Journal of Contemporary China, 17:54, pp. 71-84.

HRF, 2008, Investing in Tragedy: China's Money, Arms, and Politics in Sudan, New York, NY: Human Rights First.

HRW, 1998, Sudan: Global Trade, Local Impact - Arms Transfers to All Sides in the Civil War in Sudan, New York, NY: Human Rights Watch.

HSBA, 2007, 'Arms, oil, and Darfur: The evolution of relations between China and Sudan', Sudan Issue Brief, 7, Geneva: Small Arms Survey. 
Huang, C., 2007, 'US-China relations and Darfur', Fordham International Law Journal, 31:4, pp. 827-842.

ICG, 2004a, Darfur Deadline: A New International Action Plan, Brussels.

ICG, 2004b, Darfur Rising: Sudan's New Crisis, Brussels.

ICG, 2005a, Darfur: The Failure to Protect, Brussels.

ICG, 2005b, The EU/AU Partnership in Darfur: Not Yet a Winning Combination, Brussels.

ICG, 2006, 'Darfur's fragile peace agreement', Policy Briefing, 39.

ICG, 2007a, Darfur's New Security Reality, Brussels.

ICG, 2007b, Darfur: Revitalising the Peace Process, Brussels.

ICG, 2008, China's Thirst for Oil, Brussels.

ICG, 2009, Sudan: Justice, Peace and the ICC, Brussels.

ICG, 2010, 'Rigged elections in Darfur and the consequences of a probable NCP victory in Sudan', Africa Briefing, 72.

IKV, 2008, Sudan: Whose Oil?, Utrecht: IKV Pax Christi.

Jian, J., 2012, 'China in the international conflict-management: Darfur as a case', Global Review, Winter Edition, pp. 7-11.

Kuo, S., 2012, 'Not looking to lead: Beijing's view of the crisis between the two Sudans', in Saferworld (ed.), Saferworld Briefing: China and South Sudan, London, pp. 3-5.

Large, D., 2008a, 'China and the contradictions of 'non-interference' in Sudan', Review of African Political Economy, 35:115, pp. 93-106.

Large, D., 2008b, 'Sudan's foreign relations with Asia: China and the politics of 'looking east', Institute of Security Studies Paper, 158.

Large, D., 2009, 'China's Sudan engagement: Changing Northern and Southern political trajectories in peace and war', The China Quarterly, 199, pp. 610-626.

Lee, K., Chan, G. \& Chan, L., 2012, 'China in Darfur: Humanitarian rule-maker or ruletaker?', Review of International Studies, 38, pp. 423-444.

Macfarlane, R., 2012, 'Why has China been vilified by the West for its engagement in Darfur and to what extent is this justified?', Journal of Politics \& International Studies, 8, pp. 161-202.

Murithi, T., 2010, 'The African Union's evolving role in peace operations: The African Union Mission in Burundi, the African Union Mission in Sudan and the African Union Mission in Somalia', African Security Review, 17:1, pp. 69-82.

Patey, L., 2007, 'State rules: Oil companies and armed conflict in Sudan', Third World Quarterly, 28:5, pp. 997-1016.

Saferworld, 2011, China's Growing Role in African Peace and Security, London.

Saferworld, 2012, China and Conflict-Affected States: Between Principle and Pragmatism, London.

Tanca, A., 2006, 'Towards a comprehensive China strategy', in Zaborowski, M. (ed.), 'Facing China's rise: Guidelines for an EU strategy', Chaillot Paper, 94.

Tubiana, J., 2008, The Chad-Sudan Proxy War and the 'Darfurization' of Chad: Myths and Reality, Geneva: Small Arms Survey.

van der Meulen, E. \& van der Putten, F-P., 2009, Great Powers and International Conflict Management: European and Chinese Involvement in the Darfur and Iran Crises, The Hague: Netherlands Institute of International Relations Clingendael.

van Hoeymissen, S., 2011, 'Regional organizations in China's security strategy for Africa: The sense of supporting 'African solutions to African problems', Journal of Current Chinese Affairs, 40:4, pp. 91-118.

Williams, P. \& Bellamy, A., 2005, 'The Responsibility to Protect and the crisis in Darfur', Security Dialogue, 36:1, pp. 27-47. 
Zhang, C., 2008, 'Possibility of cooperation: China and the EU in Darfur', Shanghai Institute for International Studies International Review, 2, pp. 55-82.

\section{Websites and Newspaper Articles}

Abramovitz, M. \& Kolieb, J., 2007, 'Why China won't save Darfur', Foreign Policy, retrieved

http://www.foreignpolicy.com/articles/2007/06/04/why_china_wont_save_darfur, on 06/03/2014.

Adebajo, A., 2011, 'Gaddafi: The man who would be king of Africa', The Guardian, retrieved at: http://www.theguardian.com/commentisfree/2011/aug/26/gaddafi-legacymeddling-africa, on 28/02/2014.

Adam, A., 2015, 'Why is the world blind to the fresh threat of genocide in Darfur?', The Guardian, retrieved at: http://www.theguardian.com/world/2015/jan/16/why-is-theworld-blind-to-the-fresh-threat-of-genocide-in-darfur, on 28/04/2015.

Al Jazeera, 2010, China opposes UN Darfur report, retrieved at: http://www.aljazeera.com/news/asia-pacific/2010/10/2010102143327115287.html, on $13 / 03 / 2014$.

Ali, A.A., 2007, 'EU, China and Africa: The Sudanese experience', Sudan Tribune, retrieved at: http://sudantribune.com/spip.php?article22783, on 25/02/2014.

Avni, B., 2006, 'New to UN Security Council, Qatar sides with China', The New York Sun, retrieved at: http://www.nysun.com/foreign/new-to-un-security-council-qatar-sides-withchina/25696/, on 13/03/2014.

BBC News, 2003, Profile: Sudan's President Bashir, retrieved at: http://news.bbc.co.uk/2/hi/africa/3273569.stm, on 11/03/2014.

BBC News, 2004, Arab League backs Sudan on Darfur, retrieved at: http://news.bbc.co.uk/2/hi/3545818.stm, on 13/03/2014.

BBC News, 2007a, Darfur rebels spurn Chinese force, retrieved at: http://news.bbc.co.uk/2/hi/7111206.stm, on 13/03/2014.

BBC News, 2008, China rejects BBC Darfur claim, retrieved at: http://news.bbc.co.uk/2/hi/7507392.stm, on 13/03/2014.

BBC News, 2009, Dancing Bashir scoffs at Darfur warrant, retrieved at: http://news.bbc.co.uk/2/hi/africa/7926813.stm, on 12/03/2014.

BBC News, 2010b, China 'trying to block publication of UN Darfur report', retrieved at: http://www.bbc.co.uk/news/world-africa-11593516, on 13/03/2014.

BBC News, 2010c, Darfur arms report that angered China goes to UN, retrieved at: http://www.bbc.co.uk/news/world-africa-11748989, on 13/03/2014.

BBC News, 2012b, Sudan's Darfur region dabbles with peace, retrieved at: http://www.bbc.co.uk/news/world-africa-17225356, on 13/03/2014.

Charbonneau, L., 2009, 'Darfur is now a 'low-intensity' conflict - UN', Reuters, retrieved at: http://www.reuters.com/article/2009/04/27/idUSN27541224._CH_.2400, on 13/03/2014.

China Digital Times, 2008, China lauds Sudan's “unremitting efforts" in Darfur, retrieved at: http://chinadigitaltimes.net/2008/06/china-lauds-sudans-unremitting-efforts-in-darfur/, on $13 / 03 / 2014$.

China.org.cn, 2008, Chinese Envoy for Darfur calls for fairer media coverage, retrieved at: http://www.china.org.cn/2008-04/26/content_15019573.htm, on 13/03/2014.

Chinese Mission to the UN, 2008, China's position on the issue of Darfur, Sudan, retrieved at: http://www.china-un.org/eng/xw/t415999.htm, on 13/03/2014. 
CICC, 2008, Darfur: Possibility of Art. 16 deferral of ICC's investigation in Darfur, debate at the $63^{\text {rd }}$ UNGA and related deliberations by the UN Security Council, retrieved at: http://www.iccnow.org/?mod=newsdetail\&news=3093, on 11/03/2014.

CNN, 2009, Darfur violence becoming a forgotten war, retrieved at: http://edition.cnn.com/2009/WORLD/africa/12/10/sudan.darfur/, on 13/03/2014.

Cooper, H., 2007, 'Darfur collides with Olympics, and China yields', The New York Times, retrieved at: http://www.nytimes.com/2007/04/13/washington/13diplo.html?_r=0, on 24/02/2014.

Cooper, H., 2008, 'Spielberg drops out as adviser to Beijing Olympics in dispute over Darfur conflict', The New York Times, retrieved at: http://www.nytimes.com/2008/02/13/world/asia/13china.html, on 13/03/2014.

European Parliament, 2008, Parliamentary questions, retrieved at: http://www.europarl.europa.eu/sides/getAllAnswers.do?reference=E-20081553\&language $=\mathrm{ET}$, on 16/05/2014.

Fisher-Thompson, J., 2007, 'State's Negroponte thanks Chad for aiding Darfur refugees', IIP Digital, retrieved at: http://iipdigital.usembassy.gov/st/english/article/2007/04/200704181511101ejrehsif0.622 3871.html\#axzz2vk46H07i, on 12/03/2014.

Greenberg, I., 2008, 'Changing the rules of the game', The New York Times, retrieved at: http://www.nytimes.com/2008/03/30/magazine/30olympics-t.html?pagewanted=all\&_r=0, on $03 / 03 / 2014$.

Hansen, K., 2011, 'Chad's relations with Libya, Sudan, France and the US', Norwegian Peacebuilding Resource Centre, retrieved at: http://www.peacebuilding.no/layout/set/print/Regions/Africa/Publications/Chad-srelations-with-Libya-Sudan-France-and-the-US, on 12/03/2014.

IRIN, 2006, Africa: Summit will boost Chinese aid, retrieved at: http://www.irinnews.org/report/61472/africa-summit-will-boost-chinese-aid, on 13/03/2014.

Lavallee, G., 2010, 'Chad-Sudan deal could end Darfur insecurity, says US Envoy', The Telegraph, retrieved at: http://www.telegraph.co.uk/expat/expatnews/7196443/ChadSudan-deal-could-end-Darfur-insecurity-says-US-envoy.html, on 13/03/2014.

Le Figaro, 2006, Darfour : Notre patience a des limites, retrieved at: http://www.lefigaro.fr/debats/2006/03/09/01005-20060309ARTFIG90167darfour_notre_patience_a_des_limites.php, on 25/02/2014.

Leopold, E., 2006, 'Russia, China block Sudan sanctions', Reuters, retrieved at: http://www.globalpolicy.org/component/content/article/206/39703.html, on 13/03/2014.

Marchal, R., 2009, 'Understanding French policy towards Chad and Sudan? A difficult task', Sudan Tribune, retrieved at: http://www.sudantribune.com/spip.php?article31423, on $12 / 03 / 2014$.

Miles, J., 2006, 'China's coming-out party', The Economist, retrieved at: http://www.economist.com/node/8130602, on 13/03/2014.

Panapress, 2003, Southern Sudan peace deal scares Darfur rebels, retrieved at: http://www.panapress.com/Southern-Sudan-peace-deal-scares-Darfur-rebels--12-49367531-lang2-index.html, on 04/04/2014.

People's Daily, 2010, Sudanese President rejects mediation between government, Darfur movements, retrieved at: http://english.peopledaily.com.cn/90001/90777/90855/7070460.html, on 13/03/2014.

Prendergast, J. \& Thomas-Jensen, C., 2007, An axis of peace for Darfur: The United States, France, and China, retrieved at: http://enoughproject.org/publications/axis-peace-darfurunited-states-france-and-china, on 25/02/2014. 
Reeves, E., 2007, 'On Darfur, China and the 2008 Olympic Games', Sudan Tribune, retrieved at: http://www.sudantribune.com/spip.php?article20210, on 27/02/2014.

Reeves, E., 2008, 'Genocide prevention: 60 years of abject failure', The CS Monitor, retrieved at: http://www.csmonitor.com/Commentary/Opinion/2008/0130/p09s02-coop.html, on 24/02/2014.

Reuters, 2008, Darfur activists urge leaders to skip Olympics opening ceremony, retrieved at: http://www.theepochtimes.com/news/8-4-3/68543.html, on 13/03/2014.

Security Council Report, 2007, Sudan/Darfur, retrieved at: http://www.securitycouncilreport.org/monthly-forecast/200712/lookup_c_glKWLeMTIsG_b_3602237.php, on 13/03/2014.

Shichor, Y., 2007, China's Darfur policy, retrieved at: http://www.asianresearch.org/articles/3039.html, on 26/02/2014.

Spencer, R., 2008, 'China criticises Darfur genocide charges against Sudan President Omar al-Bashir', The Telegraph, retrieved at: http://www.telegraph.co.uk/news/worldnews/africaandindianocean/sudan/2403917/China -criticises-Darfur-genocide-charges-against-Sudan-President-Omar-al-Bashir.html, on $12 / 03 / 2014$.

Sudan Tribune, 2006a, Darfur will be foreign troops' graveyard - Bashir, retrieved at: http://www.sudantribune.com/spip.php?page=imprimable\&id_article=14272, on 12/03/2014.

Sudan Tribune, 2006b, Sudan decides expulsion of Norwegian humanitarian agency, retrieved at: http://www.sudantribune.com/spip.php?article18808, on 12/03/2014.

Sudan Tribune, 2007, Darfur displaced protest against Chinese troops, retrieved at: http://www.sudantribune.com/spip.php?article24938, on 13/03/2014.

Sudan Tribune, 2008a, Darfur rebels deny Sudanese accusations of killing Chinese oil workers, retrieved at: http://www.sudantribune.com/spip.php?article29070, on $13 / 03 / 2014$.

Sudan Tribune, 2008b, Sudan confident China, Russia to block al-Bashir indictment, retrieved at: http://www.sudantribune.com/spip.php?article28141, on 11/03/2014.

Sudan Tribune, 2009, Sudan UN Envoy blasts Costa Rica for opposing ICC deferral, retrieved at: http://sudantribune.com/spip.php?article30082, on 11/03/2014.

Suleiman, M., 2008, 'Prospects of success for the British initiative on Darfur', Sudan Tribune, retrieved at: http://sudantribune.com/spip.php?article26921, on 14/05/2014.

The Guardian, 2010, China accused of trying to block Darfur report, retrieved at: http://www.theguardian.com/world/2010/oct/21/china-accused-blocking-darfur-report, on $13 / 03 / 2014$.

The Guardian, 2015, Omar al-Bashir celebrates ICC decision to halt Darfur investigation, retrieved at: http://www.theguardian.com/world/2014/dec/14/omar-al-bashir-celebratesicc-decision-to-halt-darfur-investigation, on 28/04/2015.

Troup Buchanan, R., 2015, 'Mass rape in Darfur: Sudanese army blamed for multiple attacks on women', The Independent, retrieved at: http://www.independent.co.uk/news/world/africa/mass-rape-in-darfur-sudanese-armyblamed-for-multiple-attacks-on-women-10039536.html, on 01/03/2015.

UN, 2012, UN mission's summary detailed by country, retrieved at: http://www.un.org/en/peacekeeping/contributors/2012/Nov12_3.pdf, on 13/03/2014.

Wikileaks, 2007, China in Sudan: Rising dragon or paper tiger?, retrieved at: https://dazzlepod.com/cable/07KHARTOUM119/?rss=1, on 25/02/2014.

Williamson, R., 2011, 'Blood, oil, and Sudan', The American Magazine, retrieved at: http://www.american.com/archive/2011/july/blood-oil-and-sudan, on 24/02/2014. 
Xinhua News Agency, 2007a, China opposes US House Resolution on Darfur, retrieved at: http://english.peopledaily.com.cn/200706/07/eng20070607_382009.html, on 20/05/2014.

Xinhua News Agency, 2007b, Interview: Talking soft - Common steps helps resolve Darfur issue, retrieved at: http://english.people.com.cn/90001/90776/6275757.html, on $13 / 03 / 2014$.

Xinhua News Agency, 2007c, Special Envoy says Darfur issue needs more effort, retrieved at: http://www.china.org.cn/english/international/214792.htm, on 11/03/2014.

Xinhua News Agency, 2008a, Chinese Envoy: Western media exaggerate China's limited arms sales to Sudan, retrieved at: http://news.xinhuanet.com/english/200802/22/content_7650939.htm, on 13/03/2014.

Xinhua News Agency, 2008b, Sudan Ambassador: Int'l society should help Darfur people as China has, retrieved at: http://news.xinhuanet.com/english/200803/20/content_7829151.htm, on 13/03/2014.

Zuckerman, E., 2004, Chemical weapons in Darfur?, retrieved at: http://www.ethanzuckerman.com/blog/2004/09/15/chemical-weapons-in-darfur/, on 24/02/2014.

\section{Command Documents}

EU Council, 2004a, Council Conclusions on Darfur/Sudan, 11434/04, Brussels.

EU Council, 2004b, Council Conclusions on Darfur, 11709/1/04 REV 1, Brussels.

EU Council, 2004c, Council Conclusions on Darfur, 13303/04, Brussels.

EU Council, 2004d, EU Activities in Support of International Efforts to Resolve the Crisis in Darfur, 12025/04, Brussels.

EU Council, 2005a, Possible EU Civilian/Military Supporting Action to the African Union Mission in the Darfur Region of Sudan (AMIS II), 10218/05 REV 1, Brussels.

EU Council, 2006b, Declaration by the Presidency on behalf of the European Union Concerning the Darfur Talks, 8989/1/06 REV 1 (Presse 124), Brussels.

EU Council, 2006c, EU Civilian/Military Supporting Action to the African Union Mission in the Darfur Region of Sudan (AMIS II) - Updated Master Messages, 11388/06, Brussels.

EU Council, 2006e, Plenary Session of the European Parliament, Strasbourg, 27 September 2006: Council and Commission Statements - Situation in Darfur, 13429/06, Brussels.

EU Council, 2007, Declaration by the Presidency on behalf of the European Union on the Outcome of the Arusha Meeting, 12345/07 (Presse 186), Brussels.

EU Council, 2008b, 'EU support to the African Union mission in Darfur - AMIS', Factsheet, AMIS II/08, Brussels.

EU Council, 2012b, Lessons from the EU Civilian-Military Supporting Action to the African Union Mission in the Darfur Region of Sudan (AMIS) and Recommended Action, 9092/2/08 REV 2 EXT 1, Brussels.

European Parliament, 2004, Motion for a Resolution on the Sudan, B5-0153/2004, Brussels.

UN, 2006, High Level Consultations on the Situation in Darfur, Addis Ababa.

UNSC, 2004, Resolution 1556 (2004), S/RES/1556 (2004), New York.

UNSC, 2004, Resolution 1564 (2004), S/RES/1564 (2004), New York.

UNSC, 2005, Resolution 1591 (2005), S/RES/1591 (2005), New York.

UNSC, 2005, Resolution 1593 (2005), S/RES/1593 (2005), New York.

UNSC, 2006, Resolution 1672 (2006), S/RES/1672 (2006), New York.

UNSC, 2006, Resolution 1679 (2006), S/RES/1679 (2006), New York.

UNSC, 2006, Resolution 1706 (2006), S/RES/1706 (2006), New York.

\section{Miscellaneous}


Richardson, C., 2012, Selective Multilateral Security Cooperation? Insights from Chinese Activity on the Darfur Crisis and the Libyan Civil War.

\section{CHAPTER 6}

\section{Book References}

Barnett, R., 2009, Navy Strategic Culture: Why the Navy Thinks Differently, Annapolis, MA: Naval Institute Press.

Marley, D., 2011, Modern Piracy: A Reference Handbook, Santa Barbara, CA: ABC-CLIO.

Murphy, M., 2008, Small Boats, Weak States, Dirty Money: The Challenge of Piracy, New York, NY: Columbia University Press.

Russell, D., 2010, Who Rules the Waves? Piracy, Overfishing and Mining the Oceans, London: Pluto Press.

Shambaugh, D., 2013, China Goes Global: The Partial Power, New York, NY: Oxford University Press.

Till, G., 2013, Seapower: A Guide for the Twenty-First Century, $3^{\text {rd }}$ Edition, Abingdon: Routledge.

Windsor, P., 2002, Strategic Thinking: An Introduction and Farewell, Boulder, CO: Lynne Rienner.

\section{Book Chapters}

Cole, B., 2008, 'The energy factor in China's maritime strategy', in Collins, G., Erickson, S., Goldstein, L. \& Murray, W. (eds.), China's Energy Strategy: The Impact of Beijing's Maritime Policies, Annapolis, MD: Naval Institute Press, pp. 336-351.

Helly, D., 2009, 'EU NAVFOR Somalia', in Helly, D., Grevi, G. \& Keohane D. (eds.), European Security and Defence Policy: The First Ten Years (1999-2009), Paris: EU Institute for Security Studies, pp. 391-402.

Hirono, M. \& Neill, A., 2012, China's Engagement in Non-Traditional Security: Challenges and Opportunities for UK-China Military Cooperation, London: Royal United Services Institute.

Kupferschmidt, F., 2010, 'Multinational military engagement', in Mair, S. (ed.), Piracy and Maritime Security: Regional Characteristics and Political, Military, Legal and Economic Implications, Berlin: Stiftung Wissenschaft und Politik, pp. 62-70.

Larik, J. \& Weiler, Q., 2011, 'Going naval in troubled waters: The EU, China and the fight against piracy off the coast of Somalia', in Men, J. \& Barton, B. (eds.), China and the European Union in Africa: Partners or Competitors?, Farnham: Ashgate, pp. 81-104.

Lehr, P. \& Lehman, H., 2007, 'Somalia - Pirates' new paradise', in Lehr, P. (ed.), Violence at Sea: Piracy in the Age of Global Terrorism, New York, NY: Routledge, pp. 1-22.

Mildner, S-A. \& Groß, S., 2010, 'Piracy and world trade: The economic costs', in Mair, S. (ed.), Piracy and Maritime Security: Regional Characteristics and Political, Military, Legal and Economic Implications, Berlin: Stiftung Wissenschaft und Politik, pp. 20-27.

Pettreto, K., 2010, 'Piracy as a problem of international politics', Mair, S. (ed.), Piracy and Maritime Security: Regional Characteristics and Political, Military, Legal and Economic Implications, Berlin: Stiftung Wissenschaft und Politik, pp. 10-19. 
Snoddon, R., 2007, 'Piracy and maritime terrorism: Naval responses to existing and emerging threats to the global seaborne economy', in Lehr, P. (ed.), Violence at Sea: Piracy in the Age of Global Terrorism, New York, NY: Routledge, pp. 225-240.

Song, X., 2012, 'Challenges and opportunities in EU-China relations', in Vogt, R. (ed.), Europe and China: Strategic Partners or Rivals?, Hong Kong: Hong Kong University Press, pp. 19-36.

\section{Journal and Electronic Articles}

Chalk, P., 2010, 'Piracy off the Horn of Africa: Scope, dimensions, causes and responses', Brown Journal of World Affairs, 16:2, pp. 89-109.

Christoffersen, G., 2009, China and Maritime Cooperation: Piracy in the Gulf of Aden, Berlin: Stiftung Wissenschaft und Politik.

Ehrhart, H-G. \& Pettreto, K., 2012, 'The EU, the Somalia challenge, and counter-piracy: Towards a comprehensive approach?', European Foreign Affairs Review, 17:2, pp. 261284.

ENA, 2009, Sécurité Maritime et Lutte Contre la Piraterie, Strasbourg: Ecole Nationale d'Administration.

Erickson, A. \& Strange, A., 2012, 'Selfish superpower' no longer? China's anti-piracy activities and $21^{\text {st }}$ century global maritime governance', Harvard Asia Quarterly, 14:1-2, pp. 92-102.

Germond, B. \& Smith, M., 2009, 'Re-thinking European security interests and the ESDP: Explaining the EU's anti-piracy operation', Contemporary Security Policy, 30:3, pp. 573593.

ICS, 2009, Best Management Practices to Deter Piracy in the Gulf of Aden and off the Coast of Somalia Version 2, London: International Chamber of Shipping.

Jarle Hansen, S., 2012, 'The dynamics of Somali piracy', Studies in Conflict and Terrorism, 35:7-8, pp. 523-530.

Kaufman, A., 2009, China's Participation in Anti-Piracy Operations off the Horn of Africa: Drivers and Implications, Alexandria, VA: Center for Naval Analyses.

Kraska, J. \& Wilson, B., 2009, 'Somali Piracy: A nasty problem, a web of responses', Current History, May Issue, pp. 227-231.

Lanteigne, M., 2013, 'Fire over water: China's strategic engagement of Somalia and the Gulf of Aden crisis', The Pacific Review, 26:1, pp. 2-24.

Lin-Greenberg, E., 2010, 'Dragon boats: Assessing China's anti-piracy operations in the Gulf of Aden', Defense \& Security Analysis, 26:2, pp. 213-230.

Muratore, A., 2010, 'EU-NATO cooperation and the pirates of the Gulf of Aden', Australian Journal of Maritime \& Ocean Affairs, 2:3, pp. 90-102.

Murphy, M., 2011, 'Somali Piracy', The Royal United Services Institute Journal, 156:6, pp. 4-11.

Murphy, M., 2012, 'International cooperation against piracy: China's role, problems, and prospects', World Maritime University Journal of Maritime Affairs, 11:71, pp. 71-81.

Ndumbe Anyu, J. \& Moki, S., 2009, 'Africa: The piracy hot spot and its implications for global security', Mediterranean Quarterly, 20:3, pp. 95-121.

One Earth Future Foundation, 2011, The Economic Cost of Somali Piracy 2011, Broomfield.

Riddervold, M., 2011, 'Finally flexing its muscles? Atalanta - The European Union's naval military operation against piracy', European Security, 20:3, pp. 385-404.

Rogers, J., 2009, 'From Suez to Shanghai: The EU and Eurasian maritime security', EU Institute for Security Studies Occasional Paper, 77. 
Rotberg, R., 2010, 'Combating maritime piracy: A policy brief with recommendations for action', World Peace Foundation Policy Brief, 11.

Saferworld, 2011, China's Growing Role in African Peace and Security, London.

Thorup, M., 2009, 'Enemy of humanity: The anti-piracy discourse in present-day antiterrorism', Terrorism and Political Violence, 21:3, pp. 401-411.

Valin, G., 2009, 'La lutte contre la piraterie au large de la Somalie : De l'action nationale à l'action européenne (2008-2009)', EchoGéo, 10.

Weitz, R., 2009, 'Operation Somalia: China's first expeditionary force?', China Security, 5:1, pp. $27-42$.

Willett, L., 2011, 'Pirates and power politics', The Royal United Services Institute Journal, 156:6, pp. 20-25.

\section{Websites and Newspaper Articles}

24 Heures, 2009, Pirates somaliens : La prise d'otages sur le "Tanit » finit dans le sang, retrieved at: http://archives.24heures.ch/actu/monde/pirates-somaliens-prise-otages-tanitfinit-sang-2009-04-10, on 13/08/2013.

Al Jazeera, 2009, Somali pirates free Chinese ship, retrieved at: http://www.aljazeera.com/news/africa/2009/12/2009122845026554844.html, on 16/05/2013.

Bagenal, F., Mutiga, M. \& Jones, S., 2011, 'Kenyan police suspect Somali link after kidnap and murder of British couple', The Guardian, retrieved at: http://www.theguardian.com/world/2011/sep/11/kenya-attack-suspected-somali-links, on 13/08/2013.

BBC News, 2010a, China's anti-piracy role off Somalia expands, retrieved at: http://news.bbc.co.uk/2/hi/8486502.stm, on 15/05/2013.

BBC News, 2012a, Somali pirate attacks show sharp fall, retrieved at: http://www.bbc.co.uk/news/world-africa-20027509, on 13/09/2013.

BBC World Service, 2009, Views of China and Russia decline in global poll, retrieved at: http://www.globescan.com/news_archives/bbccntryview09/backgrounder.html, on 13/09/2013.

CCTV, 2009, China calls for integrated solution to Somali piracy, retrieved at: http://english.cctv.com/20091119/101480.shtml, on 10/07/2016.

CCTV, 2012, Escort naval forces call for strengthened coordination, retrieved at: http://english.cntv.cn/program/newsupdate/20120223/121814.shtml, on 10/07/2016.

China Daily, 2009a, Join hands to fight off pirates, retrieved at: http://www.chinadaily.com.cn/opinion/2009-04/23/content_7707171.htm, on 10/07/2016.

China Daily, 2009b, Navies seeking better ways to battle pirates, retrieved at: http://www.chinadaily.com.cn/cndy/2009-11/06/content_8921359.htm, on 10/07/2016.

China Daily, 2014, EU naval ties in search of more wind, retrieved at: http://www.chinadaily.com.cn/world/agency/2014-04-29/content_11643365.html, on 10/07/2016.

China Defense Blog, 2010, 'China to lead SHADE's anti-piracy patrols off Somalia', retrieved at: http://china-defense.blogspot.fr/2010/01/china-to-lead-shades-antipiracy.html, on 10/07/2016.

Deccan Herald, 2010, EU asks India to co-chair anti-piracy group, retrieved at: http://www.deccanherald.com/content/81099/eu-asks-india-co-chair.html, on 15/05/2013.

Economic Times, 2012, India, China, Japan coordinating in anti-piracy operations, retrieved at: http://articles.economictimes.indiatimes.com/2012-02-01/news/31012850_1_antipiracy-operations-aden-warships, on 14/08/2013. 
Erickson, A., 2009, 'Welcome China to the fight against pirates', Proceedings Magazine, retrieved at: http://www.usni.org/magazines/proceedings/2009-03/welcome-china-fightagainst-pirates, on 09/05/2013.

Erickson, A. \& Strange, A., 2013, 'China and the international antipiracy effort', The Diplomat, retrieved at: http://thediplomat.com/2013/11/china-and-the-internationalantipiracy-effort/, on 28/04/2015.

EU NAVFOR, 2011, Chinese Deputy Chief of the General Staff visits EU NAVFOR HQ, retrieved at: http://eunavfor.eu/chinese-deputy-chief-of-the-general-staff-visits-eu-navforohq/, on 15/05/2013.

Fachada, O., 2012, Piracy and armed robbery at sea, retrieved at: $\mathrm{http} / / /$ ec.europa.eu/transport/modes/maritime/events/doc/2012-03-28-piracy/2-0session2-mare-fachada.pdf, on 10/05/2013.

FCO, 2014, Foreign Secretary welcomes Japan's command of counter-piracy, retrieved at: https://www.gov.uk/government/news/foreign-secretary-welcomes-japans-command-ofcounter-piracy, on 28/04/2015.

Germond, B. \& Smith, M., 2010, The EU's anti-piracy naval operations: An evolution of ESDP's objectives and geopolitical ambitions, retrieved at: http://citation.allacademic.com/meta/p_mla_apa_research_citation/4/1/6/3/1/p416310_in dex.html, on 12/05/2013.

Gros-Verheyde, N., 2008, 'Pirates en Somalie, la Commission regrette le manque de concertation', Bruxelles 2, retrieved at: http://www.bruxelles2.eu/pirateriemaritime/pirates-en-somalie-la-commission-regrette-le-manque-de-concertation.html, on 10/05/2013.

Gros-Verheyde, N., 2010, 'Visite au QG anti-pirates de 1'UE à Northwood', Bruxelles 2, retrieved at: http://www.bruxelles2.eu/piraterie-maritime/visiteauqgantipiratesdelueatalantaanorthwood.html, on 13/05/2013.

Gros-Verheyde, N., 2012a, 'Dernières nouvelles de la piraterie (5 février 2012)', Bruxelles 2 , retrieved at: http://www.bruxelles2.eu/piraterie-maritime/20157.html, on 14/05/2013.

Gros-Verheyde, N., 2012b, 'Un équipage sino-vietnamien libéré. Taiwan et la Chine se parlent, via Bruxelles', Bruxelles 2, retrieved at: http://www.bruxelles2.eu/pirateriemaritime/un-equipage-sino-vietnamien-libere-par-les-pirates-europeens-et-chinois-deconcert.html, on 10/05/2013.

Herald Tribune, 2012, EU, China agree to regular defense, security talks, retrieved at: http://article.wn.com/view/2012/07/10/EU_China_agree_to_regular_defense_security_tal ks_v3/, on 29/03/2014.

Hopkins, D. \& Rivasseau, F., 2014, Counter-piracy update, retrieved at: http://fpc.state.gov/221827.htm, on 28/04/2015.

IMO, 2007a, Coordinated action urged as piracy threatens UN lifeline in Somalia, retrieved at: http://www.imo.org/blast/mainframe.asp?topic_id=1472\&doc_id=8213, on $08 / 05 / 2013$.

IMO, 2007b, IMO Assembly issues renewed call for action on piracy off Somalia, retrieved at: http://www.imo.org/blast/mainframe.asp?topic_id=1472\&doc_id=8751, on 21/05/2014 .

Le Point, 2013, Carré d'as : Un acquittement, quatre condamnations, retrieved at: http://www.lepoint.fr/sport/carre-d-as-un-acquittement-quatre-condamnations-01-022013-1622947_26.php, on 13/08/2013.

MAE, 2013, Piraterie en mer: La France pionnière dans la lutte contre la piraterie et promotrice d'une globale, retrieved at: http://www.diplomatie.gouv.fr/fr/politique-etrangere-de-la-france/defense-etsecurite/piraterie-en-mer/, on 10/05/2013. 
Miles, D., 2013, 'US, Chinese navies exercise counterpiracy in Gulf of Aden', American Forces Press Services, retrieved at: http://www.defense.gov/news/newsarticle.aspx?id=120675, on 30/04/2014.

Mitra, D., 2010, 'EU asks India to co-chair anti-piracy group', Sify News, retrieved at: http://www.sify.com/news/eu-asks-india-to-co-chair-anti-piracy-group-news-nationalkhnqadfjdib.html, on 14/08/2013.

MOFA, 2015, Japan's Actions against piracy off the coast of Somalia, retrieved at: http://www.mofa.go.jp/policy/piracy/ja_somalia_1210.html, on 28/04/2015.

Moore, J., 2012, 'China takes leading role in global counter-piracy operations', Defence IQ, retrieved at: http://www.defenceiq.com/naval-and-maritime-defence/articles/china-sgrowing-role-in-counter-piracy-operations/, on 09/05/2013.

People's Daily, 2013, Commander of $14^{\text {th }}$ Escort Taskforce meets with counterpart of EU $C T F-465$, retrieved at: http://english.peopledaily.com.cn/90786/8327820.html, on 29/03/2014.

Pham, J., 2009, 'The Chinese navy's Somali cruise', World Defense Review, retrieved at: http://worlddefensereview.com/pham031209.shtml, on 09/05/2013.

Phillips, L., 2009, The European roots of Somali piracy, retrieved at: http://euobserver.com/social/27966, on 10/05/2013.

Rice, X. \& Percival, J., 2010, 'British couple kidnapped by Somali pirates freed after ransom payment', The Guardian, retrieved at: http://www.theguardian.com/world/2010/nov/14/paul-rachel-chandler-released-somalipirates, on 13/08/2013.

Rider, D., 2015, EU, Japan boost anti-piracy cooperation, retrieved at: http://www.marsecreview.com/2015/02/eu-japan-boost-anti-piracy-cooperation/, on 28/04/15.

Roell, P., 2011, 'Combating piracy - China's contribution', ISPSW, retrieved at: http://www.isn.ethz.ch/Digital-Library/Publications/Detail/?id=127741, on 30/04/2014.

South China Morning Post, 2008, China navy in Somali waters far from gunboat diplomacy: experts, retrieved at: http://www.scmp.com/article/664211/chinese-navy-somali-watersfar-gunboat-diplomacy-experts, on 10/07/2016.

South China Morning Post, 2009a, A welcome opportunity for China to play its part, retrieved at: http://www.scmp.com/article/698420/welcome-opportunity-china-play-its-part, on $07 / 10 / 2016$.

South China Morning Post, 2009b, Beijing seeks lead role in piracy fight, retrieved at: http://www.scmp.com/article/697831/beijing-seeks-lead-role-piracy-fight, on 10/07/2016.

South China Morning Post, 2009c, Rescue bid shows flaws in piracy fight, retrieved at: http://www.scmp.com/article/696182/rescue-bid-shows-flaws-piracy-fight, on 10/07/2016.

South China Morning Post, 2009d, Softly, softly - so far, retrieved at: http://www.scmp.com/article/696522/softly-softly-so-far, on 10/07/2016.

South China Morning Post, 2009e, 'Too late' for navy rescue of Chinese crew, retrieved at: http://www.scmp.com/article/696270/too-late-navy-rescue-chinese-crew, on 10/07/2016.

South China Morning Post, 2010, Piracy role sets Beijing on course to build trust, retrieved at: http://www.scmp.com/article/704922/piracy-role-sets-beijing-course-build-trust, on 10/07/2016.

South China Morning Post, 2011a, PLA closer to key anti-piracy role, retrieved at: http://www.scmp.com/article/737035/pla-closer-key-anti-piracy-role, on 10/07/2016.

South China Morning Post, 2011b, PLA provides first escort of food aid ship off Somalia, retrieved at: http://www.scmp.com/article/742432/pla-provides-first-escort-food-aid-shipsomalia, on 10/07/2016. 
Seibert, B., 2008, 'EU NAVFOR - Countering piracy in Somali waters', Royal United Services Anstitute Ansis, retrieved at: http://www.rusi.org/analysis/commentary/ref:N4926E42ADC55D/\#.UY4XRKJNTag, on $11 / 05 / 2013$.

Weening, C., 2014, China sends $19^{\text {th }}$ naval escort piracy task force to Somalia, retrieved at: $\mathrm{http}: / / \mathrm{www}$.janes.com/article/46631/china-sends-19th-naval-escort-piracy-task-force-tosomalia, on 28/04/2015.

Wikileaks, 2008a, Demarche request: France must not block NATO counter-piracy discussion, retrieved at: http://cables.mrkva.eu/cable.php?id=167308, on 11/05/2013.

Wikileaks, 2008b, Horn of Africa piracy - HMG shares additional information on operation Atalanta; EU likely to request Kenyan prosecution of captured pirates, retrieved at: http://www.telegraph.co.uk/news/wikileaks-files/london-wikileaks/8304803/HORN-OF-

AFRICA-PIRACY-HMG-SHARES-ADDITIONAL-INFORMATION-ONOPERATION-ATALANTA-EU-LIKELY-TO-REQUEST-KENYAN-PROSECUTIONOF-CAPTURED-PIRATES.html, on 12/05/2013.

Wikileaks, 2008c, Spain interested in Somali piracy UNSCR, retrieved at: http://wikileaks.org/cable/2008/02/08MADRID224.html, on 10/05/2013.

Xinhua News Agency, 2010, Principled consensus on escort missions reached between China, EU, NATO, CMF, retrieved at: http://english.people.com.cn/90001/90776/90883/6883202.html, on 15/05/2013.

Xinhua News Agency, 2011, China takes proactive, open attitude towards international escort cooperation, retrieved at: http://news.xinhuanet.com/english2010/china/201103/31/c_13806943.htm, on 10/07/2016.

Xinhua News Agency, 2012a, Chinese navy escort voyages fruitful, retrieved at: http://news.xinhuanet.com/english/china/2012-12/25/c_132063153.htm, on 29/03/2014.

Xinhua News Agency, 2012b, Chinese navy's escort mission in Somali waters fully successful: envoy, retrieved at: http://news.xinhuanet.com/english/china/201203/30/c_131497403.htm, on 10/07/2016.

Zhang, T., 2015, The Chinese navy plays a strategically pivotal role in maintaining national safety and development interest, retrieved at: http://english.chinamil.com.cn/newschannels/china-military-news/2015-04/24/content_6458823.htm, on 28/04/2015.

Zhu, D. \& Xu, Y., 2009, Commander of Chinese naval escort taskforce visits No. 465 EU naval escort fleet, retrieved at: http://eng.chinamil.com.cn/news-channels/china-militarynews/2009-11/24/content_4084696.htm, on 15/05/2013.

\section{Command Documents}

Chinese Ministry of Foreign Affairs, 2009, Proposed Implementation Plan on AOR Escort Cooperation in the Gulf of Aden and the Waters off Somalia, Beijing.

EEAS, 2013, First CSDP Orientation Seminar with a Focus on EU-China Relations, Brussels.

EU Council, 2008a, 'Council joint action on a European Union military operation to contribute to the deterrence, prevention and repression of acts of piracy and armed robbery off the Somali coast', Official Journal of the European Union, L301/33, Brussels.

European Commission, 2007, An Integrated Maritime Policy for the European Union, $\operatorname{COM}(2007) 575$, Brussels.

House of Commons, 2012, Piracy off the Coast of Somalia, HC 1318, London.

UNSC, 2006, Resolution 1676 (2006), S/RES/1676 (2006), New York.

UNSC, 2008a, Resolution 1816 (2008), S/RES/1816 (2008), New York.

UNSC, 2008b, Resolution 1846 (2008), S/RES/1846 (2008), New York. 


\section{Miscellaneous}

Drossinos, G., 2009, Dangerous Waters: The International Community's Response to the Resurgence of Maritime Piracy, PhD Thesis, University of Pennsylvania.

MIT, 2009, Explaining China's Participation in Anti-Piracy Operations in the Gulf of Aden, Cambridge, MA: Massachusetts Institute of Technology.

\section{CHAPTER 7}

\section{Book References}

Annan, K. \& Mousavizadeh, N., 2013, Interventions: A Life in War and Peace, London: Penguin Books.

Faligot, R., Guisnel, J. \& Kauffer, R., 2012, Histoire Politique des Services Secrets Français : De la Seconde Guerre Mondiale à nos Jours, Paris: Editions La Découverte.

Till, G., 2013, Seapower: A Guide for the Twenty-First Century, $3^{\text {rd }}$ Edition, Abingdon: Routledge.

\section{Journal and Electronic Articles}

Arieff, A., 2013, Crisis in Mali, Washington, DC: Congressional Research Service.

Bellamy, A. \& Williams, P., 2011, 'The new politics of protection? Côte d'Ivoire, Libya and the responsibility to protect', International Affairs, 87:4, pp. 825-850.

Bøas, M. \& Torheim, L., 2013, 'The international intervention in Mali: 'Desert blues' or a new beginning?', International Journal, 68:3, pp. 417-423.

Coelmont, J., 2012, 'An attractive EU security strategy: An attractive narrative', Egmont Security Policy Brief, 34.

Cristiani, D. \& Fabiani, R., 2013, 'The Malian crisis and its actors', The International Spectator: Italian Journal of International Affairs, 48:3, pp. 78-97.

Farhaoui, F., 2013, The Great Power Struggle for Africa: The Crisis in Mali, Ankara: USAK Centre for Middle Eastern and African Studies.

Helwig, N., 2013, 'EU foreign policy and the High Representative's capability-expectations gap: A question of political will', European Foreign Affairs Review, 18:2, pp. 235-254.

Hirono, M. \& Neill, A., 2012, China's Engagement in Non-Traditional Security: Challenges and Opportunities for UK-China Military Cooperation, London: Royal United Services Institute.

ICG, 2013, Mali: Security, Dialogue and Meaningful Reform, Brussels.

Jones, B., 2011, 'Libya and the responsibilities of power', Survival, 53:3, pp. 51-60.

Kingah, S. \& van Langenhove, L., 2012, 'Determinants of a regional organisation's role in peace and security: The African Union and the European Union compared', South African Journal of International Affairs, 19:2, pp. 201-222.

Kuperman, A., 2013, 'A model humanitarian intervention?: Reassessing NATO's Libya campaign', International Security, 38:1, pp. 105-136.

Lacher, W., 2013, 'The Malian crisis and the challenge of regional security cooperation', Stability: International Journal of Security \& Development, 2:2, pp. 1-5.

Lanteigne, M., 2013, 'Fire over water: China's strategic engagement of Somalia and the Gulf of Aden crisis', The Pacific Review, 26:1, pp. 2-24.

Lee, K., Chan, G. \& Chan, L., 2012, 'China in Darfur: Humanitarian rule-maker or ruletaker?', Review of International Studies, 38, pp. 423-444. 
Menon, A., 2011, 'European defence policy from Lisbon to Libya', Survival, 53:3, pp. 75-90.

Omorogbe, E., 2012, 'The African Union, Responsibility to Protect and the Libyan crisis', Netherlands International Law Review, 59:2, pp. 141-163.

Stahl, A., 2011, 'Contrasting rhetoric and converging security interests of the European Union and China in Africa', Journal of Current Chinese Affairs, 40:4, pp. 147-173.

Techau, J., 2013, 'Will Europeans ever agree on the use of military force?', in Fabry, E. \& Rosselli, C. (eds.), Think Global - Act European IV: Thinking Strategically about the EU's External Action, Paris: Jacques Delors Institute, pp. 267-275.

Tertrais, B., 2013, 'Leading on the cheap? French security policy in austerity', The Washington Quarterly, 36:3, pp. 47-61.

Ulfstein, G. \& Føsund Christiansen, H., 2013, 'The legality of the NATO bombing in Libya', International and Comparative Law Quarterly, 62:1, pp. 159-171.

van Hoeymissen, S., 2011, 'Regional organizations in China's security strategy for Africa: The sense of supporting 'African solutions to African problems', Journal of Current Chinese Affairs, 40:4, pp. 91-118.

Vilanova, P. \& de Castro, P., 2013, 'Mali and the Sahel: From crisis to military intervention', in IEMed (ed.), IEMed Mediterranean Yearbook 2013, Barcelona: Institut Europeu de la Mediterrania, pp. 218-221.

\section{Websites and Newspaper Articles}

Anthony, R., 2012, The reluctant policeman: China, Mali and the principle of 'noninterference', retrieved at: http://www.ccs.org.za/wp-content/uploads/2012/11/RAMali.pdf, on 19/06/2014.

BBC News, 2011, Libya protests: Defiant Gaddafi refuses to quit, retrieved at: http://www.bbc.co.uk/news/world-middle-east-12544624, on 07/11/2013.

Bhadrakumar, M., 2013, 'Russia, China grapple with Mali's future', Asia Times, retrieved at: http://www.atimes.com/atimes/China/OA25Ad02.html, on 08/11/2013.

Dembele, D., 2012, 'China offers support to Mali military in fight against Islamists', Bloomberg, retrieved at: http://www.bloomberg.com/news/2012-09-26/china-offerssupport-to-mali-military-in-fight-against-islamists.html, on 19/06/2014.

Escobar, P., 2011, 'China's interests in Gaddafi', Al Jazeera, retrieved at: http://www.aljazeera.com/indepth/opinion/2011/04/201141195046788263.html, on 07/11/2013.

EU Delegation to the UN, 2011, Libya: EU Statement on the death of Muammar Gaddafi and fall of Sirte, retrieved at: http://www.eu-un.europa.eu/articles/en/article_11502_en.htm, on $18 / 06 / 2014$.

Huffington Post, 2011, Gaddafi tells rebel city, Benghazi, 'We will show no mercy', retrieved at: http://www.huffingtonpost.com/2011/03/17/gaddafi-benghazi-libyanews_n_837245.html, on 07/11/2013.

Li, J. \& Jin, J., 2013, China will neither send troops to Mali, nor will it give money, retrieved at: http://www.chinaafricaproject.com/prc-military-analysts-say-china-shouldnt-aid-malinetizens-disagree-urging-forceful-protection-of-national-interests/, on 08/11/2013.

Musakwa, T., 2013, 'Leading Africa expert in China: French intervention in Mali 'was necessary', The ChinAfrica Project, retrieved at: http://www.chinaafricaproject.com/france-china-mali-he-wenping-cass-beijing/, on 08/11/2013.

Shinn, D., 2013a, 'China's response to the Islamist threat in Mali', China-US Focus, retrieved at: http://www.chinausfocus.com/peace-security/chinas-response-to-the-islamist-threatin-mali/, on $08 / 11 / 2013$. 
Shinn, D., 2013b, Crisis in Mali poses dilemma for China, retrieved at: http://davidshinn.blogspot.be/2013/01/crisis-in-mali-poses-dilemma-for-china.html, on 08/11/2013.

Sisk, R., 2013, 'China to send combat troops to Mali', Military.com, retrieved at: http://www.military.com/daily-news/2013/06/29/china-to-send-combat-troops-tomali.html, on 19/06/2014.

Sotloff, S., 2012, 'China's Libya problem', The Diplomat, retrieved at: http://thediplomat.com/china-power/china\%E2\%80\%99s-libya-problem/, on 07/11/2013.

The Economist, 2011, China's evolving foreign policy: The Libyan dilemma, retrieved at: http://www.economist.com/node/21528664, on 08/11/2013.

Tisdall, S., 2011, 'The consensus on intervention in Libya has shattered', The Guardian, retrieved at: http://www.theguardian.com/commentisfree/2011/mar/23/libya-ceasefireconsensus-russia-china-india, on 07/11/2013.

Whitehouse, B., 2013, 'Behind Mali's conflict: Myths, realities and unknowns', Bridges from Bamako, retrieved at: http://bridgesfrombamako.com/2013/01/16/behind-mali-conflict/, on $19 / 06 / 2014$.

Xinhua News Agency, 2011, China says suspension of Libya's membership in UN Human Rights Council not a precedent, retrieved at: http://news.xinhuanet.com/english2010/china/2011-03/02/c_13756411.htm, on 18/06/2014.

Yun, S., 2013, 'How China views France's intervention in Mali: An analysis', Brookings Institute, retrieved at: http://www.brookings.edu/research/opinions/2013/01/23-chinafrance-intervention-mali-sun, on 07/11/2013.

\section{Command Documents}

Ashton, C., 2011, Declaration by the High Representative Catherine Ashton on behalf of the European Union on Libya, 6966/1/11 REV 1 (Presse 36), Brussels.

EU Council, 2011a, 3078 ${ }^{\text {th }}$ Council Meeting, Foreign Affairs, 7781/11 (Presse 66), Brussels.

EU Council, 2011b, 3082 ${ }^{\text {nd }}$ Council Meeting, Foreign Affairs, 8741/11 REV 1 (Presse 96), Brussels.

EU Council, 2012a, Council Conclusions on the Situation in Mali $-3191^{\text {st }}$ Foreign Affairs Council Meeting, $15^{\text {th }}$ October 2012, Luxemburg.

EU Council, 2013, 'Council decision 2013/34/CFSP of 17 January 2013 on a European Union military mission to contribute to the training of the Malian Armed Forces (EUTM Mali)', Official Journal of the European Union, L 14/19, Brussels.

Ferdinand, P., 2013, 'The positions of Russia and China at the UN Security Council in the light of recent crises', Directorate-General for External Policies of the Union Briefing Paper, PE 433.800, Brussels: European Parliament.

UNSC, 2011, Resolution 1970 (2011), S/RES/1970 (2011), New York.

UNSC, 2011a, Resolution 1973 (2011), S/RES/1973 (2011), New York.

\section{Miscellaneous}

Marlier, G. \& Kao, D-Y., 2011, And Then Came Libya: The Chinese Perspective on the Sovereignty and the Evolution of Use of Force Norms in the United Nations Security Council, Paper presented at the InBev-Baillet Latour Chair of EU-China Relations Annual Conference on: 'The EU, the US and China: Towards the New International Order?', 22-23 April 2011, Bruges, Belgium. 
Richardson, C., 2012, Selective Multilateral Security Cooperation? Insights from Chinese Activity on the Darfur Crisis and the Libyan Civil War.

\section{CHAPTER 8}

\section{Book References}

Annan, K. \& Mousavizadeh, N., 2013, Interventions: A Life in War and Peace, London: Penguin Books.

Till, G., 2013, Seapower: A Guide for the Twenty-First Century, $3^{\text {rd }}$ Edition, Abingdon: Routledge. 


\section{List of Interviews}

- Interview 1, French diplomat (1), Brussels, 09/11/2012.

- Interview 2, Former EU Military Staff member, Brussels, 15/11/2012.

- Interview 3, former EUSR for Sudan, Telephone interview, 23/11/2012.

- Interview 4, French Ambassador (1), Telephone interview, 14/12/2012.

- Interview 5, Former diplomatic adviser to Sarkozy, Telephone interview, 15/12/2012.

- Interview 6, EEAS official (1), Telephone interview, 20/12/2012.

- Interview 7, US State Department official (1), Telephone interview, 28/12/2012.

- Interview 8, French academic (1), Telephone interview, 07/01/2013.

- Interview 9, CMPD official (1), Brussels, 11/01/2013.

- Interview 10, French academic (2), Telephone interview, 16/01/2013.

- Interview 11, Former member of EUCAP NESTOR fact-finding mission, Brussels, 29/01/2013.

- Interview 12, British diplomat, Telephone interview, 07/02/2013.

- Interview 13, IMO official, Telephone interview, 12/02/2013.

- Interview 14, CMPD official (2), Brussels, 20/02/2013.

- Interview 15, Senior Executive at Lloyd's of London, London, 21/02/2013.

- Interview 16, Spanish naval officer, Brussels, 22/02/2013.

- Interview 17, Department for International Development (UK) advisor, London, 26/02/2013.

- Interview 18, Member of the European Parliament, Brussels, 27/02/2013.

- Interview 19, Former diplomatic adviser to Solana (1), Telephone interview, 14/03/2013.

- Interview 20, French diplomat (2), Telephone interview, 14/03/2013.

- Interview 21, Former diplomatic adviser to Solana (2), Telephone interview, 15/03/2013.

- Interview 22, Former EU NAVFOR Assistant Chief of Staff, Telephone interview, $15 / 03 / 2013$.

- Interview 23, British Ambassador (1), Telephone interview, 21/03/2013.

- Interview 24, Senior Executive at Orthongel, Telephone interview, 21/03/2013.

- Interview 25, Former CMF Deputy Commander, Telephone interview, 16/04/2013.

- Interview 26, Former EU NAVFOR Chief of Staff, Telephone interview, 07/05/2013.

- Interview 27, French diplomat (3), Telephone interview, 13/05/2013.

- Interview 28, US State Department official (2), Telephone interview, 06/12/2013.

- Interview 29, Former UN Deputy Secretary-General, Email correspondence, 19/12/2013.

- Interview 30, EEAS official (2), Email correspondence, 19/12/2013. 
- Interview 31, French diplomat (4), Email correspondence, 07/01/2014.

- Interview 32, EU Council Secretariat official, Telephone interview, 12/01/2014.

- Interview 33, EEAS official (3), Email correspondence, 14/01/2014.

- Interview 34, British Ambassador (2), Email correspondence, 20/01/2014.

- Interview 35, Former British Special Envoy for Sudan, Email correspondence, 21/01/2014.

- Interview 36, UN Department for Peacekeeping Operations (DPKO) official, Email correspondence, 21/01/2014.

- Interview 37, French Ambassador (2), Email correspondence, 21/01/2014.

- Interview 38, EU Council official, Email correspondence, 28/01/2014.

- Interview 39, Former Swedish Ambassador, Email correspondence, 20/01/2014.

- Interview 40, Former diplomatic adviser to Solana (3), Email correspondence, 03/02/2014. 